\title{
Managing Risk of Sex Offenders Released from Prisons: An exploration of how local communities respond to these events
}

By

Jordan Amy Anderson

\begin{abstract}
A thesis
submitted to the Victoria University of Wellington in fulfilment of the requirements for the degree of Doctor of Philosophy
\end{abstract}

Victoria University of Wellington 2021 


\section{Dedication}

This thesis is dedicated to Dr George Nairn Marshall, who passed away before he could read it, circle and correct my grammatical errors in pencil, and return it to me in the post. Vale, Uncle George. 


\section{Acknowledgements}

The length of these acknowledgements reflects my PhD experience - it has been a longer than expected journey with many twists and turns. It has taken a village to raise this thesis, and I am enormously grateful to the many people who have contributed to my experience and to this work.

Thank you first to Professor John Pratt, whose faith in me has been unfailing and invaluable. In sickness and in health, you have been an incredible support, and I continue to learn from you every day. Your speed in replying to emails and turning around drafts is unrivalled, and I have been blessed to have been in your orbit for the last nine years. Thank you for the many opportunities you have created for me, for your sense of humour, and for being such a thoughtful and encouraging mentor.

Dr Sarah Monod de Froideville, alongside academic rigour you have brought sunshine and laughter to my supervision team. Thank you for making time whenever you were needed, day or night; for the regular book and article deliveries I continue to find on my desk; and for the fierce loyalty and energy you devote to all of your students. Arohanui e hoa.

I have been lucky beyond measure to have had a team of informal supervisors, mentors, and learned friends throughout my prolonged PhD journey.

Thank you Dr Charles Sedgwick, whose passion and vast knowledge I have been privileged to have been on the receiving end of. Near or far, come pandemic or acute illness, you inspire me to question everything - thank you Charlie.

Dr Venezia Kingi, research extraordinaire, my fiercest supporter, and the best hugger I know - thank you for all that you bring to my life, and all you have brought to my understanding of research and of this project. $V$, it is a privilege to call you my family.

Professor Jan Jordan - thank you for your hospitality, your advice, and for being a kind ear when I have needed to talk through frustrations with research and life. 
Professor Elizabeth Stanley - thank you for the giggles, the cuddles, the sage advice, and in particular the support for myself and others when we haven't been well - Lizzy you are a true gem!

Emeritus Professor Mike Hill, thank you for sharing your knowledge, stories and personal library with me - I truly appreciate your generosity, passion, and wisdom.

To my family - Mum, Dad, Esther and Evan - thank you for making room on family holidays for my boxes of books, and for the hilarious family antics that the last five years have brought. I couldn't ask for more or better.

Thank you Liam for your patience and support, and for going with the flow. I appreciate everything you are!

Thank you to the wider Anderson and Marshall families for all of the support, the laughter, and for the (mostly unsolicited) advice. In particular my beautiful grandmother, Barbara June Marshall, who passed away while I was under examination, and would have loved to hold this thesis in her hands.

Sally Jean Day - you were forged in the fires of critical thought, and it has been an honour to share this journey with you, and to learn from you every day. I am privileged to be a de facto member of the Day clan, and I have endless love for you and your family. Thank you for all you do for me, for your friends, and for this world.

Hayley - I wish you could have joined me on this journey, but it wasn't to be. I love you unconditionally, and you travel with me everywhere I go.

Sophie - thank you for your friendship and loyalty, your reliability is unrivalled, as is your ability to communicate with a glance. You are exceptional as a friend, an academic, a teacher, and as a person. 
Trevor - thank you for getting angry at the same things I do, for always being available for a yarn (research-related or otherwise), and for being a true friend.

Fiona - a cup of tea with you is always enough to make my week. Thank you for your love, hugs, stern words, excellent stories, and for sharing your beautiful family with us.

To two fellow unionists, battlers, comrades, and friends - Brigitte and Graeme. Fighting alongside you has been an honour, and I look forward to much more scheming in the future.

To all my friends at Vic, from the $9^{\text {th }}$ floor and beyond, it has been a wonderful rollercoaster! Thanks for being on my team Reena, Hun, Max, Heidi, Sasha, Bonnie, Miles, Zoe, Lennon, Deb, Lili, Lizzie, Corrina, Nicki.

To my incredible friends - especially Hannah \& Shane, Anne, Sarah \& Ryan, Matthew thank you for the depth of your love and generosity, and for looking after me always.

Thank you to my work families, and to the crew I have volunteered with throughout this time - the SACS admin staff, the PGSA Executive, the Student Finance team, the Capital Hall team, the Disability Services team, to Sue Shone, and the JustSpeak whānau.

Nga mihi nui Tā Kim Workman, it has been a blessing to have you as kaumātua, and as a mentor in research, activism, and life.

Thank you to the Royal Society of New Zealand's Marsden Fund for the funding of this research through Professor Pratt's grant.

Finally, and most importantly for this work, my sincere and heartfelt thanks to all of the inspirational leaders I interviewed for this project. Seeking out community leaders connected me with more insight, love, and knowledge than I ever could have anticipated. Thank you all for your mahi on the ground, and for sharing with me your dedication to your people. I remember in particular those community leaders I spent time with who have passed away, and honour their contributions to their communities. 


\section{Table of Contents}

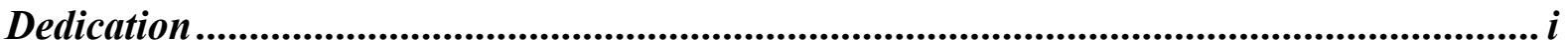

Acknowledgements........................................................................................................

List of Images.......................................................................................................... vii

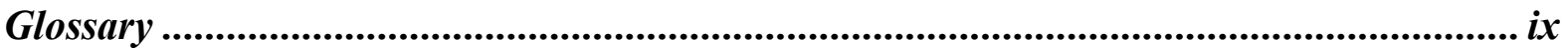

Abstract

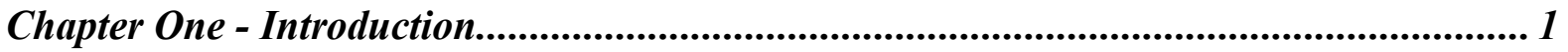

Reactive Protection: Registration \& Notification in New Zealand ..............................................2

Community Notification and Risk Society......................................................................................6

Risk and Public Protection in Modern Society ..........................................................................................8

Risk Control in New Zealand Penal Policy.......................................................................11

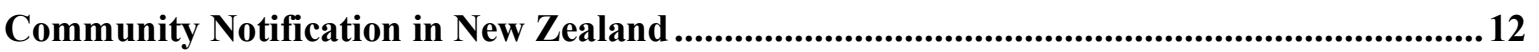

Bauman, Community Notification, and the New Zealand Case.............................................16

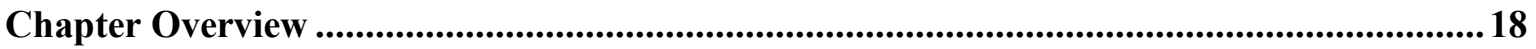

Chapter Two - Understanding Risk and Criminal Justice in the Shift from 'Solid' to 'Liquid' Society: The Centrality of Zygmunt Bauman........................................................ 20

Locating Risk in Criminology ...........................................................................................................20

Risk, Pleasure, and Pain .......................................................................................................................24

Bauman on the Implications of the Duality of Risk.............................................................25

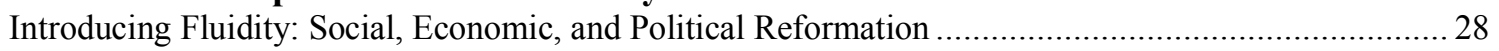

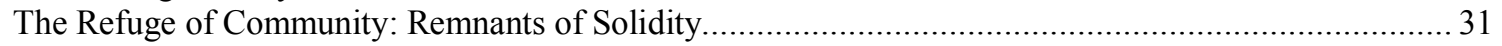

Risk and Sexual Harm...........................................................................................................................35

Risk and the Child ..................................................................................................................................40

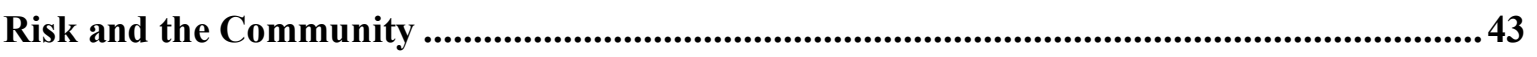

Sex Offender Policy in Community Spaces ........................................................................... 46

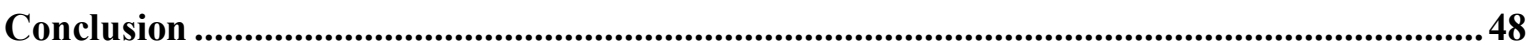

Chapter Three - Liquid New Zealand............................................................................ 50

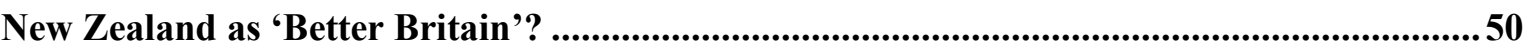

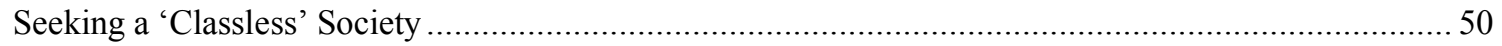

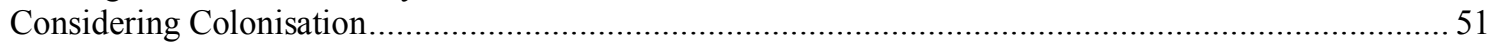

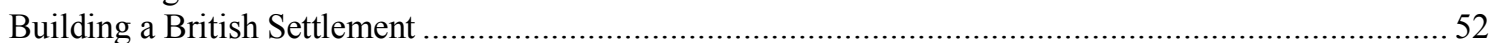

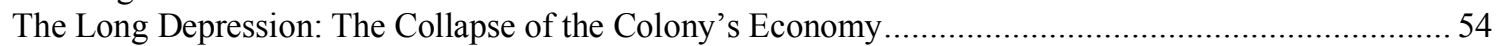

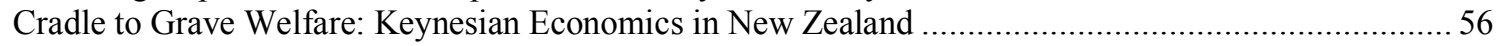

1960s and 1970s Counter-Culture and Social Progress................................................................ 58

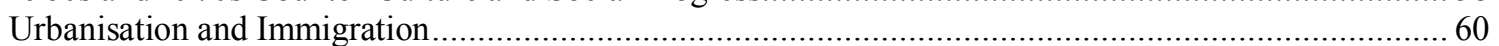

Neoliberal Reforms in New Zealand ........................................................................................62

The Impacts of Neoliberal Restructuring in New Zealand ....................................................66

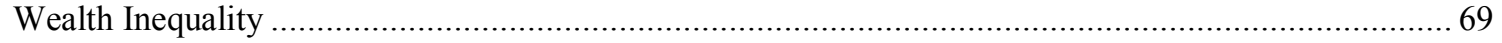

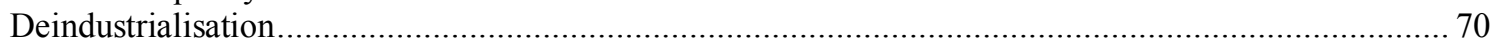

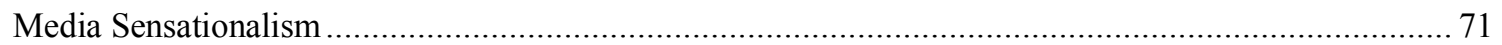

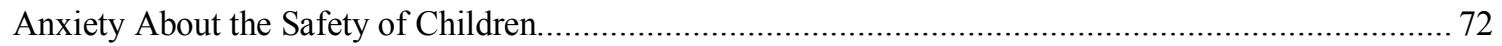




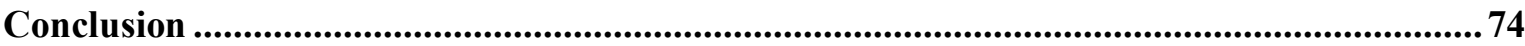

Chapter Four - The Research Process.............................................................................. 77

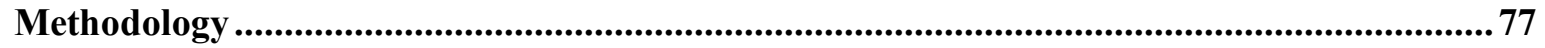

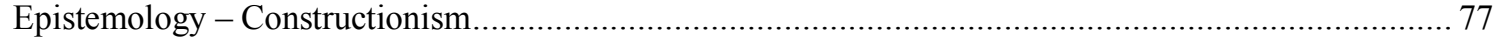

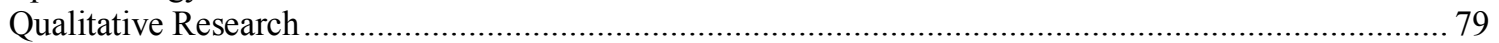

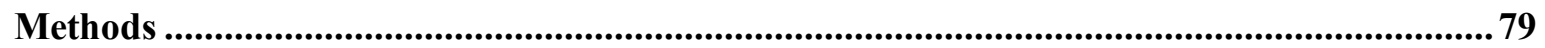

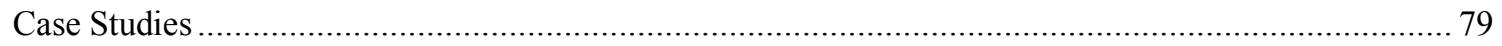

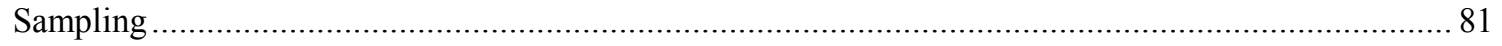

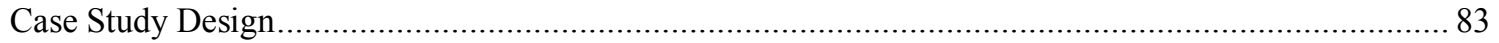

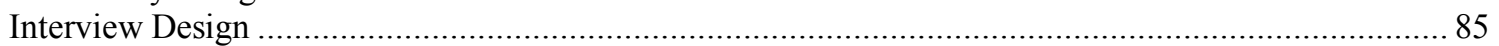

Human Ethics Committee Approval..............................................................................................8 87

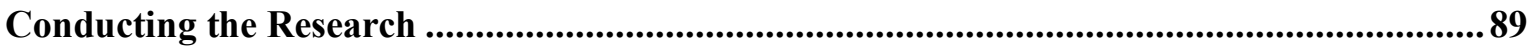

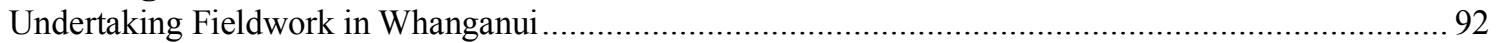

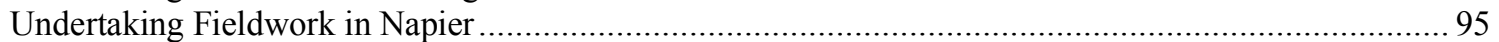

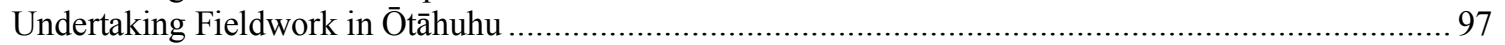

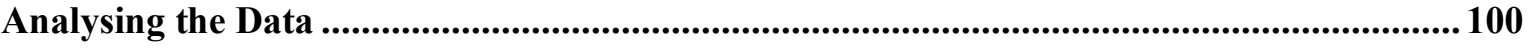

Caveats Concerning the Research Design........................................................................................... 103

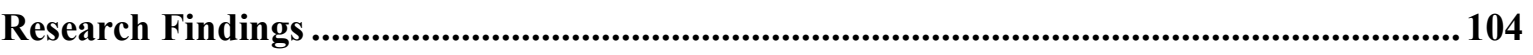

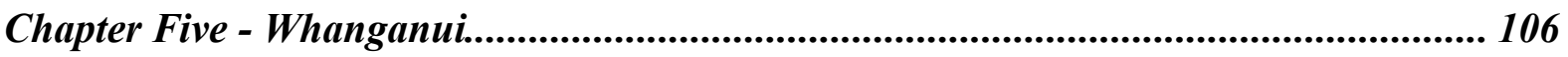

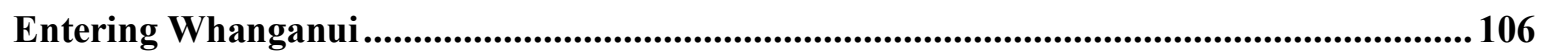

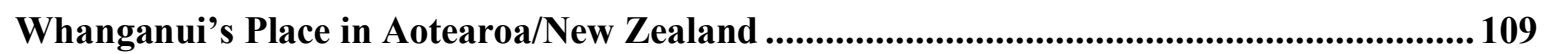

The Consequences of Neoliberal Restructuring in Whanganui ................................................111

A Proud Community with an Unfair Reputation .......................................................................... 117

Life in Whanganui.............................................................................................................................119

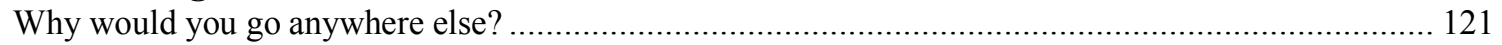

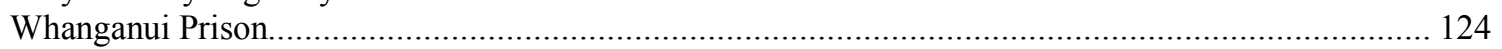

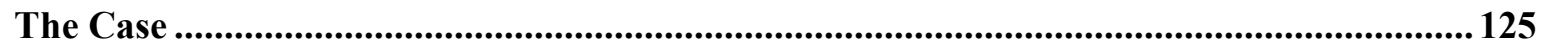

Use of the label 'Beast' - Media and Community Perspectives ........................................................ 126

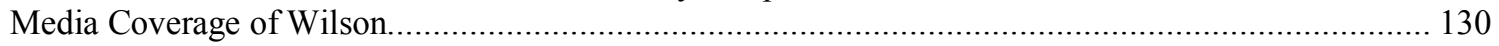

Community Leaders on the Community Reaction.......................................................................... 132

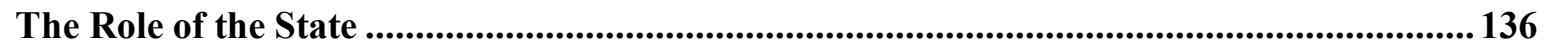

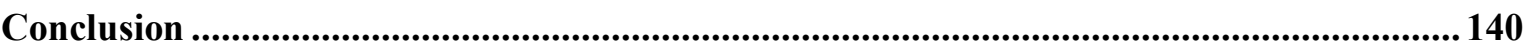

Chapter Six - Napier....................................................................................................... 142

Entering Napier ....................................................................................................................142

Napier's Place in Aotearoa/New Zealand ............................................................................................ 145

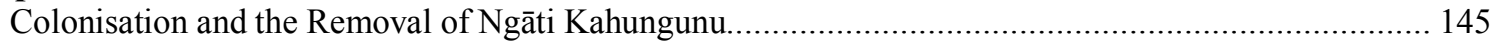

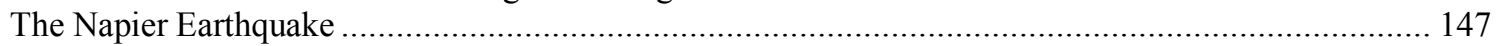

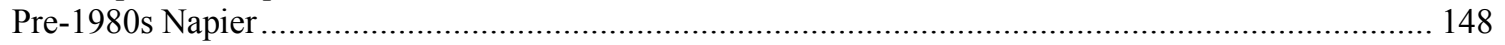

Napier Today ........................................................................................................................................ 149

A Neoliberal Success Story: The Slow Rise of the Tide in Napier.................................................... 152

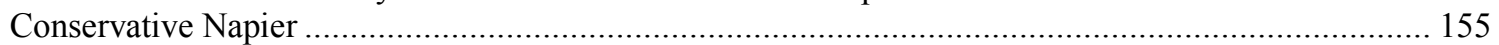

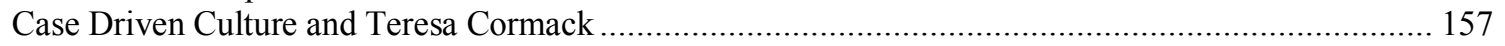

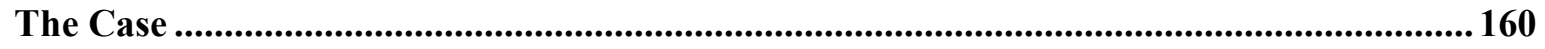

Community Reactions to the Release of Sex Offenders in Napier ........................................... 164

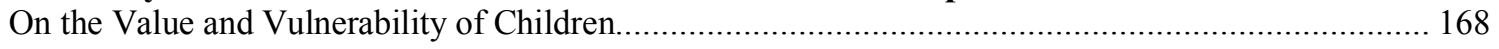




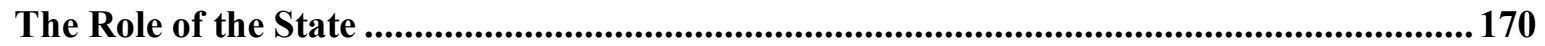

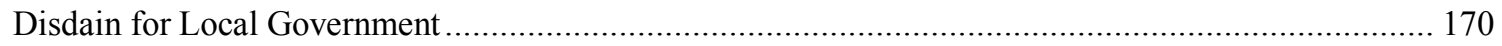

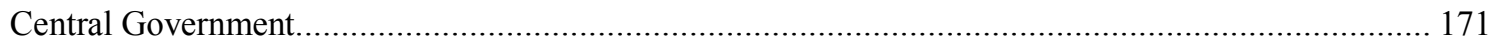

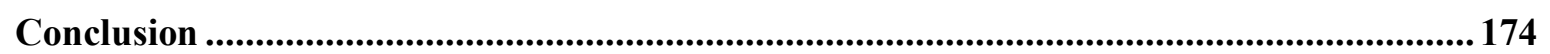

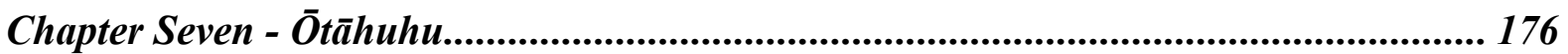

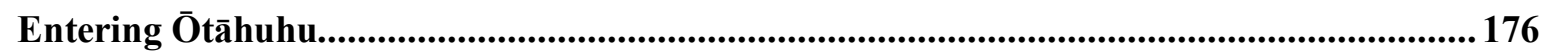

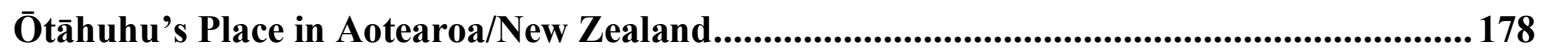

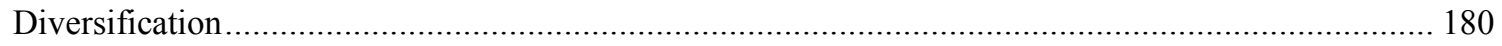

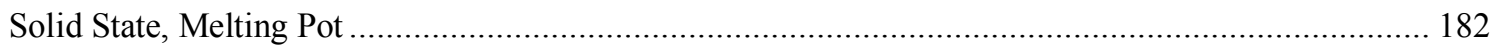

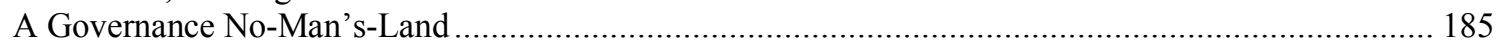

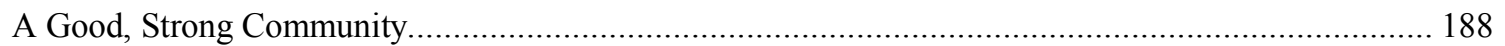

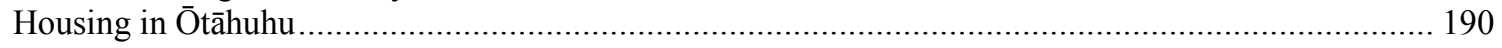

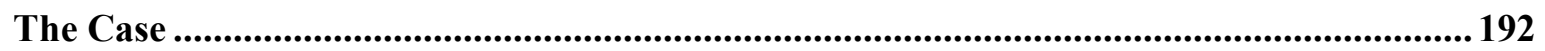

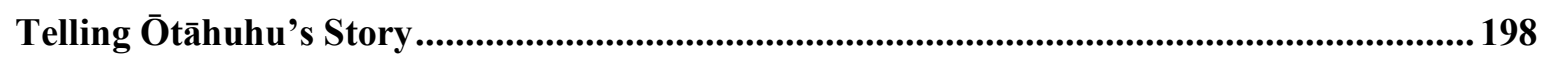

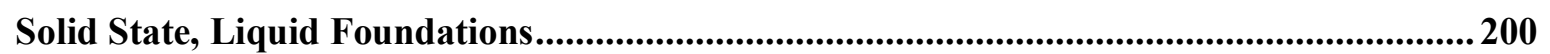

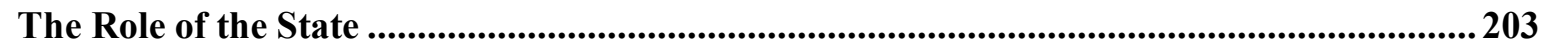

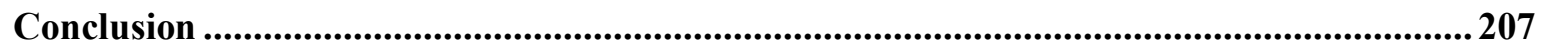

Chapter Eight - The Pain of the Thaw: Floating Ice Meets a Warming Ocean.............. 209

The Spectrum of Social Arrangements in Modern Society: Solid Modernity .........................209

The Changing Face of Community Life.................................................................................... 214

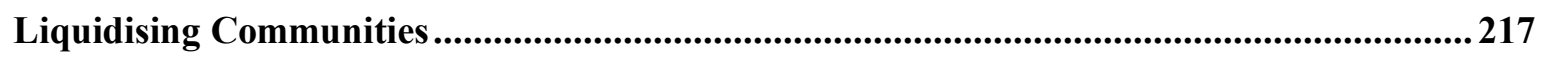

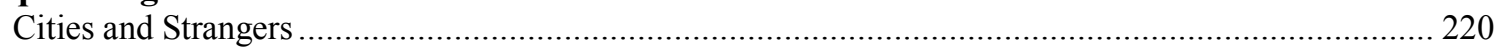

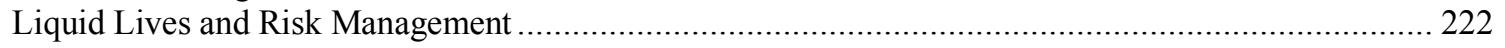

The End of Big Government and Safety Nets ............................................................................. 223

Community Notification on the Spectrum ................................................................................226

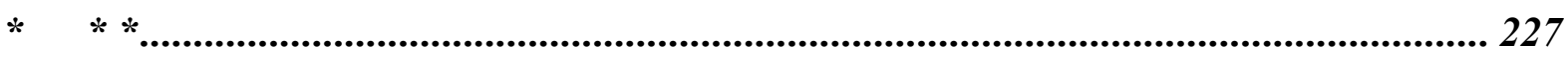

Spectacular Rescues: Spectacular Failure ..................................................................2227

De Facto Community Notification - Ad Hoc and Unhelpful.............................................228

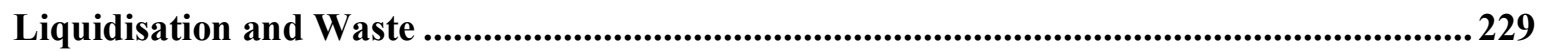

Big Wins and Big Losses ......................................................................................................... 230

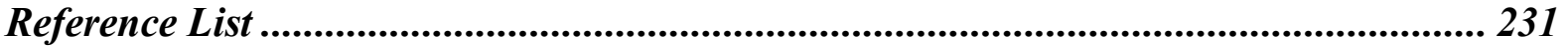

Appendices .......................................................................................................................

Appendix A - Information Sheet ….....................................................................................................

Appendix B - Consent Form .......................................................................................................

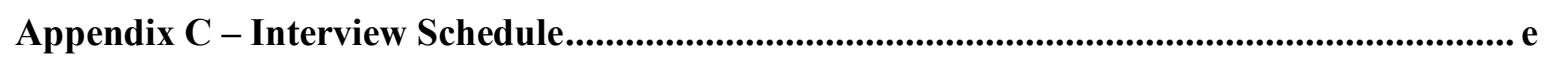




\section{List of Images}

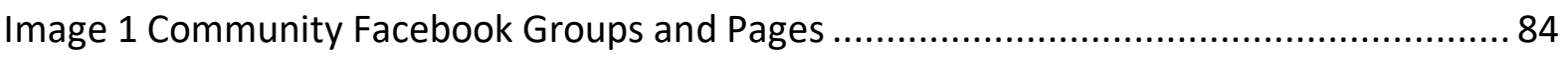

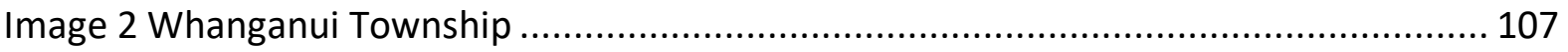

Image 3 Whanganui's Central Business District .......................................................... 107

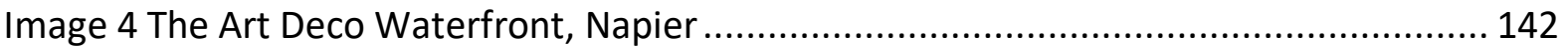

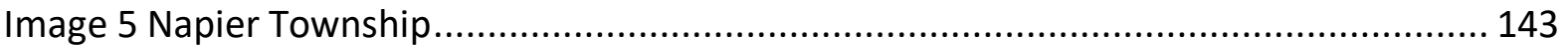

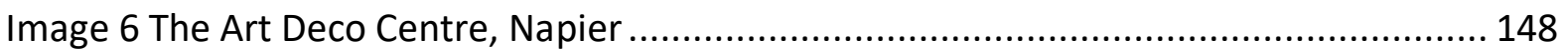

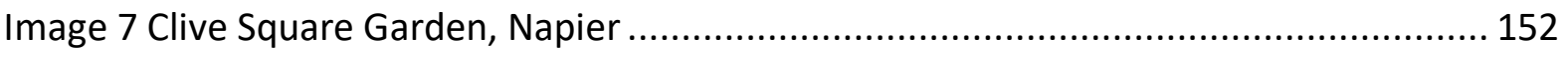

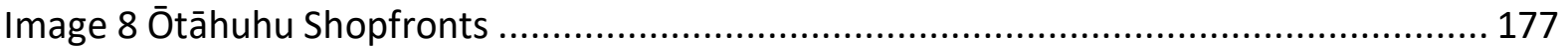

Image 9 Pasifika Clothing For Sale in Ōtāhuhu ............................................................. 177

Image 10 Predatory Lenders in Central Ōtāhuhu ....................................................... 182

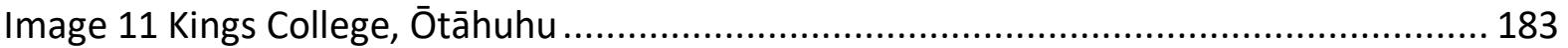

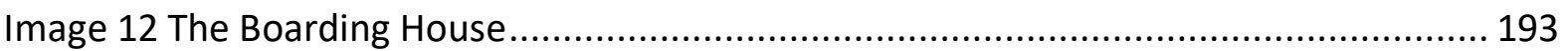

Image 13 Statement of Department of Corrections, 15 March 2018 ............................. 196

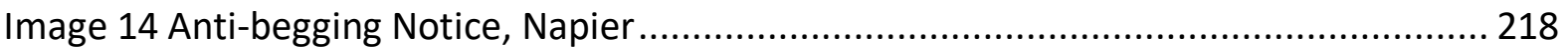

Image 15 Camera Surveillance Notice, Napier ........................................................... 219 


\section{Glossary}

$\begin{array}{ll}\begin{array}{l}\text { Aotearoa } \\ \text { awa tupua }\end{array} & \begin{array}{l}\text { Māori name for New Zealand (Māori) } \\ \text { hapū }\end{array} \\ \text { river of sacred power (Māori) } \\ \text { kinship group/s or subtribe/s (Māori) } \\ \text { kanohi ki te kanohi } & \text { face to face (Māori) } \\ \text { manaakitanga } & \text { showing respect/hospitality (Māori) } \\ \text { Pākehā } & \text { New Zealander/s of European descent (Māori) } \\ \text { pālagi } & \text { White/non-Samoan person, people or thing/s (Samoan) } \\ \text { tangata whenua } & \text { indigenous people, people born of the land (Māori) } \\ \text { taonga } & \text { treasure (Māori) } \\ \text { te Tiriti ō Waitangi } & \text { Māori language version of the Treaty of Waitangi (Māori) } \\ \text { tino rangatiratanga } & \text { sovereignty (Māori) } \\ \text { waka } & \text { canoe (Māori) } \\ \text { whakatauki } & \text { proverb (Māori) } \\ \text { whakawhanaungatanga } & \text { relationship cultivation (Māori) }\end{array}$




\section{Abstract}

Throughout the main Anglo-American democracies, state power has been tested in recent decades by the presentation of the risks posed by sexual offenders. The capacity of the state to take decisive action in these jurisdictions has been significantly challenged by neoliberal restructuring from the 1980s onwards, and criminal justice has been one of many policy areas affected by the shrinking of central state power. The development of intolerance for risk of sexual harm posed specifically by offenders released from prison has provided an opportunity for the state to take unique action to maintain an impression of control. As governments have sought extraordinary legislative and policy measures to control or remove these specific risks of sexual harm from the community, communities and individuals have responded to their place in the ecosystem of the risk society.

The release of a high-risk sex offender into a community is a microcosm of the modus operandi of the modern state, providing a context through which the operation of the modern risk society can be examined. This thesis explores the reactions of three New Zealand communities to instances of de facto community notification of sex offender release, and explains the differences in their reactions through the lens of Zygmunt Bauman's (2000a) Liquid Modernity. In each of the three case studies of Whanganui, Napier, and Ōtāhuhu I examine the processes around an instance of community release, the reactions of the community, and the impact of the incident within the community and the implications of this for our understanding of risk society. 


\section{Chapter One - Introduction}

On the $27^{\text {th }}$ October 2020, the release of a man convicted of sex offences against children into a central Wellington suburb made headlines across New Zealand's major news outlets: Notorious paedophile moves into Wellington home surrounded by kids (Hunt, 2020, October 27), Officials apologise after high risk paedophile on parole allowed to live near children (Radio New Zealand, 2020, October 27). A flurry of articles covered the case in the days that followed, chronicling commentary from community members, a local school principal, and even the New Zealand Principals' Federation, all of whom appeared to universally condemn the actions of the Department of Corrections in releasing this individual into an urban community in which 62 children were reported to be living (Hunt, 2020, October 27). The Department of Corrections swiftly confirmed to the media and the public that the individual had been relocated, and the Regional Commissioner for Corrections released a statement, insisting that "public safety is our top priority and having him live there posed a risk that we were not prepared to tolerate" (Paula Collins as quoted in Hunt, 2020, October 27).

This incident was the latest in a long line of similar cases of notifications to have struck a chord with the public in respect to their nature, timing, and media framing. In this instance, it was the media that first notified the community of the presence of this 'risk', using words like 'child sex offender' and 'paedophile' interchangeably and deploying emotive language around the 'notoriety' of the individual along with the proximity of 'kids'.

Media stories like these are one type of 'community notification' - notices which alert communities to the presence of this particular type of risk. There is an assumption in the media of universal alarm, panic, and anxiety amidst demands that the government move to 'action stations' to eliminate such risks and any further occurrence of them. The practice of community notification thus has significant ramifications for the stability and wellbeing of communities, offenders, victims, and the state. Although New Zealand has not legislated community notification, the practice occurs frequently on a de facto basis. This thesis, based around the experiences of community notification in three localities (Whanganui, Napier, and Ōtāhuhu) that have been exposed to this kind of risk, explores the ways that the 
approaches of these communities differ dramatically as does the way they respond to these matters: both in terms of the levels of their reaction and the very capabilities of their reaction. That this is so is not some sort of inherent quality of the communities themselves, but is instead a reflection of the way in which the experience of risk and ways of responding to it has been the product of governments pursuing a neoliberal mode of governance which has been instrumental in their shift towards a 'liquid' phase of modernity. Neoliberal restructuring and the ensuing shift have impacted communities across New Zealand differently - elevating the capabilities of some while proving to be a death knell for others. In this thesis I shall argue that the differential consequences of 'liquidising' during the course of New Zealand's restructuring fundamentally shapes local responses to community notification with important implications for both their ability to manage risk and the diversity of their reactions to it. To demonstrate the ways in which they do, I undertake an empirical exploration of the experiences of de facto community notification across three diverse New Zealand communities.

\section{Reactive Protection: Registration \& Notification in New Zealand}

Community notification as a regulatory process has typically encompassed measures designed to inform members of the public of a certain type of risk - that posed by the presence of convicted sex offenders who have been released into their geographic proximity. Originating in the United States in the 1990s, forms of policy transfer have delivered versions of community notification and its twin-policy, sex offender registration, to other similar jurisdictions over the last two decades, including the United Kingdom, Canada, and Australia (Jones and Newburn, 2013).

In September of 2016, legislation was enacted in New Zealand which created a governmentheld register for child sex offenders. ${ }^{1}$ Hosted by the New Zealand Police, the Child Sex Offender Register is a non-public database in operation since October 2016, with reporting and regulatory requirements coordinated and overseen by district policing teams (New Zealand Police, 2019). As of $9^{\text {th }}$ April 2021, there are 3,045 registrants on the Child Sex

\footnotetext{
${ }^{1}$ This legislation was the Child Protection (Child Sex Offender Government Agency Registration) Act 2016.
} 
Offender Register; 2,058 of whom are registered for life, and 30 of whom are female. ${ }^{2}$ New Zealand's model of registration applies exclusively to those convicted of sexual offences against children, who are placed on the Register for 8 years, 15 years, or life, depending on the severity and type of their offending, and the length of their sentence (Child Protection Act 2016, s 35). In similar jurisdictions, legislation establishing registration has often been swiftly followed by community notification laws.

Though New Zealand has not followed its registration law with any legislative standards nor requirement for public notification, community notification regularly occurs in a de facto manner through a range of mechanisms. The mixture of de jure registration and de facto notification makes New Zealand an interesting case study, particularly because the rhetoric that has driven the public notification seen in the US, Canada, the UK, and most recently Australia, has not been picked up to any great extent in New Zealand, despite the significant impact of penal populism in this country, that is, the development of penal policy in line with the perceived sentiments and aspirations of the general public rather than expert bureaucratic advice, on criminal justice developments in this country in other ways (see Pratt, 2007).

Prevention of recidivism was the main justification by politicians for the legislation of registration in New Zealand, despite the lack of evidence of any significant preventive function of the regulatory practice of registration (Hinds and Daly, 2001; Napier et al., 2018; Prentky, 1996). Then-Minister for Police and Corrections Anne Tolley explained that increasing the regulation of those convicted of sex offences against children, in addition to existing sanctions, was intended to "enhanc[e] the sexual safety of the most vulnerable members of our community, our children" (Tolley, 2015). ${ }^{3}$ Anticipating the departure this would involve in the way this country has addressed human rights in its criminal justice system, centre-right National Government representatives went on to explain that the policy would be "a balancing act between the personal freedoms of the offenders and the

\footnotetext{
${ }^{2}$ Source $=$ personal communication with New Zealand Police.

${ }^{3}$ Ms Tolley went on to lead the process for legislating the Oranga Tamariki Act 2017, which intensified government intervention into the lives of children labelled 'vulnerable' by way of their social circumstances and/or their 'potential to offend'.
} 
safety of victims and potential victims", and that "keeping vulnerable children safe is at the heart of what this Bill is trying to achieve" (Naylor, 2015). Members of the National Government explained during the First Reading of the Child Protection (Child Sex Offender Register) Bill that the passing of this legislation would violate the right to privacy of those convicted of sexual offending; however, they continued that this was a price the government was willing to pay to contain the risk presented by these individuals. The National Government lamented the strong privacy protections in place for New Zealanders that had meant "good sense has gone out the window", explaining that "this Bill is absolutely about unlocking that and cutting through the red tape to allow the sensible management of people in this area... the Bill is about managing risk" (Smith, 2015). Elements of populist language and sentiment can be observed in these debates, as MPs seek to cut through 'red tape' and side-step political correctness to do what is 'sensible'. In the end, the Bill was passed into law with significant bipartisan support in parliament - only the left-wing Green Party dissented on the basis of the violations of human rights and the New Zealand Bill of Rights Act within the Bill. The passing of this legislation was significant not only because of the effect the law would go on to have on the lives of the many people who would find themselves on the Register, but also because of the history of de facto registration in New Zealand over the preceding 20 years.

A range of unofficial registers have been curated by various interest groups in New Zealand since the 1990s. The first to garner significant public attention was the 1996 Paedophile and Sex Offender Index, which was assembled by Deborah Coddington (1996), a journalist and eventual Member of Parliament for the right-wing ACT Party from 2002-2005. The book identified the names, ages, offences, jobs, and locations of over 580 individuals claimed by Coddington to have been convicted of sex offences since 1990. With a second edition published in 2004 during her parliamentary term, Coddington (New Zealand Herald, 2003, September 17) claimed to be fighting for victims' rights, and trying to educate the public on the "dangers that exist in their communities and on their very doorstep". Lobby group and victims' advocacy organisation the Sensible Sentencing Trust has also created an online database of individuals they claim have been convicted of sexual offences (Sensible Sentencing Trust, 2018). The nature of these informal and unsanctioned registers as public meant that they served a dual purpose: both as a register and a method of community 
notification. Because of this, each of these unofficial registers has been embroiled in controversy at various times. Coddington was sued for defamation soon after the publication of her first Index (Coddington, 2012, March 11), and the Sensible Sentencing Trust was forced by the Privacy Commissioner to take down their register in its entirety in late-2018 following an investigation which found they had a "continuously negligent, cavalier, and dangerous approach to privacy" when it was revealed that they had wrongfully included a photo of an innocent man on their register after he was reported to them as a sex offender by a member of the public (Privacy Commissioner, 2018).

Early in her parliamentary term, a Members Bill drafted by Coddington was drawn - the Sex Offenders Registry Bill 2003. The Bill represented the first legislative attempt to regulate those convicted of serious sexual offences through registration (New Zealand Parliamentary Library, 2003). The Bill promised to "protect the most vulnerable members of the community, our children" (New Zealand Parliamentary Library, 2003, p. 1). It sought to establish a government-held database of sex offenders for use "as a crime-fighting and law enforcement tool" (Coddington, 2003a). Though it initially received cross-party support, the Bill ultimately failed to proceed after being tossed between Select Committees for three years. The Bill's failure to proceed beyond the Select Committee process is of particular note given the nature of this research. Considering both the relative ease and the momentum with which the 2016 Bill passed through the legislative process, we can see hear a shift in thinking. This shift is an indication of the turning of the tide away from protection of individual rights within penal systems, and toward the preservation of public safety instead.

In 2021, almost five years after the creation of the Child Sex Offender Register, the case of $D$ v New Zealand Police [2021 NZSC 2] was heard in the Supreme Court, and a majority decision deemed the retrospective application of registration to offenders convicted before October 2016 to be illegal. This result required that approximately 600 individuals to whom the legislation had been retrospectively applied would be removed from the register as of $9^{\text {th }}$ February 2021. Five weeks later, on $17^{\text {th }}$ March 2021, the Child Protection (Child Sex Offender Government Agency Registration) Amendment Bill was heard under urgency. The Bill, introduced by Minister of Police Poto Williams, served to override the decision of the Supreme Court and return all offenders who had been removed from the register following 
the Supreme Court decision. The Bill stated explicitly that the registration requirements set out in the legislation apply to child sex offenders irrespective of whether they offended or were convicted before or after the act came into force. The Bill passed into law in a matter of hours with almost universal cross-party support - only the Green Party, once again, voted against it on the grounds of the breaches to human rights and lack of evidence of the efficacy of registration. As Green MP Golriz Ghahraman (2021) stated during the First Reading of the Bill,

\footnotetext{
“this isn't a good piece of legislation. It weakens human rights in New Zealand, it undermines the separation of powers, where we've heard from our Chief Justice, our President of the Supreme Court, telling us that this amounts to a breach of the New Zealand Bill of Rights Act. So the Attorney General, the Supreme Court, we've heard from the Human Rights Commission on this, and we're doing it anyway, with very, very little good."
}

This legislative amendment constituted an extraordinary measure taken by parliament to retain a system of registration that was very clearly and publicly established as a significant contravention of human rights and legal limits. The very quick succession of these events is an excellent illustration of the aforementioned decline of protection of individual rights, and the rise of the protection of perceived 'public safety' - which, as in this situation, has been able to override long-established legal limits.

\section{Community Notification and Risk Society}

Like registration, community notification has emerged amongst attempts by stripped-back, disconnected, neoliberal governments to be seen to retain control over particularly grave risks to the community - one of the consequences of the way in which the 'Risk Society' (Beck, 1992) has broken down traditional class structures and bonds and the way of life associated with them. Pratt and Anderson (2016, p. 539) have referred to these attempts by governments in relation to risks posed by sex offenders as "spectacular rescues" extraordinary measures undertaken by governments that exceed previous limits on punishment and regulation, carried out for the express purpose of containing risk otherwise 
posed to the public and for conveying the message to the public that the government is still in control, despite all the other messages it gives about individuals needing to take care of their own risks. Such risk-driven penal policies (e.g. preventive detention, extended supervision, 'civil detention' - that is, custodial detention beyond the expiration of a finite sentence on the basis of continuing risk) seek to remove or heavily control risks within the community, therefore effectively removing responsibility for risk management from individuals and reallocating it to the state. These rescues occur despite the reality that, since the neoliberal political and economic reforms of the 1980s, much of the responsibility for both community and personal safety has been delegated to individuals. Community notification seems to occupy a middle ground among risk-driven policy responses in that it is demonstrably a process of risk delegation, notwithstanding that the state usually retains some role in the process.

When formal community notification is carried out, the government notifies individuals within communities to enable them to protect themselves against what Simon $(2007, \mathrm{p}$. 168) has called "intolerable risk", that is, unpredictable risk of irreparable harm to individuals. The idea of intolerable risk applies Beck's (1992) concept of 'uninsurable' risks initially discussed in terms of environmental risks against which society cannot insure itself to the interpersonal risk posed by strangers. Unpredictable sexual attacks by strangers fall into this category of an intolerable risk of irreparable harm - that is, sexual harm that causes both physical trauma and lasting psychological trauma.

For legal scholars such as Andrew Ashworth (2002), community notification raises important issues of human rights; for others, in the tradition of Michel Foucault (1995) and Stanley Cohen (1985) it suggests deepening of social control in the community. In contrast, I approach community notification through the prism of risk. My foundational hypothesis is that all forms of notification are intended to control, manage, and prevent risk, which then pertains to the bigger question of how risk in everyday life has become such a central feature of modern societies. In particular, risk has led penal arrangements to stretch beyond the boundaries previously set for them in modern society and has simultaneously redrawn the concept of human rights: protecting the public from risky individuals now has priority over protecting individuals from state over-reach. 


\section{Risk and Public Protection in Modern Society}

Beck (1992) argued that the contemporary preoccupation with risk reflects the unanticipated consequences of modern technology in producing new kinds of risks. In this way, social organisation has become reflective of scientific and technological development, and as a consequence, concerns about risk have brought an end to much of the stability, security, and sense of safety of the post-1945 era. The reliably solid foundations of community life have been cracked and chipped away as the state has withdrawn from areas of public life it once occupied, particularly in the form of successive rounds of neoliberal reforms.

Neoliberal political and economic reform from the 1980s onwards has exacerbated risks already present; risks that have resulted from technological development (i.e. climate change from industrial and agricultural practices) (O'Malley, 2004). Where risk was once restrained by government regulation in the form of economic controls and social welfare provisions, the tidal wave of deregulation that accompanied neoliberal reform from the 1980s onwards served to set risk free from its previous constraints. For New Zealand, this meant a rapid transition from what had been one of the most comprehensively regulated economies in the developed world, to one of the least regulated. These reforms produced some constructive effects, creating opportunities for individual advancement, enabling freedom of choice, and creating new opportunities for wealth, extravagance, and personal enhancement. But while the reforms had significant consequences for the economy and the public sector, they also produced dramatic change in the nature of community life. They produced anxiety and insecurity amongst individuals, because they systematically stripped away the previous ties and loyalties that had secured the individual's place in their community; through work, community groups, and family relationships (Pratt, 2015).

Through these reforms, formal collectives (such as unions) were largely disempowered, and collective power has continued to be eroded since that time. During the 1970 s and early 1980s there was growing disruption to the solid, cohesive society that New Zealand had become. This was reflected in growing challenges to the idea of traditional division of labour and family life as women began to join the labour force in growing numbers; social and 
environmental movements protesting over land rights for Māori and threats to New Zealand's ecology caused by some of the government's industrial policies (e.g. dam construction); and a growing sense of frustration amongst large sections of the population at the lack of freedom of choice and associated development of personal identity that government regulation prohibited. The mass protests against the 1981 Springbok rugby tour encapsulated this sense of fragmentation, cutting across class, gender and ethnic lines, and showing the divisions between traditional 'solid' sections of New Zealand and those, predominantly in metropolitan areas, longing for a New Zealand society free from its traditional ties and solid but increasingly unpopular and unsustainable foundations.

Within the 'risk society', anxiety and insecurity have had a definitive influence on the worldview of individuals, driving much penal policy development throughout the main English speaking liberal democracies in particular (New Zealand, Australia, Canada, United States, United Kingdom). In these respects, protecting the public from risk of future harm has become a prominent feature of the penal systems of these jurisdictions. As will be shown in this thesis, the particularities of New Zealand's neoliberal restructuring that began in 1984 and which saw it move, to use terminology from Zygmunt Bauman's (2000a) Liquid Modernity, from 'solid' to a much more 'liquid' consistency, meant that the state's withdrawal from many of the areas of life it once occupied created opportunities for wealth creation and self-enhancement for many in the private sector; but it also created cracks in the foundations of community life, leading to increased levels of anxiety around the risk posed by strangers now that informal community controls, warning signs, modes of integration and acceptance had broken down.

The transformation of the authority of the central state through neoliberal reforms has driven a reliance on punitive law and order regimes to provide a sense of security and stability to the public. Neoliberal restructuring entrenched free market and liberal values in the economies and social institutions of these societies. This involved the deregulation of economies; privatisation and corporatisation of state assets; the winding back of government regulation of family life, employment, and media; along with a wide range of social, political and economic reforms that served to cement liberal values, and restrict the role of the state. While punitiveness has been observed throughout these societies, it is also 
the case that there is a newfound inability, or perhaps a lack of willingness on behalf of state bodies to govern without the threat of exclusion from society using penal regulation (Bauman, 2000a; Garland, 2001; Pratt, 2015).

Of all the limitations on state intervention to come out of the 1980s, diminished state provisions of security for both the individual and the community have had a particularly acute effect. This restructuring has meant that individuals have been expected to take much more responsibility for their own risks. In return for individuals gaining much more freedom of choice around the use of their income, and how they want the course of their lives to develop, they must also accept these responsibilities in relation to self-management of risk, and responsibilisation more generally (e.g. the requirement to self-manage risks to personal health including eating, drinking, smoking, sexual health etc). Nevertheless, governments are reorganising criminal law and penal policy to provide protection in very specific circumstances, especially around certain types of risk and its management or removal - the most serious risks we might face.

In this thesis I argue that this reorganisation of criminal law and penal policy represents new political obligations of governments in risk society. These protections are only offered in very specific circumstances, and protection is not offered against a range of other potentially catastrophic risks (e.g. theft, fire, natural disasters) where individuals as responsible citizens are expected to provide their own protection (e.g. insurance, crime prevention technology). This narrow set of risks are those that are thought to be unable to be insured against and are perceived to be so serious that the neoliberal influenced governments are prepared to go against traditional liberal values and intervene to prevent the terrible harms that are imagined to result from them.

The thesis examines one example of these kinds of risk-driven actions undertaken by governments compelled to manage what they perceive as an intolerable risk - the release of sex offenders from prison. Such actions are undertaken despite the neoliberal circumstances traditionally limiting state intervention - even if it means pushing aside previous norms, principles, and conventions that had cautioned against such preventive strategies. While governments are unlikely to address systemic causes of social issues, nor 
the full scope of the problems like the sexual victimisation of children in the family, they are motivated to provide bespoke, reactive responses to specific instances of the risk posed by these ex-prisoners. Such instances become symbolic of the state's apparent willingness to act to protect those thought to be at greatest risk in these particular circumstances. These responses are believed to placate an anxious public, and therefore shore up political support. While the true magnitude of the problem of sexual victimisation of children is unlikely to be affected by these kinds of reactive government responses, this is not the intention of such action. Risk-driven responses serve to demonstrate state capacity to control these particular risks and to thereby retain support for governments whose authority might otherwise be undermined by the perception of any lapses under their watch. The execution of community notification in New Zealand gives an indication of the contours of this issue: the seemingly ad hoc nature of government action and significant intervention can be contrasted with very similar circumstances of risk exposure within communities in which government actors took no action at all, or took deeply controversial and inappropriate action.

\section{Risk Control in New Zealand Penal Policy}

The last decade has seen a range of these risk-driven preventive strategies established for adult offenders in New Zealand, including the creation of civil detention through Public Protection Orders (PPO's are indefinite post-sentence custodial detention orders for individuals deemed to be very high risk of imminent violent or sexual offending), the increase in use of preventive detention (e.g. from eleven such prisoners in 1981 to nearly 300 now), the strengthening of Extended Supervision Orders, and the establishment of the Child Sex Offender Register. Each of the penal policy initiatives listed above seeks to curtail or eliminate the risk of harm (sexual harms and harm to children in particular) from the community. The de facto practice of community notification also seeks to control these particular kinds of intolerable risks, in this case through alerting communities to the presence of the known threats that exist among them. I argue that the engagement of individuals with community notification processes is driven by the need for known risks of these types of harms to be controlled like they are for other risks, and by a tendency to distrust the state's ability to effectively manage these risks on behalf of the people. These 
incentives are variably present in any one community and are relative to its degree of liquidity. From the perspective of the government, de facto notification provides reassurance to the public, delegates responsibility for personal and family security to individuals, and therefore serves to protect the government against reputational risks.

Such measures to control risk represent a different mode of governance to that of increasing punitiveness by increasing sentence length and the associated mass incarceration, on which most of the attention of the sociology of punishment literature has been focussed to date (e.g. Garland 2001). In contrast, risk prevention guards against future crime. In the 'risk society', new principles of justice have emerged and in so doing, have reshaped much of criminal law, creating the imperative of efficiency, rather than due process. 'Due process' hinders efficiency, and a more utilitarian form of criminal justice based around efficient risk control is emerging in its place (Pratt and Lutyens, 2022). Traditional justice principles are being redefined as part of this process. They are no longer intended to safeguard the rights of individuals from the state's penal extremes, as used to be the case, but instead safeguard the protection of the community from those individuals who would put their wellbeing at risk, through many of these same kinds of initiatives which were previously thought to constitute excessive penal powers.

Within this risk-based mode of governance, it is children who are perceived to be particularly vulnerable to these intolerable risks. It will be argued that this is so because their position in modern society has become more inherently precious and pure in the course of restructuring (as well as much rarer because of demographic changes), to the extent that they therefore must be protected from risks that would otherwise endanger them. Despite the withdrawal of the state from much of mainstream public life, it has been in this area especially that throughout these jurisdictions the state has performed its 'spectacular rescues' and in the process has redefined understanding of human rights in this area: protecting the public from those individuals posing such risks now trumps the protection of individual rights from state over-reach. 
The absence of notification legislation in New Zealand has not prevented community notification procedures from becoming embedded in practice. Despite the strength of privacy laws in New Zealand (set out in the Privacy Act 1993), de facto notification occurs on a regular basis and through a range of mechanisms, both legal and illegal. These notifications vary in their legitimacy and level of formality, and are inconsistent and ad hoc. It is unclear to the public when legitimate notifications should be given, and through what channels. Similarly, it is difficult to predict when members of the public will conduct notifications, and to identify the source of the information that individuals choose to share.

New Zealand is a country with a small population well known for its social connectedness, as well as for the radical, overnight reforms which transformed the nation's comprehensively protected economy into a broadly neoliberal markets in the 1980s. New Zealand's communities are therefore environments primed for notification on a number of levels: even a small scale notification (i.e. one school principal being notified by the Department of Corrections of the release of a registered person) can very quickly become a nationwide news story due to the 'two degrees of separation' in the country - the measure of the close social distance between New Zealanders. This has only been intensified by the ubiquity of social media and the consequential speed, reach, and permanence of community notifications deployed on these platforms. Social media notifications by members of the public about a wide range of harms and offences are rampant, and vary widely in their reliability. High profile instances of sex offender notification through social media in New Zealand have included posts of varying levels of legality: the violation of name suppression through posting a name online; individuals uploading photographs of suspected 'paedophiles' acting suspiciously at children's playgrounds; copies of Police warning letters sent to school communities warning parents to be vigilant due to the proximity of 'a sex offender' posted on Facebook; campaigns for the removal from the community of specific individuals known to have offended. Social media serves as a platform for public outcry around many issues, with sex offenders and their presence in communities eliciting unusually consistent and vituperative responses. In addition to social media, members of the public in New Zealand communities have engaged in notification through the distribution of pamphlets, reporting to the media, community meetings, and word of mouth. These grassroots processes have all also occurred in response to legitimate and 
formal notifications from the government, and have led to vigilante action in a number of cases.

The de facto nature of community notification in this country has thus created significant inconsistencies in the way the practice is carried out, including by whom, how, the level of legitimacy, and the effects. While the Department of Corrections and the New Zealand Police conduct formal notifications governed by internal policy, a range of informal (and sometimes illegal) notifications are frequently carried out through leaked information, by concerned citizens, and via the media. While the power of state actors to notify has been expanded in recent years, the willingness and ability of concerned citizens and the media to participate in community notification also appears to have grown.

Legitimate methods of community notification include those regulated by internal policies and processes within government departments (for example, New Zealand Police and the Department of Corrections), and the release of details on 'public interest cases' by the Parole Board. Though these types of notifications most often violate the right of the concerned individuals to privacy, public interest and public safety concerns are considered to override privacy rights in such cases (New Zealand Parole Board, 2019). In addition to access to Parole Board reports, journalists are able to follow cases from 'list day' (the day the hearing is publicly listed in court) all the way through the criminal justice process, and follow up with publications upon an offender's expected date of release. These processes all constitute varying kinds of community notification, formal or otherwise, and all operate within the bounds of the law, despite the lack of legislative warrant and the regular inconsistency with the Privacy Act. Notifications outside of the bounds of the law also often occur with the involvement of government officials (e.g. the New Zealand Police and the Department of Corrections).

The illegal notification found to have been carried out by the New Zealand Police in Brown v Attorney General of New Zealand [2006] is an example of one such case. In 2006, Barry Grant Brown, previously convicted of sexual offences against children, had been released on parole to an address in Kilbirnie, Wellington. Following his placement in the community, two police officers, one uniformed and one plain clothed, went to Brown's house, entered, and 
took photos of him, stating that they were for 'identification purposes'. The officers then returned to the police station and prepared a flyer on the New Zealand Police letterhead containing Brown's personal details and photograph, and proceeded to distribute it throughout nearby streets and to local businesses. As a result of this community notification, Brown was the victim of physical assault on two occasions, in addition to receiving hate mail and verbal abuse from the community (Dalziel, 2008). Brown successfully sued the Police under the tort of privacy, and for Bill of Rights Act violations, and was eventually awarded $\$ 25,000$ in damages by the court. In responding to the illegal behaviour of the officers involved, the New Zealand Police claimed the officers were acting of their own volition, without instruction or permission from the Police, and that the New Zealand Police do not condone or allow any such behaviour (Atkin and McLay, 2012). The Brown case serves as an interesting example of the fractious and deficient systems in place to regulate the personal information of offenders, even within an institution with existing procedures around notification, and which today hosts the Child Sex Offender Register.

At the same time, sensational reporting on 'exceptional' cases seize the public imagination, and foster an 'absolute otherness' fostered by the perceived complete detachment of offenders (particularly sexual offenders) from social norms (Greer and Jewkes, 2005; Jewkes, 2015). Exacerbating this otherness serves to perpetuate fear among members of the public, and the media often appears to reflect wider demands for greater government intervention in the regulation of sex offenders following these kinds of events. The case studies analysed in this thesis explore the validity of the picture of community responses painted by the media through an exploration of the perspectives and experiences of community leaders.

Regardless of the lack of legislative mandate, notification evidently occurs, then, on a de facto basis in New Zealand, whatever the comments of legislators and judges to the contrary. The consequences of notification are frequently punitive for the individuals concerned, and following the completion of an individual's sentence, these consequences 
are likely to constitute further punishment. ${ }^{4}$ This research explores the contradictions of this environment that effectively legitimises forms of double punishment for such offenders, and the ways in which the government are increasingly moving to symbolically protect the public, and women and children especially, from the imagined threats posed by monsters and beasts, while they remain vulnerable to many other more significant threats and anxieties brought about by restructuring.

The depth of the neoliberal values of the state is demonstrated through the individualisation of the problem of child sexual abuse in this country, with little recognition of the systemic and social-cultural drivers of this kind of offending. This is again symptomatic of the risk society, and is demonstrative of a chief concern of the government being management of reputational risks, rather than measured control or management of risks to the public. The optics of being seen to be acting in the interests of protecting children from the intolerable risk of sexual harm from strangers takes precedence over any genuine attempt at harm reduction through evidence-based community programmes or interventions.

\section{Bauman, Community Notification, and the New Zealand Case}

Community notification is symptomatic of the permeation of the risk society into all areas of the lives of individuals, including protection against risks posed by individuals convicted of sex offences and released into the community. In New Zealand, a combination of delegation of responsibility to individuals, and spectacular rescues by the state has created an unpredictable and seemingly flexible system of regulation for sex offender control and release. The official avenues for notification are murky and inconsistent, and the unofficial (and often illegal) means of notification cause problems for communities and individuals on release alike; however, they have also been instrumental in the revelation of government incompetence and poor, possibly dangerous, decision making. This is where Bauman's

\footnotetext{
${ }^{4}$ See Judge Harrop's comments in the 2019 Hannis case regarding the 'penalty' of name suppression being lifted for the defendant as a related example of the punitive impact of public knowledge of offending on an individual who has been convicted $R v$ Hannis [2019] NZDC 1272 DC (NZ).
} 
(2000a) Liquid Modernity becomes central to the argument that will be developed in this thesis.

In that book, he argues that the fluid nature of life in modern society has brought about profound changes to all aspects of the human condition. Bauman explained that the modern state is shifting away from the hitherto solid, anchored, and hardware-focused modernity, and toward a light, software based 'advanced' modernity. The solid nature of the former had meant that western societies were previously much more dependable in their provision of services, security, and safety. However, liquidity and lightness have since come to refashion and reorganize our understandings of what is valuable in the modern world. Bauman explained that the safety nets that had previously existed in many forms, including structural features like social welfare, the dependability of the traditional nuclear family, and community ties and values, quickly began to fade into obscurity as neoliberal economic changes took effect. This economic restructuring added to the demands for greater individual freedom, including freedom to consume, after the 1970s to create the beginnings of the 'liquid state' - as was the case in New Zealand.

Since neoliberal reforms commenced, the preoccupation of individuals with risk, and the way that it narrows the possibilities of everyday life has had a defining impact on individuals and on the structure of modern society. While being exhorted to take care of themselves and plot their own way through life in the free market society that may then lead to fabulous wealth for the lucky winners, individuals now find themselves with none of the previous supports and landmarks to guide them. One impact of this has been the ways in which 'risky individuals' are seen to pose a particularly severe threat to the wellbeing of those in the community. In seeking to explain responses of communities to the release of 'risky' individuals, the thesis will show how such risks have been dispersed unevenly around New Zealand communities, who in turn demonstrate uneven responses to them.

Drawing on empirical research centred around community notification in New Zealand, this thesis demonstrates the complexities inherent in diverse communities that have their own socio-cultural histories. Within this research, I identify gaps in the Baumanesque idea that, having been set free from economic restraints, risk has then brought about the destruction 
of social cohesion, security, and collectivity - all of which assumes a homogenous population. Instead, I show how diverse communities experience 'destruction' or dissolution through their responses to community notification, which in turn allows me to make a statement about the state's use of it. The experience of community notification is shaped in large part by the level of trust the community holds for the central state and its representatives, and the contours of this experience are much more complex than the media would make them seem. The state's use of notification, as established in this research, is poorly targeted and managed, is perceived by communities as unclear and ad hoc, and therefore often has the opposite effect within the community to what the state intends.

\section{Chapter Overview}

Following this introduction, Chapter Two locates this research within the broader context of the criminology of risk, giving primacy to the contribution of Bauman, and unpacks the dual impacts of the uncaging of risk in modern society. The setting free of risk has produced a range of opportunities previously unavailable to individuals. Although these opportunities have improved the lives and lifestyles of many, there have also been profoundly harmful impacts, and the relationship between these and the benefits is explored in this chapter. Risk is examined here with particular reference to sexual harm, as well as the related position of children within the consideration of sexual risk within the community.

Chapter Three sets out New Zealand's suitability as a particularly good case study through which to assess Bauman's argument because of its size, its unique parliamentary system, and because of the way it enthusiastically undertook an aggressive neoliberal agenda from 1984 onwards. The neoliberal reforms and their impacts are assessed in context in this chapter, and the progression of New Zealand from one extreme to the other on the spectrum of regulation is considered alongside the spectrum of liquidity in terms of Bauman's Liquid Modernity.

Chapter Four sets out the methodological approach and the methods used for gathering empirical data for this project. To assess the ideas set out in Liquid Modernity in a New 
Zealand context, I carried out an investigation into the way that risk was understood in three diverse communities that had each experienced community notification: Whanganui, Napier, and Ōtāhuhu. To gather data, I conducted in-depth qualitative interviews with community leaders, those who are formally or informally charged with being responsible for the wellbeing of their community or at least a significant part of it. Community leaders who took part in my research included elected officials, school principals, media representatives, business leaders, representatives of the not-for-profit sector, healthcare representatives, and other grassroots community leaders. Within this chapter, I will describe my personal experience of seeking approval for this research through the Human Ethics Committee at my university as an excellent example of risk-driven regulation and reputational risk management by an institution.

The findings are discussed over Chapters Five, Six and Seven, these chapters tell the story of the case from Whanganui, Napier and Ōtāhuhu respectively. These chapters each illustrate the local context, before unpacking the circumstances of the community notification event and describing the community's reaction (or lack thereof). The dominant themes from the interviews are then discussed in detail, and the results are discussed as developments in our understanding of the way Bauman's Liquid Modernity can operate in an applied community context.

Chapter Eight describes a spectrum of responses to liquidity; where some individuals are willing and equipped to dive into the liquid modern world, while others cling to what remains of solid ground, paralysed by uncertainty and unable to embrace the opportunities afforded by this new mode of life. Bauman had much to say about the dire reaction of the insecure individual to risks and challenges within modern society. This thesis, however, develops and extends Bauman's theory in the empirical context of three New Zealand communities to explain their different reactions to the release of sex offenders within them. 


\section{Chapter Two - Understanding Risk and Criminal Justice in the Shift from 'Solid' to 'Liquid' Society: The Centrality of Zygmunt Bauman}

In seeking to understand the place of post-sentence regulation and other risk-driven measures implemented by neoliberal states, it is essential to analyse the construction and consciousness of risk. Within criminology, the place of risk and the way it is considered has shifted over time, and debate continues today over its causes and effects. This chapter addresses the social and political implications of the criminological literature on risk and examines the way in which risk has come to reshape much of criminal law, as well as the nature of community life. It goes on to acknowledge the literature around the duality of risk; that is, the positive impacts of the uncaging of risk on individuals and their lives, as well as the ongoing negative impact of deregulation and the winding back of safety nets. Bauman's work is particularly salient in the discussion of the effects of the duality of risk, and Liquid Modernity is examined in this context before being applied to the case of New Zealand community life.

\section{Locating Risk in Criminology}

A body of literature accounting for the impact of risk and dangerousness on criminal justice policy has been developing within criminology since the 1970s. Tony Bottoms' 1977 lecture Reflections on the Renaissance of Dangerousness, addressed the penal policy changes then occurring throughout the United Kingdom that adjusted focus from treatment, to prevention and containment of the threat of dangerousness. While the frequency of use of incarceration as a sentencing measure was declining, the use of very long sentences increased as courts sought to contain dangerousness, and the traditional and ethical limits of criminal law began to be tested (Bottoms, 1977).

Sociologist Ulrich Beck popularised the term 'risk society' in his eponymous 1992 text, in which he argued that the preoccupation of modern societies with risk is an unanticipated outcome of modern scientific and industrial development, free from the constraints of time and space, and exacerbated and perpetuated by modern media. Beck (1992, p. 26) described apocalyptic developments in the nature of risk, stating that historically, "risk had 
a note of bravery and adventure, not the threat of self-destruction of all life on Earth" whereas now it did. As such, his work focussed on the negative outcomes of risk, but with no acknowledgement of opportunities or benefits created through the harnessing of certain forms of risk. Alongside the catastrophic consequences the unleashing of risk has had for some individuals and communities, it has also produced opportunities for wealth creation and lifestyles previously unimaginable. Instead, he concluded that risk had brought to an end much of the stability, security, and sense of safety of the post-1945 era. Beck (2002) later summarised that modern life is characterised by 'risk consciousness': not only are there more risks, but the risks present within society today are created and everexacerbated by the union of capitalism and technology. As both capitalism and technology develop, so too do the breadth and depth of their terrible powers to destroy all of life on Earth.

While the idea that we are living in a 'risk society' was first discussed by Ulrich Beck (1992) in the German context, and by Anthony Giddens in the British context (1990), risk for critical criminological purposes emerged in Feeley and Simon's 1992 assessment of 'the new penology'. This work expanded the consideration of risk into the domain of parole and risk assessment specifically. Over time, the depth of analysis of risk and its determinative impact on penal policy has developed. Ericson and Haggerty (1997) and Doyle (2007) argued that the term 'risk society' has come to encompass both the original definition intended by Beck (1992), as well as the 'governmentality' element influenced by the ideas of Foucault (1991). As Levi (2000, p. 592) noted,

\footnotetext{
"this move away from the language of punishment, drawing heavily on languages of risk, management, knowledge, and common-sense - representing a mix of expert and non-expert rationalities - has developed into a strategy for advanced liberal governance in the area of criminal law."
}

Risk is now able to drive policy, regardless of a dearth of evidence or the violation of the foundational legislative and justice principles. The growth of the 'risk society' has led to the reorganisation of significant areas of penal policy: in these areas it increasingly focusses on 
preventing risks of future harm rather than responding to crime that has already been committed.

More broadly though, the message from a stripped-back state is that individuals should manage their own risks - the government cannot and should not do this for them. The governments of these societies are now much more limited in the ways they are willing or able to intervene to assist citizens, as their powers and responsibilities have been systematically dismantled over decades of neoliberal governance, delegated to individual citizens who are held responsible for risk management (i.e. managing personal health, security, financial risks). The risk driven policy agendas that are produced as a result should not be viewed as a sign of the strength of the state, but rather the opposite - they are a sign of the state's weakness. No longer equipped to take a comprehensive preventive approach to crime or risk management, governments step in to take symbolic action only when the spotlight of public attention is drawn onto the gravest risks. Simon (2007) explains that modern governments have taken to 'governing through crime': utilising anxiety and fear of crime to achieve secondary objectives (e.g. generation of political capital). The results of governing through crime have included the undermining of democracy and the increase of racial polarisation. The creation of 'the crime problem' has influenced the way individuals live their lives within society. Rather than making citizens more secure, governing through crime has fuelled perceptions of crime as being 'out of control' and consequently a culture of disproportionate fear of crime.

However, alongside the effects on the lives of individuals, the effects of neoliberal economic reforms in these societies has driven a reliance on increasingly risk averse law and order regimes, and has produced an inability to govern without the threat of exclusion from society (Bauman, 2000a; Pratt, 2015; Pratt, 2020). While governments appear to be unwilling to intervene in much of community life due to the deregulated neoliberal form of political and economic organisation (alongside the implementation of new public management), symbolic intervention can be observed in the context of criminal justice, where we see the execution of risk driven 'spectacular rescues' used by the state to shore up the appearance of power and therefore generate political capital, especially when communities are faced with intolerable risks (Pratt and Anderson, 2016). 
Richard Ericson (2007a) similarly argued that the intensification of criminalisation is the strongest public statement of authoritative certainty by a government, regardless of that government's actual level of authority and certainty. Ericson (2007a) agreed that neoliberal ideology has triggered the twenty first century anxiety about uncertainty; in particular, the consequences of the uncertain world of market-based competition. This uncertainty is pervasive throughout modern life. Governing through uncertainty has replaced the traditional risk management processes of the twentieth century, and responding to insecurity has risen to the top of the political agenda within these societies (Ericson, 2007a). Ericson (2007b) argued that the neoliberal ideology has facilitated an obsession with uncertainty, including by governments preoccupied with the consequences of the uncertain world of market-based competition. In this context, movements by government toward criminalisation and stronger sanctions become the strongest statements of authoritative certainty that can be made by the state, regardless of that government's actual level of authority and certainty. Among these kinds of state responses to pervasive uncertainty has been decisive risk driven law and order policy, including large-scale criminalisation of those deemed likely to pose risk of future harm (although they may not yet have committed a criminal offence).

Alongside criminalisation, throughout these jurisdictions a significant delegation of responsibility from governments to citizens for crime control and security has occurred (as it has for other areas of life, including healthcare and financial security). Responsibility for crime prevention and control has been deputised to businesses, schools, neighbourhoods, families, and individuals. The traditional model of criminal law has been radically transformed in the neoliberal context, leading to the erosion of due process standards in the name of risk management and security (Ericson, 2007b). One consequence of this has been the rise of the private security industry - the development of security hardware, technology, and personnel for individuals, homes, so much so that businesses have barely kept up with the voracious market for private protection which, from the 1980s on, has continued to grow (Blackstone and Hakim, 2013; Bradley, 2016; Davis, 2006). 
Garland (2006) explained that once security ceases to be guaranteed to all citizens by a sovereign state, it tends to become a commodity that, like any other, is distributed by market forces rather than according to need. It follows, then, that the movement of the state toward wholesale incorporation of free market values has allowed the commodification of security. Despite the growth of private options for risk management on the market, within the neoliberal context of risk, it is still the law that functions as the institution for responding to uncertainty and governing the future (Ericson, 2007b). The precautionary legislative process of criminalisation involves the creation of malicious demons, which Ericson calls 'Leviathans', by the state, and the subsequent legislative attack on them to reassure society that the government has firm control of security and risk. It is against such Leviathans that the state exercises its rescues to quell its citizens (Pratt and Anderson, 2016).

\section{Risk, Pleasure, and Pain}

It is important to consider that, although the unleashing of risk has had devastating consequences for some who have been left behind by liquidisation, there have been significant benefits to individuals and society through deregulation and the freeing of various kinds of risk from previous restraints placed on them. O'Malley (2004) built on Beck's work, arguing that risk, already present in modern society due to the consequences of technological development (e.g. catastrophic risks created by humans that threaten our survival such as climate change), has indeed been magnified by neoliberal political and economic developments. However, O’Malley (2010, p. 7) also discussed the potential benefits of risk consciousness, explaining that the shift toward 'risk society' may offer "the potential for the reconfiguring of risk in more optimistic, socially inclusive, and constructive fashion" than has been previously imaginable. Pratt (2020) gives many examples of the ways we harness and optimise risk for pleasure: through adventure tourism (a major market in New Zealand) for example; engagement in risky sports; international travel and so on.

The deregulation of the economy through privatisation, corporatisation, removal of restrictions on trade, and the freeing up of public currency trading created the opportunity for the generation of incredible wealth for successful entrepreneurs. The speed and scale of 
wealth accrual was unprecedented. Individuals were suddenly able to choose whether or not to take risks, which was a significant departure from the previous situation where the state held responsibility and accountability for the financial stability of citizens. Those willing to take risks might then be able to generate wealth in new ways, as well as spend their wealth to develop new kinds of lives.

Indeed, in the course of deregulation, the possibilities of everyday life were transformed. Pratt (2020) explains that the modern concept of 'lifestyle' was created during this period, and the variety in lifestyle was greater than ever before. Opportunities for wealth creation and accumulation suddenly seemed available to all who were willing to take risks becoming rich was no longer the exclusive privilege of a small upper class minority. Increasing emphasis on material wealth and its trappings were evident in the public conversations about money, and the increasing variety of ways in which it could be spent. Billion dollar industries in fashion, fitness, cosmetics, and wellness, were kickstarted in the 1980 s, and continue to grow today. Bauman (2004, p. 113) captured this phenomenon with his summarising that "beauty, alongside happiness, has been one of the most exciting modern promises and guiding ideals of the restless modern spirit." In Liquid Times, Bauman (2007, p. 57) expanded on this idea of the preoccupation of individuals with the domain of the body and the self as their last remnant of control, explaining that

\footnotetext{
"modern society, having replaced the closely knit communities and corporations which once defined the rules of protection and monitored their application with the individual duty of self-interest, self-care, and self-help, has been living on the quicksand of contingency."
}

Thus, the work of Bauman provides a particularly salient analysis of the duality of risk, as well as its effects.

\section{Bauman on the Implications of the Duality of Risk}

Bauman used the metaphor of 'liquidity' to describe and analyse everyday life in late modern society. He posited that previously, human life had been organised around certainty 
and predictability (i.e. in personal relationships, work, community life etc). Where the finite and predictable possibilities of the past could be represented by solidity, liquidity now represents the infinite and hitherto inconceivable pathways and possibilities of the present and the future. The fluid state of modern existence contrasts with the way that previous generations had a fairly clear image of their path through life. Within relatively homogenous societies like New Zealand, there had been minimal variety in levels of wealth, lifestyles, religious affiliation and tradition, family structure, and culture. These societies that fit Bauman's description of life before the 1980 s can be described as 'solid state'. People living in such societies had their lives clearly plotted, with informal social controls and state regulation serving to curb any risk of the obstruction of their anticipated and rather limited and unambitious pathway.

Liquid Modernity explains the causes and effects of the state of modern life. In this text, Bauman described the impact of the economic and political reforms of the 1980s and beyond, and how they affected individuals trying to navigate their lives within a shifting and increasingly fluid world. The extensive incorporation of private sector values into the public sector in the 1980s brought an end to the social democratic provisions of the post-1945 era, such as the cradle-to-grave social welfare and decades of state guaranteed security. The shift toward the privatisation and corporatisation of the economy was intended to foster the growth of entrepreneurialism and private sector values amongst individuals. In other words, they have to compete against each other for the rewards that neoliberalism has made available. These rewards included diversity of lifestyles; freedom of choice; and diversification of culture, taste, and experience made possible through deregulation and globalisation. According to Bauman (2000a), this neoliberal restructuring combined with demands throughout the 1970s for greater social freedoms for individuals to foster the creation of liquid modernity.

In explaining the contrast between the liquidity of today and the solidity of the past, Bauman uses the example of light and heavy capitalism. The Fordist model of capitalism involved "fixing workers to the chain", creating conditions under which they were virtually certain to serve their entire careers in one company (Bauman, 2000a, p. 58). Post-1970s, however, capital travels light, and values mobility and flexibility over predictability and deep 
roots. While capital has become light and mobile, labour has not necessarily kept up. Today, labour is often as immobilised as it was in the past, however those looking to anchor themselves to a solid and certain foundation (such as the Ford factory line) struggle to find one. The liquidity of the modern world, and the light capitalist structures that accompany it, require those wishing to succeed to become equally light and mobile in order to reap the rewards of the new structure of society.

With this transformation, the traditional anchor points that previously served to guide people through solid state life become impractical weights that compromise the lightness and mobility prized by the modern individual. In a fluid world filled with infinite possibilities for lifestyles and the accumulation of capital, it is the individual who must take risks and navigate their own uncertainty to obtain the rewards accessible to those who can travel light and chase them. Bauman (2000a, p. 61) explains that rather than the historic pursuit of a certain end through uncertain means, the liquid society instead requires individuals to consider

\footnotetext{
"in the face of all the risks known or merely guessed, which of the many floating, seductive ends 'within reach' (that is, such as that can be reasonably pursued) offer priority."
}

The result of this transformation is profound uncertainty for the individual, and the relative surety that individuals will be immobilised by the choice between infinite goals, or by the many financial and lifestyle goals that appear to be 'within reach'. In a society where nothing seems static or permanent anymore, individuals are constantly required to seek new information and adjust to new modes of life.

In a liquid society where lightness and mobility and freedom of movement are the keys to economic and social promotion and success for individuals, immobility, in contrast, "exudes the repugnant odour of defeat, of failed life, of being 'left behind'" (Bauman, 2000b). Life goals are discussed with reference to forms of mobility, and the 'good life' is one occupied with freedom of choice, and the spatial element that this has conspicuously acquiredfreedom of movement (Bauman, 2000b, p. 216). Immobility and lack of willingness to take 
risks feeds the existential insecurity of individuals within this environment. To understand this existential angst, it is important to examine Bauman's account of the drivers of liquid modernity.

\section{Introducing Fluidity: Social, Economic, and Political Reformation}

During the post-war period, the state implemented economic policies that prioritised control of risk, protection of the economy, alongside (in the case of New Zealand) the universality of the welfare state. These arrangements left little room for individuals to take risks or make gains for themselves, as society as a whole was largely protected from market volatility and risk. Bauman (2000b, p. 205) summarised that

"modern liberal societies were organised around a compromise wherein a measure of individual liberty was exchanged for collective economic security."

This economic arrangement facilitated the predictability and homogeneity typical of the solid-state society. However, the economic protections did not shield these societies from the economic crises of the 1970s and early 1980s.

The prosperity of the post-war period was brought to a sudden end with a series of events that heavily regulated post-war economies were ill-equipped to handle. The effects of the oil shocks of the 1970s rippled throughout the world, and the subsequent economic crises spread through the global economy. At the same time, the strengthening resolve of the counter-culture movement saw it growing rapidly: Black civil rights; indigenous rights; gay rights; women's rights; demands for freedom of expression and freedom of choice.

Frustration with post-war control and solidity combined with the uncertainty and instability brought by economic crises to produce growing dissatisfaction with the idea that the state should keep risk under control through heavy regulation and manipulation of market forces (Pratt, 2020). The implementation of neoliberal models of policy and economy represented a monumental shift away from collective responsibility, towards individual freedom - and responsibility for risk management that came with this. Neoliberalism prioritises individual 
freedom of choice above all else: it represents the untying of the individual from the collective structures and regulations that had previously protected them from risk and the unknown. With the deregulation and privatisation of the market, the individual was now free to make economic decisions without state regulation blocking their path - and without state protection if risk taking exploded in their face. This new model of society allowed then "a trade off of collective security in exchange for the maximization of individual choice" (Bauman, 2000b, p. 205). Management of economic risk was delegated to the individual, creating sought after freedom of choice and opportunity for previously unimaginable financial gain, as well as opportunity for dramatic failure and loss.

The plethora of social changes that occurred throughout the 1970s had begun the shift toward enabling freedom of choice for the individual. This was then taken further in the political and economic reforms of the following decade. Delegation of responsibility for financial risk and protection to the individual represented an additional transformative change for societies still coming to terms with the social transformations of the 1970s. This period was a particularly volatile time of social reform, where various rights movements and historical events triggered social policy change, as well as the new possibilities within the lives of individuals.

The traditional, predictable lives of the post-war years had been punctuated by common milestones, or anchor points. These included the selection of a lifelong career; early marriage - for example, in 1971, one third of brides in New Zealand were teenagers (Pratt, 2020); purchase of a home; and having children - the average number of children per New Zealand family in 1971 was 3.19 (Statistics New Zealand, 2021). Thereafter, for most what awaited them was a quiet retirement: the New Zealand government facilitated such aspirations by introducing a non-means tested universal pension scheme in 1976 which paid $80 \%$ of the average wage to those 60 and older (Superannuation Schemes Act 1976). However, with ensuing restructuring, as Bauman argues, these milestones no longer come with any degree of certainty or guaranteed longevity, nor are they even desired. Social movements and associated reforms afforded individuals greater opportunity to manage their lives. For women, the introduction of welfare for single mothers, as well as more widespread availability of the contraceptive pill offered the promise of freedom from 
dependency on men to finance and maintain the traditional family unit. Individuals were enabled by reforms and changing social norms to be more selective about their own destiny than ever before. In such ways, modern society began to reassemble itself in a very different fashion from before. The advancement of individual choice brought about by deregulation was prioritised over and above any sense of collegiality or solidarity with society or the state.

Within this new model of society, the traditional importance of communitarian values and social solidarity were traded for the increased value attributed to individualism. Bauman (2000a, p. 40) argues that within the liquid society, the public sector consistently "fails to perform its past role" as the strategic principles of public power have frayed into escape, avoidance and disengagement. Where the state has disengaged from and avoided its previous commitment to broad-based social and economic support, since the 1980s it has withdrawn from the provision of social services for the community. The confidence of the population in the power of their central government declined as the tendency of the state to intervene in public life was curtailed, and as the state retreated from areas of life it had previously occupied. Within the liquid society, private interests now ruled, and the state that once strongly defended the autonomy of the citizens, began to require defence itself as it continued to shrink away from its past strength and status (Bauman, 2000a).

With this rise of individualism, there has been an associated decline in the power of the state. Bauman (2000a, p. 51) argued that with the loss of the state's "awesome and resented oppressive potency", public power has lost a good part of its enabling capacity. The neoliberal reforms shifted focus toward the maximisation of individual freedom, and as a result, the public sphere has been redefined and authority has been diversified.

Prioritising individual freedom within economic and political reforms had significant effects on society. Bauman (2000a) explains that the absolute maximisation of individualism in the modernising world resulted in the demise of certainty. In the modern world, "few defeats are final, few if any mishaps irreversible; yet no victory is ultimate either" (Bauman, 2000a, p. 62). This liquidity enabled many risk takers to obtain great success, with ever-increasing opportunities and power to choose available to those with will and means. It has enabled the creation of the ultra-rich, born of capitalist excess and free market opportunity. 
Individuals like Bill Gates, Elon Musk, and Steve Jobs are therefore able to build reasonable levels of wealth into eye-watering sums. These tech billionaires that have risked it all and won big have achieved wealth on a scale previously unimagined, and are the ultimate symbols of the promise of liquid life. For those who are frozen and unwilling or unable to take such risks, the profound uncertainty of modern life could be overwhelming. In a state of uncertainty and resultant insecurity, the community has become a symbol of the traditional, solid-state way of life.

\section{The Refuge of Community: Remnants of Solidity}

Bauman (2000a, p. 182) posits that within a shifting and fluid society, the vision of community "is that of an island of homely and cosy tranquillity in a sea of turbulence and inhospitality." Community, the only shelter in a stormy sea of uncertainty offers individuals a sense of refuge, and the value of this refuge only increases as other elements of life become "ever more capricious and unpredictable" (Bauman, 2000a, p. 182). When the community becomes a symbol of a last refuge in the stormy and uncertain sea of liquid modernity, defence of the last remnants of solidity within society becomes important. This pursuit of order, predictability, and solidity is a

\footnotetext{
"desperate attempt to impose uniformity, regularity and predictability on the human world, the kind of world which is endemically diversified, erratic, and unpredictable" (Bauman, 2000b, p. 206).
}

However, the pursuit of solidity within the community is at odds with the direction in which modern society is shifting. As liquidity spreads, the traditional community as it was known melts away and ceases to exist. As Bauman (1995, p. 275) explained, "modernity spent most of its time fighting communities", and communities of this traditional sense are the natural antidote to the fracturing and anxiety caused by liquefaction.

Traditional community and the associated strong informal social controls provided protection against unpredictability and insecurity. Bauman (2000b, p. 208) summarises Nils Christie's explanation that personal familiarity creates in us a drive to prioritise 
compensation for harms done over retribution, because "we know too much" to seek the application of the narrow legal framework. However, in the liquid modern world we are surrounded by people we do not know and who we will never know, and the tendency to seek exclusion and retribution, as well as protection from strangers, is therefore greater. "Estrangement reduces, thins down and compresses the view of the other" (Bauman, 2000b, p. 208). Gone is the civility that hitherto allowed us the ability to interact with strangers without holding their strangeness against them (Bauman, 2000a, p. 104). We now seek to detect and exclude those who might threaten our sense of security, or pose a risk to the thin veil of order. In explaining this witch-hunt model of modern 'community' life, Bauman (1995, p. 274) explains

\footnotetext{
“Very seldom do 'single issues' manifest or enhance the sentiment of moral responsibility for common welfare. Much more often they mobilise sentiments against, not for... they divide more than they unite."
}

In this vein, we see the creation of temporary communities of interest fighting against a threat: to redistribute the unsavoury elsewhere, be it environmental risks, social risks, risk posed by individuals. Single issue actions attract unusual bedfellows as they are driven by the self-interest of individuals - the solidarity is not what it once was, as these individuals act together only in order to exclude a threat.

Bauman (2000b) outlines this 'paradigm of exclusion' through which order is maintained throughout modern societies. Bauman (2000b, p. 206) discusses 'order' and 'norms' as "sharp knives pressed against society... they are first and foremost about separation, amputation, excision, expurgation, exclusion". Order is an anchor, it enables predictability and is sought in particular by those overwhelmed by the uncertainty of liquid modernity. Order must be maintained, and excluding those who do not conform from the community is the result of an "impulse which draws its impetus and strength from the concern with the installation and preservation of order" (Bauman, 2000b, p. 207). To maintain this order, the excluded must be incapacitated and immobilised, for the good of all those within the community as well as the excluded themselves. Exclusion is predicated on the belief that "the excluded are unfit to be free agents", and that they would bring great harms and 
disasters upon themselves and others should they be allowed freedom (Bauman, 2000b, p. 207). Exclusion allows individuals within the community validation of the status of the excluded as 'others'. Bauman (2000b) maintained that the shift toward more punitive penal arrangements occurring across the west is a symptom of the existential insecurity generated by social and economic conditions. This existential insecurity manifests in a number of ways, including an intolerance of the 'other' - individuals who have not been able to keep up with the new social order. Threats to the new order must be physically constrained and immobilised through risk control procedures - a particularly apt punishment in the age of mobility. Society is more atomised and fractured than ever before - we live among people we don't know and will never know, and as a result of the insecurities and anxieties this produces, othering and exclusionary policies are created (Bauman, 2000b).

Within Liquid Modernity, Bauman argued that, as a consequence of the weakened, shrunken state, there exists a perpetual state of insecurity and uncertainty through which individuals must find their own way. The relinquishing of responsibility for 'society' by the state in the course of neoliberal reforms meant that individuals became responsible for their own welfare and security - the safety nets hitherto provided by the state were scaled back or removed altogether. Citizens are required to take the initiative and make the most of opportunities afforded to them. The tension between this expectation and broad ontological insecurity exacerbates anxiety and exclusion, and feeds doubt:

"in the ever more insecure and uncertain world the withdrawal into the safe haven of territoriality is an intense temptation" (Bauman, 2000b, p. 214).

Political discourse had come to be filled with 'tough on crime' one-upmanship between opposing parties, each desperate to be seen as more determined and merciless than their political adversaries (Bauman, 2000b). Increasingly, this discourse has developed into promises of risk containment, abatement, and removal, with particular attention given to controlling and restricting certain types of undesirable 'others'. The "forcible eviction" of non-conforming others from social life through imprisonment is seen as "an effective method to neutralise the threat, or at least to calm the public anxiety which that threat invokes" (Bauman, 2000b, p. 213). These threatening 'others' within the community 
crystallise the anxiety and insecurity felt by individuals, and can galvanise them into something of a collective once more (Bauman, 1995). Public safety and protection of children in particular from the ills of an unpredictable world must be ensured at all costs.

\footnotetext{
"Preoccupation with personal safety, inflated and overloaded with meanings beyond its capacity due to the tributaries of existential insecurity and psychological uncertainty, towers yet higher over all other articulated fears, casting all other reasons of anxiety in yet a deeper shade." (Bauman, 2000b, p. 215).
}

This uncompromising attitude toward protection of children that developed across the $20^{\text {th }}$ century presents an opportunity to govern through crime. Executing 'spectacular rescues' of the community's children from the threats posed by convicted sex offenders otherwise placed there by the state itself allows the appearance of a secure and helpful government, one which prioritises the needs of the community. In reality, the risk-driven rescues executed by governments rarely serve a purpose beyond shoring up political capital through being seen to be acting to protect the community - especially its children - from risk. For individuals unable to process risk calculations, any state action of this kind might appear benevolent.

As the importance of personal and public safety have grown within liquid society, the ability of the individual to manage information and responses to risk have not grown in kind. Bauman (2000a, p. 45) explained that:

\footnotetext{
"the diffusion among the unwise of genuine knowledge that was acquired by the wise would be of no help, for through its diffusion or dilution, knowledge inevitably transforms itself into opinion, prejudice, or mere belief."
}

The distribution of information to individuals unqualified and unprepared to receive it is insufficient to enable them to make informed decisions. In the case of community notification about the release of sex offenders for example, the pre-existing stigma and the media firestorms that frequently surround these cases make these situations all the more difficult for the average person to sensibly navigate once they are given information (i.e. the 
approximate location of a local sex offender on release). This is particularly salient with regard to the pursuit of the protection of children from the risks such offenders may pose to them. The construction of the child within modern society has a determinative influence on the reactions of communities to perceived threats to them.

\section{Risk and Sexual Harm}

The advent of 'spectacular rescues' and the legislative focus on controlling risks developed from the 1980s toward the aim of containing risk of sexual harms, and those harms committed against women and children in particular. In the US, registry laws for sex offenders were developed in an attempt to centralise information about their personal information and locations, and to regulate the concentration of offenders around areas where children are likely to congregate (including schools, parks, beaches, bus stops, and other public amenities). The establishment of federal legislation enforcing registration followed the 1989 kidnapping and sexual murder of eleven-year-old Jacob Wetterling. The Wetterling Act was soon expanded following the sexual murder of seven-year-old Megan Kanka in 1994. Megan's Law created federal notification requirements, enforcing the release of the information contained in the Wetterling registries to the public. Some states, counties, and cities also mandate (through local ordinances, parole license conditions, or probation orders) that sex offenders are not allowed to reside within up to 3,000 feet of locations where children are likely to congregate - essentially evicting many offenders from urban life entirely (Anderson, In Press; Pratt, 2015). The United Kingdom's Sexual Offences Act 2003 similarly bars sex offenders from visiting schools or parks (Pratt, 2015). Registration and community notification requirements again show the willingness of the state to selectively intervene to control specific types of risk.

In addition to the heavy regulation of individuals convicted of offences who have subsequently been released into the community, restrictions on the movement of those individuals identified to pose significant future risk of specific kinds of sexual offending have been enacted throughout these societies. Pratt and Anderson (2016) explain that the Sexual Offences Act 2003 sought to prevent future sexual harms in the UK by including anyone participating in, or seemingly about to participate in, a so-called 'trigger event' - activities 
including waiting outside a children's playground. This focus on prevention removes the customary presumption of innocence, and allows the state to intervene and regulate individuals before any offence has occurred. Similar controls have been created for the prevention of sexual harm in the Anti-social Behaviour, Crime and Policing Act 2014 (United Kingdom); the preventive supervision of sex offenders for up to a decade in the Parole (Extended Supervision) Amendment Act 2004 (New Zealand); and in similar legislation throughout states within Australia, Canada, and the United States.

The drive to prevent future criminality and contain risk, instead of penalising crimes already committed, imposes a new moral imperative on penal systems. The traditional framework for western penal policy incorporated foundational principles of democracy and justice, including swiftness, proportionality and equality, and with no retrospective legislation. Policies that violate these principles have in recent years been permitted in the name of the protection of community interests: governments have allowed community safety and public protection to trump all other considerations, including individual human rights. Risk has become a determinative factor in penal policy, and rather than representing the strength of the state, once again these exclusionary policies represent the loosening of the state's fragile grasp on power. Containment and removal of extreme interpersonal risk has become the role of governments eager to show their citizens that they are performing their obligations to them, and in so doing confirm and sustain their political legitimacy. In the process of so doing, rights come to be redefined in terms of the public's right to protection against these risks, rather than the individual's right to protection from arbitrary and excessive use of state power. In so doing, the state confirms and sustains its political legitimacy by seemingly offering its citizens protection from the gravest risks they face (Pratt, 2020).

The pursuit of risk management, containment, and removal by the state has occurred with little acknowledgement of the imprecision of many of the risk assessment tools and algorithms used to operationalise the aforementioned policies. Harcourt (2007, p. 5) argued that 
"the mechanics that are triggered by the use of actuarial methods in the criminal law are problematic in the vast majority of cases... the mechanics are prone to misfire."

Despite this, use of actuarial tools and methods has grown exponentially in western criminal justice systems throughout the twenty-first century. These algorithmic and psychiatric predictions of risk have long been acknowledged by experts as profoundly flawed. Psychiatric predictions in their early form were critiqued by Steadman (1973). Following his study of the 'Baxstrom patients' created by the 1966 US Supreme Court verdict that detention of an offender in a facility managed by the Department of Corrections after the completion of their sentence was unlawful without proper expert review, he concluded that psychiatric predictions of dangerousness were overly conservative (Steadman, 1973). He made the critical assertion that there was a definite "tendency to institutionalise many people who are not dangerous, rather than to inadvertently release the very few that are" (Steadman, 1973, p. 193). The discovery of the tendency to detain the many to protect society from these few dangerous individuals was exacerbated by the faith put in the reports of experts like psychiatrists, whose capacity to predict dangerousness was "firmly held and constantly relied upon, in spite of a lack of empirical support" (Rubin, 1972, p. 397). The process of psychiatric prediction of dangerousness was therefore determined to be highly unethical due to its lack of accuracy, with a failure rate of at least $50 \%$ according to Steadman's (1973) research. Experts have known for fifty years that risk prediction of psychiatric/clinical assessment is fraught by design, yet we have seen the expansion of sentences and policies built on this problematic foundation.

As McSherry (2020; 2014) explains, throughout the twentieth century, preventive laws driven by early forms of risk assessment were regarded with suspicion by judges (for the reasons outlined above), and largely fell into disuse. Following Steadman's (1973) early concerns about the catch-all effect of psychiatric tools used to predict dangerousness, in 2000 he continued to argue that more individuals than necessary were being incarcerated as a result of clinical assessments of dangerousness (Steadman, 2000). Since this time, there has been a shift away from clinical determination as a sole predictor of future dangerousness, toward more algorithmic and actuarial calculations. As McSherry (2020, p. 20) explains: 
"risk assessment tools have become a part of preventive justice schemes because of an increasing political emphasis on public protection rather than on safeguarding the rights of individuals."

Risk assessment instruments have been viewed as more objective than clinical or psychiatric assessments of future dangerousness. As Hannah-Moffat (2013, p. 279) explains,

\begin{abstract}
"actuarial instruments continue to be appealing because of their purported ability to classify offenders based on a set of 'defensible' statistically relevant factors, without the need to rely on clinical discretion, and because they offer the prospect of greater certainty."
\end{abstract}

However, McSherry (2020) explains that the use of these predictive tools and technologies remains highly contentious, and their design and use raise a litany of ethical and legal questions. For example, the use of actuarial risk prediction requires the inherently problematic application of group data to individuals, and these base data sets have frequently been criticised for lack of consideration of the diversity of the population. As Brown (2020) explains, the use of these aggregate data sets, often assembled primarily from the data of North American male prison inmates, produces a fundamental ethical problem in that individuals are being rated on a population scale compiled using the data of others. Brown (2020, p. 57) continues that such "risk assessment does not treat the individual in their specificity and individual humanity".

Hannah-Moffat's (2005, p. 31) analysis has shown room for optimism and growth within actuarial risk prediction, and the focus on a "transformative risk subject" amenable to therapeutic interventions. While Hannah-Moffat's research indicates that risk prediction technology can work to optimise rehabilitation and reintegration outcomes, as McSherry (2020, p. 38) explains, the entrenchment and dominance of "structured professional judgment" (a blend of predictive technology and clinical assessment) in countries including Australia and New Zealand, and thus retain (at least in part) the biases and problems associated with individual judgments of risk and dangerousness. 
Despite this trend toward risk prediction and containment, it is important to note that the declared purpose of criminal justice is not to predict and prevent future offending. Although imprisonment inherently serves a secondary purpose of incapacitation, the foundational principles of justice do not allow for potential future crimes to be punished. This is why there is an insistence from governments that the interaction between agents of the state and released sex offenders is purely 'regulatory'. The implementation of 'regulatory measures' avoids questions of injustice and human rights around the 'punishment' of individuals following the end of their sentences. In a similar vein, the use of 'regulatory measures' has worked the other way to funnel 'anti-social' individuals into the criminal justice system. The advent of Anti-Social Behaviour Orders (ASBO's), first used against young people in the UK, enabled police to use discretion to determine when anti-social behaviour was occurring, to serve an anti-social individual with such an order, which upon breach would constitute a criminal offence (Anti-social Behaviour, Crime and Policing Act 2014). The use of risk-based regulatory measures and sanctions has thus widened the net at both ends of the justice system.

Risk-based regulatory measures are increasingly employed by the state to cleanse the community of 'risk'. This is particularly true for particular kinds of sex offending, the risk of which policy and legislation have sought to control and remove. This could be viewed as an example of strategic ignorance on the part of the government, as they have access to evidence and advice around effective risk management in communities, and yet they choose to engage in ineffective and triggering regulatory measures instead. As McGoey (2012) argues, in this instance strategic ignorance can be a valuable asset for politicians seeking to assert expertise and shore up political support. This scenario provides a dramatic contrast with the more evidence-based penal policy process in place throughout much of the twentieth century. Pratt (2007) set out the decline of the authority of criminal justice officials in favour of populist policies which commenced in the late 1970s, when the decline of the rehabilitative ideal began to shift the penal trajectory away from its previous course which had been based around judicial discretion and Parole Board adjudication. Rather, as Freiberg (2003) confirmed, sentencing policy and decisions now needed to be made in light of the 'views of the public'. 
From Bauman's insights on the way in which post-1970s restructuring has fundamentally reorganised the possibilities of every day and the attendant anxieties and opportunities for self-enhancement that have come with this, I will now examine how shifts in the nature of criminal justice policy relate to the shifts from 'solid' to 'liquid' in community life over the same period.

\section{Risk and the Child}

The place of the child within the family and the community has shifted over time. Valentine (1996) argued that the western construction of childhood has oscillated over centuries between representing children as the bearers of original sin - "devils", or as innocent "angels". Throughout the late twentieth the discourse about childhood has reinforced the "innate innocence and vulnerability" of children, and the resulting need to protect them at all costs (Valentine, 1996, p. 586). Zelizer $(1985$, p. 3) similarly found that the end of the twentieth century saw the advent of the "economically 'worthless' but emotionally 'priceless' child" - the supremely vulnerable and precious child. In the 1970s and 1980s in particular, Best (1990) explained that the wave of progressive social reform brought with it anxieties and new anxieties about threats to children posed by devils and other threats.

Vulnerability is a defining feature of the way children are conceptualised today. Furedi (2003) took this further, arguing that vulnerability is now viewed as a defining feature not just of children, but of the human condition, which has resulted in safety becoming a core value of the modern individual. In this world of risks, strangers are not to be trusted, as they represent a risk not worth taking. In discussing risks posed to the vulnerable modern child, Furedi (2003, p. 127) describes the "neighbourhood without neighbours" - where once the neighbourhood would serve as a community with a shared interest in the socialisation of children, the modern parent is now obsessively on guard against risky strangers within the neighbourhood. With the atomisation of communities and their dispersal into the liquid society, the collectives that had previously existed to support the socialisation and upbringing of children have melted away. The construction of the preciousness and vulnerability of the child are characteristic of the late twentieth and early twenty first 
centuries (Best, 1990), and this can be compared to the attempts by early twentieth century governments to encourage citizens to take better care of children within families and communities. At the beginning of the twentieth century, President Theodore Roosevelt proclaimed that "the nation should attend as much to its child crop as to its farm crop", and the creation of a government industry around child abuse was subsequently triggered in the US (as quoted in Hacking, 1991, p. 266).

Hacking (1991, p. 266) is deeply critical of this development, calling the industry "a bureaucracy in search of a job". He is equally critical of the figures that were used to represent the scale of the child abuse problem throughout the twentieth century in the US. In 1970, an estimated 7000 children in the US suffered at the hands of abusers. By 1981, this number had exploded to 1.1 million children. As Hacking (1991, p. 272) explains, "change in reporting procedures can move us from 7000 to say 30,000 , but only change in definition can catapult us from 7000 to 1.1 million". A range of academics drew similar conclusions, sceptical of the sudden and ferocious focus on protecting the pure and vulnerable child from the evils of society - sometimes in a literal sense as in the moral panic around Satanic ritual abuse (de Young, 2004; Jenkins, 1996; Nathan and Snedeker, 1995). Hacking sought to establish child abuse as a malleable truth - impermanent and transforming. He also proposed that the changing nature of the concept will be forgotten: soon "lost to conscious memory" as we increasingly rely on its broad definition as an absolute truth (Hacking, 1991, p. 286). The rise of the child abuse movement gave credence to those 'decidedly cautious individuals' who were presented with a growing and credible threat to the safety of their children. Despite this critique of the scale of the problem and the government's bureaucratic response to it, Hacking (1991, p. 257) described the phenomenon as responsible for effecting "the most valuable heightening of awareness of his lifetime". Like Bauman, Hacking's work emphasises the fragility of norms, and the transience and impermanence characteristic of modern life.

Hacking (1991) exalts the work of Mary Douglas in his discussion of 'non-distributable risks' in relation to the sexual abuse of children. These non-distributable risks are Hacking's alternative to Pratt's (2016) concept of the unavoidable risk of irreparable harm. Hacking (2003) argues along the lines of Beck (1992) that the worst types of risks cannot be insured 
against (hence being 'non-distributable'), and that their central component is a loss of purity, coupled with pollution of the individual. Purity and pollution are central to Hacking's conceptualisation of risk. Hacking explains that they form a partnership that governs modern values as much as they have historically fixed borders between groups and determined risks. In the case of fear, the difference between 'real' and symbolic pollutants is irrelevant, because the boundaries are blurred, and symbolic pollution is what moves people to action most effectively. Child sexual abuse would be included as such an assault on purity.

Hacking (2003, p. 43) therefore proposed that the most striking new long-term fear is that for our children: "a fear that our children will be defiled, subjected to unspeakable filth". He concedes that his argument around the fear of the un-distributable risk of pollution or assault on purity fails to explain the inflated importance of the risk itself. While Rose (2000), and in a similar vein Pratt (2020), both analyse the root cause of risk, Hacking recognises that his work serves to predict how the risk will be experienced through fear and the movement of borders.

Hence children hold a unique position within the risk landscape, and a decidedly precarious position within the community. Increasingly scarce children have become increasingly precious. The birth rate in New Zealand continues to drop year on year - 2020 saw the lowest birth rate ever recorded in New Zealand (Statistics New Zealand, 2021). In 2020, the BBC ran the headline Fertility rate: 'Jaw-dropping' global crash in children being born, confirming the universality of the scarcity of children across much of the world (Gallagher, 2020). As communities within the main English speaking societies have atomised, the preciousness of children and their status as one of the few certainties in an uncertain liquid world has resulted in a multifaceted response from individuals within society. On the one hand, tolerance for strangers who would threaten to harm precious children is extremely low: community notification produces extreme adverse responses to the release of child sex offenders in particular on a regular basis. On the other hand, little action has been taken to prevent the statistically more significant risks of sexual abuse of children within the home over the same period. 


\section{Risk and the Community}

Bauman (2000a) recognised that the idea of community can be seen as a form of safe haven against the anxieties and insecurities beyond its limits, and it became a highly valued commodity itself amidst all of these insecurities. The ideal of community provides stability and security for those within its bounds, and grounds people in some form of belonging and homogeneity. It also allows the obscuring of 'otherness' and capitalises on the benefits of familiarity, including the dominance of desire for simple compensation for any harm done, over desire for retribution and punishment within the penal sphere (Bauman, 2000b). However, within liquid modernity the brittleness and transience of bonds between individuals may be an unavoidable price for the right of individuals to pursue their own goals, and yet it is simultaneously a most formidable obstacle to pursue them effectively (Bauman, 2000a). The atomisation of the community has rendered human bonds fragile, and has made individuals less tolerant of those who are different: 'other'. Growing public intolerance can be linked to a decline in social capital. The decline of social capital throughout these societies generally began in the 1970s, accelerating with the neoliberal reforms of the 1980s. Robert Putnam (2000) provides the United States as a case study of this phenomenon, utilising the official membership of community groups as a helpful barometer of community involvement and cohesion, and that American membership slumped from the 1970s onwards. The 1960s had been the peak of community group involvement and religious worship in the United States, with community activity continually increasing up to this point, and more Americans worshipping together than any time in history (Putnam, 2000, p. 19). The social capital that these networks, created through community activities and religious worship produced held value in their ability to affect the productivity of individuals and groups. As this social capital has dwindled, communities have become less cohesive, losing the stability and security by which they were once characterised. As Bauman (2000b) states, we now live in areas among people we do not know, most of whom we will never know, and this divorces the individual from any empathetic obligation he once had to his neighbour. The safe haven of the community has melted away, leaving individuals vulnerable to misunderstanding, and lacking empathy for their fellow members of society as focus has turned inward, toward the family unit. 
People desire to be among a community for their own safety, and traditional communities are becoming increasingly difficult to find in modern society (Bauman, 1995).

"Men and women look for groups to which they can belong, certainly and forever, in a world in which all else is moving and shifting, in which nothing else is certain" (Hobsbawm quoted in Bauman, 2000a, p. 171).

It is important however to consider the traditional form of community accurately, as there is a tendency to accept rosy retrospect about safe communities of days gone by - it is often the case that retrospect actually alters the perception of the 'good old days' (Bauman, 2000a). Though the community may never have been the homogenous and concerned body it is often nostalgically remembered as being, it is certainly true, as Putnam (2000) argues, that communities have become fragmented with the process of modernity. Dunkelman (2014) similarly details the impact of this fragmentation on politics and lifestyles in modern cities, where despite proximity, relationships between neighbours have 'vanished', along with the value previously drawn from incidental interaction of individuals with their local community. Despite the urbanisation and condensing of the population, spatial proximity has not translated into strength of community bonds, and the community continues to become increasingly atomised over time (Bauman, 2000b). This is perhaps most evident in apartment living, where individuals are organised into units in extremely close proximity, and yet may never interact with those living their lives metres from theirs.

Gated communities are one option for those with money to recreate the security benefits previously afforded by a tightknit, traditional community. The ultra-rich are able to add additional layers of security to their walled off homes, borrowing design techniques from overseas embassies and military command posts in search of 'absolute security' (Davis, 2006, p. 248). The design of housing and communities is one element of the broader proliferation of private security services. Although the US leads in this area, all comparable jurisdictions have generally seen the steady rise in private security registration, as well as features like patrols, hardware (home alarms etc), monitoring, armed responses (Bradley, 2016; Davis, 2006; O'Malley, 2010). As early as 2006, Davis (2006, p. 248) stated that "contemporary residential security in Los Angeles depends on the voracious consumption of 
private security services". For those unable to finance these forms of private security support, the only option is to depend on the provisions of the state. For some communities, the history of neglect and exploitation by various levels of local and central government make this dependence very difficult to accept. This difficulty is significantly exacerbated when the state knowingly distributes risks to those communities least equipped to deal with them.

Without an adequate sense of community, the "unholy trinity of uncertainty, insecurity and unsafety" can dominate the worldview of the individual (Bauman, 2000a, p. 181). The root cause of this anxiety is the absence of security surrounding the future (Bauman, 2000a). Bauman (2000a, p. 181) continues that this "unholy alliance" results in a perpetual thirst for more safety. The absence of the features of the traditional community allows the "other" who was once tolerated to become an alien, permanently locked in this condition, having been stripped of the personal uniqueness which alone could have prevented stereotyping and potentially mitigated the impact of the law (Bauman, 2000b). 'Others' of today have not always held their mysterious and threatening status on the periphery of society. As Christie (2000) explains, the personal familiarity that prevailed within the traditional community meant that concern over retribution and punishment were not often the natural reactions to harm done; instead these reactions were replaced with greater concern over compensation for harm. Bauman (2000b, p. 208) argues that estrangement has been the primary influence on the shift toward intolerance: modern community living entails living among people "whom we are unlikely to ever know". It is this estrangement within modernity that "reduces, thins down, and compresses" the view of the 'other', allowing media sensationalism to exacerbate imaginings, and resulting in a very low level of tolerance of 'others'.

Bauman (2000b) continues by arguing that among the consequences of the atomisation of the community has been the growth of the appeal of penal sanctions for the non-secure, individual. With the use of penal sanctions designed to prevent future risk, unwanted, unpredictable, and risky 'others' can be forcibly evicted from the unstable community through imprisonment, which is seen as an effective method to neutralise this threat, and consequently calm the public anxiety which they evoke (Bauman, 2000b). The threat of total 
exclusion from society through indefinite imprisonment or immobilisation within it through the form of permanent supervision, attracts the attention of the anxious individual as a certain cure for society's ills. In such ways, the dominance of insecurity and uncertainty among modern communities can aid in the perpetuation of reductionist and populist criminal justice policies, particularly those that seek to cleanse risky behaviour from society.

At the same time, the inability of individuals to rely on the state for basic security and protections has clouded the ability of individuals to consider criminal offenders, among other minority groups, as anything more than an unwanted risk (Pratt, 2014). This appears to be particularly true of individuals convicted of sex offences. The atomisation of the community exacerbates this stigma in the extreme, as individuals are almost solely reliant on the media to ascertain the details of the danger lurking in their communities (Bauman, $2000 \mathrm{~b})$. The deregulated modern media outlets do nothing to calm the fraught nerves of the increasingly isolated and insecure public: intolerance within the already atomised society increases with tabloid sensationalism, putting minorities including criminal offenders at risk. Bauman unpacks how a severe and overzealous reaction to antisocial, risky, or criminal behaviour can thus occur within the media and the community. This explanation can be applied to the experiences of sex offenders released into communities, as they are frequently presented with a barrage of obstacles to integration including negative media interest, public outcry, heavy regulation of movement, and exclusion from many spaces, workplaces, and social settings.

\section{Sex Offender Policy in Community Spaces}

The operation of the security sanction (that is, the state's restriction or removal from public space of those who threaten certain types of harm but who have not committed a criminal offence - see Pratt and Anderson, 2016) with regard to sex offender regulation in the community conforms to the two modes of social control explained by Cohen (1985): inclusion and exclusion. On a policy level, inclusion promotes integration, tolerance, diversity and absorption - the utopia of the invisibly controlling city (Cohen, 1985, p. 230). Inclusive policies spread the correctional framework selectively into parts of the community able to adhere to the layers of conditions imposed, allowing offenders to be released on a 
range of strict conditions. Exclusion on the other hand promotes isolation, banishment, and separation - the utopia of the purified city (Cohen, 1985). Exclusionary policies work to remove 'risky' individuals from the community altogether, creating a distinct separation between purity and deviance. Where incarceration has traditionally served the purpose of excluding deviant individuals from the community, with the rise of the security sanction, inclusionary policies are increasingly being superimposed onto the existing exclusionary model. This layering of contradictory inclusionary and exclusionary policies can be observed in sex offender regulation. Preventive detention, civil detention, and all forms of custodial detention are exclusionary policies that indefinitely remove 'risky' individuals from the community in the name of preventing future harm. Superimposed onto these are inclusionary policies including electronic monitoring, supervision orders, registration, and notification, all of which enable sex offenders to be released into the community (albeit the regulatory requirements dictate specific areas of the community into which they can be released). The result is a confusing landscape of risk containment and management, into which the community is involuntarily co-opted.

Cohen $(1985$, p. 218$)$ explained that "the response to real or perceived breakdown is to call for more regulation, order and control" - this is what we see with the use of law and order as a symbolic representation of state power through the execution of spectacular legislative rescues, as well as hyper-regulation of post-sentence sex offenders. Similarly, in seeking to expel unwanted or 'anti-social' individuals from society or from certain areas and communities, Sennett (1970, p. 98) argues that the fearful underbelly of the community is exposed: "the essence of the purification mechanism is a fear of losing control". The quest to exclude members of the community is driven by an exaggerated threat of fear and disorder (Sennett, 1970).

The rise of the security sanction has seen the stringent regulation of those deemed too risky, which has clashed with the traditional justice mechanisms in place to guard against excessive punishment and regulation. The result for many sex offenders has been the enforcement of regulatory mechanisms which are typically poorly designed in a hurry in order to provide a reaction to a particular incident, and for others the stark reality of indefinite detention. Through short-sighted policies not created on a basis of evidence, 
individuals convicted of sexual offences who fit the risk profile for the requirements of registration and/or notification can find themselves excluded from urban areas altogether. Due to the overlapping proximity of exclusion zones like schools, parks, beaches, swimming pools, playgrounds etc, these people can be driven to the outskirts of cities (e.g. living under motorways, sleeping rough), into rural areas, or the state may end up dispensing them to a location apparently deemed politically expendable (for example, in New Zealand, Whanganui or Ōtāhuhu).

The "risk" deemed by the state to be apparently intolerable for the home communities of these offenders is willingly transferred to rural and low socio-economic areas - the communities least equipped to manage these imported risks, and who have very little support from the state to do so. So, vulnerable communities become those most likely to be co-opted by the state as correctional spaces, without their consent, and sometimes without their knowledge. Affluent communities have been able to insulate themselves and their communities from changing social and economic conditions - including the extraction and redistribution of undesirables from their midst. Such communities have been better positioned to 'insulate home values and lifestyles' from the effects of a range of changing social and economic conditions (Davis, 2006, p. 244). It is in these wealthy areas that we see the rise of gated communities: protecting the elite few from the dangers of the outside world; while risk management of released offenders has largely been delegated to the poorest.

\section{Conclusion}

Bauman's body of work, particularly Liquid Modernity, provides a valuable lens through which the development of risk-driven penal policy and regulation in recent decades in New Zealand can be viewed. The fundamental premise of Bauman is that deregulation and neoliberal reform amongst modern societies are melting the previously solid foundations of society. This process produces both opportunities and problems, and the level of liquidity has a definitive influence on the way that individuals within these societies live their lives. For those stranded by the rising tide of liquidity, existential insecurity can be overwhelming, as they are stranded, unable to take up opportunities or move with the current. 
In these respects, Bauman's work forms the basis of the hypothesis that has been developed in this thesis, which examines the varying liquidity of New Zealand communities, and the implications and lived experiences of community notification in varying sociocultural contexts. Bauman's work does not include an empirical element, and this research develops the theory using empirical data. Chapter Three will explore the idea of a 'liquidising' New Zealand, through applying Bauman's ideas to the recent history of this country. In the results chapters, community notification will be examined as a risk response at both the government and the community level within a society that has undergone substantial and rapid social, economic, and political change in recent decades, and is therefore still wrestling with the balance between state action and inaction in a neoliberal, liquidising world. 


\section{Chapter Three - Liquid New Zealand}

New Zealand is a geographically isolated nation with a small population and relatively brief history, where neoliberal economic and political reforms throughout the 1980s and 1990s created a particularly radical transformation of the hitherto protected nation state economy. The implementation of free market values through neoliberal economic and political reforms disrupted the historic Keynesianism that had underpinned social and economic policy in New Zealand since the 1930s. The post-war promise of a quiet life where every worker was guaranteed the ability to earn a fair living to support his family was kept comfortably by the government up to the financial crises of the late 1970s. This was a tumultuous period for the global economy, and though the New Zealand government had insured its people against instability and risk to a significant extent, the global economic shocks of the 1970s tested the resolve of the promises and the strength of the safety nets provided by the state.

This chapter sets out the transformation of New Zealand from a 'cradle to grave' welfare state to its current status as a much more neoliberal society. This transition is foundational for the development of an understanding of the experience of liquid modernity in New Zealand communities, as the uncertainty created through the rapid speed of largely unforeseen and wide ranging changes in the late twentieth century in New Zealand was overwhelming for many. The extremity and rapid pace of change from the 1980s onward, and its profound effects make New Zealand a particularly fitting context through which to examine the uncaging of risk.

\section{New Zealand as 'Better Britain'?}

\section{Seeking a 'Classless' Society}

From the early days of the colonisation of New Zealand by the British, the country was referred to by (what were intended to be) charming epithets indicating its superiority to the motherland - 'Better Britain'; 'God's own country'; a 'classless' society. Edward Gibbon Wakefield, a British writer who became one of the key figures of the colonisation of New 
Zealand and Australia, engaged prolifically in this narrative. Wakefield was the founder of the New Zealand Company ${ }^{5}$ and later a Member of Parliament in New Zealand. Wakefield envisioned in these colonies a new world which preserved the best of British civilisation while avoiding its problems; where diligent workers could plausibly graduate to land ownership, and where the divide between serfdom and aristocracy seen in England would never be replicated (Phillips, 2014; Wilkes, 1994). Richard Seddon, Prime Minister of New Zealand from 1893-1906, embraced Wakefield's ideas, referring to himself as British, but "better British" for being from New Zealand. New Zealand was, in his words, "God's own country", devoid of the perils of strict class division and dense city life (Phillips, 2015). This idea of New Zealand as a 'better Britain' flowed into the consideration of the country as a 'classless society'.

\section{Considering Colonisation}

Of course, the rosy colonial ideal of New Zealand as a 'classless society' flagrantly ignored the alienation, dispossession and dislocation of indigenous Māori hapū (kinship group/s) and iwi (tribe/s) who were forced from their lands, often violently, by British colonial forces. It is important to make explicit that the trajectory of settlement described in this chapter was premised on the brutal removal of the indigenous Māori from their land through acts of war and law, and through systematic destruction of culture. While this history is not the central focus of this research, it nevertheless underscores the social and political landscapes I describe, and is seared into the 'solid' foundations of settler-colonial New Zealand (which was not an accommodating foundation for all). It follows, then, that the penal policies pertaining to the prevention of risk in these contexts will affect Māori in a manner that contravenes their human rights, but also their rights as tangata whenua (indigenous people/people born of the land) that were promised in te Tiriti ō Waitangi (Māori language version of the Treaty of Waitangi) in 1840. For this reason, I include in each of the results chapters a brief history of settler/Māori relations.

\footnotetext{
${ }^{5}$ The New Zealand Company was a private company set up in England by Wakefield, claiming to be a middleman in the sale of land in New Zealand to British settlers. Up until 1840, when the British Crown assumed the exclusive right to purchase land from the Māori people, exploitation by the New Zealand Company was extreme, including claims of the purchase of vast tracts of land from the Māori people (more than there was in the whole country) (O'Malley, 2019).
} 
For now, it is important to note that for the Māori people, from the 1800 's wealth and tino rangatiratanga (sovereignty) were systematically stripped from them by the British as the Crown employed the full range of instruments available to them to extend their control legal, political, social, judicial, and military (O'Malley, 2015). The colonial slogan “Jack is as good as his Master, and Jill is as good as her Mistress" drew British settlers out to New Zealand with the expectation of rapid wealth growth, including the opportunity of land ownership for the landless (Wilkes, 1994, p. 70). Despite the aforementioned claims that the colonial settlers had shed the shackles of class hierarchy on their voyage to the bottom of the world, there is no doubt that the presence and success of British settlers in New Zealand in the nineteenth century was built on the back of the gross exploitation, disenfranchisement, and dispossession of the Māori people (Wilkes, 1994). Following from this, with the implementation of neoliberal modes of governance and economic restructuring I will detail later in this chapter, it was small towns with significant Māori populations that tended to fare worst through deindustrialisation, deregulation and welfare reforms. Many of these small industrial towns in New Zealand (e.g. Kawerau, Wairoa, Whanganui, Tokoroa) were decimated by the impact of layers of significant changes, each serving to magnify the last: due to the intergenerational impact of colonisation, Māori are disproportionately likely to constitute the 'waste' (in Bauman's terms) of liquidising communities. In this vein, as in other colonised countries, the indigenous Māori people have been subjected to hyperincarceration on a grand scale throughout this period (Jackson, 1988; Martin, 2021; McIntosh and Workman, 2017). With the neoliberal reforms, it was therefore again the case that Māori were disproportionately and deeply disadvantaged by the actions of the state.

\section{Building a British Settlement}

Throughout the late $19^{\text {th }}$ and early $20^{\text {th }}$ century, British settlers continued to arrive in New Zealand, tempted by the advertising of the New Zealand Company, and the large amounts of cheap land available for purchase. As Wynyard (2017) explains, the (primarily British) settler population in New Zealand jumped from $\sim 2,000$ in 1840 , to $\sim 80,000$ in 1860, and the steadily increasing population drove demand for land, increasing the pressure for more land 
to be obtained by the Crown to sell to these settlers being encouraged to emigrate to New Zealand. Land wars raged throughout the late 1800 's, with settlers joining battles in which their "ruthless brutality" toward the Māori shocked even the British Imperial troops called up to defend the British settlements (Simpson, 1986, p. 161). Following these battles, the Crown used the Suppression of Rebellion Act 1863 to justify confiscation of land from Māori who "rebelled against the Crown" - further feeding in to the mass confiscation and alienation of Māori land (Wynyard, 2017, p. 19). Parallel to the brutality of these land wars, the myth of New Zealand as a 'land of milk and honey' where adventurous, hardworking settlers could leave the filth and social ills of the English cities behind was still being perpetuated in Britain, coaxing more migrants to this faraway land in the South Pacific.

As Spoonley (2017) explains, at the core of the desire to create a 'Britain of the South Seas' in New Zealand was a racial project designed to ensure that the population of this 'new' land would be almost exclusively white British settlers. Asian and Māori people were excluded through racialized 'othering', and the narrative of nationality in New Zealand drew upon the superiority of Europeans (Rattansi, 2005). Although the othering of Māori and Asian populations was quite different for each group, the end goal was the same: the creation of a white settler colony. Spoonley (2017) argues that this Euro-centric nationbuilding project did not change its core elements between the early 1800 's and the 1980s. It was through the subsequent neoliberal reforms that the reach of the state into immigration policy was hollowed out, and greater diversity in immigration began. However, the legacy of over a century of state-sanctioned racial othering had severe consequences. The 'yellow peril' was a racially motivated moral panic occurring throughout the final years of the $19^{\text {th }}$ century, during which 33 Acts were passed which specifically articulated the racialisation of Asian people (usually directed at Chinese people) (Spoonley, 2017). ${ }^{6}$ These racist immigration policies made possible the construction of a very homogenous white settler population in this colony, which came to share what became prevailing New Zealand values. These values included a high level of conformity, and a suspicion and intolerance of difference.

\footnotetext{
${ }^{6}$ Racialising legislation included measures to separate Asian workers quarters from those of other workers; implementing arrival taxes on Asian immigrants; restricting numbers of Asian people that could arrive on any ship (Spoonley, 2017).
} 
These values included a deeply embedded friendliness - a trait of New Zealanders that can be traced back to nineteenth century accounts of the local people. Captain Isaac Cooper (1857, p 30, as quoted in Pratt, 2006) said of New Zealanders: "[their] houses are freely open for the use of friends and travellers are welcomed with kindness without display." Five decades later, Duff (1941, p.82) stated that "visitors to the Dominion have often remarked on our readiness to shake hands". This friendliness and related cohesion, homogeneity, security, and conformity found in early New Zealand society led to the colony regularly being described as a 'paradise' (Pratt, 2006). Pratt (2006) explains that the moral and social environment of New Zealand contributed to this status as a 'paradise': it appeared to be a country with everything Britain had to offer, but with none of its undesirable elements, in particular the absence of the rigid British class structure.

The extremes of wealth and the aristocracy seen in Britain were not replicated in this colony to any great extent in the early days of settlement. Following the establishment of the New Zealand Company, migration to New Zealand was largely controlled through this channel, and therefore consisted of British settlers. Would-be British migrants had to meet standards set by the Canterbury Association (as quoted in Pratt, 1992, p. 30):

\footnotetext{
"[ideal emigrants should be] under 40 years old, and preferably between twenty and thirty, and he was required to produce a medical certificate and a certificate from the minister of the parish that the applicant is sober, industrious, and honest, and that he and all his family are amongst the most respectable in their class in the parish."
}

These ideals illustrate the traits being sought in new New Zealanders - not academics, artists, and thinkers, but sturdy stock: strong healthy couples who would follow the Church of England and live quiet, respectable, hard working lives.

\section{The Long Depression: The Collapse of the Colony's Economy}

The economic stability experienced in New Zealand in the 1860s and early 1870 s was attributable to a public borrowing campaign, and it was this that enabled investment in 
infrastructure including roads, rail, and bridges, as well as immigrants and land development (Easton, 2010). In other words, from early on in the country's history, there was a strong reliance on state intervention and regulation in economic development. The economy continued to grow during this period due to a nominal population increase, however before it could become self-sustaining through general taxation, the colony was cut off from international borrowing by a global financial crisis. The collapse of the City Bank of Glasgow in 1878 had run-on effects in London which served to reduce the credit available for New Zealand to borrow. The long depression lasted from the 1870s through to the early 1890s, and highlighted the isolation of the colony, as well as the necessity for high levels of state intervention for the homogenous settler population to collectivise to survive. This drive toward collectivisation triggered the beginning of the hallmark comprehensive regulation of New Zealand's economy that remained in place for almost a century to come.

New Zealand was the first country in the world to introduce a pension for the elderly funded by general taxation - the Old-age Pensions Act 1898. The means-tested old-age pension was paid to elderly people of good moral character (e.g. there were conditions excluding those who had been imprisoned), and was a symbol of the nation's egalitarian ethos. The application of general taxation in this way to universalist outputs signalled the beginning of this mode of reallocation of tax dollars, and was the first in a long line of social welfare developments designed to support New Zealanders throughout their lives. These measures produced a way of life in New Zealand that was comfortable, and also had narrow horizons: a safe, solid, and static life.

Following the advent of the Great Depression in New Zealand in the 1930s, the first Labour Government was elected in 1935. Then-Prime Minister Michael Joseph Savage implemented Keynesian economic policy in attempt to resuscitate New Zealand's economy from the severe effects of the Great Depression, creating the cradle to grave welfare guarantee New Zealand would become famous for. Savage nationalised central services including air travel, the Bank of New Zealand, coal mines, and brought others under the control of government ministers (including broadcasting, and transport) (Aimer, 2012). The First Labour Government led the nation out of economic crisis through comprehensive regulation, and entrenched the collective values that underpin the Keynesian economic system within 
legislation, and social and economic policy. As Olssen (1981) later claimed, the reforms enacted by the First Labour Government "put New Zealand back on its true course as the most advanced and humane society in the world".

Among the consequences of the implementation of the Keynesian model in New Zealand was the assurance that inequality would be limited. While the existing inequalities between Māori and Pākehā (New Zealand European/s) born of colonisation would remain for generations to come, the gap between rich and poor in New Zealand would be limited due to the design of the welfare model premised on progressive taxation, income redistribution, and universalism. Although New Zealand was not the 'classless' society it was sold as by the early colonial merchants, the astounding division between the intergenerational wealth of the aristocracy and the dearth of wealth among the working classes in Britain was indeed averted in New Zealand. The nature of immigration to the country meant that for much of the twentieth century New Zealand was an insular society, where the state largely insured against the ills and hardships of poverty and the discomfort it would bring, but with little by way of extreme wealth.

\section{Cradle to Grave Welfare: Keynesian Economics in New Zealand}

From 1935 through to 1984, economic and social policy continued to be guided by the Keynesian model. As part of this, work was considered to be a social right, and it was the responsibility of the state to ensure that all citizens willing and able to work had access to a job (Humpage, 2011). Full employment was achieved through the implementation of subsidies, controls on trade, and heavy economic regulation. During the post-war period, the state guaranteed a basic level of healthcare, education, welfare, and work to its citizens (Marshall, 1950). This included the implementation of Universal Family-Benefit payments: automatic social security payments made to all mothers to spend on her children (Baker and Du Plessis, 2018).

The promises of egalitarianism and equality were met by the state's implementation of progressive taxation and redistributive policies that shifted income from the wealthy to the poor, and made for very narrow social disparities (Humpage, 2011). In this way, the 
Keynesian model also facilitated the creation of universal access to essential services including education and healthcare: an acknowledgement of the importance of a steady supply of healthy, educated workers for a thriving economy (Humpage, 2011). During the 1960s, the New Zealand economy was thriving, and it was among the richest countries in the OECD. It was during this time that Holcroft $(1968$, p. 94) observed that:

"there can be few countries which have revealed more clearly in their public institutions a conception of the state as an extension of the family".

The lack of social distance between Pākehā New Zealanders throughout the first century of British settlement in New Zealand in particular provided opportunities to the deeply interconnected settlers, while also creating a laid back and informal culture. This interconnectedness extended to government representation - as Pratt (2006) noted, even the very highest echelons of government were directly accessible to the everyman throughout this period - for example, the Prime Minister's home phone number was publicly available in the 1960s. In this vein, Jackson and Harre $(1969$, p. 71$)$ referred to "the principle of equality which is a national fetish": New Zealanders took pride in this lack of a rigid class structure.

The tightknit safety nets provided by the state under the Keynesian model restricted the adaptability and flexibility of policy and of the economy. When the oil shocks and economic crises of the 1970s hit, the model was tested to the greatest extent since the Great Depression. With 'Mother Britain' joining the European Economic Community (EEC) in 1973, New Zealand's main export link for agricultural products was weakened. ${ }^{7}$ The predictability of life in this outpost of the motherland was beginning to wane by the 1970s, and New Zealand's connection to notions of itself as a 'low cost farm' for Britain was rapidly losing value as globalisation highlighted opportunity for Britain elsewhere.

\footnotetext{
${ }^{7}$ Speculation about Britain's entry into the European Economic Community had existed since 1961, and by the time of its admittance in 1973, the Luxembourg Agreement had become a condition of Britain's entry into the EEC - providing temporary guarantees for the purchase of New Zealand exports of lamb, butter, and cheese. This temporary agreement was intended to cushion the blow of losing the exclusive exporting agreement with Britain, and give the New Zealand economy time to adapt and pivot to a more sustainable arrangement.
} 
Meanwhile, alongside growing instability, throughout the 1960s and 1970s, as elsewhere, New Zealand was experiencing the rise of counter-culture movements. This particularly volatile period of social upheaval and reform saw various rights movements and events create opportunity for significant changes in routines and ways of life, as well as social policy change for certain marginalised groups within New Zealand society. Central issues included questions over Māori rights and sovereignty; anti-Vietnam War protests (New Zealand had sent troops to assist the US); growing awareness of environmental harm; and the growth of the second wave feminist movement - including the related demands for equality, workplace rights, and sexual freedoms. The impact of the progression of women's rights throughout this period was particularly transformative for New Zealand society, as women's ability to remain in or re-enter the workplace after getting married or having children, and to raise a family without the support of a husband were protected through a series of progressive reforms.

Amongst these reforms was the Domestic Purposes Benefit which secured the financial stability of sole parent households, and contributed to the changing attitudes around the nature of motherhood and family life. As the availability and number of social welfare benefits available to individuals expanded however, the growing burden on the state budget caused by welfare commitments combined with external economic shocks to render the Keynesian economic model unsustainable.

Meanwhile, the Family Proceedings Act 1980 shifted the focus of divorce proceedings away from finding individual fault, toward helping families and individuals plan to move forward with their lives. This legislation combined with the Family Court Act 1980 to make the divorce process accessible and easy for the public to navigate. The implementation of the legislation was immediately followed by a sharp increase in the number of divorce proceedings, which grew from 7.4 per 1,000 estimated existing marriages in 1977 to 17.1 per 1,000 by 1982 (Statistics New Zealand, 2019). With the number of marriages steadily declining from 1970 onwards, and the number of divorces peaking in 1982, it is evident that 
the institution of marriage began to lose its hitherto iron grip on New Zealand society and the conduct of personal life (Statistics New Zealand, 2019).

In part as a consequence of the increasing divorce rate through the late 1970 s and early 1980s, the social acceptability of working mothers appeared to grow. Government subsidies for formal early childhood education services were initiated following a 1986 inquiry, which meant that a growing number of children aged zero to six years were being enrolled in formal childcare and early childhood education (Goodger, 1998). Where the 1947 Bailey Report on preschool education in New Zealand had found that the prevailing attitude of the public regarding non-familial childcare was that it was reserved for "deviant families where the mother "had to work'", this attitude appeared to be softening through the 1970 s and 1980s (Goodger, 1998). Children were increasingly attending childcare - the percentage of women in the workforce rose from $30 \%$ in 1970 to $39 \%$ in 1980, and the percentage of New Zealand mothers who had pre-school aged children and were in paid employment rose from $21 \%$ in 1976 , to $32 \%$ in 1986 (Pollock, 2012).

Throughout this period, New Zealand family life experienced significant and transformative change to the post-war family unit of four through a confluence of factors. Previously dependable social traditions were in rapid decline: the marriage rate dropped from $\mathbf{4 5 . 4 9}$ (per 1,000 eligible people) in 1971 to 29.39 in 1981 (Statistics New Zealand, 2020); the rate of religious adherence to Christian-based faiths in New Zealand dropped from 82\% in 1956 to $65 \%$ in 1986 , while the number declaring 'no religion' or 'refuse to answer' increased from $9 \%$ to $24 \%$ over the same period (Stenhouse, 2011); the birth rate dropped from 3.98 in 1961 (the year the contraceptive pill became available in New Zealand), to 2.01 in 1981 (Statistics New Zealand, 2021). Meanwhile, with the aforementioned rise of the divorce rate, single parent households, and government support for non-traditional or alternative family arrangements, the nature of urban society in New Zealand was also rapidly shifting. The comprehensively regulated economy (including regulation of wages, rent controls, price controls etc) limited choice for individuals, and the New Zealand population sharply declined throughout the 1970s, and at the same time, urban New Zealand was also becoming much more diverse. 


\section{Urbanisation and Immigration}

Urbanisation of Māori commenced during the Second World War, when Māori men had been brought in to cities to support the war effort through working in industry. Following the war, increasing numbers of Māori began moving to cities seeking better opportunities. Much of the rural land that remained in Māori possession was difficult to develop, and unfit for supporting large communities. The migration of Māori from rural to urban areas has been described as the most rapid movement of any population in the world, with the number of urban Māori growing from 26\% in 1945 to nearly $80 \%$ by 1986 (Meredith, 2005). This rapid migration of Māori changed the face of urban communities, and challenged the hegemony of the British settler. Historian Michael King (2003, p. 467) suggested that Māori urbanisation stirred "challenges, prejudices and conflict' throughout urban New Zealand society, as it provided the first opportunity for Māori people to participate and contribute to mainstream cultural, social, and political life". Alongside the unrest within communities as the pace of Māori urbanisation picked up, immigration was also contributing to the changing dynamic of New Zealand's cities. 'Solid New Zealand' was developing cracks within previously dependable levels of homogeneity of class and race. These were characterised by the Dawn Raids of the 1970s on supposed illegal immigration from the Pacific Islands.

Where previously New Zealand had been a colonial society with tight restrictions on immigration from countries other than the United Kingdom (Brawley, 1993), the government had created policies to encourage migration from the Pacific during the 1960s in order to meet the demands of the labour market. In 1960, New Zealand's immigration policy was changed to allow recruitment of skilled workers for essential industries, enabling the arrival of many Pacific people, particularly from Samoa and Tonga (New Zealand Parliamentary Library, 2008). In order to meet the post-war demand for unskilled labour, a special quota for Samoan immigrants was introduced in 1970 that allowed 1,100 Samoans to obtain permanent residence each year, in addition to those already entering New Zealand for skilled work (New Zealand Parliamentary Library, 2008). The tolerance shown to workers from the Pacific Islands during the skills shortages of the previous decades abruptly ended when the market shifted, and as a result these workers were no longer viewed as an indispensable element of the economy, but as a burden on it. The social and political 
climate of racial tension and unrest drove the victimisation of Pasifika communities by immigration authorities and police, and culminated in the 'Dawn Raids' that occurred throughout the early 1970s (Anae, 2020). From 1972, the police carried out early morning raids on the homes of Pasifika families suspected of overstaying their visas, seeking to deport on the spot those whose work permits had expired (King, 2003). The violence and trauma of the Dawn Raids, often carried out in the presence of children, was accompanied by growing racist sentiment toward Pacific Islanders by the police, as well as racial discrimination against Pacific Islanders within the community (Anae, 2020). What these events reflected was the rapid pace of change in the ethnic composition of hitherto homogenous New Zealand communities, which created the conditions for worsening hostility toward new groups, and contributed to a wider sense of insecurity among those who felt the certainty of community life slipping away (Haigh, 2014). ${ }^{8}$

Another, perhaps a more universally resounding, example of the cracking of this solid foundation was the insistence by the New Zealand government that the tour of the South African Springbok rugby team go ahead as planned in 1981. Mass protests against the Springbok tour were held across the country over 51 days from July to September, with antitour protestors equating the tour to an endorsement by New Zealand's government of South Africa's Apartheid arrangements: "a meticulously planned and cruelly executed political and economic system" (Morris, 1982, p. 2). Over 150,000 people participated in the more than 200 demonstrations and protest actions associated with the tour, resulting in 1,500 people being charged with offences stemming from the protests (Ministry of Culture and Heritage, 2020). Surely the most divisive event in New Zealand's history, lines of division within society were created and emphasised during the three months of protests. The rural/urban divide was particularly evident during this period, as 'country' communities tended to support the tour while 'town' was the source of many protestors. While unionists and working class people were involved in the anti-tour protests, it was an important departure from protest history in New Zealand that a large number of those protesting (and being arrested for protest-related offences) were middle class Pākehā people. Although in the short term, those pro-tour got what they wanted - the 1981 Springbok tour went ahead

\footnotetext{
${ }^{8}$ A formal government apology for the Dawn Raids is scheduled for 2021.
} 
- a groundswell of change had been triggered. The disenchantment with the state fuelled by the Springbok tour, in conjunction with growing impatience over heavy regulations and economic controls, paved the way for a change of government and the radical shift away from heavy state control associated with it in the 1980s.

From the 1970s onwards, then, New Zealand society underwent significant social and demographic change. Social norms were being tested and renegotiated, and the certainty around ways of life and the future felt during the post-war era began to erode. It was in this environment of significant upheaval that the financial shocks of the 1970s occurred, deepening the cracks in the solid foundations of society and adding layers of complexity and alarm to the already strained social setting. By the 1980 s, the commitment of defender of New Zealand's solid mode of governance, centre-right National Prime Minister Robert Muldoon's to the continuity of post-war 'Think Big' infrastructure projects and full employment was stronger than the economy on which it relied. Following a snap election in 1984, the Fourth Labour Government were elected to govern. Despite having campaigned on a typical Labour policy platform, the Fourth Labour Government, led by Prime Minister David Lange, went on to rapidly implement radical neoliberal economic and social reforms in New Zealand. The bankruptcy of the hitherto highly regulatory (and incompetent) mode of governance then made the subsequent shift to neoliberal governance seem at first glance like an acceptable alternative.

\section{Neoliberal Reforms in New Zealand}

The deregulation, privatisation, corporatisation, and economic liberalisation represented by neoliberalism would appear to conflict with the fundamental values of the centre-left Labour Party (or, indeed, the Labour movement more broadly). Nevertheless, the electorate watched on as transformational changes were enacted through neoliberal restructuring which commenced swiftly. New Zealand's economic institutions were significantly and rapidly restructured, with large scale deregulation of the economy occurring alongside privatisation (e.g. sale of state assets) and corporatisation (e.g. restructuring and reducing the size of the public sector) (Boston et al., 1999). The values underpinning the Keynesian model were traded in for the free market, individualistic values foundational to 
neoliberalism. The principles of the Keynesian model had considered and prioritised the wellbeing and general equality of the collective society, and included far-reaching regulation which allowed the state to absorb risks from the society as a whole. Conversely, the neoliberal reforms entrenched an opposing value set; where individual rights and freedoms trump all, creating a market-based and coercive model of citizenship (Humpage, 2011).

A range of social services were cast off by the state and left to the free market during this period, as it shed its previously dependable obligations to its citizens. It is during this time that the country's first food banks were established as a charitable response to deprivation resulting from the economic upheaval (Wason, 2019). Initially an ad hoc response to the sudden demand for emergency food by those experiencing poverty following the devastating economic reforms of the 1980s - today food banks are an accepted part of the permanent social landscape (Wason, 2019). The gaps created by the government's departure from community management and security were quickly filled by private security firms and volunteer neighbourhood watch organisations, and the uptake of private healthcare and education services continued to grow.

Exacerbating the significance of this considerable pivot in governmental values was the speed at which the neoliberal reforms were enacted in this country. Reforms of New Zealand's social and economic institutions were enacted faster and in more extreme ways than was seen in other jurisdictions (including the UK and Australia) (Ramia and Wailes, 2006). Architect of New Zealand's neoliberal reformation, then-Finance Minister Roger Douglas, reflected on this pace of change in his partly instructional book, Unfinished Business (1993, p. 220-221):

"Do not try and advance a step at a time. Define your objectives clearly and move towards them in quantum leaps. Otherwise the interest groups will have time to mobilise and drag you down"

Douglas's role in neoliberal restructuring of New Zealand's economy was such that these changes are still referred to today as 'Rogernomics'. This concertedly rapid financial and trade deregulation from 1984 onward saw New Zealand swiftly move from one of the most 
comprehensively regulated, to one of the least regulated economies in the world (Humpage, 2011). Douglas explained the reasoning behind the pace and scrupulousness of the deregulation:

\footnotetext{
"throughout 1950 to 1985, the New Zealand economy was one of the most highly protected within the OECD ... the government's persistent tendency to accommodate external shocks resulted in high and variable rates of inflation." (OECD, 1993, p. 12)
}

Viewing the tendency of previous governments to absorb external shocks as an inept and unsustainable response, Douglas therefore sought to trim the fat of the state, stripping back the bureaucracy and regulation that he perceived to be hindering the country's opportunity for excellence. Douglas saw the safety nets provided by the state as preventing such excellence from taking root. Once the reforms began, Douglas (1993, p. 167-168) celebrated as he saw "the beginnings of a sense of excellence in a country that was bedevilled by mediocrity ... instead of the previous [consensus], there was momentum". 'Rogernomics' brought an end to government controls, and dramatic cuts in direct taxation alongside the privatisation of state services and assets. Gwartney and Lawson (2007) provide a powerful illustration of how far-reaching the economic reforms were, demonstrating that while in 1975 New Zealand ranked 34 out of 54 countries on a range of indicators of economic freedom, by 2005 it had moved up to third out of 141 countries measured for economic freedom.

Due to changes in global trade (including Britain joining the European Economic Community), from 1966 onward the wheels of deindustrialisation began turning in New Zealand. Deindustrialisation is the phenomenon of the secondary sector growing slower than the rest of the economy (or indeed shrinking) (Easton, 1998). The pace of deindustrialisation rapidly accelerated from 1984, as the deregulation of the economy and the withdrawal of the state from its previous commitment to full employment took effect. Where once the state subsidised industry, and engaged in large scale public works projects to ensure full employment, the neoliberal state had swiftly withdrawn from these areas (Easton, 1998). For many towns in New Zealand reliant on secondary industry for their 
livelihoods (i.e. timber processing, railway workshops, manufacturing), the rapid deindustrialisation that occurred during the 1980s had devastating effects.

It is important to acknowledge, though, that while the unemployment rate jumped to unparalleled levels - unemployment rate increased from 4\% in 1986 to $11 \%$ in 1991 (Locke, 2010) - for those in steady jobs, many were financially much better off. The reforms cut back state services and therefore significantly reduced income tax, directing a personal benefit to each taxpayer. The globalisation, technological development, and freedom of choice that were also bolstered in the 1980s gave taxpaying individuals greater choice than ever before regarding what they would spend their spare cash on: cuisine, clothing, and entertainment were all diversifying throughout this period. The Labour government was returned to power in 1987 with a considerable majority - individuals awaited the fruits promised by trickle-down economics. In New Zealand, shopping hours were no longer government controlled, and extended shopping hours gave individuals more opportunity to consume - before this, all shops were closed at weekends. The stock market ceased being the sole domain of professional experts, and individuals were able to dabble (or risk it all) as if they were playing in a casino, and were able to dream of more expansive horizons for the course of their lives as a result. In this new environment, it was possible to go to Sydney for a few days without having to get permission from the government to take foreign currency out of the country, as had previously been the case in the final days of the Muldoon administration's desperate attempts to shore up 'solid state' New Zealand.

Nevertheless, the neoliberal reforms broke the promises of cradle to grave welfare, universalism, and full employment; deregulated the nation state economy; and opened New Zealand to extensive foreign investment and trade (Kelsey, 1995). Alongside the withdrawal of the state from its previous role as protector of the economy, social and political institutions were also overhauled with similar frenetic speed. The Broadcasting Act 1989 deregulated the media; state assets were rapidly sold off to mostly offshore private companies (e.g. State Insurance, NZ Steel, Telecom, Air New Zealand); corporatisation was effected through the State Owned Enterprises (Restructuring) Act 1986, reorganising and corporatising what remained of state owned enterprises and the public sector along the 
lines of New Public Management - ruthlessly prioritising efficiency and private sector values (Shaw and Eichbaum, 2011).

Neoliberal thought, which considers individuals as self-interested and rational actors, considers unemployment, bad health, and poor education as the results of lack of responsibility for risk management and prevention on the part of the individual - as such, the theory promotes the removal of progressive taxation policy and the winding back of redistributive policies (Humpage, 2011). It is up to the individual to accept the consequences of their choices within the free market. This meant that healthcare and education did not go untouched, and New Zealand saw the introduction of user-pays systems for healthcare for all but the very neediest individuals, as well as for tertiary education, winding back the Keynesian era universalism and associated consideration of healthcare and education as the basic rights of citizens.

When the Labour Government was voted out after two terms, the National Government took up the neoliberal reigns with fervour, unencumbered by the traditional commitment of the centre-left Labour Party to social welfare payments and worker's rights. Then-Finance Minister Ruth Richardson went on to introduce the 'Mother of All Budgets' in 1991, slashing welfare, while continuing this government more broadly continued to cut back regulations. The 1991 Employment Contracts Act transformed the labour market in favour of the rights of employers, individualising employment negotiations and crippling the hitherto powerful union movement (Boston et al., 1999).

With both major political parties in New Zealand embracing neoliberal economic policy, the reforms and the free market values driving them became increasingly entrenched over time. Outside of government, external pressure groups emerged to encourage this direction, and to represent the interests of particular groups in the reorganisation of government services. The New Zealand Business Roundtable (now known as the New Zealand Initiative) was formed in 1986 as a group of 60 chief executives of the country's largest businesses seeking to contribute to "sound public policy" and advocating for continued economic liberalisation (Gwartney and Lawson, 2007, p. xx). 
Thus, neoliberalism in New Zealand was entrenched in a broad range of areas by successive governments from 1984 onward. A fundamental element of liberal theory, and therefore of neoliberalism, is the maintenance of a small state. We see this within the neoliberal reforms in New Zealand through the implementation of New Public Management, the model put in place to strip back and reorganise the public sector in line with the structure of the private sector. Douglas (1980, p. 56) objected to the self-maximising nature of the state bureaucracy, infamously stating that "a bureaucrat, once created, has a life completely independent of his creator". Similarly, the sale and corporatisation of state assets reduces the investments of the state, and surrenders institutions to the will of the free market to the greatest extent possible. As the state was stripped back and the free market values became entrenched, risks were increasingly delegated to individuals. Within neoliberal thought, the individual is a rational actor, able to measure risks and take responsibility for their own gains and losses. Where the Keynesian state had attempted to shield citizens from such financial risks (among others), the neoliberal state rapidly opened up the market and delegated a broad range of economic, social, and political risks to the individual. The impact of this delegation of risk to individuals in New Zealand has been profound.

\section{The Impacts of Neoliberal Restructuring in New Zealand}

The coalescence in the 1980s of the many social and political factors discussed in this chapter generated a range of consequences. The sheer scale of change experienced by New Zealanders through this time was significant. The result of this scale of change was that the predictability of the post-war era appeared to be dissolving. Life paths had previously been mapped around various certainties for many New Zealanders (e.g. participation in community life, church attendance, education, healthcare, employment, marriage, childrearing, retirement etc). These previous anchor points that had secured an individual in their identity and in their community were now being dismantled, and individuals were being left to navigate their own way through a less predictable life.

In exploring this unpredictability, it is important to acknowledge the dual nature of the freeing of risk from its former state-imposed constraints. As Pratt (2020) explains, the duality of risk presents the opportunity for incredible success, as well as the possibility of 
catastrophic failure. In New Zealand, the deregulation of the market meant the opening of the New Zealand Exchange (NZX) as well as the opening up of currency trading for the first time. Greater riches than had previously been within reach were now accessible to those willing to risk it all. The stock exchange in particular provided New Zealanders willing to take risks with opportunities for significant financial gain. Small businesses could be listed on the NZX and grow more quickly than the nation had ever seen (here we see the early success of now-staple New Zealand businesses like Michael Hill Jeweller and The Warehouse). For some individuals, this produced opportunity for rapid generation of significant wealth - for example, former Prime Minister of New Zealand John Key, raised in a state house as the child of a solo mother and Holocaust survivor, built a fortune as a foreign exchange investor on the NZX in the 1980s - his net worth was \$65 million in 2017 (National Business Review, 2017).

During this period, the emergence and cultivation of the new concept of 'lifestyles' transformed the daily lives of many New Zealanders. In addition to the scale of economic opportunity for individuals opening up the possibility of immense wealth to anyone, there were more and more luxuries on which individuals could spend their money. For the average worker, there was a tangible fiscal benefit to the deregulation of the economy, as it meant significant cuts to direct taxation, leaving more money in their pockets. This money could then be spent on exotic cuisines recently arrived in the country, expanded fashion ranges available at shops open later than ever before. The construction of the cult of consumerism began during this period. Even in New Zealand, where 'tall poppy syndrome' has traditionally seen those who stand out being cut down to size (a consequence of the egalitarian myth), we see the emergence of an annual public 'Rich List' from 1987, as well as the foundation of a Business Roundtable to lobby for the interests of business. The celebration of risk and the boons it could bring into individuals' lives shifted New Zealand's culture, affecting every New Zealander.

The deregulation of the market occurred alongside globalisation and the rapid advance of technology. This confluence of factors delivered lifestyle changes to New Zealand with greater diversity and variety than ever before. With immigration - from Asia especially now - and globalisation accelerating throughout the 1990s in particular, new opportunities for 
indulgence and pleasure were opening up: a much greater variety of exotic cuisines and restaurants, for example in contrast to the bland fare that Holcroft $(1968$, p. 40$)$ reported in the 1960s:

\footnotetext{
"if the proprietors of cafes, some of whom have come from countries with notable traditions in the use of food, are asked why they make no attempt to introduce a little more variety, they declare that customers will not touch the unfamiliar, and are quite happy with braised sausages and a dab of mashed potato."
}

The range of products available for purchase in shops and through catalogues was growing; exposure to different fashion - the luxury brand Louis Vuitton opened its Auckland store in 1991 - and lifestyle opportunities was expanding, offering much greater diversity in taste and choice. This broadening horizon of lifestyles was particularly visible in the main cities: those that transitioned into a more liquid form with the most speed and least resistance. For some, the massive changes of this period compounded into life-altering anxiety. Unemployment, financial loss, and political change continued into the 1990s, where immigration from hitherto unfamiliar and suspect areas of the globe (Vietnam, Cambodia, China) and globalisation continued to change the face of New Zealand's labour market and landscape. Indeed, while Louis Vuitton and similar outlets now catered for one end of the market, a flurry of $\$ 2$ and charity shops catered for the other. Uncertainty and unpredictability became a feature of modern life in New Zealand, with some individuals able to harness the benefits of the new arrangements, and others frozen by them.

\section{Wealth Inequality}

Once famous for its egalitarianism, following the neoliberal reforms, 'Better Britain' has become a nation increasingly divided by a significant wealth gap. Following the commencement of restructuring in the 1980s, by the 1990s, New Zealand had dropped to being one of the poorest countries in the OECD (Briggs, 2007). This drop in average wealth occurred as part of the polarisation of liquidisation -the 'haves' win big, while the 'have nots' are consequentially pushed toward poverty. Although New Zealand's wealth inequality today is only slightly worse than the average among developed countries, the growing gap 
between rich and poor demonstrates profound inequality within New Zealand society. Nevertheless, New Zealand still harbours the egalitarian myth. Today, the average New Zealander in the poorest half of the population has a net worth of $\$ 12,000$, with an average of just $\$ 4,000$ in the bank, leaving them especially vulnerable to financial shocks (Rashbrooke, 2020, August 31). The wealth of the average New Zealander overall is $\$ 92,000$, 68 times less than the average of the median person in the top $1 \%$. The wealthiest $10 \%$ of New Zealanders own $59 \%$ of the nation's assets, versus the poorest half of the population who own just $2 \%$ of the nation's assets (Rashbrooke, 2020, August 31). The severity of this wealth gap has increased over time, and is a fitting illustration of the extremes that neoliberal economic policy has created within New Zealand society.

The magnification of the divide between rich and poor saw child poverty rise sharply in the early 1990s, a consequence of the National Government's 'Mother of All Budgets' which slashed benefits (cutting welfare benefits by between ten and $30 \%$ for many beneficiaries with children, including the disestablishment of the Universal Family Benefit in 1991), and the commencement of the state charging market rents (as opposed to income-related rents) for state housing tenants (Boston and Chapple, 2015). Meanwhile, while affluent New Zealanders are able to pay to access superior private healthcare and education for themselves and their families, state provision of these previously universal services has become increasingly run down since this time as a result of decades of chronic underfunding. The inequality of access to healthcare and education in particular reinforces and perpetuates this wealth gap, while the neoliberal economic system by default continues to reward individuals who possess capital (i.e. those who are born into wealthy families).

\section{Deindustrialisation}

Deindustrialisation and globalisation have impacted the entire New Zealand social and economic landscape, and have cemented the reliance on the global economy for the secondary processing of the materials produced by primary industry in this country. In addition to widespread unemployment caused by the closure of heavy industry in New Zealand, the shift from an economy reliant on industry/manufacturing to one structured around service provision has created dependence on the interconnected network of the 
global market. For example, New Zealand has a sizeable forestry industry and some of the largest pine plantations in the world, with exports supplying $1.1 \%$ of the world's total supply of industrial wood, netting an annual export revenue of NZ\$6.8 billion (1.6\% of New Zealand's GDP) (Ministry of Primary Industries, 2021). Despite the dominant position of forestry in the New Zealand market, as a consequence of deindustrialisation, the country is descending into a timber shortage that is worsening over time. While top dollar is being paid for export logs, the capacity and willingness of domestic companies to increase production of timber for the New Zealand market is non-existent (Radio New Zealand, 2021, March 30 ). The effects of this timber shortage are widely felt, particularly within the context of a housing crisis - the public housing waitlist hit 22,521 in December 2020 , up $51.5 \%$ on the year prior (Ministry of Social Development, 2020). Within a booming domestic construction market, and in the context of government promises to significantly increase the construction of state housing (having largely abandoned the large scale provision of state housing and sold off state housing stock during the restructuring of the 1980s), a paralysing timber shortage in New Zealand is a particularly interesting example of the operation of the deregulated market, and the risks that exist for states dependent on global markets for goods and services.

Global market participation has created great affluence in some parts of New Zealand, urban areas especially, derived largely from offshore trade, while those areas where a comfortable living standard and solidity and cohesion that had been the product of manufacturing frequently found that they had been left behind - or were forced to rebrand themselves to avoid being left behind.

\section{Media Sensationalism}

The result of the deregulation of the media through the Broadcasting Act 1989 was the creation of increasingly tabloid-style media (from the two channels that were available before this legislation came in, to the hundreds now available to consumers - there was now no public service element to television watching), which developed alongside the digital technology that has since enabled the creation of the 24-hour news cycle. The presentation of news was transformed, as Cook (2002, p. 140-141) explained: 
"This faster paced news is cheaper to produce requiring less time per item and so less research and background information, and appeals to advertizers who prefer fast paced programmes on many subjects rather than one consisting of a lengthy analysis of fewer issues"

The flooding of the news media with reports of risks of all kinds remains overwhelming for individuals trying to make their way through life in an increasingly uncertain and unpredictable world. In addition to natural disasters and other calamities New Zealanders have been exposed to in recent years (earthquakes, flooding, tsunamis, droughts, pandemic), there are other unpredictable risks constantly on display in the media (shark attacks, car accidents, criminal offending, sexual victimisation). The saturation of the media with detailed reports of these kinds of unpredictable risks is thought to foster insecurity. In the case of the announcement of 'Beast' of Blenheim Stewart Murray Wilson on parole in 2012 , in the three weeks between the announcement and his release date, the Dominion Post (Wellington) published 22 feature articles and editorials on the case; the New Zealand Herald (Auckland) nine; and The Press (Christchurch) six (Pratt, 2020). As Pratt (2020) explains, this media coverage seems to magnify the perception that the state appears unable to offer further protection from 'monsters' after their punishment, and is therefore placed in a position to have to defend its legitimacy.

The social theory behind this cause and effect - restructuring and change creating risk aversion - shows that risk aversion conversely creates insecurity, rather than facilitating the creation of security that it seeks (O'Malley, 2004). While explaining the risk to someone (e.g. in a newspaper article) may on the surface seem to provide an opportunity for the management or avoidance of the risk, in fact the result is the production of anxiety and insecurity about that risk. The insecurity created and exacerbated by confrontation of risk is worse for its scientific nature, because the more that science reports to have discovered, "the more it demonstrates that life is saturated by risks" (O'Malley, 2004, p. 2). 
Anxieties about the safety of children increased throughout this tumultuous period (Best, 1990). The atomisation of New Zealand communities resulting from the economic reforms of the 1980s combined with the increasing mobility of individuals in modern society, means that individuals are more likely to live away from close family, and are less likely to know those living within their own community. Fukuyama (1995) confirms this decline in trust that results from the breakdown of previously dependable social structures. Where geographical proximity to family and homogenous lifestyles had previously meant that children remained in the care of family, the changing nature of society meant that this was no longer necessarily possible for many families.

As Pratt (2005) explained, modern childcare often consists of handing children into the care of people who are essentially strangers. The growing estrangement of individuals from one another within the modern community serves to compress the view of the stranger, and the lack of knowledge caused by this social blindness can result in individuals assuming the worst about the people in their midst. This estrangement is exacerbated by the sense that any risk posed to a child is inherently more threatening within modern society, due to the scarcity and preciousness of children. As elsewhere, as the number of children being born in New Zealand has decreased - the birth rate almost halved in the two decades from 1960 to 1980, dropping from 4.03 in 1960, to 2.03 in 1980 (Statistics New Zealand, 2021). With this scarcity, so there has been increasing awareness of risks to children's health and wellbeing (Pratt, 2005). In addition, the widely held view, inflamed by the sensation seeking media, that crime was increasing in New Zealand throughout this period, valid or not, increased the perception of danger to vulnerable children posed by 'others' in the community.

One illustration of the heightened anxieties about the safety of children within the context of the return of mothers to work, and the transformation of lifestyles in New Zealand, was the Christchurch Civic Creche case. Considered by many New Zealanders today as one of the most egregious injustices of modern times, ${ }^{9}$ Christchurch Civic Creche employee Peter Ellis

\footnotetext{
${ }^{9}$ Peter Ellis served 15 years in prison in New Zealand, and died of cancer in 2019 before his conviction could be overturned. In an extraordinary departure from existing legal regulations, the Supreme Court of New Zealand decided in September 2020 to allow a posthumous appeal of Ellis's convictions to proceed. This appeal is currently being heard by the court.
} 
was imprisoned for crimes relating to the sexual abuse of children in satanic rituals in 1993 (Hood, 2001). Police interviews of 118 children produced a range of allegations of physical and sexual abuse against Ellis, including him forcing children to participate in 'satanic' rituals allegedly conducted within the creche complex (Eleven, 2015). This was one episode of the satanic ritual abuse moral panic, which swept through all of the Anglo-American societies in the 1980s and early 1990s (Nathan and Snedeker, 1995). Despite a complete lack of physical evidence in any case that has ever been brought before a court, decades later, hundreds of people remain imprisoned for crimes related to satanic ritual abuse throughout the world.

In addition, there were a number of high profile sexual murders and attacks of women and children throughout the late 1980s and 1990s that exacerbated existing anxieties about the safety of children in particular, and about the changing nature of community life. The 1987 abduction and sexually motivated murder of six-year-old Teresa Cormack in Napier while she was walking to school (discussed in more detail in Chapter Six) had a profound effect on the lives of New Zealanders, in the same way that the 1981 murder of Adam Walsh, another six-year-old child, did in the US (Waxman, 2016). Following Teresa's murder, parents across the country refused to let their children walk to school, and it is still seen as a risky activity today (Hosking, 2018, July 2). A slew of convictions of high profile serial rapists regularly splashed across the media in the 1990s magnified the perception of the risk of sexual harm from strangers in the community. ${ }^{10}$ Key cases combined with the effect of the deregulation of the media (and the associated adoption of tabloid-style reporting) to produce the perception of the risk of sexual harm in particular as something that cannot be insured against.

\section{Conclusion}

Economic and political reform, along with the social liberation and restructuring of this period, had a determinative influence on the lives of New Zealanders. This influence created

\footnotetext{
${ }^{10}$ Mark Stephens (known as the Parnell Panther) was sentenced in 1985 to 12 years in prison for offences against two women; Malcolm Rewa was sentenced to preventive detention in 1992 for offences against 25 women; Joseph Thompson (known as the South Auckland Serial Rapist) was sentenced to preventive detention in 1995 for offences against 47 women and girls; Stewart Murray Wilson (known as the Beast of Blenheim) sentenced in 1996 to 21 years in prison for offences against 42 women and girls (discussed in Chapter Five).
} 
insecurity and exacerbated anxieties about personal safety. Where the state and the solidity and stability of community life had once provided guarantees of security as part of a general commitment to the insurance against and abatement of risks, economic and social restructuring meant that there was now nothing separating the individual from an array of dangers awaiting them each time they entered public space. These reforms had led to the systematic dismantling of safety nets that had, until this time, provided security to citizens.

In the aftermath, we see the beginning of what becomes an intense preoccupation with certain types of risks - those perceived to be unavoidable, unable to be insured against, but capable of causing terrible harm - thus making them intolerable. In contrast with the traditionally certain pathways of community life in New Zealand, liquid modernity by nature means that the destination of the individual is "endemically and incurably undetermined" as the concept of community itself dissolves (Bauman, 2000a, p. 7). Within the new liquid state, all norms are fragile, and the form of all identities is therefore magnified (Bauman, 2000a). Within liquid modernity values including mobility, flexibility, and individuality gain significance, and success is attained by those individuals elastic enough to seek it for themselves. Within this model of society, the traditional importance of communitarian values and social solidarity is traded (as it appears to have been in New Zealand) for the increased value attributed to individualism and the pursuit of personal success that this is thought to bring with it.

As the state has retreated from its previous omnipotent role as risk manager, individuals in a liquidising society have been burdened with responsibility for these risks previously held by the state. For some, rather than a burden, this has been the breaking of shackles, and the advent of wide ranging freedom of choice. For others, the torrent of risk unleashed upon them has been overwhelming, with existential insecurity and anxiety becoming part of their experience of modern life. For these individuals in particular, the presence of risk of what I have referred to in this thesis as 'irreparable harm' posed by released sex offenders in the community is one that is truly intolerable. Based on observation of the media, it seemed on the surface that it is these circumstances that have triggered spectacular rescues by the New Zealand government in the past. Thus, through examining the experience of community notification in three different areas in New Zealand, I will map the contours of 
the relationship between the state, risk, and the community in relation to the level of liquidity of each area. 


\section{Chapter Four - The Research Process}

This chapter sets out the strategy and process behind this research. The sensitive nature of the events and experiences I wanted to examine led me to seek out methodologies and methods that would centre the experiences and voices of communities that had been notified via de facto means that one or more sex offenders had been placed into their vicinity, as well as provide an adequate framework through which I could analyse and understand the data I would eventually collect.

The empirical research that I carried out was built upon a foundation of qualitative grounded methodologies. In exploring the manifestation and drivers of the risk society in New Zealand through this research, I was drawn to the experiences of communities themselves. I sought to uncover the nuance of how individuals and groups navigate the terrain of risk and uncertainty, as well as their relationships with various state actors within this. In-depth, qualitative research enabled me to capture the 'view from within', that of the experts on community life and experiences - community leaders - that was so central to my research aim, and that other approaches would not necessarily facilitate. By nature, this design means that this research is not representative, and it does not seek to be representative. The research approach detailed in this chapter sets out the justifications for, and methods of, conducting research into the experiences of community notification and associated risk within communities, each with various degrees of adaptation to liquid modernity. In turn, it will provide an empirically driven development to the work of Bauman, and the way that the theory of Liquid Modernity may be understood in an applied context.

\section{Methodology}

\section{Epistemology - Constructionism}

This research was built on the foundation of constructionism. My objective was to understand the ways in which communities in liquidising New Zealand had experienced community notification, which required me to seek out voices from within communities 
themselves. The constructionist paradigm assumes that, rather than having a predisposed nature, humans construct their own social world (Fuller and Loogma, 2009). Crotty (1998) explained that within constructionism there is no objective truth: meaning comes into existence in and out of our engagement with the realities of our world. Meaning is constructed, and therefore different people may construct meaning in different ways - even in relation to the same phenomenon (Crotty, 1998).

Constructionists argue that any action undertaken by a person is shaped by different kinds of knowledge: scientific, but also cultural and experiential knowledge. As Berger and Luckmann (1967) explained, the ideas of 'reality' and 'knowledge' pertain to specific social contexts, and the relationship between reality and knowledge must be included in the exploration of any social phenomenon. In exploring the construction of reality, the subjective truths and experiences of individuals should be assigned significant value. Epistemologically, constructionism was the most appropriate paradigm to adopt when exploring the lived experiences of the communities I engaged with for this research.

Social constructionism is primarily concerned with explaining "the processes by which people come to describe, explain, or otherwise account for the world in which they live" (Gergen, 1985, p. 3). It equally enables understanding of the "complex world of lived experience from the point of view of those who live it" (Schwandt, 1994, p. 118). Because this research focuses on the perceptions of risk and their consequences, social constructionism is particularly suitable to build understanding of the variety of truths that exist for participants. Using this paradigm has enabled clearer understandings of the range of perceptions of risk and danger at the community level, and of the phenomenon of community notification more broadly. Social constructionism acknowledges and affirms that meaning and understanding can emerge from interactions between people, and that it emerges "neither objectively or subjectively, but inter-subjectively" (Fuller and Loogma, 2008 , p. 74). This affirmation of the importance of interaction on the formation or construction of meaning and belief is particularly important for this research, as the manifestation of solidarity, risk, and community notification itself are all dependent on interacting networks of people. The design of my work follows in the tradition of Merriam (1998) and Stake (1995) in that it is based on a foundational assumption that knowledge is 
constructed or interpreted, rather than discovered. Having acknowledged this, it is important to set out how the design decisions for this research were made.

\section{Qualitative Research}

Constructionism, by nature, pertains to qualitative methodologies. Qualitative inquiry legitimises participants as a central source of information and, in doing so, gives the research process emancipatory potential (Grbich, 2012). It allows the lived reality of participants to take centre-stage, and focuses on the way they view their world (Grbich,

2012). Similarly, qualitative research is valuable as it is in-depth, and acknowledges the lived experience of those who are involved in the research. Due to the sensitive nature of research on communities who have experienced sex offender release and notification, and my intention to facilitate a detailed exploration of the lived experiences of notification and sex offender release in New Zealand communities, qualitative research was the clear choice for the design of this project. The following section will introduce the specific methods I employed to examine the experiences of the phenomenon of community notification in New Zealand.

\section{Methods}

\section{Case Studies}

In seeking to understand the complexity and nuances of the communities I would be engaging with for this project, I chose a case study method. Case study research was most appropriate for application to this project because it "is a versatile form of qualitative inquiry most suitable for a comprehensive, holistic and in-depth investigation of a complex issue in context." (Davis and Wyatt, 2021, p. 9).

Yin (1994) defined a 'case study' as an empirical inquiry that investigates a contemporary phenomenon within its real life context, especially when the boundaries between phenomenon and context are not evident. In light of this definition, case study analysis has been employed in this study in an effort to explore the similarities and differences between 
instances of the phenomenon of community notification, the associated communities, and the examination of the boundary between this context and phenomenon. Although case study research has been critiqued for its potential lack of generalisability (cf Berg, 1998), as Gómez and Kuronen (2011) explain, the strength of case study research lies in the rich detail of the in-depth empirical data. Although a single case study may not be broadly generalisable, there is significant utility and interpretive value in a series of well-designed case studies that have been carefully analysed (Gómez and Kuronen, 2011).

Engaging in case studies is a methodological strategy, within which particular methods are employed (Hartley, 2004; Stake, 2000). Case studies are not a specific method in and of themselves, but a strategy within which a range of methods can be incorporated. Whatever methods are included, case studies should be replicable, consistent, and immersive, and therefore have the potential to provide useful qualitative and quantitative data. For these reasons, Davis and Wyatt (2021) characterise the case study approach as versatile, unique, and necessary for shining light on the impacts and consequences of the actions of powerful groups in society. Flyvbjerg (2011, p. 303) explains that case study analysis allows for the "development of a nuanced view of reality", and case study analysis is therefore particularly suitable for the study of social groups like communities (Hakim, 2000).

Case study methods have been underutilised in the social sciences. Once thought to be unsuitable for social research due to lack of generalisability, subjectivity, and only suitable for pilot studies, they are now recognised for their considerable value. Flyvbjerg (2006, p. 241) described case study analysis as "a necessary and sufficient method for certain important research tasks in the social sciences". Similarly, Baxter and Jack (2008) affirm that the nature of case study research makes it particularly appropriate for sensitive research, while Davis and Wyatt (2021) have recently determined that the case study is now held in higher regard than ever in the social sciences. Daly (2018) is also of this view, as is evident in her analysis of case studies in criminological research, where she unpacks some of the most famous case study analyses in criminological history (e.g. Erving Goffman's Asylums, Stanley Cohen's Folk Devils and Moral Panics) and validates their legitimacy. 


\section{Sampling}

The choice of cases to explore and analyse was one of the first significant decisions that needed to be made once I decided upon case study analysis as the methodological strategy for this research. Even before I started to explicitly search for cases of de facto community notification in New Zealand to consider, I stumbled across them in the newspaper, on my personal social media pages, and in many conversations. Sampling was therefore an important consideration for this research, as there was such a large range of cases available for potential inclusion, and it was important to purposefully select cases that would produce the most useful data.

In choosing cases to analyse, Flyvbjerg (2006) explains that a representative sample is unlikely to yield the most information. Rather, the choice of atypical or potentially extreme cases can reveal more information on the context, actors, and mechanisms of the phenomenon being examined (Flyvbjerg, 2006). In the end, my sample choice employed what Patton (1990, p. 183) called "combination or mixed purposeful sampling". Purposeful sampling strategies enable researchers to select, based on the needs of their research, information-rich cases through which they can learn the most about the issues of central importance to the purpose of their research (Patton, 1990). Mixed purposeful sampling enabled me to combine two common purposeful sampling methods: extreme case sampling (in this case, instances of notification that have attracted major media and community attention and reactions), as well as maximum variation sampling (in this case, the addition of this element enabled me to include a third case which did not produce a significant media nor community reaction).

Based on these sampling techniques, I selected three instances of de facto community notification in New Zealand communities: two that garnered substantial media attention and public engagement, and another that did not attract the same level of interest, media coverage, or community reaction ( $a$ 'failure to launch'). The intention of selecting this range was to provide as full of a picture as possible of the circumstances in which notifications both occur and generate a significant response, and those in which they do not. I chose to conduct three in-depth case studies as my time and funding were limited, and three cases 
would provide plenty of opportunity for comparing and contrasting within and across the sample I had selected. Although I considered a range of salient factors when looking for instances of community notification to study (geographical location, socio-economic status of the community, timing of the event, outcome of the incident, race/age/gender of the individual/s at the centre of the incident, style of notification) - I chose to focus on one criterion in particular: the community reaction to the incident. Although the other factors remained in my mind as I set up my mixed purposeful sample, the three cases I chose were primarily selected due to the nature of the community response to the incident, with some consideration of location and timing in terms of ease of access to the communities I would need to engage with.

The first case selected was the 2012 notification of the Whanganui community by the Department of Corrections that convicted rapist Stewart Murray Wilson was to be released on parole in this area. This was the case that had initially sparked my interest in this phenomenon as a research topic, and one I had conducted some research on already (cf Pratt and Anderson, 2016). Although this incident had occurred six years before my research commenced, a somewhat sizeable amount of time having passed given what I wanted to achieve, the significance of that incident was such that every person I spoke to in Whanganui during my fieldwork immediately knew and clearly remembered what I was referring to.

The second case was selected because it did not garner significant public nor media attention. In 2017 the Hawkes Bay Today newspaper reported the release of a convicted child sex offender who was paroled to an address in a Napier suburb. I discovered this case because I happened to be in Napier on the day that the story was published in the local newspaper, and read about it there. By the time of my entrance into the Napier community to carry out this research, one year had passed since the individual's release, meaning it was still a fairly recent event to discuss with local people.

Finally, the third case I selected was the March 2018 revelation by 1 News that 16 sex offenders (including some high-risk child sex offenders) had been placed by the Department of Corrections into a boarding house in Ōtāhuhu. I discovered this case through the 1 News 
online story which was shared widely on the social media site Twitter. I was then able to follow the case from the initial media notification onward, and arrived in the community just three months after that initial notification.

Having decided on the case study approach, the methods within the case studies were the next important element of the research design to confirm.

\section{Case Study Design}

Anchoring my research within each community was appropriate given the intimately community-based nature of the practice of community notification. As soon as my sample of cases was selected, I sought to immerse myself as much as possible in the communities I would be engaging with. As a starting point, I joined a range of community Facebook pages for the three locations, remaining a member of these groups throughout the three years of undertaking this research. These included Whanganui Buy/Sell/Swap, Napier News, Otahuhu CRIME Prevention (sic), and Otahuhu (sic) (see Image 1). I also began following the local media outlets on social media and directly through their websites. Immersing myself in these online communities and consuming the local media along with the comments and views of the locals through social media was an extremely useful starting point for gaining an understanding of the communities I was engaging with. Once I did have the opportunity to physically immerse myself in the communities, I was well prepared with knowledge of the current events and local concerns of each community, allowing me to much more effectively communicate with the people I met in each place about their concerns and experiences of community life. 
Image 1 Community Facebook Groups and Pages

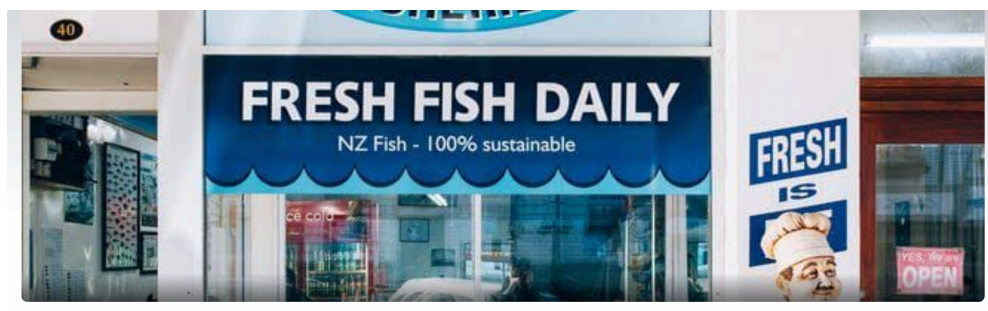

Buy Sell SWAP WHANGANUI
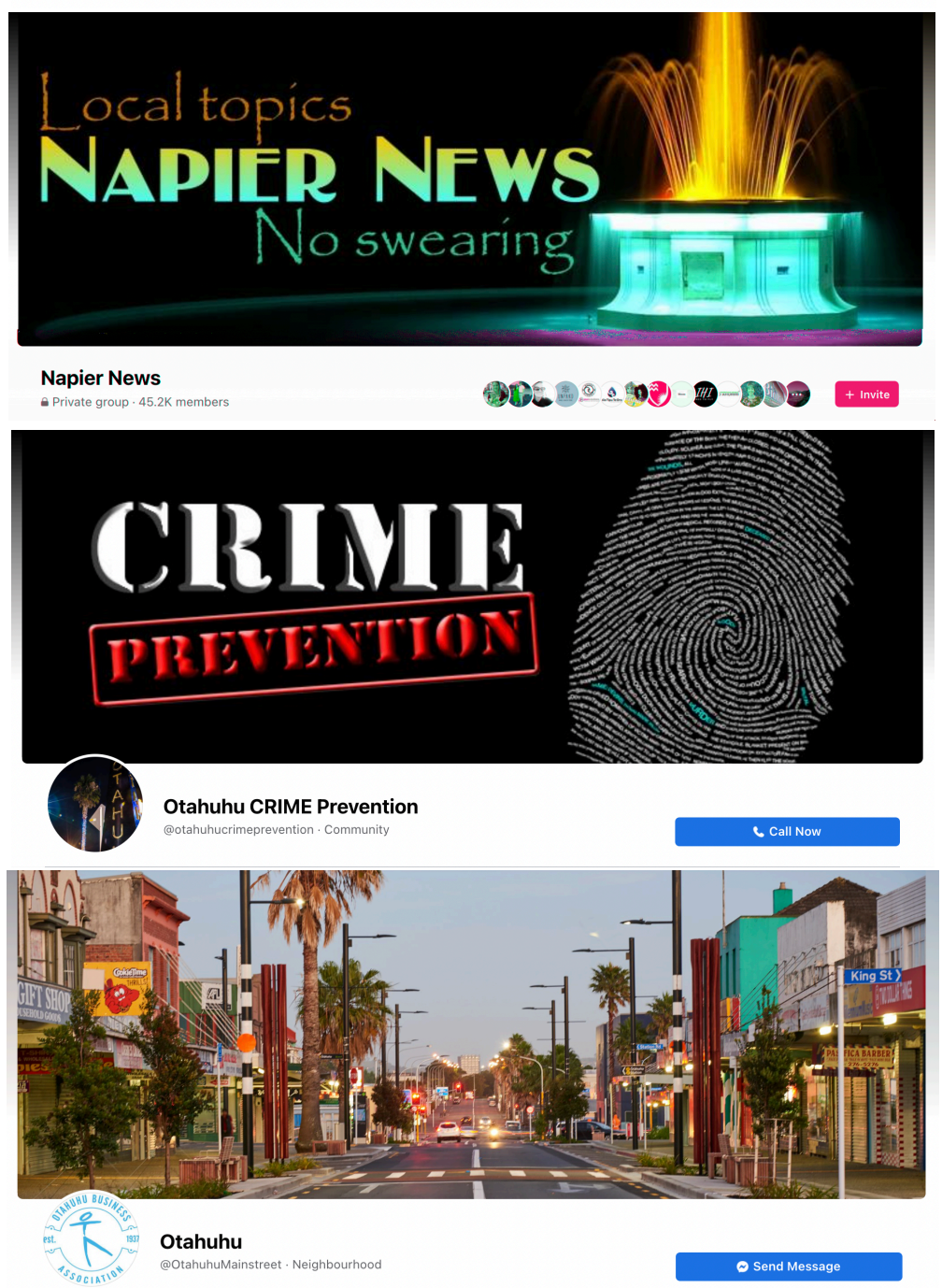

Facebook pages and groups for the communities of Napier, Whanganui, and Ōtāhuhu, respectively (each screenshotted from Facebook, 2020)

Next, I conducted an exploration of the history of each community, alongside a rudimentary demographic analysis of each. This involved the collation of government data and reports, including data from the Census, and Parliamentary Library research in particular. These documents provided demographic information and helped me to begin building a foundation of understanding of these communities: their populations; voting patterns; 
population statistics; health outcomes; and socio-economic data. Already thinking in terms of liquid and solid ways of life, these statistics and reports allowed me to start mapping the experiences of the three communities over time, and forming an outline of what the lives of community members might look like before detail was added through interviews.

\section{Interview Design}

I quickly dismissed the idea of explicitly interviewing victims, offenders, or actors within the workings of the criminal justice system itself. ${ }^{11}$ Victims, offenders, and those working within the criminal justice system were not best placed to give a fair and well-informed assessment of the community response to risks, and the drivers of this response. Rather, my goal was to explore the lived experience of notification within a range of communities in which it has been carried out. Immersing myself in the media and online communities of each of my case study communities also enabled me to easily identify who would likely be responsible for managing risks in each community. Following selection of the cases that would constitute my sample, I decided that within each case, I would interview these 'community leaders'. By nature, notification cannot work without some level of support from the community, and community leaders would therefore have some insight as to why community notification has had the level of success it has had in each of these locations.

The definition of 'community leader' is of central importance to the design of my case studies. Larsson et al., (2006) defined 'community leaders' as any of the following: an elected or appointed city official; an administrator from healthcare, education, or industry; a civic activist, lobbyist, clergy member, or other individual who may vote for appropriations for public health programmes, influence policy, set priorities, or advocate on behalf of a specific subgroup of the community. Although this definition is a useful starting point, for this research, I have intentionally classified community leaders in a very broad sense. 'Community leaders' within this research includes individuals who are a direct representative of a community subgroup, or as holders of a role as spokesperson for some section of the community. I was able to identify a range of community leaders in each

\footnotetext{
${ }^{11}$ Although I did not seek these types of participants out explicitly, community leaders with experience in each of these three areas participated in the research.
} 
community from across the five sectors commonly involved in community-wide decision making: government/policy, education, business, grassroots community groups, and media.

The selection of community leaders to invite as participants in each community was to allow for insight into the operation of various layers of formal governance and operational function of the community infrastructure, as well as the lived experience of those within the community. Community leaders can be considered an excellent source of knowledge within communities for a range of reasons. Although their legitimacy, tacit knowledge, and level of experience will vary by nature, they all have some level of legitimacy in representing various sections of their community. Community leaders are all, in some way, immersed in the business of their community, and are therefore often called upon to act on issues. Similarly, they often field complaints and calls for action on issues. There is currently no data on the views of community leaders in New Zealand (or elsewhere, as far as I could tell) about community notification, nor any about the views of community leaders on any number of law and order/criminal justice issues.

I considered face-to-face interviews to be most appropriate given the sensitivity of the subject matter of sex offender regulation, and the related necessity of building rapport with participants before being able to broach the topics I needed to discuss. Conducting face-toface qualitative interviews also allowed me to utilise my interpersonal communication skills to pick up on nuances of speech or body language that could be important for interpreting what was said, and to witness each participant conducting themselves within the community that had esteemed them.

All participants were asked whether or not they agreed for the interview to be recorded, all agreed, and interviews were recorded using an audio recorder. However, on many occasions, participants asked for the recorder to be turned off, or would not allow for the recorder to be turned on while they either discussed their personal experiences, or asked me about my experiences and views 'off the record'. In these situations, I allowed the participants to guide the conversation. Throughout the interviews, including during instances where participants asked for the recorder to be turned off, it was not unusual for participants to become emotional. Emotional distress was unsurprising to me given the 
subject matter of the interviews. One example of this was in Napier, where six-year-old Teresa Cormack has been abducted and sexually murdered 31 years earlier, participants became emotional discussing their memories of, and connections to, this tragic case. Similarly, discussions of sex offender regulation policy led to participants reflecting on the offenders they had encountered throughout their lives and careers.

I applied for and was granted approval from Victoria University of Wellington's Human Ethics Committee (ID 25737). I did not expect, however, that the process of gaining approval would become an early illustration of institutional risk consciousness and reputational risk management, something I would later argue could explain the intent of community notification on behalf of the state. For that reason, and to alert other researchers to the risks of risk-focused criminological research in an applied setting, I include a description of my ethics application process in the next section.

\section{Human Ethics Committee Approval}

I was, and remain, deeply committed to carrying out research in an ethical manner and was therefore enthusiastic about applying to the Committee for approval to proceed with my research. Following my submission of the lengthy application form detailing the methods and design of my research, I was notified that my application had been assigned to an overseeing shepherd, and that it would be considered at the next full meeting of the committee. This was during a period, within the social sciences in particular, when the Human Ethics Committee had established a reputation for making comments irrelevant to the ethics of the study, and for handing down inconsistent findings and amendment requirements to students (anecdotally, particularly to younger female students). A colleague who sat on the committee at the time advised me to attend the meeting, which I did.

My colleague had warned that the relatively conservative Human Ethics Committee would likely see my research as a 'high-risk' project. Despite my initial protests that, in my view, this was a low-risk project involving interviewing respected community leaders about their communities (not, for example, interviewing victims or offenders), he explained that the 
committee was often concerned with issues that are not ethics-related, that I should be prepared to defend the appropriateness of me undertaking this type of research at all, and I should be prepared to detail the measures I am taking to protect my own personal safety. My colleague also explained that in his capacity as a representative on the Committee, he often felt that he had to remind the members that the Committee's job was, in fact, only to assess the ethics of the application, not the design of the research, its worthiness, or risks to the university's reputation. This summary was particularly intriguing to me within the context of the study of risk.

To prepare for my attendance at the Committee meeting, I made a list of responses to the potential weak points I could imagine in my own application. My secondary supervisor similarly made notes on aspects she believed could possibly be perceived by members as problematic. None of the areas we had highlighted or prepared for were noted in the meeting. Rather, the shepherd of my application asked me a series of questions that had already been answered in the body of the forms I had submitted and requested that I add in detail that was patently already there.

Another committee member interjected that she had three children working in the Department of Corrections, and that I needed to understand that "these offenders are nasty pieces of work" who might pursue me should they find out about my research. This member recommended that it would be essential for me to text my supervisor before and after every interview and to notify the Police of my intention to interview people about these cases in each location. On this point, I argued successfully that there is little utility in me informing the Police in Whanganui about my intention to interview community leaders there about the Beast of Blenheim case, as he is held indefinitely in prison, and the case is already very public. However, I was still required to inform the Napier and Ōtāhuhu Police in advance of my intentions to conduct this research (as anticipated, I received no response to either email). Similarly, when the chair of the committee (after qualifying herself as an expert on Privacy Law, and warning me of the risk of legal action against me for bringing these cases back into the public eye) announced that "you have to understand Jordan, that these people have done their time", an ironic statement in the context of a study about a state action that fundamentally undermines the finite principle of custodial sentences. 
Concerns about the risks posed by the location of my interviews were also frustrating, as some committee members saw public locations (e.g. cafes) as too risky to discuss the cases my research examines, while others argued that I would be at risk if I conducted the interviews in private (e.g. in participants' homes/offices).

In the end, I was subjected to 25 minutes of questions by the Human Ethics Committee, in a frustrating demonstration of misunderstandings about the nature of my research and the risks associated with it. Rather than genuinely considering the ethics of what I was doing, including how to manage the actual risks (as I felt I had), it felt as if the members were acting as guardians of the institution's reputational risks. Tellingly, both of my supervisors had prior warned me not to expect a meaningful process of reflection and amendment in the pursuit of ethically sound research, indicating that for our institution at least, criminological inquiry by its nature is thought to be 'risky', and especially so, perhaps, for young women who wish to study anything related to sex offenders.

\section{Conducting the Research}

In practice, the case studies developed throughout the process and in relation to each community culture. In this section I explain the way I conducted this research, and briefly discuss the differences in the experience of carrying out research in each of the three locations.

From the initial list of community leaders I assembled based on publicly available information, I used the snowballing technique to create a list of other potentially suitable participants. My method for participant selection initially followed the McCauley et al., (2015) study. The scale of this project necessitated a limited scope, and I was able to reach out to all of the people suggested to me (usually 1-3 by each of my initial participants), and interview all of those who were available. Due to the sensitivity of the topic and the hesitance of many people to trigger anxieties about this topic, it was vital for the snowballing technique for me to build rapport with gatekeepers in order to then be given access to centrally important community leaders who were not otherwise publicly accessible. 
In all three cases, because of the public-facing nature of the people I was seeking to interview, most of their contact details (or those of their support staff) were available online. This was true of school principals, elected officials, staff from non-government organisations, and media representatives in particular. I went into this fieldwork with a short list of names I was familiar with from the media coverage of the notification incident in each case, and a list of email addresses I had secured from various websites. I emailed a range of community leaders prior to departing for each set of fieldwork, explaining the nature of my research and sending through my Information Sheet. If I didn't hear back from them within a few days, I rung them and explained what I was trying to do over the phone. Once I had secured a couple of interviews through this cold-calling, I initiated the technique of snowballing. Having set up at least four interviews in advance in each location, in mid2018 I travelled to each of the communities I was engaging with to conduct my interviews. My travel costs for this research were paid through a small grant from the Faculty of Humanities and Social Sciences Joint Research Committee. This funding enabled me to spend between one and two weeks in each of the three communities that constituted my case studies.

I conducted 33 semi-structured interviews with community leaders overall, which ranged in length from 30 minutes to three hours across the three communities. The participants interviewed across the three communities have therefore included elected officials, school principals, ex-Police officers, community sector representatives, interest group representatives, and journalists. Although this research did not include a gendered analysis, I aimed to keep the gender balance as equal as possible when recruiting participants. This was most difficult in Napier, where it seemed that more men held the accessible, publicfacing community leadership roles I began my recruitment with. In Whanganui I interviewed four men and seven women; in Napier I interviewed eight men and three women; and in Ōtāhuhu I interviewed five men and six women. Although participants were not specifically asked, two participants disclosed experiences of sexual violence. Clearly, the topic area triggered some participants, and understandably, they had particularly strong views around punishment and law and order with respect to sexually motivated crimes. 
Similarly, although participants were not asked specifically to identify their ethnicity, a number of community leaders discussed belonging to certain ethnic groups. In Whanganui, participants primarily identified as $P \bar{a} k e h \bar{a}$; in Napier, participants were predominately Pākehā or Māori; and unsurprisingly, those from Ōtāhuhu were predominately Tongan, Samoan, or Māori. In anonymising participants for the purpose of presenting the research findings, I have therefore chosen to use numbers instead of pseudonyms. This is due to the difficulty in retaining anonymity while also selecting culturally appropriate pseudonyms.

I assured confidentiality and anonymity for the participants in order to encourage their full disclosure. Across the full sample I refer to participants by their role type (e.g. school principal, elected official, journalist), and within each case I refer to participants solely by a reference number (Participant 1; Participant 2, and so on) with no reference to their position within the community specifically. Due to the size of the communities I have engaged with, simply referring to the experience of a 'school principal' or a 'media representative' in that area could reveal their identity.

When inviting community leaders to participate in this research, I was explicit in my invitation that I was seeking their personal views, memories, and perspectives of the case. This was also clear on the Information Sheet participants were provided with (see Appendix A). It is impossible to separate the personal and professional experiences of individuals in leadership positions, so, I did not seek the official views of institutions, I sought the experiences and beliefs of those individuals the community has chosen as its leaders. I wanted to hear about the nuances of the personal experiences of these community leaders, because this would produce the most genuine representation of their memories and perspectives on the events I was asking them to recall. Aggregating responses within and across cases would then ensure the individual participants remained confidential. My intention was that these factors would combine to encourage participants to answer questions freely and frankly to the greatest extent possible.

The Interview Schedule (see Appendix B) covered three main areas: community context (history of the place, community concerns), the incident (recollection of what happened during the incident, recollection of the community reaction), and policy responses 
(benefits/risks of registration and notification). The interviews with community leaders explored the nature of the concept of 'community'. I inquired about the nature of their particular community and its nuances, their understanding of any issues that pose a threat to the community, and asked participants to recall their memory of the unfolding of their community's particular case of community notification. The semi-structured nature of the interviews enabled me to elicit comparable information from participants in each community, while also allowing room for discussion topics any participant particularly wanted to raise. The interview data gave me great insight into the chronology of events in each case and allowed me to understand the many threads that contributed to the complex reactions that communities had in each case.

In exploring the experiences of three communities through the perspectives of their leaders, new and much more complex stories of the reported events I was researching were revealed. This research frequently provides counter-narratives to the national media coverage of these cases and at the same time is demonstrative of the power of the media to shape national conversation around events regardless of what may actually be happening on the ground. Overall, I was particularly mindful of the contextual conditions that may (or may not) support practices of community notification within the communities included in this sample. While the results from these cases do not necessarily provide a representative result, they reveal what the community leaders I interviewed have to say about their communities and notification at the time that I spoke to them. However, the research generated useful insights that can be more broadly applied. Next, I give a brief account of the fieldwork in each case study to highlight the way it would evolve in relation to each community setting.

\section{Undertaking Fieldwork in Whanganui}

Prior to conducting this research, I had never been to the city of Whanganui. Upon arriving, I was surprised that the label of 'city' applies to this place. As of the 2018 Census, Whanganui's population was 45,309 . With no links into the community and no familiarity with it beyond my lengthy examination of media articles about the release of the 'Beast of Blenheim' to this location, I was initially concerned about my ability to generate the right 
connections and relationships necessary for this research in Whanganui. I was also aware of the potential challenges posed by the time that had elapsed since the incident at the centre of this case had occurred - six years is a long time. Upon arriving in Whanganui however, it very quickly became evident to me that Whanganui locals were more than happy to discuss their memories of Stewart Murray Wilson's release and the media furore that surrounded it, and that their memories were clear. This willingness to talk extended to community leaders, who, without having met me, promptly responded to my initial emails requesting interviews. I got the sense that this was the first time many of my participants had been asked to take part in this kind of social research. Of the 13 cold call emails I sent before departing for Whanganui, seven responded to schedule emails with me. As it would turn out, compared to Napier and Ōtāhuhu, this was a strong response rate. Once my interviews in Whanganui commenced, I was able to connect with four further participants through snowballing.

One of the challenges I experienced to a particularly intense degree in Whanganui was the need to fit in with the schedules of my participants. Full schedules are built into the roles of many community leadership positions, so it was important while conducting this research for me to be as accommodating as possible with the timing and length of my interviews. Where participants only had a half hour, I modified the interview schedule to fit their timing requirements. The scheduling demands of my participants and my flexibility with accommodating them led to a situation where I had no interviews on a Tuesday, and then had five interviews on the Wednesday. Although this was not ideal, having the flexibility to work with assistants and participants with full calendars to slot in where they had lunch breaks or could give apologies to meetings enabled me to conduct the interviews.

While conducting each of the three case studies, participants usually expressed curiosity about who else I would be talking to. Often this was in the context of participants providing suggestions and contact details about other community leaders I could arrange to talk to, and was therefore helpful for my snowballing and network building in this respect. My participants in Whanganui were notably insistent when asking me who else I would be talking to, and many were disappointed when I explained that I couldn't disclose who else I was meeting with due to the confidential nature of the interviews I was conducting. I came 
to understand this as an indication of two things. Firstly, I saw it as an indication of the nature of the Whanganui community network as remaining fairly solid and deeply connected. Participants explained to me that Whanganui is the kind of place where you find a job and stick to it - several of these community leaders had held their jobs or been within the same organisation for decades. Secondly, the particular intensity of the curiosity about who else I would be interviewing was likely a result of the divisions created within the community in the response to the announcement of Wilson's release. The factions and personality politics were explained to me by several participants off the record, usually after the interview once the recorder had been turned off, and once I had built good rapport with a participant. Two of my participants went as far as to issue serious warnings to me about interviewing particular individuals who had been involved in the public conversations about Wilson's 2012 release, disclosing terrible behaviour and experiences they had had. In these situations, I could do little but express my gratefulness for their concern for my wellbeing, and empathise with their experiences of harm.

During the week I spent in Whanganui, I enjoyed building relationships with participants and getting a feel for community life. One disappointment I had was my inability to build relationships with Māori community leaders in Whanganui. I reached out to Māori community leaders whose contact information I could find online in the same manner in which I contacted all other participants. Going in to Whanganui, I was conscious of the significant Māori population within this community - $26.3 \%$ of the local population identifies as Maori (much higher than the national average of 15.9\% (Statistics New Zealand, 2018)) as well as the lack of participation of Māori leaders in the public conversation and commentary around Wilson's release. I cold-called a range of community and iwi leaders, and I understood when I did not receive a response. As a Pākehā researcher without personal connection to this whenua (land), and without rapport or existing community connections that would have aided entry into the Māori community, I remained an outsider. If I had had more funding and time, I would have liked to spend a longer period of time in Whanganui in order to spend the time needed to build relationships and build an understanding of the Māori community in Whanganui. 


\section{Undertaking Fieldwork in Napier}

I felt the most comfortable making connections in Napier because it is a community I consider myself loosely affiliated with. Nevertheless, Napier was the location where I sent the most interview inquiries and requests with no response. Of the 21 emails I sent during the period before my fieldwork in Napier, I had six positive responses. Although some community leaders or their assistants responded to me declining my request, the majority did not respond to any of my contact. This was particularly disappointing for elected officials, and this was the only instance in this research of elected officials providing no response or acknowledgement of my contact at all. Of the eleven participants I interviewed in Napier, six were respondents to my cold-call emails. The other five were the result of connections made through snowballing from earlier interviews.

I was very conscious of my relationship to the Napier community when planning my fieldwork there, as it is the city I spent most of my childhood in. Though I have lived away from Napier for ten years now, the abductive approach I took to research was particularly useful prompt to question my assumptions about the local community. Abductive research (explained in detail later in this chapter) required the constant examination of the interplay between my hypothesis and the data I was collecting, and the interrogation of both as the research progressed. This acted as a helpful cue to check my logic and assumptions about this community and its experiences to ensure I was not building an argument out of preconceived notions or personal opinions based on my experience growing up in Napier. Inevitably I ended up interviewing community leaders with whom I had some kind of connection: people who knew my parents, worked at organisations I had been a part of, or whose path had crossed with mine in the past. I believe this was unavoidable, due to the two degrees of social separation in New Zealand reducing further once you shrink the borders down to a single city. As of 2018, the population of Napier was 62,241 , and like Whanganui, had a higher than average Māori population $-24.5 \%$ of Napierites identify as Māori, versus 15.9\% in the general population (Statistics New Zealand, 2018).

I designed this case study with an awareness that my positionality would need to be managed and checked throughout the process. Including this case was important due to its 
nature as a kind of 'failure to launch' - by definition, a difficult scenario to find. In fact, I only stumbled upon the case myself when I opened the newspaper during a trip to visit my parents and found the mugshot and a half-page article detailing the crimes of a convicted child sex offender who was about to be released back into the Napier community. I was sure that this media notification was going to trigger a reaction that would follow the pattern of Whanganui, and then there was nothing. It was by chance I found the case, and it was important to include in this research as a comparative indicator: to investigate why some of these kinds of cases do not cause significant backlash amongst the public.

One of the requirements of the Human Ethics Committee for this research was that I use pseudonyms where possible to protect individuals at the centre of instances of community notification from further exposure to public attention. This was not practical in Whanganui, where Stewart Murray Wilson's identity is common knowledge. I had also previously published work explicitly naming Wilson. In Ōtāhuhu this was not necessary, as the neither I nor the public knew the identities of the offenders involved in the boarding house case. In Napier however, the individual at the centre of this 'failure to launch' case was named in the media. To avoid drawing further attention to the individual's identity after the case had not gained traction with the initial release of identifying details, I have used the moniker 'Individual X'. Reference details I obtained on this individual have been noted in footnotes as having been drawn from Individual X's records (e.g. from Parole Board reports). I have not altered the other details of the case however, as these provide important context for this research (including the nature of the offending, the sentence, and the risk classification).

The participants I interviewed in Napier were generally the most cautious in the way they talked about the issue of risk and sex offender release. The case I focussed on in Napier was not widely known (four of my eleven participants knew of the details of the case when I raised it with them). This was despite the fact that only one year had passed since the halfpage article and mugshot were published in the local paper. However, this media piece did not generate traction nor follow up articles, and it is possible that the bulk of the community leaders I spoke to in Napier either never knew of the specific release of the individual at the centre of this case, or it had not made an impression on them. This meant 
that the conversations I had with participants about risk and community notification in Napier were broadly theoretical, whereas in Whanganui and Ōtāhuhu every participant (along with very likely every community member) knew of the details of the case and were able to connect their strong views to a specific example. Without this anchor in Napier, many conversations touched on old scars, for example the case of the sexual murder of sixyear-old Teresa Cormack in Napier in 1987 (discussed in Chapter Six).

\section{Undertaking Fieldwork in Ōtāhuhu}

Ōtāhuhu, an outer suburb of Auckland that sits on the cusp of South Auckland, was the first of the three community case studies I visited for this research. It was also the smallest - the suburb's population was measured as 15,165 in the 2018 Census, with the highest Pasifika population in the country $-48.9 \%$ Pasifika peoples dwarfing the average of $8.1 \%$ in the general population (Statistics New Zealand, 2018). ${ }^{12}$ I first became aware of the case I would examine in Ōtāhuhu through a notification on Twitter just minutes after the national news outlet 1News had broken the story based on a leak from a Department of Corrections staff member. I followed the story closely over the following week, and attended the community meeting about the incident from Wellington via livestream. Once the funding and ethical approval for my research came through, I hurried north to Ōtāhuhu as soon as I could, and arrived in the community within three months of the instance of community notification at the centre of this case study. This meant that memories of the event and how it unfolded were fresh, as was the emotion. This presented challenges, and I believe the proximity in time of my interviews to the event led to the largest number of disclosures of sexual victimisation of the three cases.

In terms of going to Ōtāhuhu, although I was already familiar with Auckland, and had spent a significant part of my childhood in the nearby suburb of Māngere Bridge (which secured me social capital with a handful of locals), I had not spent any time in this particular community. As in Whanganui, this presented a challenge in terms of my legitimacy as an

\footnotetext{
${ }^{12}$ The suburb of Ōtāhuhu does not constitute a 'territory' within the Census breakdown, so this figure is drawn from the Census data for 'Ōtāhuhu South'.
} 
outsider to this community seeking cooperation from busy community leaders on a highly sensitive topic.

In Ōtāhuhu, the follow-up phone calls I conducted for those who did not reply to my initial phone call ended up being vital to my process of securing interviews. Initially commenced out of courtesy combined with the time pressure of my research, it was the conversations during these phone calls that secured several key interviews for me. The community leaders I was calling were very direct with me, asking me questions about my intentions with the research; whether I cared about the community; whether I had looked up what they had already said publicly on the issue; and whether I care about their community. I took these intense conversations as an opportunity to establish my genuine care for the Ōtāhuhu community, and interest in their experience and what it all meant. For the most part, it seemed that once the participants were satisfied that I cared about the community, and that there was something they could contribute, and therefore something to be gained in getting together for an interview, they were happy to make time to meet with me. In these conversations, I focussed on the community itself, and how I wanted to hear from them about the nature and concerns of its leaders, as well as the reaction to the specific case.

Snowballing was extremely effective in Ōtāhuhu, and I was linked into five of the eleven participants I interviewed in this community this way. I asked the particularly wellnetworked participants at the end of their interviews "is there anyone else you think I should be talking to, who you would classify as a community leader?", and relied heavily upon community 'gatekeepers', who assisted me in accessing some of the less-public facing leaders of the community. One such gatekeeper gave me specific instructions for contacting one grassroots community leader: "they won't trust you unless you say I sent you" (Participant 1). Despite the crowded schedules of all eleven participants I interviewed in this community, they made time to discuss this case with me. Some gave apologies to meetings, moved commitments back, or had me come into their workplaces to squeeze an interview in on their break.

During the interviews, most of the people I talked to emphasised the importance of kanohi ki te kanohi, or face-to-face conversation, within their communities. Some openly shared 
that they would not have met with me had I not followed up my email with a phone call. The leaders of this community act not only as representative voices, but as protectors of its reputation, its people, and its stories. McIntosh's (2004) commentary on South Auckland's status as a social laboratory of New Zealand were front of mind for me going in to this community in particular. I was also conscious of my own utility to the people whose time I was taking, and whose experiences and perspectives I was recording. This feeling was strongest in Ōtāhuhu, where community leaders are fighting the most severe social issues out of the three communities in this research. I contended with frustration over how I could act to assist or contribute to improving the situation faced by these overworked community leaders, but like Armstrong (2012, p. 8) also had to "be realistic" about what the contribution and the outcomes of my research would be. For many of the people who shared their thoughts with me, it was not their first time being interviewed by a social researcher. In this context, I was particularly grateful for the openness and the frankness of the leaders I spoke to, and for their trust in my ability and intention to convey and analyse their community's perspectives and experiences.

The majority of community leaders I spoke with were persistently positive advertisements for the Ōtāhuhu community. Although they acknowledged issues within their community of varying levels of seriousness, they were quick to invite me to the annual Curry Festival, inform me that both heavyweight boxer David Tu'a and former Prime Minister David Lange were graduates of Ōtāhuhu College, and that their \$28 million free-entry swimming pool is the envy of South Auckland. Those who did not live in Ōtāhuhu went to great lengths to explain to me the level of their commitment to this community despite living elsewhere, and that they feel more a part of this community than any other. The quiet pride and open defensiveness of the Ōtāhuhu community leaders I interviewed was almost universal.

It was within this context of pride and protectiveness that most of my interviewees told me their experiences. This combined with the experience of physically being in the community of Ōtāhuhu to create a genuinely positive and heartening experience. I entered this community aware of the chronic social ills faced by its people: poverty, unemployment and underemployment, homelessness. I was therefore very happy to experience more interaction with strangers than in any other place I have ever been in New Zealand or 
internationally. The majority of people I passed on the street took the time to greet me, many of whom asking how I was. When walking less populated streets (for example, the street with the boarding houses on it which is predominately industrial), locals also out and walking around were quick to strike up conversations. The people of Ōtāhuhu were overwhelmingly welcoming and warm.

\section{Analysing the Data}

The goal of analysis is "to uncover patterns, determine meanings, construct conclusions and build theory" (Patton and Applebaum, 2003, p. 67). More generally, Neuman (1997, p. 426) explained that data analysis generally means "a search for patterns in the data", and that subsequent interpretation of the patterns through the lens of theory and social context allow us to assign these patterns meaning. In conducting my case study research, the search for patterns and themes within and across cases began very early on in the process of gathering data. Through early immersion into online communities and continuing throughout the fieldwork I conducted in each community, patterns became evident from the very beginning of this research.

C. Wright Mills (1959, p. 159) wrote that "the most admirable scholars within the scholarly community... do not split their work from their lives. They seem to take both too seriously to allow such dissociation, and they want to use each for the enrichment of the other". Mills' words certainly resonate with my experience of having conducted these case studies, immersing myself in a physical and online sense into the business of these communities. Mills' argument integrates well with the practice of the flexibility of both case study design and thematic analysis, both of which rely heavily on the subjective decision-making of the researcher.

I considered thematic analysis to be particularly well-suited for the case studies I was conducting. Braun and Clarke (2006, p. 78) described thematic analysis as both a "foundational method for qualitative analysis", and a flexible tool which provides detailed and rich accounts of data. Thematic analysis is compatible with research such as mine which 
is undertaken from a constructionist foundation, and this method of analysis works well with the examination of experiences, events and meaning within communities.

Braun and Clarke (2006, p. 82) define a 'theme' as being "something important about the data in relation to the research question, which represents some level of patterned response or meaning within the data set". In this research, the identification of themes commenced in earnest while I was interviewing my participants. As common responses and experiences were raised, I often felt like I could see the section titles and quotes leaving the mouths of the community leaders I spoke with. In analysing the themes within this research, it was important to examine themes both within each discrete case study, as well as across the three cases, with sensitivity to the nature of the broader societal context. This allowed for identification of the similarities and differences across the full sample, and brought depth and insight to the research.

Data, its collection, and its analysis are inevitably shaped by the prior knowledge and experience of the researcher, and are thus theory-laden (Kennedy, 2018; Kelle, 1995; Hanson, 1965). In analysing my data, an abductive approach to thematic analysis was important. Abduction encourages the formation of a provisional hypothesis informed by theory, which can then be pursued through empirical investigation (Charmaz, Thornberg \& Keane, 2018). The abductive approach differs from inductive analysis, as it combines datadriven analysis with a theoretical frame, and requires constant interaction between the hypothesis and the data. The abductive approach therefore has the benefits of both datadriven analysis, and the non-prescriptive use of theoretical hypothesis. Thornberg (2012) explains that this approach is particularly useful for situations where data may call for modifications in existing theoretical understandings.

The construction of the questions included in my semi-structured interviews were therefore informed by theory, and the abductive approach to the identification and analysis of themes ensured that they were strongly linked to the data themselves. I was not seeking to fit my data into a pre-existing coding framework or necessarily my own theoretical hypothesis. Although it is impossible to guard against researcher bias entirely, the use of an abductive analytical process provided some assurance of a data-centred process. In carrying out 
abductive thematic analysis, as per the process set out by Braun and Clarke (2006) (as set out below), from each interview onward I set out to identify themes diversely and as they arose. This analytic process affirms the constructionist paradigm, and allows for analysis within and across cases. As Braun and Clarke (2006, p. 85) explain, thematic analysis "seeks to theorise the sociocultural contexts, and structural conditions, that enable the individual accounts that are provided".

I transcribed my own interviews to begin formally analysing the data, sending verbatim transcripts to all participants who requested them to provide the opportunity for any desired amendments. Riessman (1993) affirms that the process of transcription is, in and of itself, an excellent way to start familiarising yourself with the data, and Braun and Clarke (2006) also argue that a far more thorough understanding of the data is generated through having transcribed interviews yourself. Transcription was also useful in commencing the iterative process of thematic analysis, in which it is vital to constantly move back and forth across and within the data set in a recursive process (Braun and Clarke, 2006). From the initial interviews, throughout transcription and beyond, I was coding my interviews for interesting features using a combination of note-taking on printed copies of transcripts, and highlighting and commenting on Microsoft Word documents. The level of initial coding highlighted elements in the data including: 'family', 'community action', 'linked circumstance to government', 'economic deprivation', 'definition of community', 'disdain for media', 'knowledge of sex offender theory', 'personal experience of sexual harm', 'suggested alternative practice', 'deference of state actors'. From the dozens of codes generated in the through, inclusive, and comprehensive coding process, I was able to group them to determine a series of broader themes to analyse. Grouping themes was complicated by two of the interviews, which were filled with outlier statements and experiences. Part of the intention of this analysis is to "retain accounts that depart from the dominant story in the analysis" (Braun and Clarke, 2006, p. 89), however these remained mostly separate from the consistent themes found across the other 31 interviews. I identified a range of consistent themes. These were broader than the codes and were prioritised for analysis based on a combination of prevalence within the data set, significance to the phenomenon being examined, and my determination as the researcher of the relevance to the research question. These themes included: 'neoliberal 
history/features linked to experience of phenomenon', 'distrust of the government (local and central)', 'conditional support for government (actors/policies)'.

Alongside identification of general themes in the vein of Braun and Clarke's thematic analysis, I was able to utilise case study analysis techniques suggested by Yin (2003), including pattern matching, explanation building, and cross-case synthesis. Determining themes within each case allowed me to more easily compare and contrast the three case studies with one another, pattern matching between Whanganui and Ōtāhuhu in particular, and engaging in cross-case synthesis and comparison across all three cases. My experience of the process of analysis was that, through transcription and coding alone, I became so acquainted with the data that comparing the cases became second nature, as quotes, experiences, and examples would flood into my mind at each step.

\section{Caveats Concerning the Research Design}

The underpinnings of this research are informed by theoretical constructs, primarily that of Zygmunt Bauman in Liquid Modernity. This informed the areas of discussion explored with participants throughout the semi-structured interviews carried out for this project. I interviewed people in public-facing community roles and people working for the community, and the opinions of these individuals may differ from the views held by average community inhabitants. Therefore, findings from the interviews in the three areas should be interpreted with caution - as mentioned earlier, by nature this case study research is not representative, nor does it seek to be representative.

Although participants were asked to give their personal views as individuals rather than as representatives of any organisation they may be affiliated with, or any formal position they may hold, their views were bound to be coloured by the organisation they belong to and their roles in the community. However, intersecting identities and experiences are the reality for any interview subject, and this does not compromise the quality of the data collected for the purposes of this research. 
The total sample size of 33 met the expectations I set for this research of at least ten community leaders in each location. The gender balance of participants appeared to be reflective of the approximate gender split of public-facing community leaders in each location, and I was satisfied with this element of my sample. A gendered analysis of responses would be an interesting area for future research, however this was outside of the scope of this project. Similarly, a critical race analysis of responses would be a valuable area for further exploration. As aforementioned, although this research did not involve racial analysis, I would have liked to have been able to secure a more ethnically diverse sample in order to reflect the community populations as closely as possible. Though I was confident that the sample of participants in Ōtāhuhu accurately reflected the diversity of the community, this was not so in Napier or Whanganui. In Whanganui in particular, I had hoped for higher numbers of Māori participants. The funding limitations in particular prevented me from being able to spend the amount of time in Whanganui that would have been necessary for me to build relationships with local iwi and leaders in and amongst the Māori community. I was also very conscious of my position as a Pākehā researcher, and that my research adhered to a Pākehā framework (Irwin, 1994). Without the resources for appropriate whakawhanaungatanga (relationship cultivation) and manaakitanga (showing respect/hospitality), I did not feel comfortable pursuing iwi leaders and other Māori community leaders in the same way I pursued public-facing community leaders (e.g. elected officials). Again, this is a necessary area for future research.

\section{Research Findings}

The following three chapters constitute the results of this research. Chapter Five delves into the Whanganui community, where participants unpacked the devastation of the neoliberal reforms for this city that was once a hub of industry. In Whanganui I observed a community with deep roots into the remnants of their solidity - fractured as it is. Chapter Six provides a significant contrast, examining the more liquid nature of Napier, a city with impeccable branding and a beautiful aesthetic. Napierites I interviewed detailed the boon of neoliberalism and globalisation for their city: tourism, trade, and opportunity abound for individuals able to grasp it. Although there were certainly remnants of solidity and the frustrations that accompany it, Napier immediately struck me as a more liquid location, and 
the community was thus less severely affected by the release of a 'risky' individual. Chapter Seven journeys into the community in Ōtāhuhu. Historically stereotyped as part of the dangerous area of South Auckland, in Ōtāhuhu I found dedicated leaders committed to contributing to improving the lives of their tightknit community. Similar to the experience of Whanganui, the people of Ōtāhuhu have suffered significantly as a consequence of deindustrialisation and neoliberal reforms, and retain precarious solidity today as gentrification and liquidity come lapping at its shores. 


\section{Chapter Five - Whanganui}

Ko au te awa. Ko te awa ko au.

I am the river. The river is me.

Whakatauki (proverb) of local iwi in Whanganui

\section{Entering Whanganui}

Arriving into Whanganui on a Sunday afternoon in July 2018 , I observed a city asleep. It had been a four-hour bus journey, as Whanganui's small airport has very limited services that do not extend to Wellington. During the two kilometre walk through the centre of town from the bus station to my riverside accommodation, I passed only two other people. It was a calm day, and the restored heritage buildings that line the main streets of Whanganui stood along the route as relics of the city's past. The city does not have shopping malls or outer suburb hubs - Victoria Avenue is Whanganui's prime shopping destination. On Victoria Avenue, the handful of chain clothing stores and fast food establishments that I recognised were dispersed amongst instant finance providers, takeaway shops, second hand stores, as well as empty storefronts dotted along the main street. The cafes I passed were of the old fashioned style where you fill your tray and shuffle around to the till before collecting your own cutlery and seating yourself - a style rarely seen in central city dining establishments in those New Zealand cities that had adapted themselves to a much more consumer oriented economy, and where service had become a more central feature. Coming off the main street, there was an eerie stillness with businesses closed, the gates to the police station locked, and no traffic on the streets. 
Image 2 Whanganui Township

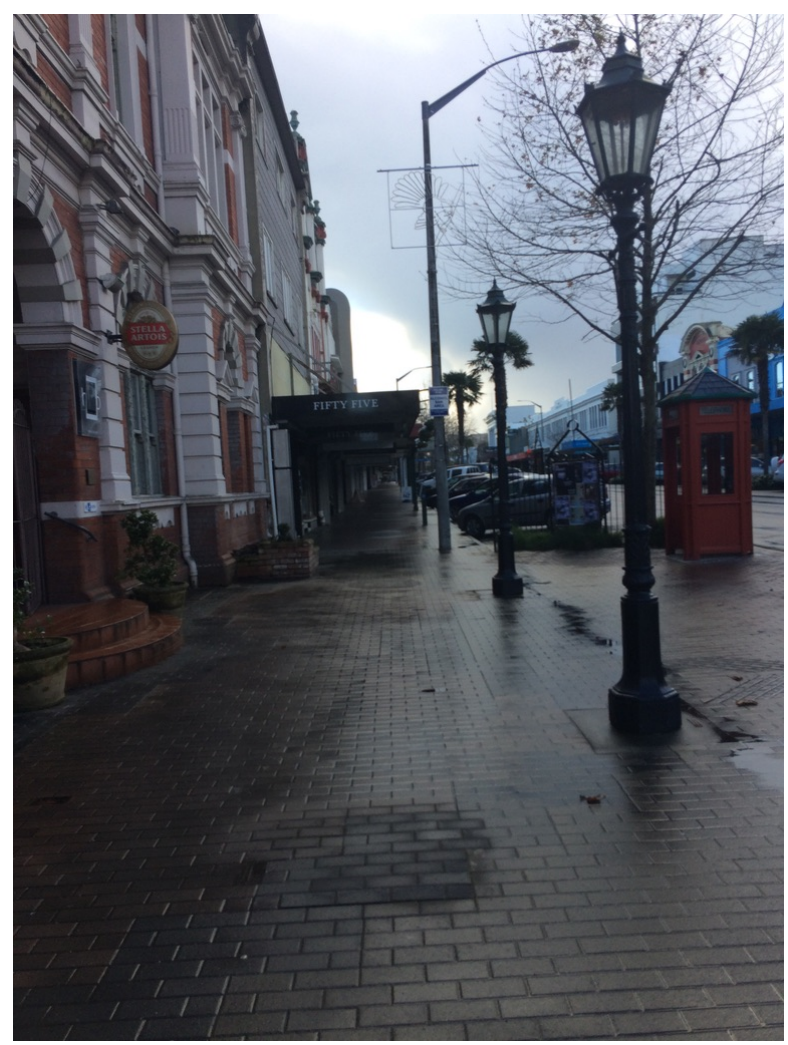

The beautiful buildings and empty streets of Whanganui's township (2018)

Image 3 Whanganui's Central Business District

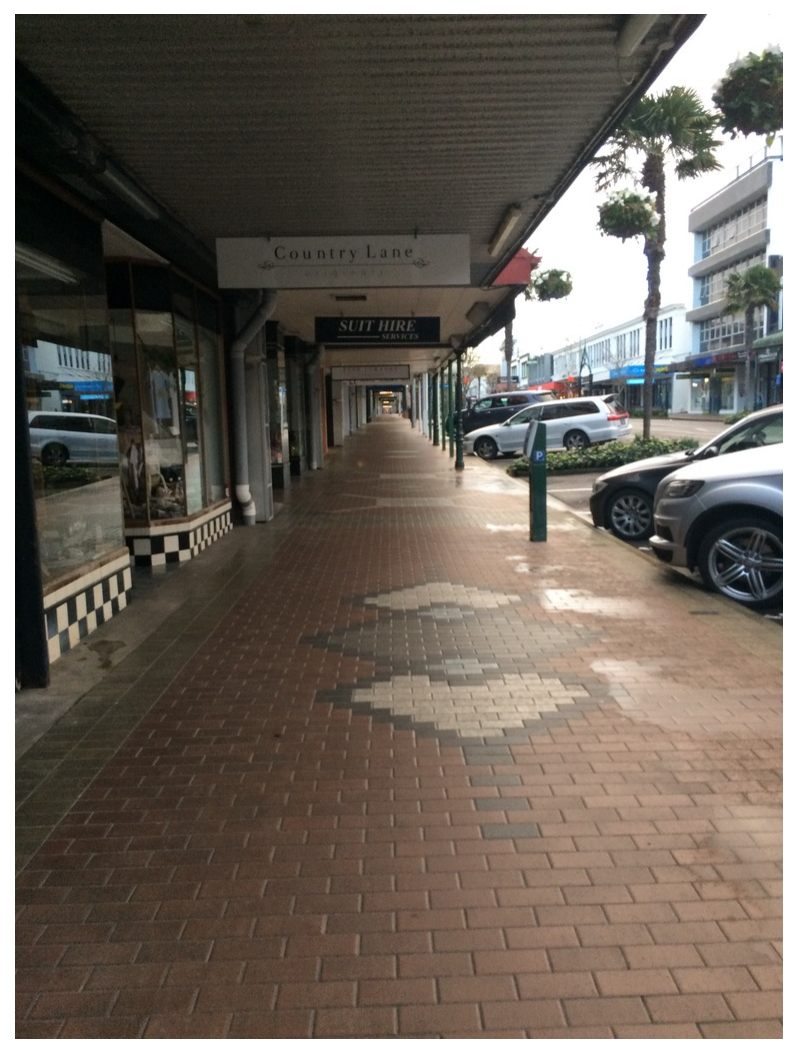

As shown in Image 2, the immaculate and empty streets of Whanganui (2018) 
On arrival at my accommodation, the owner expressed curiosity about the purpose of my stay, asking what I was doing in Whanganui. Upon hearing a brief summary of my research, and discovering that I had gone to university with his son, he promptly provided me with the details of a prominent community leader he knew well. This connection was to prove invaluable for my research. Upon distinguishing myself as connected (in some very small way) to this location, the residents were typically very happy to assist me in whatever way they could. This obliging and friendly disposition is one of the characteristics of traditional, 'solid' New Zealand, and particularly apparent in situations where I was able to demonstrate the two degrees of separation explained in Chapter One.

It was later that first day when I set out to explore the river that the locals of Whanganui emerged: walking, running, cycling along the water's edge. The central importance of the river for the community was immediately apparent - although at the same time, there has been little attempt to turn this community facility into a commercial enterprise with bars and cafes dotted along the edge. Rather, the river is preserved much as it has always been, with steamboat rides available to those looking to explore it further. Later, in my conversations with each of the community leaders I spoke with, I would learn that the river is vital within both $P \bar{a} k e h \bar{a}$ and Māori communities:

"One thing that really binds everybody is the river. The river is really important to the town. You know, I think it would be impossible to live in Whanganui and not have some contact with the river... just the heart of the community. People just really love the river passionately, not just local iwi but Pākehā as well. I just couldn't imagine Whanganui without the river." (Participant 12)

"The river is what the community relates to. It all comes back to the river... from the mountains to the sea - that's what we're pretty much about ay." (Participant 21)

"The presence of the river makes a huge difference in this community in a way that is not really tangible, outsiders can't really get it, but I do think it makes a difference because it's kind of physicality with the mountain at one end of our district, the river 
coming through and then the sea. There's a dynamic that is difficult to explain." (Participant 20)

\section{Whanganui's Place in Aotearoa/New Zealand}

The Whanganui River is the longest navigable river in New Zealand. Prior to colonisation, the land around the river was the most densely inhabited in the country. Relationships, communication, conflicts, and trade existed between hapū and iwi in the lands surrounding the Whanganui River for several centuries before colonisation. The river has always been a vital arterial trading and communication route, and has always held spiritual and ancestral significance for Māori.

Where the river had historically brought life and spiritual connection to the local people, its navigability and accessibility eventually delivered devastation to hapū and iwi, bringing British settlers onto their lands. Colonisation brought to the area dispossession and injury hitherto unimaginable to tangata whenua. In the same way that traditional life had been centred around the river for centuries, the settler outpost of Whanganui (known as Petre from 1842-1854) was built around the banks of the lower Whanganui River. Whanganui was the second settlement after Port Nicholson (Wellington) to be established by the New Zealand Company, with British settlers arriving to the area from early 1841 . The initial (alleged) purchase of 40,000 acres of land on the banks of the lower Whanganui River from 27 chiefs for $£ 700$ worth of goods was contested for many years to come, and was the basis for fundamental tensions between Māori and settlers, as well as upper and lower river hapū and iwi (Prickett, 2002).

After prolonged government engagement with tangata whenua, this significance of the river was formally recognised by the Crown in March 2017, when the Te Awa Tupua (Whanganui River Claims Settlement) Act was passed into law, recognising the Whanganui River as a legal person (New Zealand Parliament, 2017). The recognition of the river as a legal person, a living being, and as awa tupua (river of sacred power) occurred as part of a Treaty of Waitangi settlement between the Crown and a group of local iwi following negotiations and petitions to parliament on the issue dating back to the 1870 s. 
Situated on the western coast of the lower North Island, the physical beauty of Whanganui is striking: the river, mountains, beaches, native bush, as well as extensive gardens, classic architecture, and a large number of historic buildings. In the early days of settlement, Whanganui was considered to be an outpost of Wellington, so when violent clashes between colonial settlers and Māori erupted in the Hutt Valley in the early 1840's, Whanganui settlers were concerned (Prickett, 2002). By 1847, Whanganui became a garrison town, with permanently occupied stockades. Throughout the 1840 's and the following decades, there were a number of sieges and violent outbreaks in the area surrounding the Whanganui River. Whanganui was the location of several significant conflicts within the New Zealand Wars (Ryan \& Parham, 2002). By 1870, the British military presence eased, and the development of the British settlement began in earnest.

Throughout the early 1900s, suburban Whanganui was developed, and industry was established at pace: freezing works, ${ }^{13}$ woollen mills, wool stores, phosphate works, railway workshops, ${ }^{14}$ as well as a port, hospital, and landmark buildings including the opera house, observatory, and rowing club (Beaglehole, 2015). Whanganui became a city in 1924 after passing the threshold of 20,000 inhabitants, and was the largest settlement in the country outside of the four main centres (Auckland, Wellington, Christchurch, Dunedin). Although Whanganui was badly affected by the Great Depression, it flourished with the economic recovery of the post-war era, with industry and manufacturing recovering, and then intensifying during this period. Whanganui became increasingly connected to other New Zealand centres with the development of an airport and air cargo in the 1950's, during which time state housing investment in the Whanganui suburbs also helped to revitalise the city. The post-war era brought stability and opportunity to the city of Whanganui.

Whanganui's origins of strong industry, trade, and agriculture. However, the city's early prosperity and popularity as an attractive place to move to and live in are hard to imagine

\footnotetext{
${ }^{13}$ Freezing works were New Zealand's first large-scale industrial plants - facilities at which meat was processed and frozen for export. For over a century from 1882, most of New Zealand's meat was shipped as frozen carcasses to Britain (Tolerton, 2010).

${ }^{14}$ Until the 1980s, the New Zealand government owned the national rail network, and the construction of locomotives and wagons, as well as the maintenance and repair of trains and railways was conducted in a network of 'railway workshops' across the country.
} 
when looking at it today. Though maintaining its natural beauty, the township does not outwardly appear to be thriving in any kind of economic/entrepreneurial sense, and it has the feeling of being a relic of a different time.

\title{
The Consequences of Neoliberal Restructuring in Whanganui
}

Whanganui was severely impacted by neoliberal restructuring from the mid 1980s. With new public management taking hold, government offices in Whanganui either moved to nearby Palmerston North, or closed entirely (Beaglehole, 2015). Deindustrialisation saw the closure of much of the industry on which the city's economy relied: the railway workshops, the freezing works, the mills. My Whanganui participants explained the impact as follows:

\begin{abstract}
"The community was very much decimated in the 1980s, particularly with major government departments leaving Whanganui. The freezing works closed down, railways closing down, that had a huge impact on the community. You could walk up the main street and it was just shop after shop after shop that was empty. You'd see the youth in a lot of unemployment. The youth wearing black and it was just a sense of depression and dismalness and things like that." (Participant 13)
\end{abstract}

"The big trauma that Whanganui is still living through would be the East Town Workshops closing in the 1980 s... it provided a massive amount of employment. When that closed in the mid-1980s, there was a major trauma in Whanganui... massive unemployment" (Participant 16)

\footnotetext{
"seeing the devastation... I was staggered because there' $d$ been the railway workshops had closed here, one of the freezing works, massive unemployment. It was like the whole world had changed." (Participant 15)

"It was devastating, absolutely devastating. There was just a cloud of depression over the place you know. Who would come here, it was just dreary... we've since had perhaps some of the worst social statistics anywhere in the country" (Participant 13)
} 
The comprehensive restructuring, privatisation, and corporatisation undertaken by the Fourth Labour Government in the 1980s created a crisis for Whanganui, from which the city was unable to recover for decades to come. Some argue, as Participant 16 does above, that the city is still recovering today. While economic revival and social investment by the government had helped Whanganui to recover following the Great Depression, the divestment and deindustrialisation undertaken in the 1980s disabled the manufacturing heart of the city's economy, and sent unemployment rates in the area soaring. In 1986 there were approximately 27,000 working people in Whanganui; with the closure of the railway workshops 1,000 jobs were lost, and the sale and corporatisation of New Zealand Post saw services centralised with another 500 jobs lost (Stowell, 2011, February 19). This was part of nationwide unemployment crisis, with the unemployment rate amongst the general population almost tripling from 4\% in 1986 to 11\% in 1991, and the rate for Māori more than doubling from 11\% in 1986 to $25 \%$ in 1991 (Locke, 2010).

Though the magnitude of the impact of the restructuring is difficult to measure, examination of social statistics in Whanganui today go some way to illustrate the reaches of the disadvantage this 'left behind' community still experiences. One useful marker of this has been the population: in 2013, Whanganui had an urban population of $38,088-$ a net decrease of 2\% since 1966 (Beaglehole, 2015). Meanwhile, the population of New Zealand increased 62.9\% during this period, moving from 2.7 million in 1966, to 5 million in 2018. In fact, the 2018 Census record of the Whanganui urban population increase (up $7.5 \%$ since 2013) was the first on record since the 1980s (Statistics New Zealand, 2018). This was an indication that, until very recently, Whanganui was a place that people escaped from, not to.

As of the 2018 Census (Statistics New Zealand, 2018), there were 45,309 people living in the Whanganui District (an increase of 7.5\% from the 2013 Census, as stated above). The Māori population of the district was $11,910: 26.3 \%$ of the local population surpassing the $15.9 \%$ of Māori in the general population. Although Whanganui has a significantly larger proportion of Māori than New Zealand generally, the proportion of New Zealand Europeans $(P \bar{a} k e h \bar{a})$ is also higher: $79.2 \%$ in the Whanganui District versus $70.2 \%$ of the general population. This 
reflects the lack of broader ethnic diversity in the Whanganui community: the proportions of other ethnicities in the Whanganui District are significantly lower than the proportions in wider New Zealand: Pacific peoples (3.6\% versus $8.1 \%$ nationally), Asian (4.1\% versus $15.1 \%$ nationally), Middle Eastern/Latin American/African (0.5\% versus 1.5\% nationally).

Whanganui is at or above the national average in a range of social statistics indicating its status as a 'traditional' provincial city. The share of those working in the manufacturing industry in Whanganui is the highest of any electorate in New Zealand (16.6\%). The level of Christianity is slightly higher than the national average in Whanganui (37.3\% versus $36.5 \%)$ although this has steadily declined over the last three censuses (as it has throughout New Zealand). The district also features in a range of negative social statistics. In the 2018 Census, the Whanganui District was above the national average in unemployment $(5.1 \%$ versus $4.0 \%)$, and the proportion of those not in the labour force (38.3\% versus $31.3 \%$ ). There were more regular cigarette smokers (17.8\% versus $13.2 \%$ ), a higher proportion of the population with limitations on their ability to undertake activities (9.7\% versus $6.5 \%$ ), and a significantly lower than average median income $(\$ 24,400$ versus $\$ 31,800)$. Overall, Whanganui's population is less diverse, less mobile, less healthy, and less affluent than New Zealand is generally.

\footnotetext{
"It's a community that has had less access to tertiary education (even though it's got some very good schools); you've got an older population; a sicker population; a population that has had less disposable income and has been on lower wages than comparable cities." (Participant 14)
}

In these respects, Whanganui is a slow moving and solid community in a world where lightness and mobility are valued. The static and traditional nature of this solid community and its deep roots emerged in a variety of forms during my interviews. Community networks are easily navigable for locals, and the 'two degrees of separation' are certainly evident here. The deep roots of participants within Whanganui lent themselves to stability and constancy, confirming the fixed nature of the community:

“This is the seat of my family, although I don't have very many relatives here. My 
ancestors arrived here in 1879, they came from England on a ship and went to Wellington, didn't even set foot in Wellington, just transferred from a sailing ship into a coastal trader, and then came up the Whanganui River and set foot on Putiki, so that was their first experience of New Zealand... some of us never left, we settled in." (Participant 13)

"Whanganui is reasonably well connected... there's very easy contact. Because of the size of the place, people who are in positions of you know, 'authority' if you like, you meet them in different roles." (Participant 15)

"You know people's parents and grandparents all your life you know, which suggests the population is quite stable. I wouldn't say it's a conservative town, but it's a town that changes in increments rather than radical change." (Participant 16)

Participant 16 explained this comment on conservatism in terms of the unusually large presence of religious movements of Christian origin in Whanganui:

\footnotetext{
"One of the oddities of Whanganui is it's got this multiplicity of Christian sects or groups: Quakers, Seventh Day Adventists, Rātana ${ }^{15}$, a big Brethren community, St Anthony's (the pre-Vatican II Roman Catholics who do the Latin mass)... you do have quite a strong element of religion. It's not political at all though, so we're not conservative in that way."
}

Although the recorded rate of Christian religious fellowship (of all denominations) in Whanganui is only slightly higher than the national average, the variety of Christian sects and denominations are an interesting and unusual characteristic of the local population. It might be that the solidity and predictability of the Whanganui community combined with its agriculture-adjacent economy and relatively low land prices to create a kind of refuge for

\footnotetext{
${ }^{15}$ The Rātana Church is a Christian-based faith and political movement founded in 1925 by Tahupōtiki Wiremu Rātana, whose annual birthday celebration in January each year remains an important political event. The 2020 Rātana celebrations attracted the leaders of all major political parties, including the Prime Minister and the Leader of the Opposition (Trevett, 2020).
} 
alternative religions in this area, while at the same time the presence of these sects might make the city more inward looking, protective, and suspicious of outsiders.

Participants were unanimous in their promotion of Whanganui as an ideal place for families with children. The geography, the schools, the community, and the laid back pace of everyday living were consistently boasted by community leaders as the jewel in the crown of Whanganui.

\begin{abstract}
"Everything you could imagine is here for kids... we breed them and support them to compete on the national scene. We've got amazing primary and high schools here." (Participant 19)
\end{abstract}

"Kids are very much our prime export. We make good kids here." (Participant 16)

\begin{abstract}
"Whanganui is perceived as a great place to bring up kids, because there's lots of sort of facilities, sports facilities, connections like that. I think there's this popular thing that it takes a village to raise a child. In my role... I appeal to people and say 'let's look after the kids in our backyard'. I appeal to that sense that we're a community and the children, they're not just other kids down there, there actually is a sense that we have responsibility for every child." (Participant 15)
\end{abstract}

"You can have a quality of life with your family here, and a connection with your kids here that other places just don't have." (Participant 18)

The impression of Whanganui as a great place for families has been taken up as part of the city's attempt to rebrand itself by delivering on the national promise of New Zealand as a good place to bring up children that was propagated in the 1950s, but in doing so it's 'solid' way of life still predominates. Discover Whanganui (2021), advertises this element of community life as one of the top reasons to move to the city:

"Whanganui is a great place to raise a family. In fact, it's one of the most common reasons new residents have for choosing it. Great schools, community events, 
opportunities in sport and arts, and a relaxed pace of life give kids all they need to succeed"

The confidence of community leaders in the quality of their city is typical of the pride many local people with whom I interacted took in their home. This extended to the point of defensiveness for many local people. A common descriptor that community leaders used when describing Whanganui was 'insular': the local people - those who have been left behind, as it were, in the course of restructuring - form extremely strong social networks which outsiders can find difficult to meaningfully penetrate. One participant explained to me that she had lived in the area for around sixteen years, so was considered by many in the community to be a newcomer. In the same vein, several participants (of Pākehā descent) proudly traced their ancestry back to the early settlement of the lower river lands in the 1840 's. There was much talk of the 'legacy' families in the community - those whose names are well known to all in town as community stalwarts going back generations.

This traditional nature of the Whanganui community lends itself to exclusivity as well as insularity. A common thread among the community leaders I interviewed was the stubbornness of the people of Whanganui about their standalone identity as a community. This was often characterised as 'defensiveness', and insistence that the community is not understood in its own right by government.

"People are really proud of Whanganui, almost to the point of being defensive about it." (Participant 12)

Participant 12 went on to explain the distinctiveness of the city from nearby, larger, Palmerston North is a particular bone of contention amongst the community:

"Whanganui likes to be really separate from Palmerston North. You know it's a constant source of irritation that it's Manawatu-Whanganui, ${ }^{16}$ when really the two communities are quite separate, even though they're only an hour apart."

\footnotetext{
${ }^{16}$ Manawatu-Whanganui is the national electorate in which the city of Whanganui sits.
} 
While the community leaders of Whanganui are reliable in their espousal of the benefits of community and family life in this place, the reputation of the city has been consistently negatively affected by a series of incidents and stories that have generated negative media attention on the national stage.

\section{A Proud Community with an Unfair Reputation}

Whanganui's reputation has been hampered by a range of bad-news stories in national media, much to the disappointment of the proud and defensive local people. In 2014, prominent New Zealand economist Shamubeel Eaqub published a book in which he examined the economies of New Zealand regions and set them out against their closest comparable nation-state economy - Whanganui was compared to the notoriously unstable economy of Greece (Eaqub, 2014). In an interview about his research, Eaqub had inferred that Whanganui was a 'zombie town' that may have to close: "you know it's going to be devastating for those communities, but it's going to be better for New Zealand" (Owen, 2014, July 12). One community leader noted this specific incident as a point of anger amongst locals:

\footnotetext{
"The community is incredibly caring about itself, and it is staunchly defensive as to the view of Whanganui on the national stage. We heard Shamubeel Eaqub refer to Whanganui a few years ago as a 'zombie town' and the community were quite rightly hacked off - he may have been some academic making an observation, but the community were at the sharp end of that criticism that didn't take account of the stuff that the town had had done to it by outsiders, and the way it had responded." (Participant 14)
}

More recently, in 2018, New Zealand comedian Guy Williams published an opinion article on national news website Stuff entitled Give Whanganui a Chance, in which he asked "what's wronganui with Whanganui?". He speculated that New Zealanders' views of Whanganui have been significantly influenced by the reign of Michael Laws as Mayor in the 2000's. In 
justifying the "flood of bad press" Whanganui has received, Williams (2018, September 16) explained:

"I break this stream of bad press down in to three basic categories: 1. Michael Laws' strange reign as mayor. 2. Constant stories about gang problems (sometimes started by Michael Laws) and 3. A bad work trip to cover what turned out to be a bleak story... involving Michael Laws... not surprisingly."

Although unscientific, this opinion article got to the heart of how many New Zealanders characterise Whanganui today. Michael Laws was mayor of Whanganui from 2004 until 2010, during which time he was also a talkback radio host often either in the national headlines, or generating them (for example, he let it be known that he not only favoured the restoration of capital punishment, but also said he was prepared to be the executioner himself). Laws can be viewed as a "charismatic entrepreneur" who saw the opportunity to generate personal and political benefit through "outflanking traditional modes of power and morality", and serving to exacerbate or inaugurate moral panics (Joosse, 2018, p. 994). Among the campaigns Laws was involved with were some of the news stories outsiders would best know Whanganui for today, even over a decade later. These included the gang patch bylaw (an attempt to outlaw the wearing of gang patches in the city), and efforts to block the formal correction of the spelling of the Māori name for the city from 'Wanganui' to 'Whanganui'. These two campaigns that became high profile media stories are among those that have had particularly significant and lasting impacts on the Whanganui community. Still today, the use (or omission) of the ' $h$ ' in the spelling of Whanganui is viewed by many locals as a political statement, particularly on Māori relations and the place of Māori in New Zealand society - those that use the ' $h$ ' are publicly declaring themselves and their organisation to be inclusive of Māori. Those who do not include the ' $h$ ' are declaring their opposition to local iwi, and insistence on the use of 'Wanganui' is considered a mark of anti-Māori sentiment by much of the community, as well as a symbol of political correctness. My participants had vivid memories of this debate:

"It was very, very divisive. You know the iwi felt very strongly that they wanted 
the name spelt correctly as they saw it, and then on the other side it was like well you know, me and my parents and my grandparents and my great grandparents, we were all born in Whanganui without the ' $h$ ' and that's how it's always been, and Māori wasn't even written down until 100 years ago so how can they say that the ' $h$ ' is wrong? It was just madness." (Participant 13)

[on the most concerning events to have happened in the community in recent decades] "putting the ' $h$ ' in the name! That got people really worked up!" (Participant 22)

Although national headlines have cast Whanganui in an unfavourable light over recent years, and social statistics outline a city suffering the symptoms of prolonged disadvantage, the Whanganui community I was welcomed into was tightly knit, deeply interconnected, and above all, caring. In the face of the ravages of the neoliberal reforms, and the decadeslong consequences of deindustrialisation in particular, the community has turned inward and sought to pour its energy into applying often sparse resources into care for their own.

\section{Life in Whanganui}

While the Whanganui District includes the city of Whanganui and its immediate surrounds, as well as Whanganui National Park to the north, the bounds of the Whanganui Electorate cover a significantly larger area. Whanganui electorate boundaries were adjusted prior to the 2017 election, with the lines moving to incorporate Stratford and Opunake to the northwest. The Whanganui electorate therefore covers large rural areas, with vastly different characteristics to the community in the city itself.

In the 2017 general election, although the centre-right National candidate and political newcomer Harete Hipango won by a margin of a 1,706 over first-time centre-left Labour candidate Steph Lewis, the new electoral boundaries likely had an influence on this (New Zealand Parliamentary Library, 2017c). As McDonald (2017, September 26) explained in the Whanganui Chronicle following the 2017 election, "a detailed look at how the Whanganui electorate voted by polling booth shows clear divides between Whanganui and South 
Taranaki, rural and urban, and high and low socio-economic status". McDonald (2017, September 26) summarised the situation concisely: "if the Whanganui electorate did not include South Taranaki, Labour's Steph Lewis would be Whanganui's new MP". The evidently left-leaning city is represented by a centre-right Member of Parliament due (at least in part) to the extension of electoral boundaries further into rural Taranaki.

It is the urban Whanganui community that forms the unit that community leaders I spoke with identified as 'their community'. This community has endured the series of government decisions since the 1980s that have resulted in many of the negative social outcomes detailed in this chapter. Following the deindustrialisation, neoliberal restructuring, and new public management put in place by the Labour governments of the 1980s, the National governments of the 1990s continued in the same vein: cutting benefits across the board, and continuing to privatise and corporatise the public sector. For Whanganui, policy decisions actioned in Wellington compounded year by year, creating dire conditions for the city which are remembered vividly by most, and are considered by many to remain in place to some extent today. In addition to the effects of the nationwide economic restructuring and reform, Whanganui was specifically and severely affected by closures of large stateowned manufacturing facilities (including the East Town Railway Workshops) as well as freezing works and education and training institutions. No longer an outpost of Wellington, the symbolic distance between Whanganui and the capital has become vast.

When talking to community leaders, this distance between the Wellington-based central government and the people of Whanganui was frequently highlighted. They seemed to be saying that the people of this community do not understand, nor feel understood by, the state: they represent different modes of existence, as Whanganui retains a culture of solidity now difficult for government officials in Wellington to conceptualise.

“There's a huge part of the population that's just totally static, and they don't really know what happens outside... they are totally disconnected from central government. The seat of government is only $200 \mathrm{~km}$ away in Wellington, but it is miles apart in terms of the government and Wellington knowing how provincial cities work, and 
what the struggles are for provincial towns and people that live in them." (Participant 13)

"There is definitely an element of the community that thinks that anything that comes from central government is designed to shaft Whanganui." (Participant 12)

"Whanganui is sceptical of the decisions central government makes. Because of the loss of the East Town Workshops and the decisions that they have made which have had a huge effect on the community directly. They feel that they've always had the pointy end of that stick, and they are critical of central government making decisions that affect their daily lives. If you look at Whanganui, it's suffered badly with some of those decisions." (Participant 14)

The disdain for 'Wellington' and things associated with it extended beyond my interviews and into my interactions with local people, as it did in Ōtāhuhu (see Chapter Seven). I noted that participants became visibly more comfortable when I explained that I was not from Wellington myself, and that I grew up in Napier (another provincial North Island city). My identity as a provincial export became particularly valuable in connecting with community leaders in Whanganui, and reduced the social distance between my participants and myself. This value was further increased when I confirmed that I had no ties nor formal relationship with the central government myself, and that this research is not associated with any government project.

\section{Why would you go anywhere else?}

The strength of the Whanganui community can be measured in a number of ways.

'Tightknit' is common parlance when referring to effective communities, and my experience of Whanganui and its community leaders was epitomised by this term. Each of the leaders I spoke to, whether elected officials, NGO staff, media representatives, ex-Police officers, or other community representatives, appeared to have a comprehensive understanding of the interrelation between elements of the community, a strong sense of the history of their city, and a nuanced comprehension of the social issues facing the people there. One measure of 
community strength and social cohesion is the voluntary sector. Participants proudly proclaimed Whanganui to be the 'volunteering capital' of New Zealand, with the Whanganui Chronicle confirming that the city has the highest number of registered volunteers per capita in New Zealand (Wilson, 2018, November 9). Participant 16 referred to Whanganui's as consistently having the "highest levels of volunteerism in New Zealand".

This was reinforced by the claim that there were $1600-1700$ clubs and organisations within the community, and that this is representative of high levels of social capital in the city.

"I think that its social capital is distinctive from other towns... there's a lot of very good social capital here in Whanganui... the organisations that are within the community, the ability to network with government, council, and not-for-profit sector is second to none in New Zealand" (Participant 13).

With all of these organisations naturally comes a series of smaller communities within the broader geographical community, and alongside communities of interest lie smaller communities within the suburbs of Whanganui. My participants explained to me that the characteristics and identities associated with various suburbs in Whanganui are particularly strong, and usually linked to long-established and embedded socio-economic class.

\footnotetext{
"People will classify you straight away by your suburb. So like we live in Gonville, I mean this is kind of a middle-of-the-road street, but Gonville is like you know, 'Gangville' is the joke. If you live in St John's Hill, there's a stereotype. There are definitely kind of different characteristics of different suburbs." (Participant 12)
}

I didn't understand the St John's Hill reference until I met with one participant who had lived there as a child, and had to overcome the connotations of hailing from 'Snob's Rock', from which the affluent are seen to look down on the rest of the city:

“St John's Hill is known as Snob's Rock - if you live on the hills you're rich, if you live on the flat, you're not." (Participant 16) 
Although the stereotype of the wealth of St John's Hill is somewhat demographically accurate, and the local private school, Whanganui Collegiate, is among the most expensive schools in the country, the wealth gap in the city is much less significant than that of New Zealand generally. Over time the divide between rich and poor in Whanganui has become less stark, unlike much of the rest of New Zealand. Participants explained the spread of wealth and deprivation in the city:

\begin{abstract}
“There's an intimacy in Whanganui where you don't have a poor suburb. You can't go to one suburb and say that's the poor suburb. If you look at the Deprivation Index for Palmerston North, it looks like a pretty neat cannonball has gone right through Highbury. For Whanganui, it might have a few bigger pieces of grapeshot but it looks like it has been shot by a shotgun." (Participant 16)
\end{abstract}

\begin{abstract}
"The community has definitely got a strength. It's got some polar opposites in a way too - it's got a small group of people who are quite significantly wealthy, it's got quite an extensive middle class of people who are on average incomes, and it's also had, because it's been based around manufacturing and production, it's got a large group of people who are on lower incomes who have therefore been very vulnerable to changes in industry." (Participant 14)
\end{abstract}

In this vein, the 2018 Census (Statistics New Zealand, 2018) showed that a slightly higher proportion of Whanganui locals owned or partly owned their homes than the New Zealand average (55.2\% versus $51.3 \%$ ). The median weekly rent was significantly lower than the national average: \$200 in Whanganui versus the New Zealand median of \$340. However, house prices have rapidly increased over recent years in Whanganui, reaching a new median price record in September 2019, increasing 45.5\% from the previous year (Whanganui Chronicle, 2019, October 26). In 2018, economists determined that the rental yield of the Whanganui/Manawatū region to be the highest in the country (Dudman, 2018, July 16). Despite the significant increase in prices, the cost of living remains significantly lower in Whanganui than in the main centres (e.g. Wellington). Despite lower median rent, and higher levels of home ownership, the community leaders I spoke with considered the national housing crisis to have hit Whanganui hard, with rents noticeably increasing along 
with homelessness and transience. A 2018 report compiled by Council-funded group 'Safer Whanganui' outlined issues with rental price increases, shortages of rental properties, and transience among the least affluent individuals and families in the city. The report detailed that high rents, low supply, and unfit housing stock are among the issues perpetuating the lack of access to housing in Whanganui (Safer Whanganui, 2018). During my time in Whanganui, I observed several people begging outside the supermarket; however there was not a visible homeless population on the scale of Wellington or Auckland.

As in any community, fractures within the Whanganui community exist between socioeconomic groups, suburbs, Māori and Pākehā, and between the broader rural electorate and urban residents. These fractures may be lessening over time in some respects, as Participant 16 explained:

" $20 \%$ of the population are Māori or thereabouts. There's a little bit of a social stratification, but I think as generations go on, that it's losing its kind of status split and becoming more bank balance derived." (Participant 16)

Despite the existence and acknowledgement of fractures, rivalries, and stereotypes, the Whanganui community has a strong identity. Notably, this community identity has not expanded to welcome its prison, despite the facility's location within the geographical bounds of the city.

\section{Whanganui Prison}

Built in 1978, Whanganui Prison is located ten kilometres outside of the city in Kaitoke. The facility has capacity for 581 prisoners and held 538 people, or $5.5 \%$ of the New Zealand prison population as of December 2019 (Department of Corrections, 2019). The 2018 Ombudsman's Report on the unannounced inspection of Whanganui Prison confirmed that at that time, the prison was fully staffed with 235 full time equivalent staff (Boshier, 2018). For a relatively small city, the local prison is therefore a large employer, and a significant contributor to the local economy. Despite this, the community typically hold the facility in contempt, many believing it only serves to bring crime and bad press to the community. 
Moreover, it was the location of Whanganui Prison, and the nature of the community and the effective operation of its community agencies, that attracted the attention of the state in relation to the release of notorious sex offender Stewart Murray Wilson.

The Case

"We'd had crisis after crisis... suddenly it was like everything was settling down. My colleague said 'you won't believe what I've just heard!'” (Participant 16)

In August 2012, the Department of Corrections announced that high profile convicted sex offender Stewart Murray Wilson - the 'Beast of Blenheim' - would be released on parole in Whanganui the following month. In 1996, Wilson was sentenced to 21 years imprisonment for serious sexual and violent offending against sixteen women and girls, including rape, attempted rape and indecent assault, and had been incarcerated at Rolleston Prison in Christchurch (New Zealand Parole Board, 2012). The offences for which Wilson was sentenced spanned over 22 years, from 1972 to 1994, and also included charges of stupefaction and bestiality (New Zealand Parole Board, 2012). Wilson was convicted as a serial offender. Both an opportunist and a groomer, he had committed violence against children and family members, and was considered by the Department of Corrections to be high risk for the duration of his detention and on his release. In October 2008, the Chief Executive of the Department of Corrections had applied for an order guaranteeing that Wilson would not be released before his maximum applicable release date of 1 September 2012 (New Zealand Parole Board, 2012). There was no legal provision available to detain Wilson indefinitely past this date, meaning that he would eventually have to be released.

Wilson was released on parole under the most stringent conditions to have been handed down by the Parole Board at the time: restrictions on his movement, including live tracking of his whereabouts using GPS technology (the first use of the technology for this purpose in New Zealand); prohibition of non-approved contact with women, as well as children under 16; restrictions on transport (including the specification of scooter riding); as well as prohibition from internet use, visiting the library, the bush, church, and Alcoholics Anonymous meetings. Additionally Wilson was required to live (and initially to pay rent) in a 
state house that had been relocated behind the wire of the grounds of Whanganui Prison (Pratt and Anderson, 2016). Following significant community and media interest noted earlier in this thesis, Wilson was formally released to an address within the Whanganui Prison grounds in late August 2012.

Community notification in Wilson's case progressed in an unusual fashion, as the Department of Corrections took unique actions due to the notoriety of the individual that was to be released. These measures included top Corrections officials (including then-CEO Ray Smith) going to Whanganui in person to carry out notification of select community leaders. Although the intention behind this visit appeared to be the careful and surgical management of notification of a delicate release process by Corrections senior managers, the result did not reflect this intent. The public were very quickly notified through media releases originating from these initial notifications, and Corrections almost immediately lost control of the process they had clearly intended to very carefully manage. The Department of Corrections were the target of much of the frustration, fear and anxiety expressed by the community. Community leaders expressed their frustration about this process during their interviews:

"I think a lot more could have been done by Corrections to help our community understand how and why things were going to be okay... by targeting one Councillor with their notification, unfortunately Corrections fed the monster, so he was able to froth it all up in the community - fear! Danger! Fear! Danger!" (Participant 18)

"There was no communication from Corrections with the community, then bang! It was front page media stuff. Very frustrating." (Participant 17)

Once the story hit the media and the public were notified in this way, media sensationalism fed into and propelled the cycle of anxiety experienced by individuals within the community. 
The label 'Beast' was consistently and zealously deployed in headlines and articles covering the case in every major newspaper in New Zealand, and in televised coverage of the case. Local newspaper the Whanganui Chronicle $e^{17}$ published an incredible 59 articles about Wilson between the announcement by the Department of Corrections and his release, in addition to the extensive coverage in the national newspapers noted earlier. In the three days immediately preceding his release, the coverage accelerated, with thirteen articles relating to Wilson published in the small daily paper. The headlines of the six articles about Wilson published in the Whanganui Chronicle on August 292012 included: 'The Tar and Feathers Mob Ready for Wilson', 'Kaitoke Pupils to Learn About Wilson's Arrival', and 'Beast Battle Not Over Yet'. The sentiment of the articles in the local paper regarding Wilson's release was overwhelmingly negative, with less dissenting and reasoned coverage than the Dominion Post. ${ }^{18}$ Of all of the articles published in the Dominion Post regarding Wilson's release and its effects, 53\% had the term 'Beast' in the headline. Of those same articles within the period between the announcement of Wilson's release and the release itself, $56 \%$ provided detailed repetition of the nature of Wilson's offences and the details of his sentences. The Whanganui Chronicle was comparatively modest in its coverage of Wilson's release, and the word 'beast' only appeared 25 times in the six months between the announcement of Wilson's release and his recall to prison. In September 2012, a complaint was laid with the New Zealand Broadcasting Standards Authority regarding the use of the moniker 'Beast', to which the Authority responded "it has become a well-known nickname and the broadcaster cannot be held responsible for its continued use" (Dominion Post, 2013, February 5).

Among the myriad articles in every major New Zealand newspaper chronicling the facets and angles of the Wilson case were rare outlying opinion pieces warning of the danger of the level of media participation in the case. Reverend Bob Franklyn (2012, 1 September) of the Palmerston North Methodist Church, penned a dissenting opinion piece in the Dominion Post warning of the way that the "media's use of emotive language is inciting fear and

\footnotetext{
${ }^{17}$ As at December 2020, the readership of the print newspaper was 38,000 (Roy Morgan, 2021). The total population of Whanganui in December 2020 was approximately 47,500.

${ }^{18}$ As at December 2020, the readership of the print newspaper was 211,000 (Roy Morgan, 2021). The Dominion Post is New Zealand's second-largest newspaper in terms of circulation, and is considered Wellington-based.
} 
hatred in the community." A small minority of media outlets shared the sentiment Franklyn expressed, and Radio New Zealand and local paper, the Marlborough Express ceased using the term 'Beast' in their coverage of Wilson's release (Mediawatch, 2012). This sentiment that the use of the term 'Beast' and that the sensational media coverage of the case posed considerable risks was shared by many of the community leaders I spoke with in Whanganui.

"I felt very uncomfortable with [the use of the term Beast]... you knew that kind of thing would engender fear in people." (Participant 12)

"I'm always concerned about the way that media in particular report crime and punishment, and how that's sensationalised... The media referred to him as the 'Beast of Blenheim', it was a high interest story for them and they just perpetuated it page after page after page, week after week after week. Every little bit of information they could get, it was just in the public eye constantly... It created a fear that was baseless, but anything to do with sex offenders does create that kind of fear, because people don't understand what the basis of how the sex offenders think and work is, and what the control is on people with those kinds of offences when they come out into the community." (Participant 13)

The views of community leaders on the response of their community to Wilson's release are valuable in painting a more nuanced picture of what happened in Whanganui. Within the context of the sequence of negative press stories that had brought the provincial city into the national spotlight over the years leading up to the 2012 announcement, Whanganui was perhaps low hanging fruit for sensationalised media coverage. As community leaders explained, the previous negative press combined with individual actors and the nature of the situation to produce this result:

"there had been so many things happen in the few years before that that had gotten Whanganui a lot of negative publicity. You know, there was the gang patch bylaw, and 
that started with the shooting of a little girl from a Black Power pad, ${ }^{19}$ you know the drive by shooting that was in 2007 . So then the gang patch bylaw, ${ }^{20}$ and that was just huge... the town was just in a complete uproar over that whole thing, really divided. The ' $h$ ' in Whanganui, you know, Michael Laws himself when he was Mayor was quite keen on attention. He got a lot of attention whenever he said almost anything, and a lot of it was controversial... I think a lot of people thought here we go again, Whanganui is being shafted. It's another thing to bag on Whanganui about." (Participant 12)

"It just wasn't logical that the town thought that this quiet frail, mid- to late-60s man, whose modus operandi was to groom and then seduce people into a situation to take advantage of them and abuse them. [Wilson's] victims were all adult women, but the community were worried about a boy scout camp that wasn't far away... it didn't bear any logical scrutiny. But, a lot of the fear was promoted by people who had an interest in getting people frightened and keeping them frightened for political purposes." (Participant 14)

"There was quite manipulative stuff going on in the media from particular people." (Participant 16)

"There was a combination of two things going on at the same time: the fact that it was happening here and 'how dare you?' As well as an individual using the situation and manipulating the media for personal gain... it would have been really interesting to know what would have happened without an individual whipping up panic over the situation." (Participant 18)

\footnotetext{
${ }^{19}$ This comment is a reference to the 2007 death of two-year-old Jhia Te Tua, who was shot dead while sleeping on the couch in a gang-related drive-by shooting.

${ }^{20}$ Then-Mayor of Whanganui Michael Laws introduced a controversial bylaw in 2009 which was passed by Council to ban gang patches from the central city area in Whanganui. The Prohibition of Gang Insignia bylaw gave police powers to fine patch-wearers $\$ 2,000$ and confiscate gang-related insignia. In 2011, the bylaw was found to be unlawful (Taonui, 2011).
} 
It is therefore all the more important to consider the memories and perspectives of those who were on the ground at the time, and particularly those who were immersed in leadership roles within the community as the media does not provide an accurate record of events. However, it remains difficult to determine the extent to which the media caused the levels of public concern and fear in Whanganui. The public reaction in Whanganui was significantly influenced by the media coverage of, among other things, the public reaction in Whanganui.

\section{Media Coverage of Wilson}

Following his conviction and through the duration of his sentence, media coverage of Wilson and his case had been minimal. Aside from periodic references to denied appeal applications, reports of parole denial, and a couple of outrageous claims by Wilson that made national news, ${ }^{21}$ he remained largely absent from the media spotlight between his initial imprisonment at Rolleston Prison in 1996, and the announcement of his release in 2012. Though the construction of his image in the media as a 'frenzied sex beast' started out slowly in the coverage of Wilson's 1996 trial, at the other end of his sentence, the announcement of Wilson's release prompted a frantic response from the print media in New Zealand. With a stream of articles chronicling case developments and community reactions to Wilson's pending release, the response of the press confirmed what Judith Baxter (2012, 31 August) wrote in an opinion piece immediately preceding Wilson's release date, "he will never be free from the title 'the beast' - the news media will make sure of that".

According to the media, the reaction of the Whanganui community to the announcement by the Department of Corrections that Wilson was to be released in their town was overwhelmingly negative. The national and local media relayed opinions of outspoken residents alongside the developments in the case. The media also covered in-depth the attempt made by two local councillors to take coordinated action against the central state

\footnotetext{
${ }^{21}$ In 2003, Wilson made headlines following his distribution of a doctored letter from then-Minister of Justice Phil Goff. The manipulated letter stated Goff's confirmation that Wilson had suffered a miscarriage of justice, and that the case would therefore be reviewed.
} 
to block the release of Wilson in their city. On August 12 2012, local councillors Ray Stevens and Michael Laws organised the 'Banish the Beast' town meeting, which was attended by approximately 200 people (King, 2012). It was reported that at the meeting, the people unanimously supported a proposition that the Whanganui District Council attempt to step in and stop the placement of Wilson in their town, regardless of cost. According to King (2012) the sentiment of the people in attendance was consistent: they were angry that Wilson had been allocated to Whanganui without consultation with the people, and they stated that the risk that Wilson would pose to the Whanganui community, along with any future offenders the Department of Corrections should choose to place there, would be too great to tolerate. King (2012) reported that among the themes of discussion at the meeting was the need for legislative reform to ensure that offenders like Wilson were never released in the first place. In response to the initial 'Banish the Beast' meeting and two further town meetings, the Whanganui District Council agreed to take legal action in an attempt to prevent Stewart Murray Wilson from being released in Whanganui (Emerson, 2012a).

Jay Kuten (2012, August 22) crystallised the reaction of the community in his article in the Whanganui Chronicle in the week before Wilson's release that "the parole of Stewart Murray Wilson at Kaitoke represents a significant failure for this community". In addition to the public 'banishment' meeting, the less sensationalist community meeting attended by the Department of Corrections held in the weeks prior to Wilson's release; and the lodging of an application by the Whanganui District Council for judicial review of the Department of Corrections decision to parole Wilson in Whanganui; members of the community took coordinated action against the 'Beast' as well. Members of the Whanganui District Council aided shopkeepers in the mass filing of trespass orders against Wilson, intended to prevent his free passage within the central business district (Emerson, 2012b). Though Wilson's parole conditions had severely restricted his freedom of movement within the town already, councillor Ray Stevens stated that “it's important to show this man that we don't want him here. We don't want to see him, we don't want his money, we don't want a bar of him" (quoted in Emerson, 2012b). The attempt at an orchestrated shunning of Wilson, arranged by two city Councillors, drastically diminished any likelihood of his effective reintegration following his release. 
Because of the tendency of the media to both generalise and sensationalise (Greer and Jewkes, 2005), it was particularly valuable to ask the community leaders who were on the ground at the time about their recollection of the response. Although the six years that had elapsed between the Corrections announcement and the interviews would certainly have influenced both memories and emotions, it was evident in speaking with community leaders that in retrospect at least, they viewed the Corrections approach to the case unfavourably. Community leaders were unanimous in claiming that the people of the community were unsettled by the Corrections announcement. Therefore, the community reaction can be accurately characterised as negative, and there was certainly an elevated level of fear across the community following the announcement of Wilson's release. Community leaders described the reaction of their community to the announcement:

\footnotetext{
"It snuck out in the community that Stewart Murray Wilson was going to be moved to Whanganui and released into our community, and there was just an immediate outrage of people saying 'stop dumping dangerous people in such a vulnerable community'." (Participant 17)
}

"The whole of Whanganui was in uproar about it." (Participant 21)

"The general reaction was that we don't want him, find somewhere else for him. He doesn't come from here so take him somewhere else. The second reaction was one of absolute fear. It was an irrational fear, there was no rationality about it. It was an irrational fear in terms of what this guy might do... it's difficult to put it into words, but the feeling of the community was palpable. It was such that you could almost cut it with a knife." (Participant 13)

"Hysteria. I mean, there were a lot of people who were like 'oh I don't really care'. Or
you know, like 'oh yeah I see why they're doing it'. I guess the loudest reaction - the
squeaky wheel gets the most oil - the loudest reaction was the hysteria" (Participant 12) 
Some participants who had levels of expert knowledge on the matter unpacked the illogical and uninformed nature of the perceptions of risk driving the fear and panic about Wilson in the community:

"Within the Whanganui community - no more than anywhere else in the country you've got some really serious offenders that have been released from prison and are living in the community. But you could tell that there was going to be a lot of public concern about [Wilson]... you know sex crimes usually happen with only two people in the room. They usually involve people who know one another, and frequently involve people who are charged with caring for the other party. The fear that people have is that they're going to be attacked: dragged into the bushes and raped. In fact, they're far, far more in danger of offending from people they know - and frequently from people they know and love. A lot of the fear [in this case] was born out of ignorance." (Participant 14)

“...as if he was going to be in the main street to start with, I mean Corrections aren't that stupid. As if he was going to go along flashing or you know, open his trench coat or something I mean it was just absolutely ridiculous. It created a fear that was baseless, but anything to do with sex offenders does create that kind of fear, because people don't understand what the basis of how the sex offenders think and work is, and what the control is on people with those kinds of offences when they come out into the community. So some of those statistics are absolutely great, they're the least group out of 15 all the offending categories likely to reoffend!" (Participant 13)

It is difficult to separate out how much of the fear being discussed here can be attributed to the facts of the release, and how much was caused by the nature of the media reporting of the case, which perhaps contributed to infectious mass panic (as we saw in New Zealand and other countries with the frenzied descent on supermarkets at the beginning of the COVID-19 pandemic). Certainly, the nature of Wilson's offending combined with his status as an outsider to this defensive and insular community to produce a characteristic negative reaction amongst community members, notwithstanding that the prison itself was such an 
important local employer. Before the news of the release was widely known, community leaders with inside knowledge were concerned about how the announcement would be received, though some expressed understanding of the Department's choice of Whanganui under the circumstances:

\begin{abstract}
"Someone said they had heard a rumour or something that Stewart Murray Wilson is going to be released here. My immediate thought was oh no, this is going to turn into such a drama. I just knew it straight away - this is going to be a massive drama." (Participant 12)

"[Corrections] can't really place him anywhere in the country. There were only two places in the country they wanted to place him because of victim-related issues. Whanganui was probably the better out of the two cities in New Zealand that could possibly take him and have the skills to look after him." (Participant 13)
\end{abstract}

This extended to participants' considerations of how they should manage their own communications and reactions as leaders in the community at this time:

\begin{abstract}
“In my own reaction, I was conscious that I didn't want to be on the wrong side of a public argument. I tried to keep a fairly neutral stance to see how it played out in the public meetings and the chatter." (Participant 16)
\end{abstract}

"It was quite hard to know which way to go" (Participant 17)

More generally, there were a range of responses from community leaders to the news of Wilson's release to their community. Many expressed empathy with Wilson's situation alongside their concern for their broader community.

\footnotetext{
"I mean I wouldn't say that I felt sorry for him because, you know he obviously had done some really awful stuff, but I do remember reading through the conditions and thinking wow, that's tough for anybody to live under those circumstances." (Participant 12)
} 
"I've only ever seen Mr Wilson as a human being. Yes he's offended, well twelve good people on a jury say he has offended, he maintains his innocence, that's between him and his maker (or whoever else he's accountable to). For me... he deserves respect because he's a human being, regardless of what he's done." (Participant 13)

Although Whanganui's community leaders generally expressed understanding of the necessity of Wilson's release, they were in little doubt about his ongoing risk of reoffending.

"My view is he would do it again as soon as he could - he would groom and he would abuse... but he is a human being, and where do you draw the line with humanity?" (Participant 18)

\begin{abstract}
"It is really difficult. Do I think he's at high risk of offending? I think he's at very high risk of offending." (Participant 13)
\end{abstract}

"Corrections said look, there are all these conditions, if he steps out of line, ${ }^{22}$ he's going straight back into prison. People are like 'oh my goodness if he steps out of line', and he did step out of line. He didn't actually harm anyone but he broke his conditions, and he went straight back into prison, exactly what Corrections had said would happen." (Participant 12)

Practically speaking, Wilson's parole conditions, of which there were seventeen, were almost entirely incapacitating and left him very little freedom of movement or association (New Zealand Parole Board, 2012). ${ }^{23}$ These restrictions were in place to balance the risk, which the Department of Corrections had consistently determined to be high. As it turned out, these comprehensive controls were effective in preventing further offending during Wilson's release. They were successful in segregating Wilson from the general public to a

\footnotetext{
22 'Stepping out of line' in this instance referred to Wilson breaching his parole conditions, and therefore being sent back to prison.

${ }^{23}$ Wilson's parole conditions, as set out on page 125 , included intense restrictions on his movement, communication, and association.
} 
significant extent (although not entirely). Participant 13 reflected on Wilson's limited time out in the community prior to being recalled to prison:

“Mr Wilson hasn't been attacked, but there have been occasions when members of the public have gone up to him and have abused him. I think that is a direct response to the fact that he's very recognisable... Now that people know, and there's a lot of people that know because he goes to the same supermarket, he's a man of habit, goes to other particular stores, the majority of those people don't mind, because people have come to understand that he's just an old man. They look at him and think, 'how can this man be a threat to the people of Whanganui?' You know, what they see, the perception of what they see to what they've read doesn't tie up, and they think 'oh, he's really quite old isn't he?"”

The effects of a lengthy prison sentence on the health of an elderly man, now described as "frail" by Participant 14, did not appear to have been considered by the community at all: the 'Beast' identity given to him transformed him into some sort of uncontrollable, insatiable sex monster. In fact, the actuarial reality of the risk was essentially irrelevant in this series of events. Despite the comprehensive controls in place to prevent any opportunity for Wilson to reoffend, the case had a deeply unsettling effect on the community, with at least some segments of it becoming frantic and extremely agitated at community meetings and in interactions with the media.

\section{The Role of the State}

The media furore and the reactions of the Whanganui community in the months leading up to Wilson's release were a reaction to the unwanted entry of a person who constituted an intolerable risk into an already fragile, traditional, solid-state community. Wilson was the 'Beast of Blenheim', the absolute embodiment of the 'other', and he represented a symbolic threat to the security of the Whanganui community - whether the man actually posed danger was irrelevant once his image was formed in the media. Regardless of the disdain members of the community may have for 'others', in this case for Wilson, the state remains 
bound by foundational principles of justice as well as laws and policies, to release those who come to the end of their sentence.

Community leaders I spoke with had varying levels of involvement in the announcement of the release, so expressed differing understandings of the way that representatives of the state handled the situation.

"I was quite impressed that both the Council and Corrections had front-footed it and they seemed as far as I could tell to be being completely open. They explained the conditions under which he was being released. I mean legally he couldn't be held any longer, he had to go somewhere. You know, all this talk about 'throw him back in jail', well no they couldn't do that. I think there was concern, and then yeah, there were a couple of people who I felt really jumped on the bandwagon and were really stirring up hysteria. Saying that the Mayor had failed the town, I mean, I don't actually think Whanganui was really given much of a choice. I don't think the Mayor could say 'oh actually no, we don't want him here' because nobody would have wanted someone like that in their community. Some of the stuff that came out of the public meetings... it was just really emotional stuff. People publicly outed themselves as sexual abuse victims and saying 'having this man in our community is so traumatic for me because I'm a sexual abuse victim'. It's like, well you're not one of his victims, and yes, it's awful what's happened to you, but there's sexual abuse victims in every community." (Participant 12)

\footnotetext{
"One point that I made at the time was that a very bad sex offender from Whanganui was living in exactly the same circumstances in Rolleston [Christchurch], so what can we expect?" (Participant 14)
}

Community leaders wrestled with the fraught issue of sex offender release, but broadly acknowledged the traditional limits on the law, including the concept that laws exist in particular to protect the individual from the excessive powers of the state. 
"There are lots of occasions where the Department has no good common sense, because they're so used to ticking the boxes and ensuring that people are compliant and this sort of thing, that they miss out on the opportunities and the other side of the coin... he probably is a political prisoner in a sense." (Participant 13)

"I mean you couldn't stop the guy from interacting in the community in some way. He was technically a free person, but he had about as much control over him as a free person in New Zealand can have." (Participant 12)

The idea of Wilson as a political prisoner is interesting, particularly given the actions the government took in the wake of the announcement of his release. Within weeks of the announcement of Wilson's release, and in the midst of the continuing media fallout, thenMinister of Justice Judith Collins submitted the Public Safety Bill to parliament. The Public Safety (Public Protection Orders) Bill enabled indefinite post-sentence detention of extremely risky offenders. Collins (2013) argued during the parliamentary debate on the Bill that introducing civil detention measures in New Zealand was necessary, and that "people must ask themselves whether they would place someone who has a very high risk of imminent and serious sexual or violent offending in any community in New Zealand, let alone their own". The presumption of intolerance to risk of all communities illustrated in this statement provided the justification for overriding previous limits on sentencing and post-sentence regulation of offenders, obstructing their human right to be free from arbitrary detention.

The objective of the Public Safety Bill was to "protect members of the public from the almost certain harm that would be inflicted" by those to whom the law would be applied (Public Safety Bill 2012, s4.1). The Bill stated that it is not an objective of the law to punish those against whom a Public Protection Order would be applied. The law would therefore not be considered a 'punishment' by the state, despite the provision for indefinite postsentence detention of offenders. The Public Safety Act 2014 has since been implemented as New Zealand's version of 'civil detention', and has provided an indefinite post-sentence regulatory measure available for serious offenders who had been handed finite terms of imprisonment and would otherwise have been released into the community at the end of 
their sentence. Public safety is the primary consideration within this legislation. The rights of the public to safety from potential future offences therefore supersedes the right of the individual to freedom in the cases to which it will be applied, as the law essentially penalises dangerousness, reversing longstanding principles of natural justice.

The headline Dangerous Pedophiles to be Caged Indefinitely was published in the Dominion Post on 11 May 2012, the day after then-Minister of Justice Judith Collins announced the 'green lighting' of the Bill creating public protection orders (Vance, 2012). In reference to the proposed introduction of public protection orders, Collins stated "we're not going to sit by and wait for people to come out of prison... who have refused to undertake rehabilitation and have indicated they might commit further atrocities" (Vance, 2012). Collins dismissed reports that this legislation targeted Wilson (which would have been illegal due to prohibitions on retroactive application of legislation), stating that "basically, this is about keeping children safe from child sex offenders - the sort that once upon a time would have been committed to a forensic mental health unit" (Vance, 2012). However, the small number of serious sexual offenders that the proposed public protection orders legislation would target - only between five and twelve offenders over the next decade, likely included Wilson. Though the legislation would not be completed in time to capture Wilson, the symbolic action of the state in providing an option to indefinitely detain serious offenders at the end of their sentences was a bold move toward curtailing such a risk, and it was very likely influenced by Wilson's impending release (despite Collins' denial).

Various state actors and agents pushed against the limits of the law during the process of Wilson's release. The Parole Board handed down the most restrictive and stringent parole conditions ever required of a releasee in New Zealand. At a local level, representatives responded in kind, with the Whanganui Council calling for Judicial Review of the Department of Corrections decision to place Wilson in Whanganui. Individual Councillors encouraged Whanganui community members to trespass Wilson en-masse. This case elicited unusual and extreme reactions from a range of representatives at various levels of central and local government, and demonstrated the ways in which certain types of risk are forcing us to reconsider the limits of criminal law and the way such risk-prevention measures reconfigure previous understandings of human rights. 


\section{Conclusion}

In the Wilson case, though many leaders in the community expressed understanding of the position of the state, the proclaimed needs of the community were valued more highly by decision makers. Accounts of the profound negative impact of state action on the community throughout the last four decades bring much-needed context to the extreme reactions some community members had to the Wilson case, and the extent of the negativity of the general community reaction. Whanganui is a static community that has avoided the reach of liquid modernity. It has, in Bauman's terms, been left behind in the frenzied race to success pursued elsewhere. Despite the trauma this community has endured, the trade-off of the relative stasis of the city is accepted and preferred by its people, as they do not have to tolerate the risks and insecurities that accompany the trappings of modernity. That is, until the state delivers risks to its doorstep. Communities like Whanganui react against the waning state power when their members feel that their traditional liberties are at risk, and the state has little power remaining to resist such attacks (Bauman, 2000a). This was evident in the Wilson case, where the state demonstrably scrambled to find alternatives and compromises for the community, eventually choosing to house Wilson on the grounds of the prison under guard (an ultra vires measure), and passing legislation to prevent similar situations from ever arising in the future.

Whanganui has managed, to a great extent, to retain the solidarity and stability of a traditional community in the face of overwhelming external change. This is because the city has been left behind in the wake of liquidisation: it is an iceberg in a sea of change and uncertainty. The features of modern society that Bauman argues produce the great bounties of the modern world are simply not present in Whanganui, and those seeking such bounties must therefore leave to find them. The requirement for the successful individual in the liquid modern world to be mobile realistically dictates that any local seeking the archetype of modern success would have already left Whanganui (Bauman, 2000a). The worries of fast-paced modern life, including uncertain old age prospects, precarious urban living conditions, and the risks that mobility in search of success and riches brings with it, are not felt in this community. The local people remain sealed off from many of the 
unsettling changes brought about by liquidisation, and retain many of the benefits of traditional, solid-state community life. The levels of solidarity in this community have enabled effective mobilisation of the community in response to a perceived threat. This is the case for better or worse, as we can observe in the case of Wilson's release, where the anxieties and fears around the situation were further exacerbated by individuals seeking political and personal gain at the expense of the community's sense of safety and security.

The Department of Corrections announcement and media amplification of Wilson's release was a breaking point for many in this community who had been suffering the compounding effects of detrimental government policy for a generation. Having missed out on many of the opportunities of reform and liquidisation, the community of Whanganui was especially allergic to the idea of taking on more than its existing share of the risk, particularly if it was to be allocated to them by the central state. The external interference of the Department of Corrections became a threat against which the community mobilised (with dramatic and well publicised assistance from 'charismatic entrepreneurs' and the media). The media and community reactions were ignited by the outrage that the community felt at the interference of the state. This interference was perceived as further confirmation that the state did not understand, nor care about this community that had been left behind in the process of building up the neoliberal influenced urban centres. 


\section{Chapter Six - Napier}

\section{Entering Napier}

Arriving in Napier via air, it is easy to geographically orient oneself. The Esk River is the first clue, winding 43 kilometres through a patchwork of paddocks and undulating farmland to the sea. Hawke's Bay is visible from the sky in all its glory, stretching from Mahia Peninsula, jutting out at the Port breakwater, and around to Cape Kidnappers. Parallel lines of Norfolk pines delineate Marine Parade, with the art deco Sound Shell and landmark building 'The Dome' easy to spot from above. Napier Hill dominates the city as the only topographical anomaly overlooking the otherwise flat suburban spread around the coast. Coming in to land, planes cross over the expansive Ahuriri Estuary, still enormous even after much of the area's suburban land (as well as the airport) rose from its depths during the 1931 earthquake.

Image 4 The Art Deco Waterfront, Napier

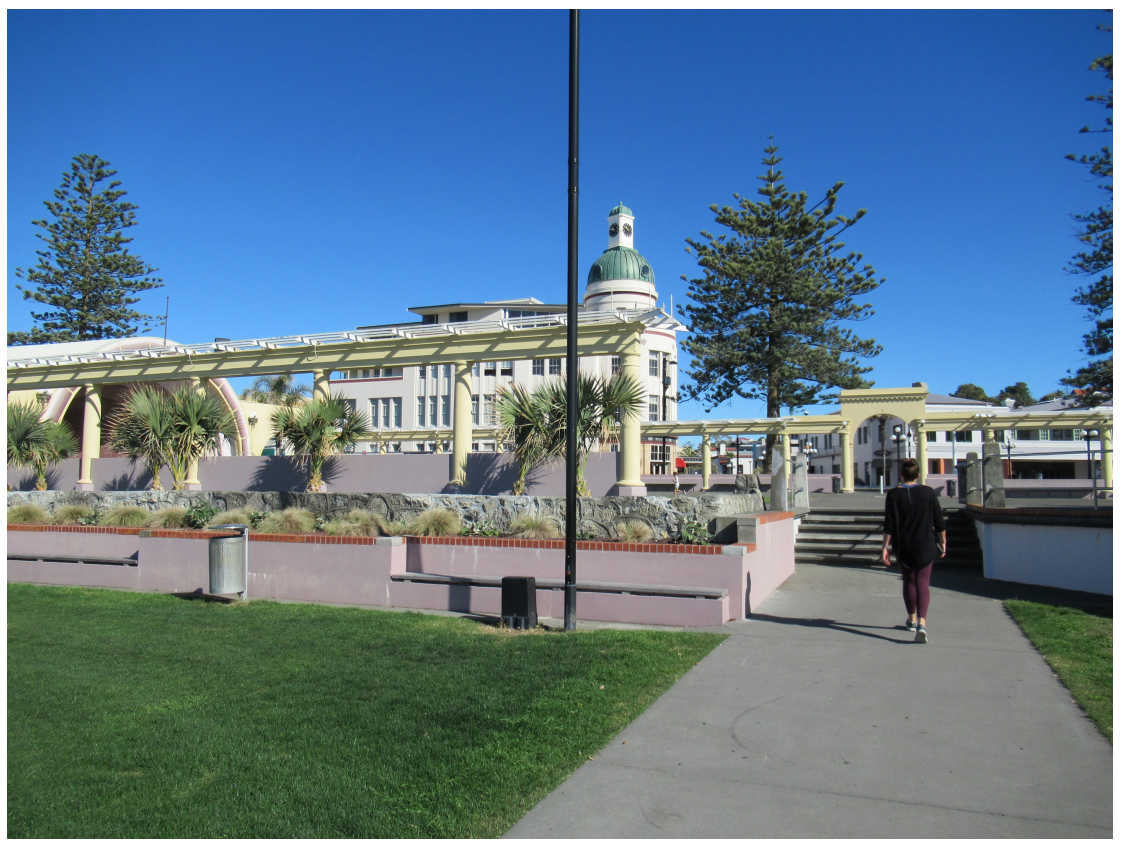

'The Dome' and the iconic sound shell on Napier's waterfront (2021) 


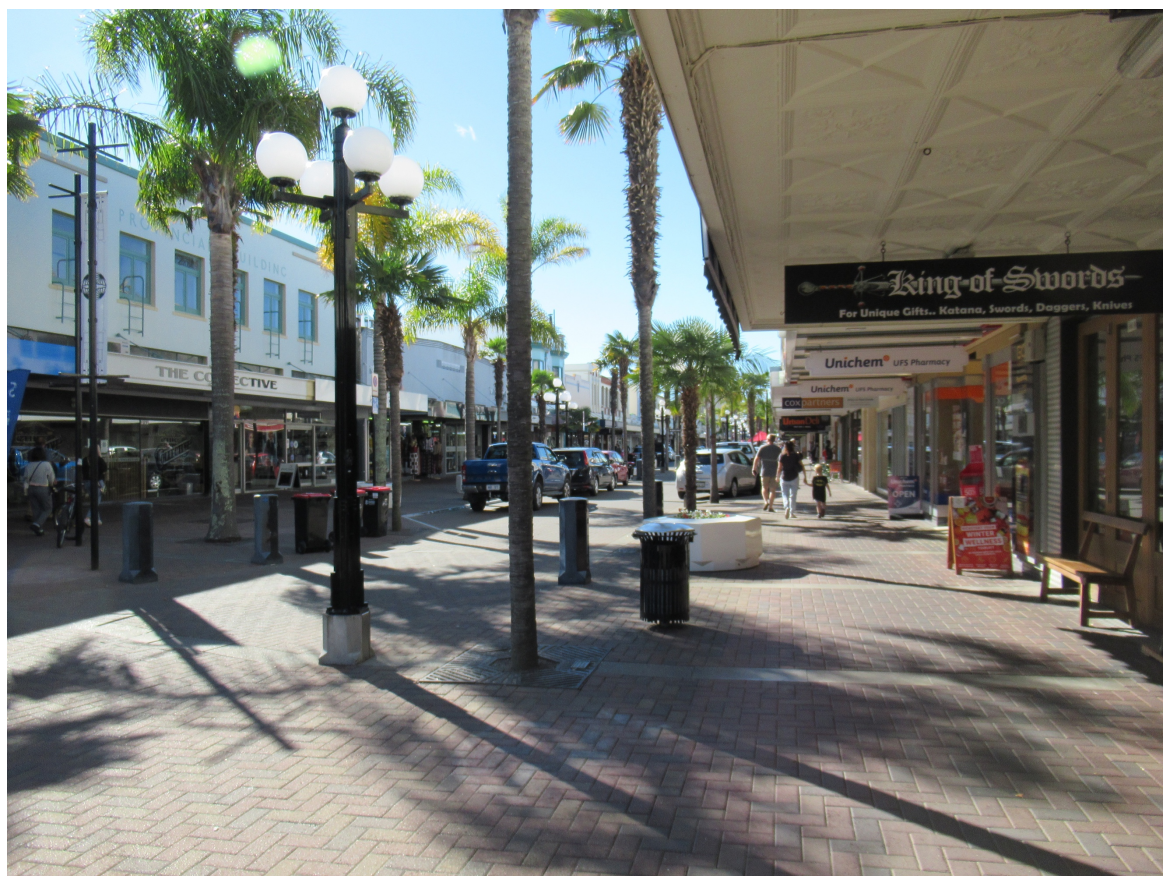

Looking down Emerson Street, the main shopping centre in Napier (2021)

Napier has a certain scenic beauty, with immaculate gardens, tree-lined streets, picturesque beaches, and unique architecture. Known as one of the 'art deco jewels of the world', it is a striking city to observe filled with period architecture from the 1930s, around which the city's contemporary brand has been successfully constructed. Much of the local tourism centres around Napier's art deco status, with an annual Art Deco Festival attracting tens of thousands of attendees each February, and large groups of headset-wearing tourists being shepherded through the main streets on daily guided tours throughout the summer. The recent advent of cruise ships visiting Napier has brought increasing numbers of international tourists to the city. A 'Shipwatch' section of the local paper - Hawkes Bay Today ${ }^{24}$ - gives details of upcoming cruise ship berths and allows locals to brace for the influx of outsiders each day. Napier is a city that constantly welcomes the presence of strangers, with them the lifeblood of their tourism spend. In contrast to Whanganui, downtown and coastal cafes not only provide service but a vast array of coffees, teas, and other menu items that signal the commitment to international tastes and exotic lifestyles. This contrast is also evident in the attempts by each respective city to brand themselves - Napier has executed highly successful branding campaigns centring on the suite of attractions listed above, while

\footnotetext{
${ }^{24}$ As at December 2020, the readership of the regional print newspaper was 72,000 (Roy Morgan, 2021). The total population of Napier in December 2020 was approximately 65,000.
} 
Whanganui's recent campaign, centring around kayaking on the river, has been much less successful

Making my way into Napier, I weave through roundabouts to my accommodation. The twin cities of Hawkes Bay, Hastings ${ }^{25}$ and Napier, both have an unusually large number of roundabouts, and few sets of lights controlling traffic. This allows drivers to wind their way through the city, and creates space for beautiful landscape design, with floral arrangements filling the centre of each traffic circle. The climate in Napier is milder than much of the rest of the country in winter, and Napier hotly contests the title of 'sunshine capital' each year with the South Island city of Nelson. The immediate visual impression of this city is one of thriving affluence - for its small size, Napier is exceptionally well manicured, has a remarkable variety and quality of cuisine, upmarket cafes, shopping, and bespoke tourist experiences on offer.

Upon my arrival in Napier in August 2018, a dramatic and unusual case was dominating the local news. A manhunt involving the New Zealand Police Armed Offenders Squad was underway for a '175 kilogram male gang member on the run'. Helicopters were buzzing overhead throughout the first two nights I spent there. On the Sunday prior to my interviews commencing, there was news of a violent stabbing at a local marae (Māori meeting ground). The Monday that my interviews began, there was a high-speed daytime police chase down the street where I met with several of my participants. That same day, a local journalist had published an exposé on the synthetic cannabis issue in local suburb Maraenui, which went on to make national headlines and became the talking point of the week on national radio (Bradley, 2018). ${ }^{26}$ It was a strange but poignant start to my time in Napier, given why I was there, and a reminder that the picturesque façade covers significant

\footnotetext{
${ }^{25}$ Hastings is a city approximately 17 kilometres inland from Napier (a 20 minute drive). The population of Hastings is 88,000 , and Napier and Hastings are often referred to as 'twin cities' due to their proximity. ${ }^{26}$ As Bradley (2018) explains, synthetic cannabis is a chemical cannabis substitute - up to 70 times more potent than cannabis - that was sold legally in dairies and convenience stores in New Zealand between 20052014. The active ingredient is a synthetic cannabinoid that is more toxic and dangerous than the THC found in cannabis, and between 40-45 deaths were recorded from the substance in the 2018 year. Now illegal, the addictive substance is now being produced in Napier's poorest suburb, Maraenui, for distribution throughout the region, and was regularly referred to by participants as a significant source of community concern.
} 
inequality and social issues throughout the broader community of the city today. As Participant 23 explained,

"There's a significant underbelly of poverty and deprivation in Napier. People think Napier is quite a rich town and overall it's not... we don't necessarily have a strong and stable economic base here, in spite of what you hear." (Participant 23)

\section{Napier's Place in Aotearoa/New Zealand}

\section{Colonisation and the Removal of Ngāti Kahungunu}

The 1931 earthquake marked the beginning of a new era in Napier, with the clean lines of art deco design obscuring the traditional colonial settlement that had existed before. The land that today constitutes Napier was obtained by the Crown through a particularly violent and painful series of colonising actions carried out against the local iwi. Napier (also known by its Māori name, Ahuriri) was the coastal centre of the sprawling lands of the third-largest iwi in the country, Ngāti Kahungunu. Having already experienced unprecedented attacks from northern iwi who had been armed with muskets traded with the British, by the 1850s, Ngāti Kahungunu were under more direct attack from the British Crown. Formally established by the Crown in 1855, the city of Napier was named for British Commander-inChief in India, General Sir Charles James Napier - a fitting tribute considering the violence of colonisation executed by the British in both India and Napier. Many of the streets and suburbs of Napier were named in the same style, commemorating the colonial era of the British Indian Empire.

By 1859, an estimated 1,404,700 acres of land had been 'purchased' from Ngāti Kahungunu in Hawkes Bay, with just 3,000-4,000 acres of the ancestral lands remaining for the Māori population to live on (Whaanga, 2017). The Native Lands Act 1865 was an important instrument of colonisation used against Ngāti Kahungunu, designed to individualise collective ancestral land ownership to effectively free up land for Crown purchase. ThenJustice Minister Henry Sewell (1870) described the aims of the legislation at the time as 
both "to bring the great bulk of the lands of the Northern Island... within the reach of colonisation" and
"the detribalisation of the Māori - to destroy, if it were possible, the principle of communism upon which their social system is based and which stands as a barrier in the way of all attempts to amalgamate the Māori race into our social and political system"

Two decades after the implementation of this legislation in 1865, Member of Parliament Robert Bruce (1885) celebrated its success:

\footnotetext{
"we could not devise a more ingenious method of destroying the whole of the Māori race than by these land courts. The natives come from the villages in the interior, and have to hang about for months in our centres of population... They are brought into contact with the lower classes of society, and are exposed to temptation, the result is that a great number contract our diseases and die."
}

In Napier, this legislation was extremely effective in dislocating and alienating Māori from their traditional lands. Discontent over the immense dispossession and alienation experienced by Ngāti Kahungunu and the establishment of the Native Lands Court were drivers of the foundation in the 1870s of the Hawkes Bay-based 'Repudiation Movement', which rejected all previous land sales and leases to settlers and the Crown. Some prominent European settlers allied themselves with this movement, reportedly out of concern for the welfare and rangatiratanga (sovereignty) of local Māori, but also to advance their own strategic interests in disputes with fellow landowning Europeans in the area (Pollock, 2015). Even when claiming to be supporting the interests of local Māori, colonial settlers in Napier were exploiting iwi for personal gain. Ngāti Kahungunu would go on to lose virtually all of its ancestral lands, with reparations only beginning to be made through cases in the Waitangi Tribunal over a century later. The scale of this loss and the lasting impact of the specific experience of colonisation and race relations in this area has had a lasting effect on the community, which remains divided on indigenous issues. For many Pākehā people in Napier, as noted by those I interviewed, there is a convenient lack of knowledge and understanding 
of the history of conflict and exploitation in this area. For local Māori, the intergenerational impact of colonisation can be observed in the negative social statistics, as well as the proportion of tangata whenua in the lowest socio-economic areas of the city today.

\section{The Napier Earthquake}

At 10:47am on $3^{\text {rd }}$ February 1931, a deadly earthquake rocked the city of Napier. Measuring 7.8 on the Richter scale, and lasting two and a half minutes, the Napier earthquake remains the worst civil disaster that has ever occurred in New Zealand in terms of loss of life, with 256 deaths recorded. Occurring mid-morning on a Tuesday, the loss of life and injury was exacerbated by the number of people in the city, and at work inside buildings and schools. Brick buildings were universally destroyed, and many homes made of timber and other nonbrick materials were severely damaged by the collapse of brick chimneys. To this day, buildings will not be constructed using bricks in Napier. To make matters worse, ceramic gas lines throughout the city were severed, and the earthquake was swiftly followed by devastating fires that consumed what remained of many buildings in the central city. Eleven city blocks were burnt out in the ensuing fire, killing many of those who had remained trapped in the rubble. The hospitals in the area were severely damaged and unusable, and the Navy were called in to provide medical care in makeshift sites established at the local racecourses. Following the disaster, tent cities were erected by the Army, women and children were sent out of the region, and able-bodied men were required to stay behind to perform search and rescue amongst the charred rubble. The remaining community banded together to get through the crisis, relying on goodwill and the generosity of neighbours for their survival.

The trauma, devastation and death caused by the Napier earthquake had a defining influence on the city's development (at that time, a fairly indistinct port settlement), and the living memory of this event has a powerful influence on the narrative of the city and its inhabitants. During the earthquake itself, the land around Napier rose 2.7 metres. This forced the shoreline back and drained much of the Ahuriri Lagoon and inner harbour, creating hectares of usable land in an instant and therefore solving the issues of lack of space for settlement and farming that colonial settlers had struggled with since their arrival 
in the 1830s. With the city destroyed, central Napier was rebuilt in the contemporary art deco style of the period, which, though unremarkable at the time, would begin to attract tourists 50 years later.

\section{Pre-1980s Napier}

The 1931 earthquake holds a central position in the creation of memory and narrative within the city of Napier. Remembered solemnly as a devastating act of God for much of the $20^{\text {th }}$ century, the framing of this historic event began to change in the 1980 s. Parallel to the neoliberal reforms, the Art Deco Trust was formed in 1985 in Napier to begin advertising the attractions of the city to visitors (Art Deco Trust, 2021). Prior to the formation for the Trust, the architecture of Napier was a fact of life as much as the architecture of any other New Zealand city. Napier had been a traditional and relatively static, solid state provincial city throughout the mid-twentieth century. Life in Napier during this period was predictable and secure. The foundation of the Art Deco Trust symbolises the steps the community began to take toward embracing liquidity from the 1980s onwards.

Image 6 The Art Deco Centre, Napier

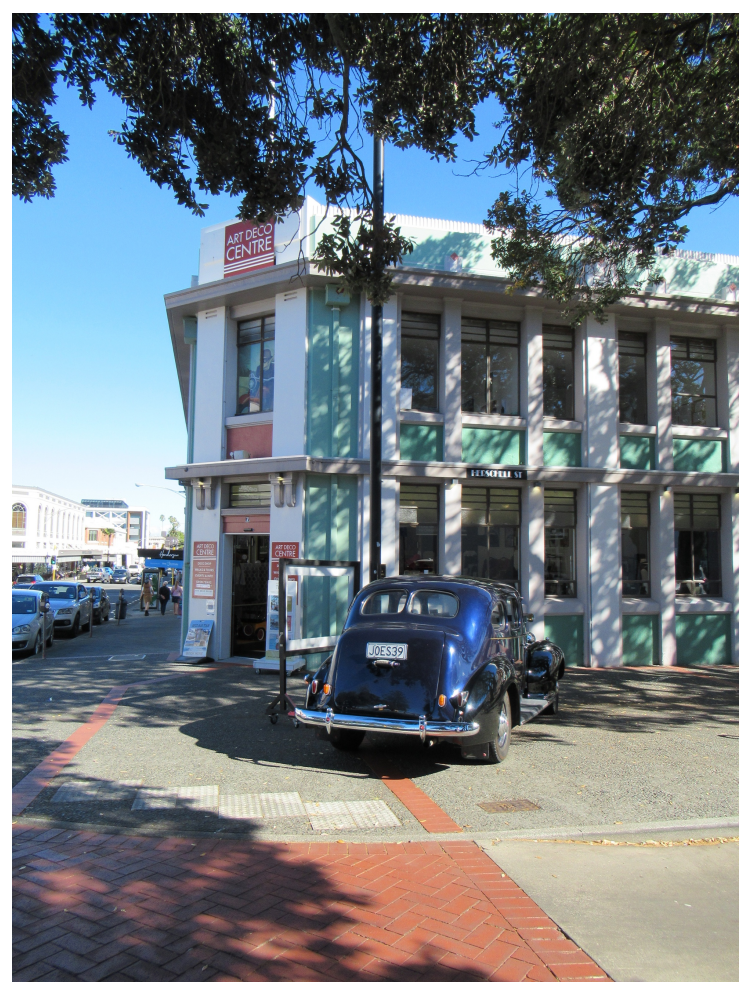

The Art Deco Centre is run by the Art Deco Trust - a key driver in the rebranding of Napier since the 1980s (2021) 
With the Art Deco Trust began the construction of a brand for a city that now depends heavily on tourist dollars, in addition to the breakthrough it made in the 1980s to the global wine market. Over time the city has embraced the transition to the service industry, and has become renowned throughout New Zealand as part of the successfully brand 'Hawkes Bay Food and Wine Country'. The tourism industry in Hawkes Bay generated \$664 million in 2019, with Napier being a significant element of this regional effort. The Hawkes Bay NZ (2021) visitor website boasts that Napier is "home to many fine wineries, fabulous restaurants, bars and cafes". During the summer season, the cruise ships bring between $80-$ 100,000 visitors to Napier, while the annual Art Deco Festival attracted 40,000 visitors in 2019 (Hawkes Bay Tourism, 2020). As the dependence on tourism has increased, the focus on enabling this income stream has also grown. While elements of the population of Napier struggle with serious social issues, the most pervasive of which being poverty, local and central government funding are poured into preservation of the beautiful art deco façade of the city, while chronic social issues fester, unseen by visitors.

In addition to the cruise ships, domestic tourism continues to increase as significant local events gain popularity, including regular food and wine events; art deco events in the summer and winter; a variety of cycling, running, and walking events; and winery concerts attracting top global artists (e.g. Mission Concert headliners Ray Charles, Eric Clapton, Rod Stewart, Sting). Napier Prison, the oldest prison in New Zealand, was closed as a correctional facility in the early 1990s, and reopened in 2002 as both a tourist attraction and a television show set (the Prison was used in two boot camp/'scared straight' style reality shows). In addition to the growth of tourism and the wine industry, another example of the effect of globalisation on the Napier economy has been the importing of cheap labour from Vanuatu, the Philippines, and the Pacific Islands to pick fruit for international export through the city's port. Since the neoliberal reforms, much of Napier has slowly but surely embraced liquidisation and its associated individualisation, creating an impression of success and fluidity on the city's surface.

\section{Napier Today}


As of the 2018 census, Napier city had a population of 62,241 (Statistics New Zealand, 2018). This has slowly and steadily increased over time, as reflected in the last three census counts. This indicates that the city has been thriving in a way that Whanganui has not, and therefore that Napier is a place to escape to, not from. Napier's family statistics are near on the New Zealand average, with 31.9\% never married nor in a civil union (compared with the NZ average of $35.2 \%$ ), and $47.0 \%$ married (not separated) (compared with the NZ average of 48.6\%). The number of Napierites with children is slightly higher than the national average, with $18.7 \%$ reporting three children compared with the national average of $16.0 \%$, and $24.5 \%$ reporting no children, versus the $30.8 \%$ national average. The presence of higher than average numbers of children in the city is of particular note, given the nature of the case I examine in this chapter.

In a similar vein to the demographics of Whanganui, Napier is not as ethnically diverse as New Zealand on average; however, the Māori population in the city is considerably higher than the national average. $24.5 \%$ of Napierites report being of Māori descent, versus $18.5 \%$ nationally. The European ethnic group makes up $81.2 \%$ of the Napier population, versus $70.2 \%$ of the national population. Interestingly, the percentage of Napierites identifying as 'European' has increased since 2006, so the city is becoming less diverse over time. Napier has a significantly lower percentage of Asian residents than the New Zealand average, with $5.0 \%$ reporting their ethnicity as Asian in Napier compared with $15.1 \%$ nationally. It is unsurprising, then, that while $72.6 \%$ of New Zealanders were born in New Zealand, the proportion is higher in Napier, with $83.5 \%$ of Napierites born in New Zealand. The population of Napier therefore reflects a much more traditional colonial-New Zealand demographic breakdown than we see elsewhere in the country (for example, in Ōtāhuhu see Chapter Seven).

The average income levels in Napier are slightly lower than the national average, as is the number of people employed fulltime. Being a regional city, the cost of living is lower than that in the urban centres: as the 2018 Census confirmed, the weekly rent in Napier is $\$ 280$, versus a national average of $\$ 340$ (Statistics New Zealand, 2018). The number of people with qualifications is slightly lower than the national average, and the number of people 
studying is also lower. Again, this can be expected of regional non-university cities in New Zealand.

The city of Napier is around about average in New Zealand in terms of socio-economic data. However, Napier can be broken down into suburbs that reveal a significant divide in terms of wealth, education, employment, access to amenities, home ownership, and lifestyle. While Whanganui has a wide scattering of deprivation throughout most suburban areas of the city, the lines are clearer between the 'haves' and the 'have nots' in Napier. For example, while the average income in the Napier suburb of Maraenui (a suburb with a majority Māori population) was $\$ 20,200$ as of the 2018 census, it was $\$ 37,700$ in Bluff Hill a suburb just a ten minute drive away (Statistics New Zealand, 2018). Much like the wider picture of New Zealand society, the Napier community divides into smaller subsets that have a much greater disparity of wealth and wellbeing than is conveyed in the averages of the census. This was reinforced by the almost universal resistance of my participants to the idea of a 'Napier community'. As Participant 28 explained to me, "I think people do not see Napier as a whole. They identify with their part of Napier." In a similar vein, Participant 24 told me "I see a lot of diversity and disparity in the way that a city like Napier is." This disparity is sometimes stark, for example the clear presence of homeless people occupying Clive Square Garden (an inner-city garden created as an equivalent to the English village green). Although it is possible to refer to Napier broadly in some respects, it is important to consider the exceptions, and the disparities that exist behind these generalisations. 


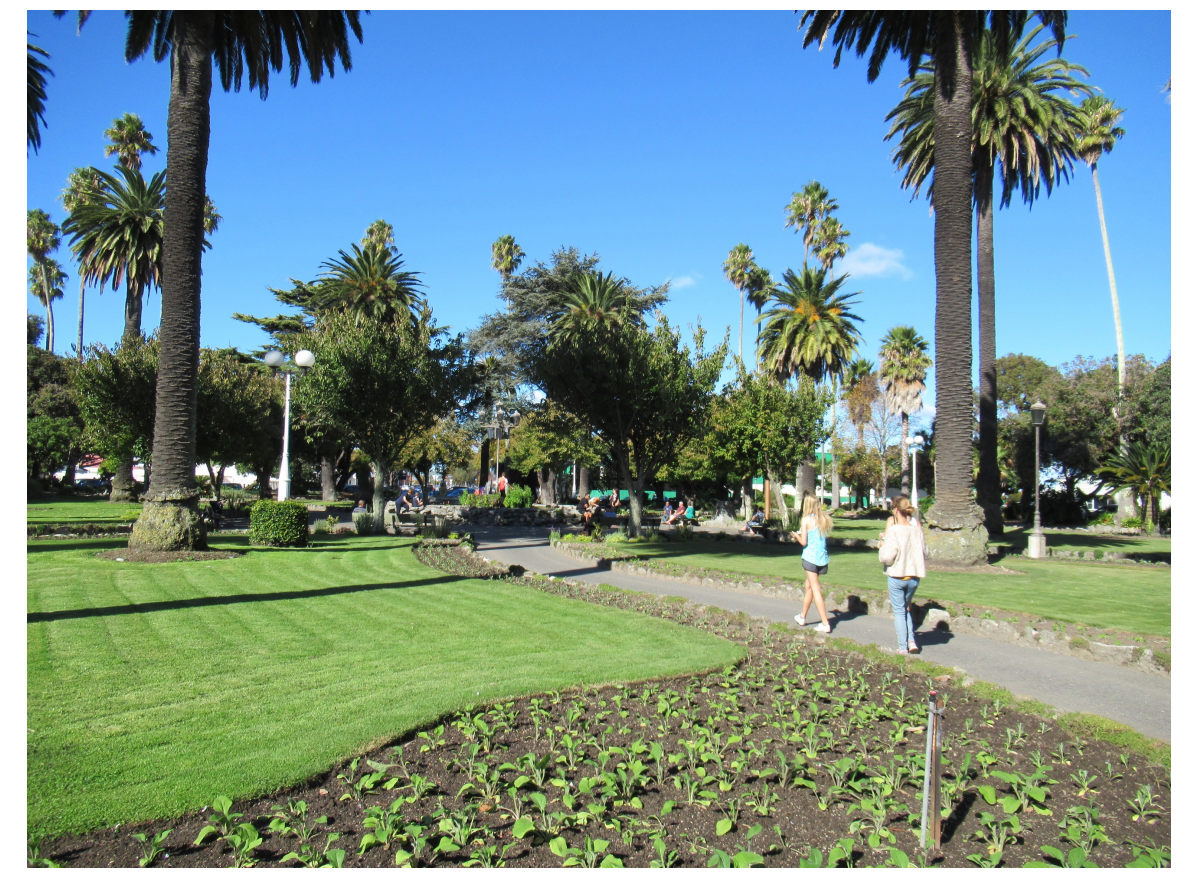

By day a tourist attraction, by night a gathering place for beggars and homeless people (2021)

\section{A Neoliberal Success Story: The Slow Rise of the Tide in Napier}

While the neoliberal reforms of the 1980s were the death knell for many of New Zealand's industrial towns, the city of Napier appears to have experienced a net benefit over time. The city was never historically reliant on heavy industry (unlike the neighbouring city of Hastings), and it has consistently maintained its status as a successful port city. The combination of the port and the region's suitability for growing produce has resulted in a fairly stable economy over time. The development and investment in the local service economy is what has helped the city begin to thrive. Although Napier has not been immune from financial crises and downturns, it has not been as severely disadvantaged as other towns and cities in New Zealand, including solid state towns close by in Hawkes Bay (e.g. Wairoa, Hastings).

Currency deregulation and globalisation from the 1980s have enabled the tourism and global trade that fuel much of the local economy in Napier. Before Covid-19, cruise ship passengers flooded the main streets; one participant mentioned his belief that the 
friendliness he is observing on the streets lately can be traced back to an awareness of the presence of these tourists in the city:

"I think Napier is a very friendly community, and I think you could probably put that down to a number of things. We are relatively small, we've got a port, we've got the tourist thing - it seems to have been that Napier people are very aware of what the port and the tourism brings into the community you know, and that may have sparked the friendliness that we're starting to see on the streets here." (Participant 26)

As a regional New Zealand city, the people of Napier are considered fairly relaxed and friendly. However, this disposition does not extend to perceived threats - not to personal safety necessarily, but to capital. Participants I interviewed linked this to offender release in terms of property values in particular. During conversations with community leaders, the tendency of individuals in Napier to prioritise individual interests over and above any community-mindedness was evident is the 'NIMBYism' ('not in my backyard' sentiment) present in Napier:

"I think that sadly in our community we have an attitude of 'not in my backyard'. That's how people are. It's the same with housing and the establishment of state housing... as soon as they say 'we're going to put it next door to you', people say 'absolutely not, that's going to devalue my property!'. It don't know what the answer is, but that's how people think... so many things here are around people seeing the value of their own property being reduced, and not just by things like offenders." (Participant 27)

"We had a really nasty reaction here when a house was purchased by a mental health provider. A petition was made, people claimed they would be too frightened to go out their doors with mad people threatening them and all this sort of thing, well, five, six years on, there hasn't been a squeak out of any of them. I think the neighbours stirred it all up in their own interest to protect their property values... It's the 'not in my backyard' thing. I always say 'look, would you rather know that these people are supported, in a supportive environment, or would you rather have them scattered 
around or homeless you know where they're much more a risk to the community and to themselves... sometimes this ugly thing rears it's head and says 'we don't want anybody different from us'" (Participant 23)

“People say 'oh we don't want them here' and I ask them 'well where do they go?' and they just say 'anywhere but here!" (Participant 32)

This prioritisation of individual financial interests over community is a reflection of neoliberal values in action. While fear may play a role in the reactions of individuals against those placed in supported living in their community, reactions are driven by the selfprotection reflex in defence of threats to capital. Personal gain is prioritised over community spirit or neighbourly goodwill, as the individualisation championed within the neoliberal reforms has melted into the identity and way of life of the local people in Napier.

Although Napier is not a beacon of neoliberal success, neoliberal values such as individualism have become engrained here to a much greater extent than can be observed in Whanganui. The result of this has been the broad acceptance of responsibilisation by local people, and the absence of a sense of community in the city. A further consequence of the entrenchment of neoliberal values is the inequality evident in the city. There is a growing homelessness crisis in Napier, and during my time there I observed many more people begging on the streets than were observed in Whanganui. With individualisation comes the dangers of bootstrap theory, and a dearth of community-mindedness when it comes to issues such as those detailed in Bradley's (2018) highly regarded expose on the synthetic cannabis issue in Maraenui, Napier's poorest suburb. In this vein, around this time, the Mayor of Napier unsuccessfully attempted to outlaw begging within the city, lamenting that "[g]iving to beggars is, in essence, directly supporting drug use, aggression, and crime in our beautiful city" (Dalton quoted in Smith, 2017, March 17). Individualisation and free markets benefit those in Napier with the ability to dive in and make the most of the opportunities now available to them, however the most disadvantaged and vulnerable in the community then suffer from the lack of collectivised support and associated protections from risks. One participant contrasted the values of European cities (specifically those that reserve Sundays for family and faith) and more neoliberal Napier: 
“They've got values, better values than what we've got. We haven't got those values. We're putting so many pressures on families to work, and manage their own risk, everything." (Participant 29)

Within the context of an increasing wealth gap, a growing homeless population, and a declining sense of community, Napier still remains fairly conservative.

\section{Conservative Napier}

As a criminologist who comes from Napier, I am especially aware of the general conservatism of my hometown. Known for being the territory of formerly influential law and order and victims' rights lobby group the Sensible Sentencing Trust, the views of its founder, right-wing farmer and victim advocate Garth McVicar have come to be associated with the area through his prolific media presence throughout the early-2000's. Recognition of local conservatism arose in each of my interviews with community leaders.

“Napier is very, very conservative... you can't blame nice people for being conservative if they don't know any different. You can't blame them." (Participant 29)

"I think Napier is quite a conservative community. There is a small pocket of quite liberal thinkers, but they tend to think that they have a bigger voice and representation than they actually have. The conservative population are the silent majority. There's a big chunk of people out there that never get behind a placard, but they vote, and it's not a left-leaning seat as far as the party vote goes." (Participant 31)

"Napier is very parochial. It's reasonably relaxed, and particularly a quite conservative community. Change is difficult here." (Participant 27)

This conservatism came to intersect with race in several of my conversations with community leaders. In telling me about the distinctiveness of the Napier community, 
participants noted an intersection between conservatism of people in Napier and Māori rights and history in particular.

"We love our art deco and that heritage, and the history that's here. Although, if you're talking about history, most people wouldn't have a clue about the history before you know, 1900. When I talk to them about the pã that used to be in the estuary where Shed 2 is now, and the 180 people that got slaughtered there, people have never heard of it." (Participant 31)

"Well I think you've got to go back to [Napier's] history, and the conservativeness. With the Hawkes Bay Club and the Masonic Hotel was where the farmers would go up there. So, you can go back to when Paul Reeves was designated Governor General, he's the only Governor General never given a Black-Tie Dinner at the Hawkes Bay Club, and that's because he was Māori... they had a show of hands in the Club, and at that time, about $60 \%$ to $70 \%$ would have left the Club if he was given a Black-Tie Dinner." (Participant 29)

"I've been feeling critical of Napier because of its lack of inclusiveness. So maybe not so much a lack of diversity, but representation." (Participant 28)

In the 2017 election, Napier elected a Labour Member of Parliament (centre-left), however the highest percentage party vote went to National (centre-right). One consequence of what my participants refer to as the 'conservatism' of Napier is an aversion to change. The incumbent candidate certainly holds this benefit in any election here. Participant 29 explained to me that change therefore takes concerted effort and strategic leadership to succeed: "if the public really, through leadership, are drip-fed something, they'll change." This has evidently been the case with neoliberalism, which many Napierites appear to have embraced.

Supplementing the aversion to change, my participants explained to me the general apathy of the people of Napier toward civic issues and current events. In the increasingly individualised society in which New Zealanders, and particularly Napierites, live, it takes a 
specific kind of issue to elicit a significant public response. As Participant 31 explained to me of the people of Napier, "if there's a call to action on a touchpoint - their pockets or their kids - then they'll come out." One such example of the 'threat to children' touchpoint being activated was the case of the sexual murder of Teresa Cormack in 1987.

\section{Case Driven Culture and Teresa Cormack}

It was in June, 1987, when six-year-old Napier schoolgirl Teresa Cormack went missing. She had set off from home to walk to school in the morning, and it was only when she failed to return home by $4: 30 \mathrm{pm}$ that the alarm was raised, and her mother came to discover that she had never arrived at school that morning. Over the following days, a search party involving 600 local volunteers searched for Teresa. Eight days after she went missing, her body was found buried in a shallow grave at local Whirinaki Beach. The kidnapping, sexual violation, and murder of Teresa Cormack remained unsolved for well over a decade. It was only in 2002 when advances in DNA technology allowed police to test the evidence collected at the crime scene against samples collected from suspects at the time, and that local man Jules Mikus was convicted and sentenced for the abduction, sexual violation, and murder of Teresa Cormack.

Just four years prior to the sexual murder of Teresa Cormack, 14-year-old Napier schoolgirl Kirsa Jensen had gone missing while riding her horse at Awatoto Beach. In September 1983, Kirsa left home after school on her horse and never returned. Her horse was found wandering alone at nearby Tutaekuri River, and Kirsa was never seen again. Her case remains unsolved. Though the Jensen case does not seem to have had the same lasting cultural impact as the Cormack case, it was very high profile at the time and is still discussed in the media today (see Mulligan, 2020).

The murder of Teresa Cormack in particular had a significant influence on the behaviour and worldview of many people - particularly families - in Napier. This child was a perfect example of Christie's (1986) 'ideal victim' - an individual who is very readily afforded the full status of victimhood due to their meeting a series of criteria: the victim is weak in relation to the offender; the victim was operating in a socially approved manner during the time of 
their victimisation; the victim can be considered blameless for their victimisation; the offender is a stranger to the victim; the offender is unquestionably bad/evil; and the victim meets expected social norms. As a representative of 'ideal victimhood', Teresa Cormack's murder resonated significantly with the public, and the media coverage had a lasting impact. Local people in the community anecdotally recall that day being the last day they were allowed to walk to school, and the beginning of a different style of parenting which would echo across the country. Community leaders I spoke to recalled a sense of beforeand-after the murder of Teresa Cormack, and some detailed the behavioural changes that they believe to have stemmed from this case.

"The Teresa Cormack case changed the way people regarded the safety of their child." (Participant 28)

"I mean a lot of people say, you know we just used to run the town as kids and it was never thought of, yeah it was a pretty devastating story when you think about it. A little girl on her way to school who perhaps turned around and didn't go to school and she was roaming around free, so you know, it's probably a very good indicator of why there are so many vehicles outside the school before and after 3 o'clock... I would say anecdotally, it was back when I was training when Teresa Cormack went missing, and you know it was discovered that she'd been murdered, someone made the comment to me that 'you would be horrified to realise how many on the Police watchlist live within a mile of Richmond School' where she went missing from, and I've always sort of thought about hat in the back of my mind you know. That information that Police have about the number of potential people in the community would be quite confronting" (Participant 24)

One participant went further, arguing that it is because no such formative case has happened in recent memory that people's concern over crime, and particularly sexual crime, does not appear to be elevated at present.

“The crimes that triggered us aren't happening anywhere near the frequency that they were. The crimes against children, the sexual abuse against children, that type of 
thing. The Teresa Cormacks, the Kylie Smiths, ${ }^{27}$ the Karla Cardnos, ${ }^{28}$ those crimes. There's been a huge reduction in homicide stats and that type of thing. So maybe people are seeing some benefits. As I said, you wouldn't fill a public hall with people concerned about crime in this community at the moment... as a community I don't think we're seeing the prolific level of crimes that we were seeing. I think the community are sort of prepared to wait and see. No doubt if what Andrew Little is proposing backfires, ${ }^{29}$ and we see a spike in the number of child abuse crimes and killings, I think the community will get motivated again, whether it's by us or by someone else. I think New Zealanders are pretty proactive. We're a fairly tolerant people, but when we get wound up we're prepared to stand up for what we believe." (Participant 26)

The much more common view held by my participants was that the potential for concern to be activated amongst the community is always there, and all it requires is a single person to be the catalyst. This fits in with the kind of "charismatic entrepreneur" character seen in Michael Laws in Whanganui (Joosse, 2018, p. 994). Some participants in Napier referred to this person as a 'warrior' or a 'champion' who would take it upon themselves to generate concern in the community over a particular case or offender.

"I'd say [concern over sex offenders] would be as high as anywhere in the world if it was fired up. If it was fired up the same way... we'd be as bad as the worst of them, but it's an underbelly thing... I mean, if [sex offenders] had been something near to this man Dalton's ${ }^{30}$ heart, he would have done the same thing. But beggars are more of a screwpoint to Dalton than sexual offenders, so it's just, I mean a Mayor can't be everything to everybody. You know, we're all different, but if Dalton had had sexual

\footnotetext{
${ }^{27}$ Kylie Ann Smith was a 15-year-old girl who disappeared in November 1991 while riding her horse after school in the small Otago town of Owaka. Paul Bailey was sentenced to life imprisonment for rape and murder. ${ }^{28}$ Karla Cardno was a 13-year-old girl who disappeared in May 1989 while riding her bike 500m down the road from her home to the dairy in Taita, Lower Hutt. Following a high profile six-week-long search involving the public, the Army, the Police combing the area day and night, Cardno's body was found in a shallow grave on a Wellington beach. Paul Dally was convicted the following year and sentenced to life imprisonment for abduction, rape and murder.

${ }^{29}$ Then-Minister of Justice Andrew Little was leading a project called Hāpaitia te Oranga Tangata-Safe and Effective Justice, which sought to "find long term solutions to improve community safety and the way justice works" (Ministry of Justice, 2020).

${ }^{30}$ Bill Dalton was the Mayor of Napier at the time of this interview.
} 
offenders as Laws did have sexual offenders as a paranoia, Dalton would have done it too." (Participant 29)

\footnotetext{
"Was there a champion? That's invariably what happens with any issue, right, there's a few champions of that issue, whether it be a good one or a bad one, who take it and drive it. Now that could be the case in any community. There's no doubt that if you have a leader in your community who takes the issue on, then that's going to get a whole lot more momentum... The risk [of community notification] is that you get a leader within that community that takes exception to it and creates a shitstorm. That's the risk. The risk is that ultimately there's so much negative publicity about it that you can't house that person there." (Participant 31)
}

So, for the community leaders I spoke to in Napier, there were two common ingredients necessary to create a high public interest story. The first is a 'touchpoint issue' - an issue affecting people's wealth or children. Within sociology more broadly, children are a known touchpoint issue for the triggering of moral panics (Wright Monod, 2017). The second is a champion of the issue - a high-profile individual providing moral leadership and keeping the issue alive in the media. This is a particularly astute observation in the context of this case, because it appears that one of these ingredients was missing in the case of the release of Individual X to Napier in 2017.

\section{The Case}

In April 2017, the Hawkes Bay Today newspaper published a half-page story detailing the release of a convicted child sex offender to a Napier suburb. The article contained the offender's name, photograph, and a description of his crimes. Sharpe (2017, April 18) detailed in the article that the offender had four victims between the ages of six and 16, with offending occurring between 1990 and 2008. The offender's indecent assault of a sixyear-old girl was detailed in the article. He was seen by a community patroller assaulting the girl in a car in a popular local park, and the patroller followed the car home to report the incident to the girl's mother. The offender had befriended the girl's mother and taken responsibility for driving the girl to and from school each day. In the case of his earlier 
offending, he had been a babysitter to a previous victim. At the sentencing in 2008 , the offender simulated firing a pistol from the dock at the parents of his victims, and received a further three months in prison for this action. He was sentenced to a total of nine years and nine months in prison for serious sexual crimes against four victims, including three counts of rape, three counts of indecent assault, two counts of unlawful sexual connection, and one count of perverting the course of justice. ${ }^{31}$

This offender came up for parole in April 2017, and refused to attend the hearing with the Parole Board, telling the Board that he would prefer to complete his full sentence, and that he would refuse to comply with any of their requirements. The report from that hearing of the Parole Board details the offender's refusal to claim responsibility for the offending for which he was convicted. The offender maintained that he had not offended against any of the four victims, and he alleged collusion and conspiracy between the victims, their families, and the police. During his time in prison, he participated in 14 psychological treatment sessions on the basis that he 'hypothetically' offended. The Parole Board noted that this was "a curious position". The Parole Board report concluded with the statement "psychological opinion is to the effect that he is a high risk sexual offender. In our judgement he remains an undue risk to the safety of the community."

Despite the particularly disturbing facts of the case, and Offender X's status as a child sex offender, a groomer, and an historically insidious threat to children, the media reporting of this case generated little ongoing public interest. Although there were many critical and negative comments on social media posts about the article at the time of its publication, one year after the offender's release was reported in local and national news, of the community leaders I spoke to, only two were aware of the offender by name, and one other knew vaguely of his crimes upon description. One participant who did recall this specific individual said of him:

"Well in that case it kind of was, the guy really - he's a particularly nasty offender, who made a pistol signal at his victim's mother as he left court... The way he was

\footnotetext{
${ }^{31}$ Conviction details were drawn from Individual X's 2017 Parole Board report.
} 
found and that was by the community patrol who saw him offending against a sixyear-old girl." (Participant 25)

In this case, there was no community champion - no 'charismatic entrepreneur' (Joosse, 2018) - seeking to block his release, or to stir up a reaction within the community. For a situation of this kind, the media reporting was relatively benign, and did not appear to be seeking to sensationalise the case. In addition to the presence of a 'touchpoint' issue, and a champion of the issue, a third ingredient necessary in creating a high public interest story is perhaps a high level of media interest. This is particularly true within the current media landscape, where the 24 hour online news cycle retires anything that does not quickly generate high levels of ongoing interest and engagement. In the case of Individual $X$ in Napier, although the fairly lurid details were published along with some commentary from the family of the victim, there was not sensationalism or tabloid-style reporting of the case. One of my participants explained:

\footnotetext{
"Yeah, I think you know the role that the media play is quite significant. I mean, you've asked before about you know, locally had there been issues, and the media here really haven't, not that I can recall, haven't really chased things like this although I'm sure that they could you know. There's got to be people convicted of child sex offending living nearby, and yet it hasn't been prominent. So that's, you know that does show the power that the media can have." (Participant 24)
}

Although many of my participants were surprised that they had not been more aware of the case I was examining, few displayed outrage over the news of his release, or much more than mild surprise. This was not universal, and one participant who had been involved in discussions about Individual X's release through their role described their memories of conversations about frustrations within the community about this release:

\footnotetext{
“People weren't happy about him coming back. Some people that I was associated with that knew the case and were associated with the victims wanted bad harm to come to him! Some of them had no association at all, but knowing what he had done to a child was enough to justify castration for them." (Participant 32)
} 
To have only two community leaders with an awareness of the case, and only one of those who had picked up on negative sentiment within the community, certainly set the experience of offender release in Napier apart from that in Whanganui. With the history in Napier of schoolgirls going missing in the 1980s, with one becoming the victim of a very high profile sexual murder, it could be expected that there would be a higher level of attention on these kinds of issues in this community. Nevertheless, the level of knowledge of this specific case, and therefore concern, was generally relatively low among community leaders. This combined with the existing expertise of community leaders around offender release.

As I had observed in Whanganui, many community leaders in Napier demonstrated a clear and evidence-based understanding of the reality of the risk released sex offenders pose to the community, and the usual form sexual offending takes in the community:

"Sex offenders have a high rate of rehabilitation, and there are very concentrated programmes that are done with them while they are incarcerated." (Participant 27)

“Corrections won't ever let some of these people be free from monitoring... at the end of the day, you might as well say to these offenders that 'your privacy is gone' - they lose all their privacy... a lot of them are illiterate, have mental health problems and addictions. We're always going to have these people, we just need ways to support them." (Participant 30)

"What does this risk look like? Well who knows - they look like your neighbour, like an uncle... who is a sex offender? It could be anyone inside or outside of your doorway" (Participant 32)

"You're sort of so conscious of the risk all the time anyway, because a lot of the cases that get picked up are within families... I think these offenders are the unseen... people don't notice until their attention is drawn to it." (Participant 33) 


\title{
Community Reactions to the Release of Sex Offenders in Napier
}

With the level of understanding of offender release amongst community leaders I interviewed, it was interesting to note the generally high levels of faith in the systems in place to rehabilitate and reintegrate sexual offenders. Participants demonstrated a level of familiarity with the typical processes of rehabilitation and reintegration, and empathised with the role the central state has in attempting to reintegrate released individuals into communities who hold often inaccurate and potentially harmful beliefs about sexual offending.

\begin{abstract}
"Well occasionally, whoever is released, it is risky. It's a risky world, but you're only feeding more ignorance into the good work that the back-room boys have worked on for years to enable these people to become more human... I mean, it's connected with improving our quality of life for everybody. But it's never looked at because most people in Napier would say... I'd say $80 \%$ of Napier would think you can never cure a sex offender. Yep. Might be more. Hopeless." (Participant 29)
\end{abstract}

\begin{abstract}
"These people have done their time. They've served the sentence that has been deemed appropriate for them. You've got to try and let them get on with their life. If it's proven that they've been rehabilitated, then that should be where the matter ends. That's my approach. Having said that, no one's ever come and lived next-door to me and you know, I might have grandkids one day, and I ask myself, would I feel the same way? I suppose if I knew that they'd been rehabilitated, and I have faith in the system that they've been rehabilitated. It's the most likely crime that people have the chance of turning around... We can't afford to keep locking people up the way the country has been." (Participant 24)
\end{abstract}

"People just have to realise that they get out of prison at some stage. They are people like us, they're amongst us." (Participant 25)

It seemed that many of my participants were struggling with the knowledge of what they know to be true based on the evidence in contrast with their own personal experiences and 
preferences as community members. Although many expressed an understanding of the effectiveness of New Zealand's rehabilitation programmes, this often conflicted with their concern for the wellbeing of their own families, inherent 'NIMBYism', and views that regardless of the evidence, the bulk of the community will continue to vehemently reject these released individuals.

"[Public notification is] not a good idea because they will be harmed, and people will be worried about their house prices and things. I mean, one of my sons was abused, so when considering it, I think yeah, I'd want to know. As someone that works in the field though, I don't think it's a good idea at all." (Participant 32)

"If anyone had even slightly harmed my daughters, man, I would have been like a wild beast." (Participant 33)

"When you read about [sex offending] you know, they just don't, these people you know they're just different. They do look at kids like that, they'd rather not normally, most of them, but they do. But it's when they act on it, but not everyone, I mean most people - I'd say $90 \%$ of people would go for the castration or put them on an island solution." (Participant 25)

“There's a perception about these people, whether it's right or wrong, there's a perception based on the crime that they've been accused of, and it's a perception that it will manifest in future criminal activity of a similar nature. I think that there's a perception that once you're a paedophile or a sexual criminal, that's it, it's in your system forever... you only have to have one sexual offender reoffend once they're out, then the perception is that they're all going to reoffend. 'Can't take the chance, don't want them in my neighbourhood.'” (Participant 31)

While there was an element of hope amongst the community leaders I spoke to regarding the state of rehabilitation and reintegration run by the Department of Corrections, indicating trust in central government bureaucracy, the more immediate risk and public perceptions prove to be more powerful in influencing behaviour. The responsibilisation of 
parents has been significant, and parents appear to have taken that burden on. Participant 25 provided an example of this in regard to a released sex offender living in his community:

\begin{abstract}
"The chances of them reintegrating aren't good. I've had big debates with my wife about this because she, you know that guy that was at [redacted] Road, it does raise all sorts of questions. We've got two young kids, you have to be careful. There are some things you don't let your kids do, and she was very uneasy about this guy, and I said well look there's probably two other paedophiles on that road. You know my wife doesn't want to walk that road, you probably pass four other sex offenders on your normal walk - this is just one you know about. So the precautions you take with your kids should be taken all the time anyway. You know there's things that every parent does - you don't let your six-year-old walk to the dairy alone."
\end{abstract}

The ultimate responsibilisation of parents can be observed in this anecdote, and the consideration of how parents could have allowed such an individual into their families and access to their children. This extended to victim-blaming sentiments, which served to shift some of the blame for the sexual victimisation of children away from offenders, and onto the parents of child victims:

\footnotetext{
"Often in my experience the victims have come from families or situations where there's been a large degree of trust placed in someone. And you are thinking that you - you're left thinking two things. You're left thinking that it's a bit strange that they would have trusted someone that much, and two, that guy must have been really good at convincing that family that he could be trusted - and it's the latter one that really scares you. Anyone who's been tricked into anything will feel that they could be susceptible to someone like this getting them somehow." (Participant 25)
}

The existence of this kind of insidious threat is one of the drivers behind broad calls for community notification. The majority of my participants did not support large scale notification, and recognised a wide range of risks that would be associated with notification for victims, offenders, and the wider community. However, many of them were supportive 
of a limited form of notification, and tied this back to their own lives and personal desires to be informed of this kind of situation if it should emerge in their own community.

"I think we should be transparent, but the level of transparency - I don't think the entire community needs to know. People in that direct vicinity, with a number of meetings and giving people some education and understanding around it I think that can work. I'd be horrified if that had happened next-door to me and I wasn't aware and I wasn't able to prepare and educate my own family for that scenario." (Participant 31)

The stance of my participants invariably came back to a discussion of their level of trust in the central state to manage risk. There was a high level of risk consciousness demonstrated throughout my interviews, as individuals leaned into the individualisation of uncontrollable risks. In this vein, one particularly experienced community leader eloquently explained their opposition to community notification on any level:

“Well you can't notify [the community] now because they're ignorant, you know. If you gave them information that had nothing to do with them it wouldn't be good information... in fact it just think it reinforces the unknown. And reinforced, the unknown becomes worse than the known now." (Participant 29)

The lack of knowledge and community understanding perpetuates uncertainty that can be manipulated, as it was in Whanganui, by those willing to mobilise their own 'strategic ignorance' (McGoey, 2012). Other participants expressed similar sentiments in their discussion of the halting effect that public notification would have on the community in Napier:

"I think Corrections keep it quite low key with offender release here... I think if they weren't you'd have the negatives outweighing those talking about the positives, and then that's it. It won't work." (Participant 30) 
"The reality is that we would never be able to house a prisoner if the Department of Corrections did public notifications." (Participant 33)

Although community leaders view Napier as a population that would be vulnerable to anxiety and misinformation if they were to be notified of offender release, this has not played out in the case of Individual X. The community in this case lacked a 'charismatic entrepreneur' willing to agitate and manipulate the situation for personal gain, which was the scenario observed in Whanganui. Perhaps more importantly, based on the interviews I conducted, it appears that the delegation of responsibility for personal safety to the individual has been more enthusiastically taken up in Napier than elsewhere. While in Whanganui participants were talking about how "it takes a village to raise a child" (Participant 15), in Napier the individual responsibility for the wellbeing of children sits squarely with that child's parents. This is a departure from the more community-minded and family-centred condition that existed in this city prior to the neoliberal reforms.

\section{On the Value and Vulnerability of Children}

The innate vulnerability and value of children was raised in the majority of the interviews I conducted in Napier. Within this more liquidised community, the place of children as fragile and vulnerable was an interesting departure from the discussions of children as "prime exports" (Participant 16) in Whanganui. The nuances of the way children were discussed also reflected risk consciousness to a significant extent: the value and vulnerability of children was conceptualised in relation to the presence of intolerable risk:

"I think when we look at other adult victims, we look just instinctively, we kind of - let me out this another way. With kids, we know there can be no explanation whatsoever... They weren't drunk or on drugs, they weren't walking alone at night somewhere - I mean just because you are walking alone at night doesn't mean you should be... We always think okay, there is a victim. But we don't think oh shit that's we want to know a bit more about that victim, what were the circumstances? You know, sometimes that's actually really relevant. Sometimes they were in a 
relationship with them, or there's a real dispute over whether it was consensual or not, and that's relevant. But with a kid, it just doesn't matter." (Participant 25)

"Children are so innocent. They don't know the power of a person who has set out on a journey of grooming. They don't know, they're innocent. That's not to say that a woman who is 35 that gets raped was up for it, l'm not saying that at all, it's still terrible, it's hideous don't get me wrong, but on the scale, children are totally innocent and naïve." (Participant 31)

“Children's innocence might make them more vulnerable, and that they're easier to end up in a situation where you know, as adults we're appalled by it but kids might not see it unfolding... and I suppose just that natural instinct of wanting to protect your kids from a perceived danger." (Participant 24)

These conversations reflected elements of Christie's (1986) 'ideal victim' theory, (as discussed above in the Teresa Cormack case), and participants slipped into discussions of the legitimacy of children as victims compared to that of adult victims. The crux of the issue for the purpose of this research is that participants agreed that children are unable to predict and manage risks posed to them, and that adults (parents in particular) hold a duty to protect children. Participant 28 concisely explained this:

"Children are a taonga [treasure]... I think it is part of who we are to value them. Family connections are tangible for us in a way no other relationship often is" (Māori translation added)

Nevertheless, children do experience serious harm in New Zealand society, which raises a question also crystallised by Participant 28: "If we see children as valuable, why do we treat them with abuse and neglect? We haven't even admitted, really, the extent of the abuse of the past." This question could also be asked of the state, whose role in preventing harm to children has extended to ineffectual and controversial legislative reform without evidence of significant reduction in harm, or improvement in circumstance for children. 


\section{Disdain for Local Government}

The relationship of the community with various levels of state power is a useful indicator of liquidity. While Napierites expressed irritation and anger with local government, there was a deeper respect present for the central government (alongside some frustrations). This is the opposite of what I found in the more solid state community of Whanganui. I was taken aback throughout my interviews in Napier by the intensity of the disdain for local government, particularly for the Napier City Council. Voter apathy was one of the consistent issues raised by community leaders, alongside frustration with the level of upset from many who likely do not participate in local government elections. Although participation in local government elections was higher than the national average in Napier in 2019, with $50.03 \%$ of voters returning papers, versus a national average of $41.7 \%$ (Local Government New Zealand, 2019), this is still an objectively low voting rate. My participants outlined the situation in Napier:

"[Voter apathy] is one of the perennial frustrations. There's not a lot in the way of participation, but there's a lot in the way of grievance... Napier City Council in my view is one of the poorest, one of the least transparent and least debate-focussed that I've seen. It's not a particularly open Council, and I think that you see that materialise in it coming up with things that are unexpected. There's also not a lot of community involvement here, so it's sort of both ends - so the Council comes up with the proposal for say a velodrome, which just seems to have come out of the blue (it's died a natural death now) but it really should never have materialised." (Participant 25)

"I mean the Mayor that we've got now, because he's a sharebroker it means he can run the city. That's his mentality. To get through that, to get through that success mentality of money, you can look at most councillors, they are there because they were good at making money. So they haven't got time for [community building] you see." (Participant 29) 
Despite having a higher voter turnout than the national average, it is still a fairly low level of engagement, particularly given the significance and frequency of the well-publicised issues the people have had with local government. Recent issues have included the contamination and subsequent chlorination of drinking water, overwhelmed stormwater systems, inconsistent recycling services, inappropriate Council spending and investment (e.g. the Velodrome plan, the shift of the Onekawa Pools without public consultation), and deceptive Council behaviour (the rebranding of the War Memorial Centre as the Napier Conference Centre). The voter turnout in 2016 was $43.85 \%$, so it is possible that the $6.18 \%$ increase in voting turnout in 2019 was a reaction to the frustration with the actions of the Council over the previous term (Hawkes Bay Today, 2019, 14 October). As a broader measure, the voter turnout in the Napier electorate in the 2017 general election was 83.2\% (compared with a national average of 79.01\%) (New Zealand Parliamentary Library, 2017b). The frustration of my participants with local government was universal, and many were passionate about changing the local government at the 2019 local election in order to lead the Napier community in a more favourable direction (and away from the concerns generated by the Council at the time).

\footnotetext{
“In order to communicate and make change: you've just got to put your feet under the table of leadership and control your emotions, be friendly, bullshit them - which is possible if you've got that patience... the Napier community will only deal with change when leadership changes." (Participant 29)
}

While the disdain for the actions of local government was deeply felt and universal, there was a more positive outlook on central government among my participants. Despite a general distrust of politicians, my participants demonstrated respect for the work of the "back-room boys" (Participant 29) and those within the machinery of central government.

\section{Central Government}

Those who are immersed in the Napier community see the way that the state is managing its own reputational risk clearly in cases of offender release and beyond. The politicians are a part of this problem, as they are unquestionably concerned about reputational risk, while 
the bureaucracy is seen to be doing its best under the often problematic leadership. My participants explained their outlook on this arrangement:

\begin{abstract}
"the government brings the policy in to develop communities, whether it's good or whether it's bad... and we're often being controlled by ignorance... when good work is being done, it's the back-room boys again, not being listened to by the media to get good news out... and when it's bad, you can't blame them for not stepping out of whatever for fear of losing their jobs." (Participant 29)

"I know I'm not the only one that thinks it, but the way law and order and increasingly education and being used by politicians to gain votes, it sickens me. It sickens me. So I admire the current government for trying to actually get in and try and change things." (Participant 24)
\end{abstract}

The placement and reintegration of sex offenders in the community ultimately relies upon high levels of trust in the central government's ability to effectively manage any residual risk these individuals may pose. Although Napierites I spoke to tended to appreciate the work of the central state bureaucracy, they demonstrated suspicion of politicians, and an understanding that risk for personal and family security has been delegated to them. While central government is respected as the creator of the climate for business, taxation levels, and similar important considerations for liquid citizens, there is little patience shown for individual state actors. Although they feel they should be able to trust the central government to manage such risks, the nature of sexual harm as irreparable leads to a tendency to be apprehensive of the state's ability in this regard.

\footnotetext{
"My expectation would be that the state is containing the risk, but there's plenty of examples of the government not doing stuff effectively. You must trust them, but at the point they break that trust, it's going to be very hard to trust them again." (Participant 31)
} 
The extent to which the success of reintegration depends on trust in the state can be demonstrated in the comments of one particularly conservative community leader. This participant explained that:

"People in the community find [the perceived lack of transparency in sentencing] quite offensive you know, and they really don't understand the system like people like us, who are involved in it, and who understand it. They say well he got nine years and he's up for parole now, well, that's the law. So that triggers an 'anti' response from the community. You know it's something we tried to change, let's start talking about being a lot more honest about what the sentence should be, and let's encourage the media to put that out there you know." (Participant 26)

This participant went on to equate notification with necessary government transparency:

"In my opinion, openness and honesty is the best way to deal with everything,
anything. I think there are some, no doubt, vigilante type people in the community who I suppose are a risk or a danger. But they'll be a minority, whereas the risk of not informing the community is turning more people into vigilantes when they find out, because they just mistrust the system at that stage - rightly or wrongly. You know, if you're not dealt with as an adult and honestly, then you mistrust whoever it is trying to feed you the information, if you have to extract it. So, I'm a great believer that New Zealanders would respond a lot better to an open and honest system, and I mean right through - not just talking about sex offenders, I mean the justice system, full stop." (Participant 26)

This participant recognised the challenging background of many offenders, and expressed a willingness to accept what are essentially departures from the foundational principles of justice in responding 'spasmodically' to them:

\footnotetext{
"A lot of these kids have been brought up in an environment that you could possibly predict that they are going to become an offender, or have greater chances of becoming an offender. Until we start to deal with that, then we've got to accept that
} 
we're going to get some spasmodic type tools for us to protect ourselves." (Participant 26)

Throughout this discussion, the participant conceded that if the state could do their job well, and intervene appropriately and early, then the system could be trusted without the need for notification.

"If you got to that extent that the law is being used the way I believe it should be, then I believe you've got to trust it yep. There isn't going to be a perfect system, there will still be failures, absolutely. We're dealing with human nature." (Participant 26)

Obviously the definition of the use of the law in this statement is a significant variable, but these statements once again support the idea that notification is, at its foundation, driven by distrust of the central state.

\section{Conclusion}

In the case of sex offender release I examined in Napier, there was no extreme community reaction, and knowledge of the case was very limited even amongst community leaders. In Napier, the lack of a strong and coherent community network likely had a significant influence on this lack of reaction. While certain subgroups of Napierites identify strongly as 'communities', the lack of coherent community identity in the city more broadly lends itself to distancing from the issues and experiences of others in the area, and a general lack of solidarity. The amorphous population here differed significantly from the more tightknit and closely networked community in Whanganui.

In my interviews with Napier community leaders, three ingredients were identified as necessary to create a high public interest story of any kind (not just regarding sexual offending): the presence of a 'touchpoint issue' affecting people's money or children; the presence of a champion (or 'charismatic entrepreneur') providing moral guidance and representing the situation in the media, and high levels of media interest in the story. The case of Offender X lacked a champion, and though one large article was published in the 
local paper and on a national news site, there was no sensational or continued reporting of the case in local or national media.

The nature of the idea of a 'touchpoint issue' as raised by my participant is particularly neoliberal, and confirms the reach of neoliberal values amongst these community leaders. My participants agreed that in order to generate significant public interest, an issue usually needs to personally affect an individual's wealth or children in order to draw their interest. This is demonstrative of a high level of individualisation, and a departure from community mindedness. While the case of Offender $X$ could have been viewed as impacting children more broadly, the lack of a direct and individualised threat meant individuals were not spurred into defensive action.

Napier is a city that, on the surface, approximates the national average measures of population health and socio-economic condition. It is a city that has experienced some of the benefits of neoliberal reform, with the existence of inequality and disparities providing further evidence of the entrenchment of neoliberal values. For these reasons, it is all the more important as a case study in this series, as it represents a different facet of New Zealand society to those found in Whanganui. In Napier, we can observe that same level of distrust of the state (particularly local government authority) still exists within the population, however the people in this city are, to a more significant extent than Whanganui, willing and able to take individual responsibility for protecting themselves and their families from risk. 


\section{Chapter Seven - Ōtāhuhu}

\section{Entering Ōtāhuhu}

The drive south from the central business district to the suburb of Ōtāhuhu presents a microcosm of the diversity of the city of Auckland. Great South Road forms an arterial connection between the heart of Auckland central and the southern suburbs of New Zealand's largest city (approximately 1.6 million people). The road itself is relentlessly bustling. The scenery transforms during the journey from upmarket retail centre Newmarket, through leafy upmarket Remuera, into commercial Greenlane where the road becomes part of State Highway 5, through industrial Penrose, and into Ōtāhuhu and beyond. Long considered a boundary zone between Auckland city and South Auckland, entering Ōtāhuhu truly feels like stepping over the threshold into the South.

Entering Ōtāhuhu for the first time, I was immediately struck by the sudden and intense police presence. The Police Station looms large as you drive into the township from the north, and I observed more police officers and cars about at 7:30am on a Monday than I could ever have expected. Walking around the town centre to get my bearings, people interrupted conversations in other languages to acknowledge me, or to greet me warmly. The drone of the traffic from state highways on either side of the row of shops was constant. Looking up at the shop overhangs, CCTV cameras (monitored 24 hours a day by a local security firm run by an ex-All Black) followed me from one end of the town centre to the other. I watched shop owners pull up protective roller doors and bless their shops before filling their entrances with goods. Many shops were covered in brightly coloured fabrics with intricate Pacific patterns. I later discovered that people from all over Auckland come to Ōtāhuhu to buy the best quality Pacific clothing in town. 


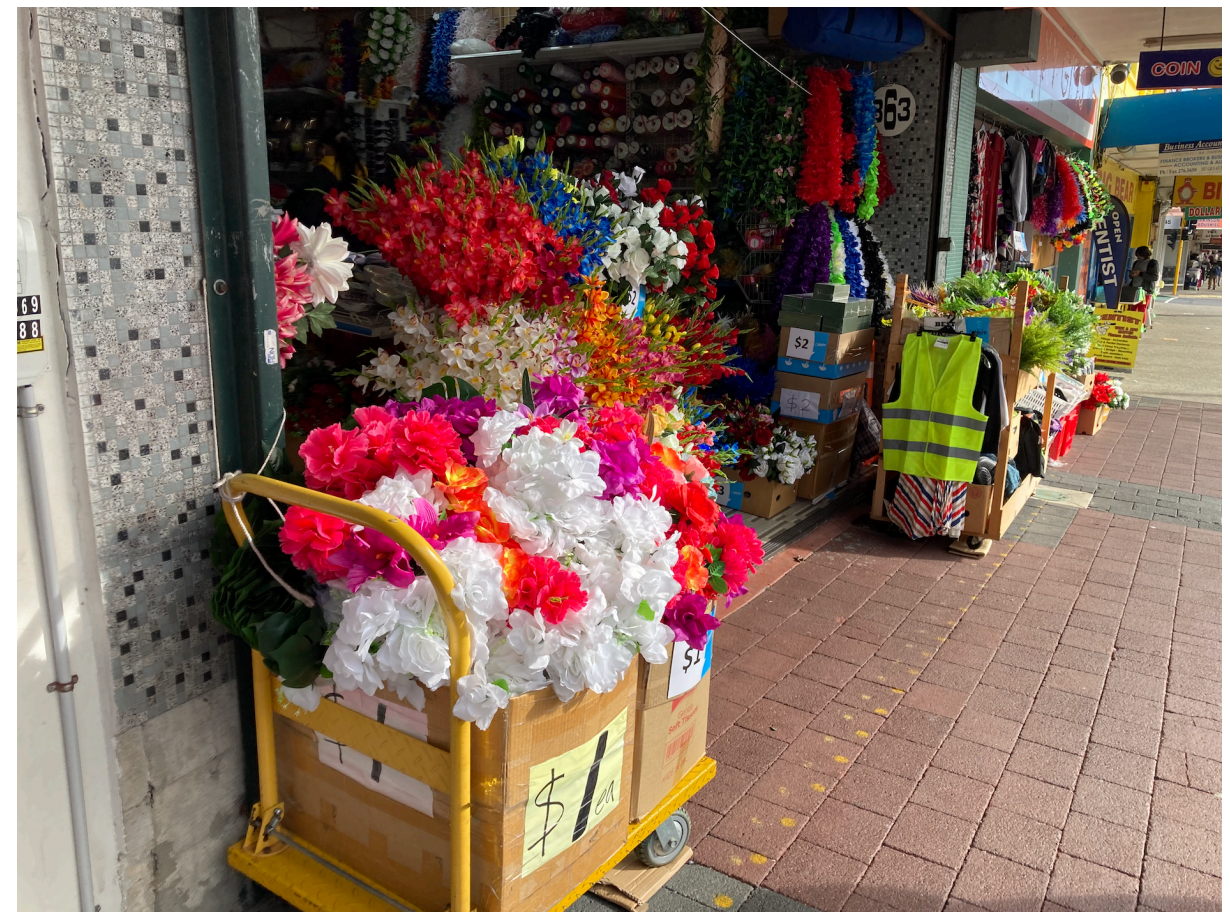

The cheap and cheerful shopfronts typical of the main stretch of the local shops (2021)

Image 9 Pasifika Clothing For Sale in Ōtāhuhu

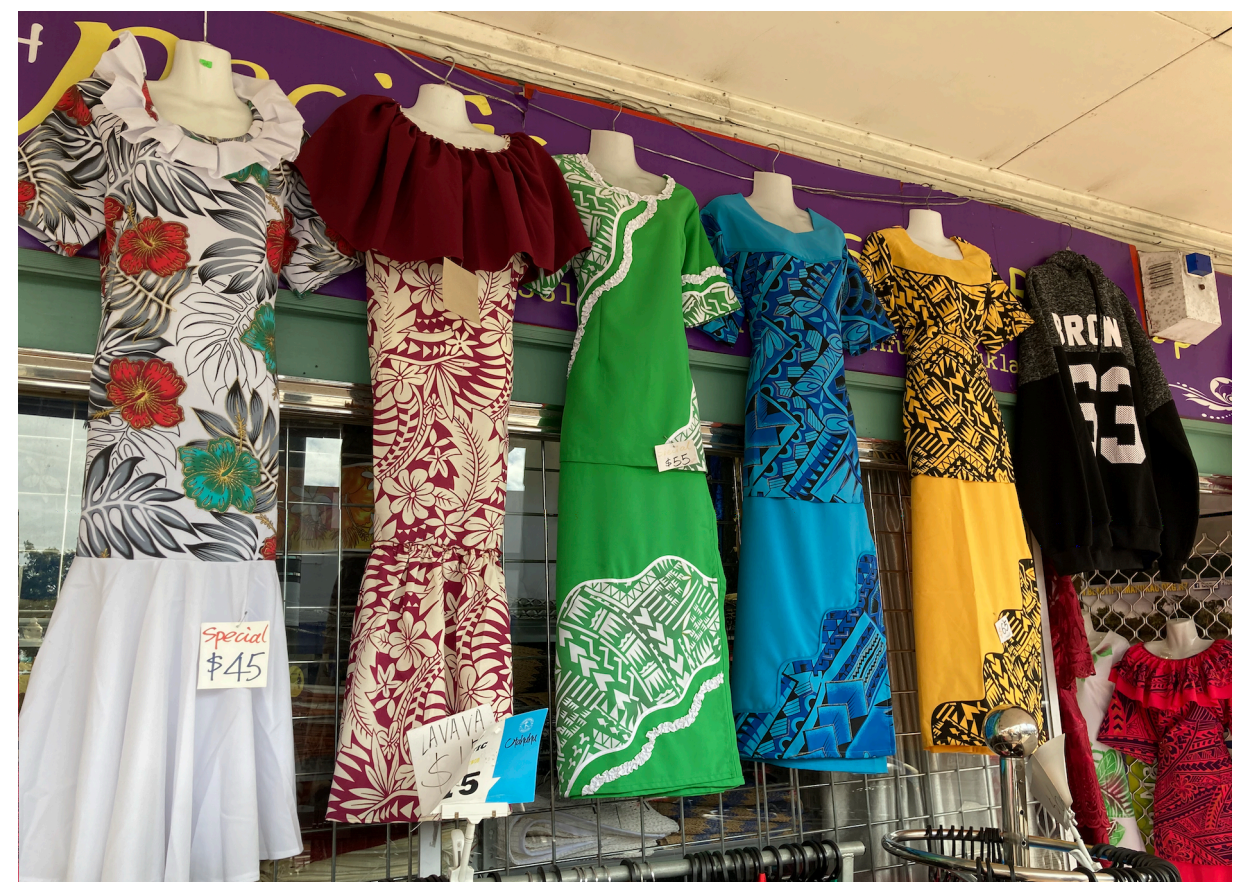

Colourful patterned clothing features in many of the shopfronts in Ōtāhuhu (2021)

The suburb itself is very small - an isthmus between enormous neighbouring suburbs Māngere, Papatoetoe, and Ōtara - as of the 2018 Census Ōtāhuhu had a population of 
15,165 (Statistics New Zealand, 2018). Ōtāhuhu's population is diverse, and Pākehā make up a comparatively small minority - a significant contrast with much of the rest of New Zealand where Pākehā dominate the general population (70.2\% as of the 2018 Census). Ōtāhuhu is home to a significant Pasifika population, with almost half of the suburb's population identifying as 'Pacific Peoples' (48\% as of the 2018 census). Tongan flags lined the streets of the township, the bright red adding to the vibrancy of the area, and confirming the relevance of the suburb's affectionate local nickname:

“It's known as Little Nuku'alofa, which is the capital of Tonga. It's just like being at home again. You walk down the street and see people in their mats and speaking not just Tongan, but other Pacific languages." (Participant 10)

Ōtāhuhu has not always been dominated by a Pasifika population, with its mid-century status as an upmarket shopping centre for lower-middle class Pākehā Aucklanders still alive in people's memories, and a long history that stretches back to the earliest arrivals of Māori people in New Zealand lying beneath the surface of the present-day buildings. The first Tainui ${ }^{32}$ waka landed in Ōtāhuhu, and new entrants to New Zealand have settled in this area ever since. The large Pasifika and immigrant population occupying the area have arrived through the nearby international airport and made this place their home, confirming that as long as people have walked on the lands of New Zealand, Ōtāhuhu has been a gateway to the world. As part of this constant regeneration and newness, the identity of Ōtāhuhu has continued to shift and change over time.

\section{Ōtāhuhu's Place in Aotearoa/New Zealand}

The construction of present-day Ōtāhuhu began during the British colonisation of New Zealand. The 1902 edition of the Cyclopaedia of New Zealand explained that the area was set up as a military settlement of "Pensioners" who were part of a chain of such settlements on call to defend Auckland in case of Māori "invasion". The location of the fencible settlement on the narrow link between Auckland and the south made it a particularly

\footnotetext{
32 Tainui are the local iwi of Ōtāhuhu.
} 
valuable position of defence for colonising forces. In this vein, the British invasion of Waikato was launched from this settlement in the 1860 s. As colonisation progressed, the cheap, flat land of Ōtāhuhu and its easy access to central roadways, railways, and waterways, set this area up as ideal for the development of heavy industry.

The first freezing works opened in 1905, followed in quick succession by the arrival of two more freezing works companies, as well as railway workshops, and factories producing rubber, chemicals, soap, candles, and fertiliser. Through colonial settlement the early history of the Ōtāhuhu township saw it populated primarily by British settlers, though the proximity of industry and the concentration of unskilled labour and market gardens (typically run by Chinese New Zealanders) in the area have ensured a level of diversity which has significantly increased over time. Today, Ōtāhuhu is a picture of diversity, with one of the highest proportions of residents born overseas in the country: $49.4 \%$ versus the national average of $\mathbf{2 7 . 4 \%}$ (Statistics New Zealand, 2018).

The significance and swiftness of the transition from the Ōtāhuhu township being a shopping centre primarily for Pākehā people, to a much more diverse and Pasifikadominated area was highlighted by Participant 5:

\footnotetext{
"Way back in the day the community was European, but there's one shop that I know of from that period way back in the day that is still there and the owners are still there. When you have a look at the shops and who owns them, that gives you an indication of the massive shift of ethnicity and culture over a short time." (Participant 5)
}

Ōtāhuhu is a boundary zone in variety of ways. As noted earlier, it is an isthmus, the narrowest point of the islands of New Zealand, though no evidence of the Tāmaki River nor the Manukau Harbour can be seen nor heard from the town centre. The geographical bounds of the area separate what is commonly understood as 'Auckland' from 'South Auckland'. As Mclntosh (2004, p. 138) explains: 
"South Auckland, more than any other part of Auckland, is associated with the place where poorer Aucklanders reside, if not with outright poverty". Amongst the deprivation and negative indicators, South Auckland is stereotyped as dangerous and is often "stigmatised, even criminalised." (McIntosh, 2004, p. 135)

In addition to its status as a geographical boundary, and a ward marker for governance purposes, Ōtāhuhu acts as a buffer between the boundaries of informal territories of wellknown New Zealand gangs including Black Power, the Killer Beez, and the Mongrel Mob. The suburb could be described as having a liminal status, which has become more important as the community has diversified over time.

\section{Diversification}

The transition from mid-century Pākehā shopping centre toward a very diverse and primarily Pasifika community in Ōtāhuhu was referenced in the majority of interviews. Participant 1 explained some of the pains of this transformation, touching on the social issues that plague the community today:

"We have such a massive history in Ōtāhuhu. You get some of what you call the oldschool Ōtāhuhu people that probably aren't too impressed with what you see now, because back then it was pretty, it was vibrant, it was financially stable. The whole infrastructure of the community was vastly different to what it is now. Then you get the more recent arrivals that enjoy the current vibrancy of Ōtāhuhu, acknowledge the fact that we have some issues around anti-social behaviour, our boarding houses, things that you wouldn't get away with in other communities." (Participant 1)

The anti-social behaviour referenced here was another point addressed by most participants, and one about which community leaders were clearly defensive. Several explained to me their views on the causes of crime in the area, including the anti-social behaviour of young people. Participant 9 unpacked the cultural nuance of the appearance of problematic or dangerous behaviour in the community: 
"There's a lot of dysfunction, but it's dysfunction in the sense of a pālagi (white/nonSamoan) world. It's functional in an island setting, it's not functional in a pālagi setting... when you're isolated from all of the supports of the island community, people don't realise that you can't behave like we're behaving. All of the village structures are gone, and it's not conducive to success here." (Participant 9, Samoan translation added)

In this vein, participants also explained to me the importance of the core community and the reconstruction of a sense of a village setting, with both a sense of family and the accountability of family. This was emphasised as all the more important in the face of neglect by the state.

"We're all here to look after one another... for me, it's not just a community. It's a family. Community is being there, for whatever happens." (Participant 7)

"The community is very family-like, they are always looking out for each other even if they're fighting against the system, they're all together doing it. What's sad is that sometimes they barely get heard, especially by people in power." (Participant 2)

In keeping with this style of replicating the village or family setting, the mode of communication with the community named as most effective by almost all participants in Ōtāhuhu was face to face discussion. The intersecting effects of deprivation, the large number of residents whose primary language is not English, and lower than average levels of internet access in this community combine to render social media and other forms of communication that are not face to face less effective than in most New Zealand communities.

"Face to face is so important. You get it straight from the horse's mouth... there's no misunderstandings, no confusion. It's about respect." (Participant 5)

"Kanohi ki te kanohi [face to face] is much stronger, we prefer that here." (Participant 11, Māori translation added) 
The prioritisation of in-person communication and village-style community structures lend themselves to a solid-state existence for the people of this community, who appear to be very conscious of their presence in an increasingly fractured and melting world.

\section{Solid State, Melting Pot}

The intersecting identities of the Ōtāhuhu community begin to emerge from observation alone. The mixed use of the space is clear to see. Industrial areas are in close proximity to the main shops, and are also punctuated by residential buildings and houses. Although there are just two cafes in Ōtāhuhu, both serving basic fare (for example, muffins, scones, meat pies, milkshakes), all major fast food outlets (including McDonald's, Burger King, KFC, Subway, Nando's) have a dominant presence. In the central township, extortionate payday loan providers seem to have outlets on every corner, and the streets are lined with $\$ 2$ shops.

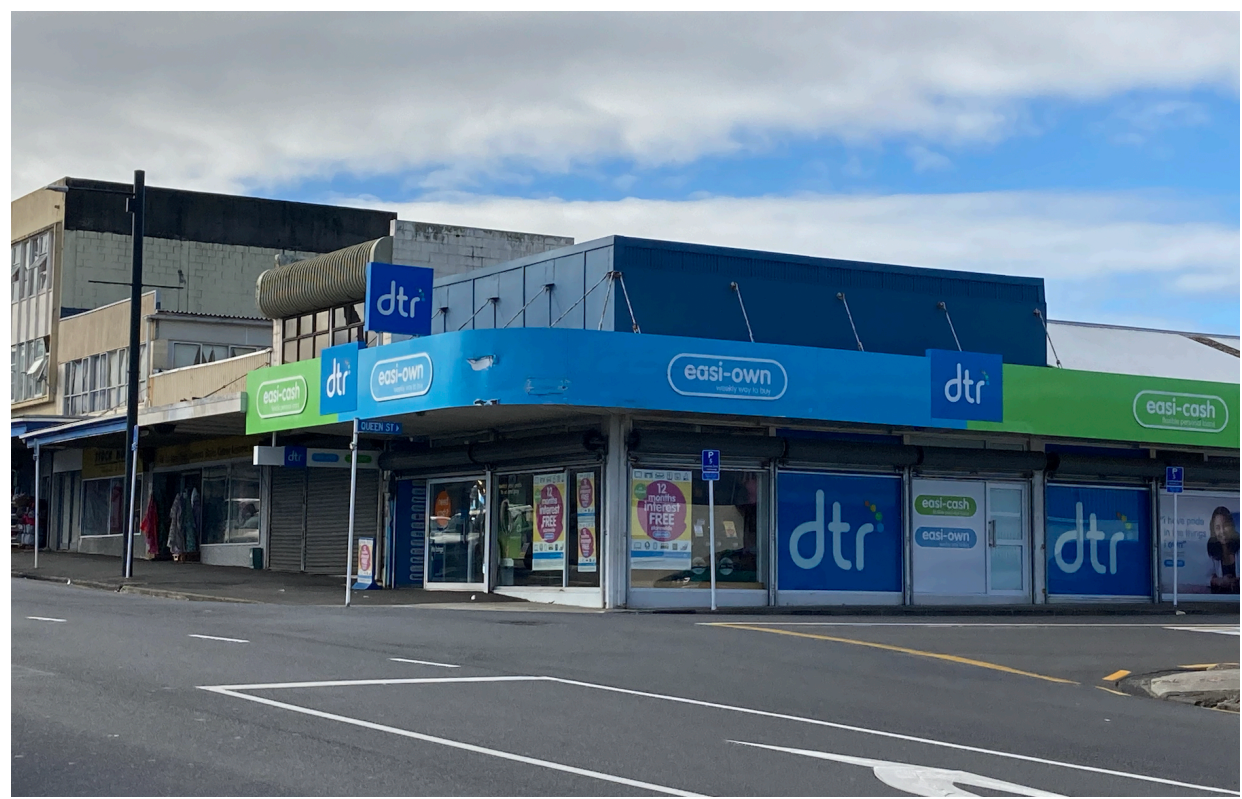

Predatory lenders feature prominently along the main streets of Ōtāhuhu (2021)

There are around a dozen schools dotted along the arterial roads, a very large number for a relatively small suburb. Among these schools is impressive variety, including: Catholic and 
special character schools; a charter school (run for Pasifika students in the Pasifika tradition); a special school for children and young people aged five to 21 with special needs; a Montessori school; a collection of large state schools. One school stands out among the others: King's College, the country's most exclusive private school (it costs $\$ 40,525$ for a 13 year old boy to board at the school for the 2021 year (King's College, 2021)), is an island fortress on the outskirts of Ōtāhuhu. The college is separated both physically by tall fencing, as well as figuratively, with the stark wealth gap between its students and those on the other side of the fence.

Image 11 Kings College, Ōtāhuhu

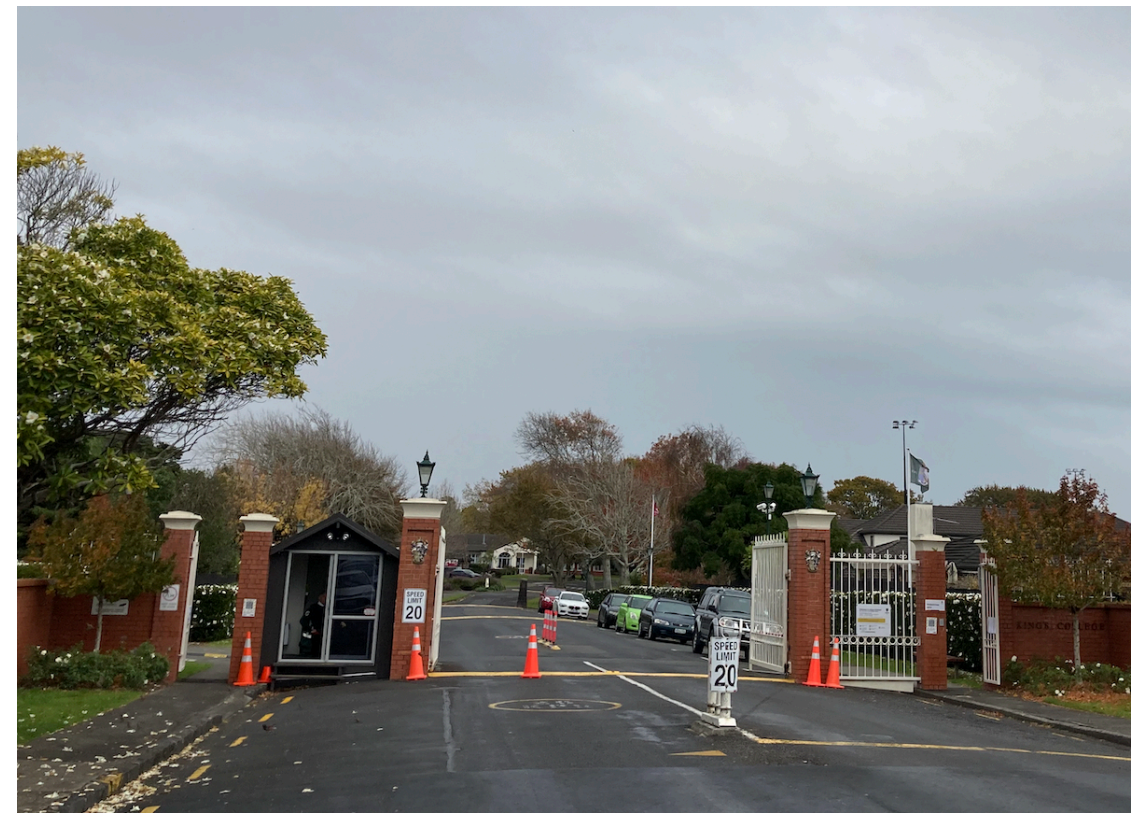

Throughout the day while the main gate of Kings College is open, a guard sits in a booth vetting all who enter the fortified grounds (2021)

Among the most expensive schools in the country, the walled campus stands out as an unusual destination for the children shuttled in and out each day from more affluent areas of Auckland. Often explicitly exempted from the descriptions of community of those I interviewed, the school is an alien feature of this area. It serves as a symbolic reminder of the wealth enjoyed in other parts of Auckland that has often come about at the expense of those residing in Ōtāhuhu. 
Places of worship are another regular feature of the streets of Ōtāhuhu, with the full range of Christian denominations well represented, including a large number of Pacific churches, as well as Buddhist, Hindu, and Sikh temples, and two nearby mosques. As Participant 9 explained, for this community, "the church is the urban village". This sentiment also serves as a reference to the traditional Pasifika way of life being replicated in pursuit of a solid foundation for community here. Participant 2 described how they characterise the suburb for those who ask - "the number of crimes are equal to the number of churches". While places of worship typically provide social support for the community, several participants highlighted and expressed concern about another side of this strong church presence: particularly around the tradition of tithing (particularly strong among Pasifika churches).

"The churches put pressure on the people, especially with the pressure to keep donating. Some people keep second jobs just to be able to keep donating." (Participant 2)

Despite concerns expressed by some members of the community over the funding models of some churches, the bulk of my participants named the centrality of the church as a key element of the Ōtāhuhu community and its identity. The variety of places of worship and the respect with which they are regarded by residents, and with which they regard each other, was consistently references as an indication of the success of the multicultural community. Church communities and places of worship have helped to establish a new kind of solidity for community members otherwise adrift in the liquidising world. As in Whanganui, these communities provide structure, tradition, and a built-in, tightknit community. It is of interest as well that in both Whanganui and Ōtāhuhu, we see higher numbers of churches and religious groups that require a heavy commitment of time, and money of their followers, as community members' lives have been built on the more solid foundations of their church.

It is clear from both observation and participant insight that a variety of cultures and ways of life exist here, and that this community is continuing to adapt to its environment over time. This has included adaptations to the failures of both local and central government to 
provide support to the community, as well as active harm being caused to this community by the state.

\section{A Governance No-Man's-Land}

In recent history, Ōtāhuhu has been a void for local and central governance. One of the consistent issues perpetuating this void is the drawing of ward and electorate boundaries. From 1865, the Ōtāhuhu Highway Board governed the local area. The Board became the Ōtāhuhu Borough Council in 1912, followed by the amalgamation of Ōtāhuhu with Mount Wellington to form Tāmaki City in 1985. In 2010, the Auckland 'supercity' was created, enveloping all other local authorities within the largest scale conurbation of its kind in the South Pacific. Ōtāhuhu may be a solid community left behind for Bauman's purposes, but has also been left out in a more literal sense by successive central and local government actions. For decades, Ōtāhuhu occupied a boundary zone between two local government jurisdictions, where neither Council would take responsibility for them. Even today with Auckland's evolution into a supercity, Ōtāhuhu is the supporting act to a much larger South Auckland suburb within the Council ward system. In the view of the community leaders I interviewed, the local government - traditionally responsible for rats, rates, roads and rubbish, has consistently and to this day - failed on all four counts.

Prior to the 2010 establishment of the 'supercity' the boundary separating Auckland City from Manukau City was drawn along Ōtāhuhu's southern border. This ruled Ōtāhuhu out of the Manukau City bounds, excluding the suburb from perhaps its more natural community. Although technically included within the bounds of Auckland City, as the southernmost suburb of the large district, it was largely out of sight and out of mind for both government and citizens. The frustrations that this in-between status caused the people of Ōtāhuhu cannot be overstated. The ineffective nature of the local governance of the area has undoubtedly contributed significantly to the many ills the community leaders of Ōtāhuhu described to me. The linkages between effective democracy and social capital must then be questioned (cf Webster 2015). In the 2016 local government elections, of the 63,851 enrolled voters in the electorate, 49,157 votes were cast from the Māngere-Ōtāhuhu ward, 
representing a turnout of approximately $77 \% .{ }^{33}$ This compares extremely favourably to the low national turnout to local government elections amongst the general population in 2016 (42\% according to Local Government New Zealand, 2016). Despite frustration with the local government, the community have continued to turn up to vote in significantly greater numbers than the national average. While the community expressed distrust and disdain of the local government system, the individuals that represent Ōtāhuhu and are known by the community were held in consistently high regard. As I would go on to find with the Police and central government, while the people of Ōtāhuhu have very little faith in institutions and the state, their village-style network has produced high levels of trust in individuals they know (the local MP, local Board members, local police officers etc).

In this respect, the views of participants in Ōtāhuhu were the reverse of those in Napier: in Napier, there was almost universal disdain and frustration with the local government, while the central government were not considered to be an obstacle for the community. In Ōtāhuhu, there was universal disdain and frustration with the central government (with some individual actors exempted), was well as the local government structure, elected representatives for the community were widely respected for their actions and work ethic. For Whanganui, the most solid of the three communities, participants were the most pessimistic about both layers of governance: there was a universal contempt for central government, and local government mechanisms and representatives were also generally viewed with very low trust.

Ōtāhuhu, for central government purposes, occupies the northern section of Auckland's Manukau East electorate, which also includes the much larger southern suburbs of Papatoetoe and Ōtara. Although Ōtāhuhu is distinctive as a community, its demographics are similar to those of its neighbours. A post-election report on the demographics of the Manukau East electorate in 2017 confirmed once again the scale of the disproportionality of the deprivation in these communities when compared to New Zealand averages (New Zealand Parliamentary Library, 2017a). Within Manukau East, the median family income is

\footnotetext{
${ }^{33}$ A number of these votes would have been cast from this area for other electorates, however this is the closest to an accurate statistic I can get for local government election turnouts in this area. These numbers were obtained through an OIA request to the Electoral Commission.
} 
$\$ 50,700$, compared to $\$ 72,700$ for New Zealand as a whole. Half of all households in the electorate are renting (46.9\%), and 9.2\% report no heating in their homes. Manukau East has the highest number of people on the sickness benefit of all electorates $(4.9 \%$ of the population over the age of 15, versus $2.3 \%$ NZ average), and the second highest proportion of people on the unemployment benefit (4.9\% versus NZ average of $2.7 \%$ ). It holds the lowest percentage shares of any electorate for access to a cell phone $(70 \%)$ and access to the internet (56.7\%). The population of this area is younger than the New Zealand average, with elevated proportions of every age group between 0-29 years. Interestingly, in the 2016 national elections there was a lower voter turnout in Manukau East compared to the New Zealand average (66.1\% versus the national average of $79.7 \%$ of registered voters). Turning to Ōtāhuhu more specifically, virtually the entirety of the suburb sat at 9 or 10 on the 2013 Index of Deprivation (1 represents the least deprived, 10 represents the most deprived). The area is a Labour Party stronghold, with centre-left Labour consistently winning the electorate vote, the party vote, and the Council seats for the area.

The impression that central government is not listening to the people of Ōtāhuhu, nor providing the foundational support the people need and should be able to expect from the state, was conveyed in an example shared by Participant 2:

\footnotetext{
"The government are not pumping funding into actually developing the place. When the Council does put money in, like the $\$ 17$ million they are spending stripping out parking and putting cycleways through the main street, they're not developing the buildings around or doing what the community have asked for and people are angry they can't afford cycles. Māngere ${ }^{34}$ has done it and nobody cycles because they just can't afford it."
}

Some members of the community have channelled these frustrations into coordinating action against local and central government decisions that negatively affect Ōtāhuhu. In planning and executing these actions, members of this 'core' community have shown perseverance and astute targeting in the planning and execution of their collective actions:

\footnotetext{
${ }^{34}$ Māngere is a large suburb bordering Ōtāhuhu to the south-west.
} 
"The core people are always putting their hands up to be involved, it's the same people that fought for the swimming pool and the rec centre after the John Banks ${ }^{35}$ threw them out of the ten-year plan. You know, we had a big protest march all the way downtown for that, hundreds of people and petition signing by all the kids. Everyone on the steering group went and made submissions to Council and so forth. They did enough to get it onto Len Brown's ${ }^{36}$ radar as an election promise for the first supercity election, and he came through... although there is a significant percentage of the community that churns and moves through, there is that core underneath that has seen it all before and have taken collective action before, which informs their responses." (Participant 4)

The frustration of the community with the neglect of the local and central government galvanises the commitment to the village for many of these 'core' community members. These core community members are acutely aware of the individuals in positions of power who are making decisions that have caused them harm, and they carefully target their protests and responses using this knowledge. Within this solid state community, members find refuge in one another, and in the relationships and deepening roots produced in this kind of environment. Community members in Ōtāhuhu vehemently defend their way of life, and are highly aware of the liquidising forces lapping at their feet (gentrification in particular).

\section{A Good, Strong Community}

Mclntosh (2004, p. 135) has described South Auckland as being cast "as a social penitentiary whose residents are unable to break through the constraints of poverty, unemployment, and other forms of social disorganisation". While Ōtāhuhu is diverse and vibrant, its vitality is often overshadowed by its long list of negative social indicators, including the crime rate hinted at by participants. Historically an industrial hub, Ōtāhuhu was heavily impacted by the economic restructuring of the 1980s. The decline of industry during this period,

\footnotetext{
${ }^{35}$ Former conservative Mayor of Auckland.

${ }^{36}$ Former progressive Mayor of Auckland, the first mayor of Auckland as a 'supercity'.
} 
including the closure of large employers in Ōtāhuhu such as the railway workshops and the freezing works, led to the particularly severe negative impact of neoliberal restructuring on this community.

Despite the long list of negative social indicators, and the beginnings of a struggle with gentrification (and associated skyrocketing house prices), the community of Ōtāhuhu is resilient and relatively tightknit. Although there are layers of transience, particularly with the number of people now homeless or living in their cars in the area, I was told by participants about a particularly strong community base of core members here.

"[Ōtāhuhu is] a good hardworking community, which a lot of people have discounted... but we're doing great things." (Participant 10)

One grassroots community leader slowly started crying when I asked them 'what does community mean to you?' Others also became emotional when I asked this question, as another community leader explained to me, "Ōtāhuhu runs in the blood" (Participant 7).

In planning for my interviews, I expected that in interviewing people who are widely regarded as 'community leaders', I would be talking to people who were committed to their roles. The level of commitment that I went on to observe frequently in Ōtāhuhu went far above what I could have expected, and certainly above and beyond their job descriptions. On two separate occasions, community leaders offhandedly mentioned that they personally pay for people's groceries, petrol, or power bills when they see families in need, with one emphasising the importance of charity, and the other explaining in detail the logistics of getting up at 5am to sneak groceries onto the doorstep of their struggling neighbour to ensure they never knew who had delivered them. While a local media representative was unpacking the issue of homelessness in the area for me, they reminded themselves that a new family had been spotted living in a car in the park, and made a verbal note that they 'must go down there' to see what they could do to help. One school principal asked that we move tables to conduct their interview from a spot where they had a full view of the entrance of their school, and proceeded to keep watch over the school throughout our hour 
together. Such community-minded comments and gestures were frequent, and demonstrated the level of care with which these leaders conduct their various duties.

\section{Housing in Ōtāhuhu}

Within the context of a national housing crisis, for the community of Ōtāhuhu, the growth of the number of boarding houses have come to represent the deprivation and exploitation of the local people. Participants lamented that Ōtāhuhu has the largest number of boarding houses per capita in the country. The demand for private boarding houses demonstrates the lack of social housing available for those without alternate accommodation options, and the often exploitative models target some of our most vulnerable community members. In 2015, the Department of Building and Housing presented a report on boarding houses to the Social Services Committee. The report found that boarding houses typically cater to the most vulnerable groups in society, including those on sickness and invalids' benefits, those with drug dependency or emotional issues, foreign nationals, and those on short term or precarious contracts (Department of Building and Housing, 2015).

Boarding houses are typically concentrated in low socio-economic areas with high levels of deprivation. One notable exception is a large facility in an upmarket central Auckland suburb, which received over 100 objections from concerned residents during the consent hearing; nobody with any choice wants a boarding house in their neighbourhood (Cumming, 2000, September 6). A 2018 discussion document issued by the Ministry of Business, Innovation, and Employment (2018, p. 41) acknowledged that boarding houses are conceptually built on a problematic foundation:

\footnotetext{
"Boarding house tenants might be more vulnerable to exploitation by landlords, have more limited knowledge of their rights, and be less likely to exercise their rights or lay a complaint due to a lack of alternative accommodation options. In general, it is likely to be more difficult for people in boarding houses to hold their landlords to account in the same way that tenants in the general rental market can, especially if their landlord lives on the premises."
} 
There is an awareness among Ōtāhuhu's community leaders that the prevalence of boarding houses in this area is not a problem experienced by other communities, and that the scale of the issue is fairly unique to South Auckland. In particular, the demand for boarding houses in this area and their quality reflects the poverty and desperation of some of the community's most vulnerable members. Tenants living in boarding houses are more likely than the general population to have a disability, to have mental health issues, to be unpartnered, to be unemployed, and to be reliant on a benefit (Statistics New Zealand, 2013). In the absence of social housing provisions for people meeting these criteria, the potential for exploitative private housing models is created, as it has been in Ōtāhuhu.

The makeup of the Ōtāhuhu community has changed significantly over time, and the composition of the community is likely to continue to transform over time. In recent history, Ōtāhuhu has primarily been the home to migrants from the Pacific and parts of Asia, as well as more established Pasifika communities. It sits at the 'most deprived' extreme of the Deprivation Index, ${ }^{37}$ and the social indicators set out in the previous section give some illustration of the realities of life in this area. However, Ōtāhuhu's location on the cusp of 'central' Auckland has meant that it has been swept up in the Auckland property market. The relative affordability of homes further south has brought 'newbies' into the community who may not have otherwise naturally settled here. As Participant 1 explained, "the community is gentrifying". Participant 1 also considered the impact of the early stages of gentrification, and the way that the community starts to fracture and dissolve:

"you have a new wave of people coming over and buying houses here - their kids don't go to school here, they don't shop here, they might not even walk their dog here... because of what the community looks like at the moment not looking like what they want, they literally just live here." (Participant 1 )

A range of community leaders mentioned the generally high quality of the housing stock, including high numbers of highly sought-after 1950s state houses. The median value of a house in Ōtāhuhu has experienced an accelerated increase, surging $21 \%$ over the last five

\footnotetext{
37 The Deprivation Index is an integrated data set that draws together data on indicators including crime, education, healthcare, employment, housing and income.
} 
years (although this is quite low for New Zealand standards). Although this increase is reasonable in the context of the heady Auckland property market, it is notable given that "this has always been a Housing New Zealand area" 38 (Participant 5). With lower socioeconomic groups driven further south as housing affordability wanes in Ōtāhuhu, the composition of the community here is likely to change dramatically in the near future, with gentrification taking hold with the rise in housing prices, and the growth of the wealth gap in New Zealand more broadly. For now though, this community apparently serves a purpose for the state - as a repository for individuals deemed too risky to reside in their home communities or elsewhere.

\section{The Case}

“There's hardly any news about Ōtāhuhu, and when you hear about it, it's usually not very pleasant." (Participant 10)

In March 2018, a national news media network in New Zealand exposed the presence of sixteen high risk sex offenders living in a South Auckland boarding house. ${ }^{39}$ TVNZ revealed to an unsuspecting public that these sex offenders were on various forms of community release in Ōtāhuhu and were being managed by the Department of Corrections, whose decision it was to place them in close proximity to local schools, parks, childcare centres and churches.

\footnotetext{
${ }^{38}$ Housing New Zealand is the national state housing provider.

${ }^{39}$ This number is contested: my interviewees consistently claimed that the number was sixteen, while the Department of Corrections publicly claimed the number was eleven. There is also dispute over whether there was one single boarding house, or whether 16 people were spread across two neighbouring houses.
} 


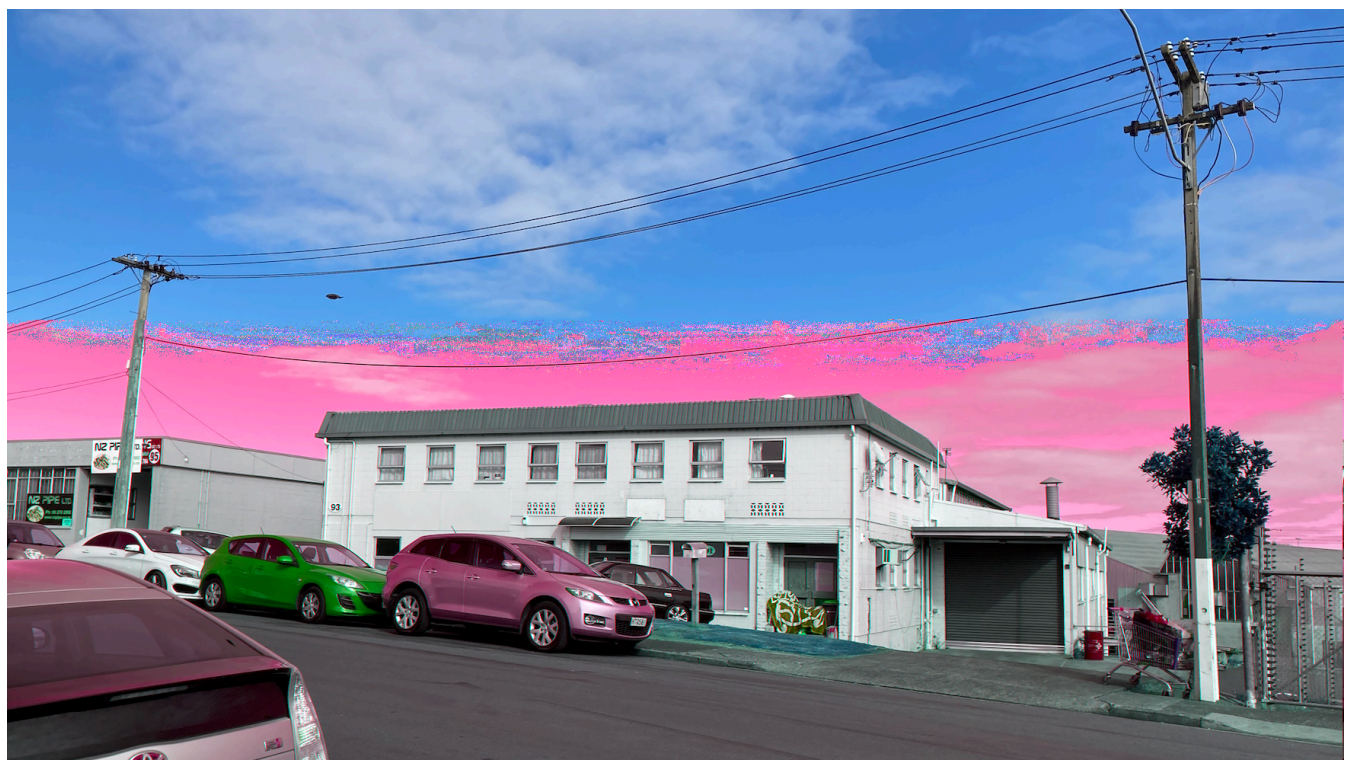

The boarding house at the centre of the controversy in Ōtāhuhu (2021)

Initially, the reaction of the Department of Corrections to the media attention was to contest the number of offenders (their Commissioner claimed publicly that it was, in fact, eleven offenders). Meanwhile, both the community reaction and the media coverage gained traction over the subsequent days, with all national news networks and newspapers picking up the story, and more details, perspectives, and interviews with concerned locals published each day. Participants described their shock at hearing the news, as well as the reactions they observed within the community:

"I found out on the six o'clock news and I was mortified. The fact that the justice system released all those people into that building - it's disgusting." (Participant 8)

"When I heard the news, it was a real shock for me. We had no idea. I thought I knew my community and who was there, this fell under my radar. Most of the time when we walk around our community... we feel safe. We just had no idea that there were these offenders that were mixing and mingling, some of them had gone close to schools and set off their bracelets. That was the main concern for me was that they were out and about without us knowing... and a lot of people were really concerned at the public meeting, and were feeling really insecure." (Participant 10) 
"The community went into panic. People locked down their streets, they were really worried when they found out they were there." (Participant 11)

Some community leaders observed a more nuance version of the reaction of panic, which swept through certain elements of the population. As Participant 9 explained:

"I think it only hit the area of those that have some level of education. For the average person, everybody is resigned - 'what can we do about it? We can't do anything about it.'” (Participant 9)

Participant 2 observed that this instance of offender release was reminiscent of other similar, recent incidents in nearby suburbs which coloured the community's perception of the Department of Corrections treating South Auckland, and Ōtāhuhu specifically in this instance, as a 'dumping ground':

"There is a pattern here, and the community knew that - the same thing had happened in Māngere and Corrections moved the offender just in time for the community meeting there as well. People were angry." (Participant 2)

On Monday $12^{\text {th }}$ March, the Ōtāhuhu Business Association (which serves as a kind of community hub) created a Facebook event for a public community meeting about the situation that week. By Wednesday $14^{\text {th }}$ March, the Department of Corrections had declared that three offenders had been moved, and that the placement of the others was under review. On Thursday $15^{\text {th }}$ March, seven days after the story broke, and on the morning of the public meeting that local community leaders had arranged to discuss the issue, all of the remaining offenders who had been living in the boarding house were removed from the property and relocated by the Department of Corrections. Nevertheless, the public meeting went ahead, and spirited demands for notification and greater levels of information sharing throughout the community were shared among attendees.

The public meeting held on the evening of $15^{\text {th }}$ March 2018 was the first of its kind in the Ōtāhuhu community with this level of media and social media traction. Although some 
community leaders had longer associations with the area, and could remember community meetings following a series of youth gang murders in the early 2000 's, ${ }^{40}$ for most community leaders, this was the first such meeting they had been involved in. The meeting was well attended, with over one hundred community members filling the Town Hall. It started out with the announcement that all of the offenders are now gone, and mention of a statement provided by Corrections that would be put up on Facebook for people to read later (see Image 13). There were short speeches by Local Board and Parliamentary representatives, and then the floor was opened to questions. Concerns for community safety were raised around the 'dumping' of offenders from other New Zealand communities in South Auckland, as well as the particular type of offending these individuals were alleged to have been involved in, the following quotes transcribed from an online video stream of the public meeting demonstrate:

"these offenders want to join in on Ōtāhuhu's dirty little secrets"

"give the housing to the people living in cars, not child sex offenders... they are not our people"

"stop the secrecy - sexual abuse thrives in secrecy"

However, a strong undercurrent of understanding was evident in the majority of questions and statements from those in attendance:

"they were just dumped"

"we need to look for solutions... we have to have an open heart"

“Auckland Council hasn't been listening to the community about boarding houses... [the complaints are] falling on deaf ears"

\footnotetext{
40 In 2005, rivalry between local youth gangs led to the retaliatory murder of Lio Naea in his home (see Gower, 2007, August 18).
} 
There was also vocal frustration with the failure of the Department of Corrections to attend the community meeting. Although the Department sent a 'media statement' as well as a two-page explanation of the issues with housing sex offenders, those at the meeting were asking why Department representatives were not willing to front the community themselves. Although local Member of Parliament and Cabinet Minister Jenny Salesa arrived to the meeting and passed on a message from the Minister of Corrections, the statements did little to appease the frustration of the community members.

Image 13 Statement of Department of Corrections, 15 March 2018

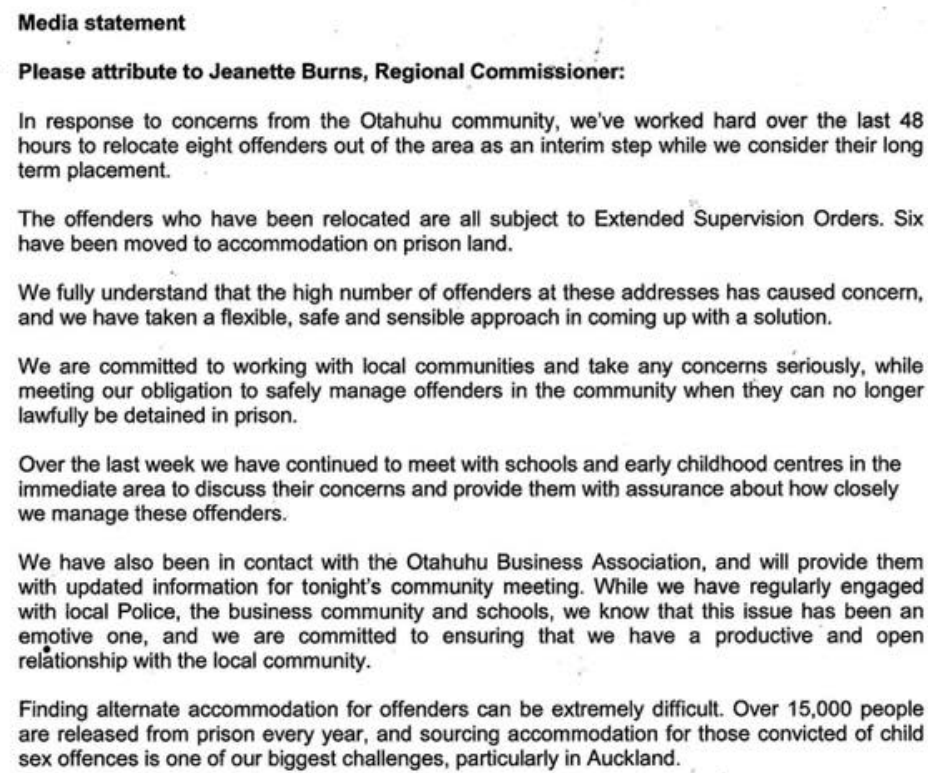

We have also been in contact with the Otahuhu Business Association, and will provide them with updated information for tonight's community meeting. While we have regularly engaged with local Police, the business community and schools, we know that this issue has been an emotive one, and we are committed to ensuring that we have a productive and open relationship with the local community.

Finding alternate accommodation for offenders can be extremely difficult. Over 15,000 people are released from prison every year, and sourcing accommodation for those convicted of child sex offences is one of our biggest challenges, particularly in Auckland.

Department of Corrections statement for Community Meeting, posted by the Ōtāhuhu Business Association to the public Facebook page 'Otahuhu' (sic)

This case presents a fraught and complex example of community notification. In this instance, community notification was apparently initiated through the leak by a Department of Corrections staff member to a journalist. The Department later claimed to have engaged in limited community notification around this case before the media picked up the story, informing select community leaders of the presence of at least some of the offenders living on this property.$^{41}$ Much to the disappointment and vocal frustration of many attendees at

\footnotetext{
${ }^{41}$ All of the community leaders I spoke to in Ōtāhuhu disputed this claim, though some were approached by the Department after the media had picked up the story.
} 
the public meeting, the Department refused to share any information about the new location of the individuals who had been moved out of the boarding house that morning. Demands for more information and transparency around state decision making on placement of offenders were voiced at the meeting. Locals were asking: why their community? Several attendees voiced concerns that echoed the media coverage of the case: that South Auckland, and in this instance Ōtāhuhu, was being used by the state as a 'dumping ground' for those deemed unfit to reside in other New Zealand communities. Rather than a complete intolerance to risk, or even to the presence of sex offenders, the concerns expressed at the public meeting and in interviews centred on exasperation with the actions of the state, and frustration with being shouldered with the risks that other New Zealand communities had apparently rejected as intolerable.

As I observed in both Whanganui and Napier, the leaders of Ōtāhuhu generally demonstrated a high level of understanding and empathy with the experience of individuals released from prison, including sex offenders. This also combined with some frustration over the misunderstandings rampant within the community during the media coverage of this case in particular.

"At the meeting all I could think of was hold on, you're just missing it completely. People can make mistakes, can go to prison, but they will come out. They will live next door to us. They will live in our communities, and you can't say they can't. I think also that people are oblivious that we do have sex offenders living in our communities, and that's life." (Participant 3)

"If we just keep beating them down, there's absolutely zero chance of them making a life for themselves. If you show them some love though - that's what our culture is about - the sad thing is we're either about showing some love or we'll kill you. The same guy lifting his hands in church in the morning can be handcuffed for murder you in the afternoon." (Participant 9)

"Generally you find that people are very ignorant about who is in their community... the public are really not very well informed, and the things that the public get very 
upset about are perhaps the wrong things given the actual risk in their communities." (Participant 11)

\section{Telling Ōtāhuhu's Story}

For some community leaders, the origins of this case go back further than the media story that broke on $8^{\text {th }}$ March 2018. In 2015, at the AGM of the Ōtāhuhu Business Association, industrial property owners from Huia Road complained about a boarding house being run out of a factory which was not fit for residential occupation. This building had no consent to operate as a boarding house, and the neighbouring property owners expressed concern that, zoning and nuisance aside, the factory had not been appropriately remodelled for residential use, and lacked necessary fireproofing, ablutions, and facilities for residential occupation. Following the group's inquiries, a retrospective application for consent was lodged by the high-profile former Member of Parliament and Councillor who owned the property. The neighbouring property owners objected to the granting of a retrospective consent, and also sought legal support. It was during this drawn out process that the group were told that it was "a boarding house for people who are not allowed to live in residential areas" (Participant 1).

In this vein, a 20161 News report (Taylor and Hobbs, 2016, November 30), exposed the under-the-table employment of individuals on Extended Supervision Orders at the house for less than minimum wage, breaching the order's requirements due to lack of supervision and proximity to primary school children. In 2017, Stuff reported on the boarding house operating without consent, quoting the former owner of the factory "Why was the boarding house allowed to operate without consent? Why didn't Council shut it down immediately?" (Fernandes, 2017, October 30). In this article, the manager of resource consents for Auckland Council explains that "The supervised accommodation is for residents who have restrictions placed on [them as to] where they live by government or healthcare providers" (Fernandes, 2017, October 30). In the absence of any state provided provision for them, the owner claimed to be facilitating the accommodation of "mental patients and ex-prisoners" out of a desire to provide the best possible option for these people, while a neighbouring property-owner acknowledged that the owner "may have good intentions, but not in Huia 
Road." (Fernandes, 2017, October 30). For the community leaders I spoke to in 2018 , this person came to symbolise the insider privilege and dishonest conduct that is often associated with the state and their representatives in this community.

By $8^{\text {th }}$ March 2018, when the media were calling around the community looking for comment, one leader explained:

"We got a little bit confused because [the media] says sixteen sex offenders, but the boarding house itself only has ten beds. So I was like, where is the other boarding house? As a group of people who have been objecting to this boarding house, we knew everything... we knew what buildings [the high-profile former-MP and Councillor] owned... we knew which one the consent was concerning... we didn't find out where the other one was until the day of the [community] meeting... it was two doors down... Corrections admitted there were eleven in one house, and there was (sic) more in another house... which also wasn't consented, and was owned by the same person." (Participant 1 )

Once again, the word of Corrections could not be trusted. Not only had the Department knowingly placed high numbers of sex offenders in (at least one) non-consented boarding house, they still appeared to be obstructive as the community attempted to take control of the situation. This was an example of a broader distrust of institutions and the state. While expressing respect for individual members of the organisation, several of the community leaders explained to me that the police in the area are problematic. They explained that there are specific officers that they trust, just as the media was exploitative and could not be trusted, but there are several individual journalists who were loyal to the community and could be relied upon. In the same vein, participants explained that the central government couldn't be relied upon, but we can trust our local MP to do what she can to help our people. Even in the wake of Corrections shifting these offenders, Participant 4 described the cloud of suspicion that still hovered over the Department:

"I think [the action the community took] was effective - it staunched the wound caused by Corrections. Although, there's still quite a lot of suspicion about where they 
have gone, and whether they've just been moved en masse elsewhere." (Participant 4)

On the whole, the leaders I interviewed spoke with deep insight about the causes of the issues affecting their community, and the way that the policies of successive local and central governments had frequently coalesced to disadvantage their community. Some of the older leaders in particular have clear memories of the redundancies resulting from the closures of factories and the freezing works. Many linked the lack of willingness of local governments to invest in infrastructure for their community to the array of related problems they experience: surface flooding during every rainfall due to the rainwater drainage not being fit-for-purpose; rubbish dumping in local parks due to ongoing issues with local rubbish collection; the social issues stemming from a glut of liquor licences dispensed by the Council in the small area; and, of course, the operation of illegal boarding houses stocked by the state itself with ex-prisoners.

\section{Solid State, Liquid Foundations}

The Ōtāhuhu case would indicate that neoliberal restructuring and the emergence of liquid modernity have severely disadvantaged and paralysed some communities - those who have been left behind (Bauman, 2000a). However, throughout my time in Ōtāhuhu, I found that this community is not filled with anxious individuals fractured from one another and clinging to the remnants of a dying, irrelevant value set. As in Whanganui, I found rather the opposite, this community is tightknit, perceptive, and very familiar with the causes and effects of their social problems.

For residents of Ōtāhuhu, the actions of the state in setting risk free during the neoliberal reforms served to destabilise their lives and bring about an era of deprivation and fragmentation. In the face of these ongoing challenges, Ōtāhuhu has established a new grip on a more traditional form of community - it has strong informal social controls, and despite an overlay of transience, the base of the community is tightknit. The community have created their own village. Despite this, the impact of neoliberal restructuring and the liquidisation happening all around them is still felt strongly in this community today, with 
levels of unemployment and deprivation consistently above the national average. Within this context of deprivation, exploitative housing practices have flourished, including the boom in the number of boarding houses in this area.

In Ōtāhuhu, the boarding houses have become symbolic of the ongoing exploitation of local residents by the state, as well as those who would seemingly profit from the misfortune of others. Members of solid-state communities like Ōtāhuhu and Whanganui can be illequipped to keep up with the pace of the liquid modern world, and individuals within them can therefore end up at the mercy of those possessing the modern virtues of mobility and flexible capital. It appears that in Ōtāhuhu, the state is enabling the exploitation of those most vulnerable in society by those more equipped to thrive. For years, this community has been fighting against the Council granting any more consents for boarding houses due to their predatory and exploitative practices, and this fight came to a head when it was revealed that the Department of Corrections had placed sixteen offenders in a boarding house (or houses) that had not received necessary consents for safety and housing adequacy.

Within the context of this case, the desire of the community for transparency can be understood. This community was exposed to risk by the state in this case, and responded with demands for information to enable them to manage their own risks. This included the suggestion from every community leader I interviewed for some level of community notification in future, whether that be full public notification, community specific notification, or targeted notification of community leaders only. The experience of discovering the existence of this risk through sensational national media stories was jarring for local residents, including community leaders who felt unable to shepherd their community through the situation. As two community leaders I interviewed explained:

"The unfortunate thing about finding out like that - if we all found out via 3 News, that means everyone goes into shock, panic, and you're not able to get around the community and say all right, hold up everybody. Because no one actually knows where they are, and that's probably not important, but there was no kind of leader in the community that could say it's okay, l've been aware of it, and here's how we can manage 
our way through this and navigate it. There was none of that, and all of us were caught off guard, and that's what I found unacceptable... [community notification via the media] does nothing for the cultural intelligence that exists in the community as well, we could've dealt with it a whole lot better." (Participant 6)

For the people of this community, the presence of sex offenders presented a dual issue: the moral threat of there being sex offenders in a community with large numbers of children and vulnerable people and the threat of being stepped on once again by an uncaring state. The inability of the community to trust the state, and the Department of Corrections in particular, to have their best interests in mind, was the main driver behind community leaders in Ōtāhuhu calling for more community notification.

Though the media coverage focussed heavily on the risk of sexual harm posed by the 16 individuals placed in Ōtāhuhu, many of the leaders I interviewed, as well as a significant number of people at the public meeting, were primarily concerned with the failure of the state to comply with its own regulations, and to act in good faith for the protection of vulnerable members of the community. The risk of sexual harm to children was raised; however, rather than having a crisis reaction to this threat, many of these community members understood the realities of offending and appreciated that many of these people had been around for a while without incident (cf Ilea, 2018). Some community leaders demonstrated a nuanced understanding of the reality of prisoner release and reintegration. Participant 3 expressed frustration at the lack of understanding within the community about reintegration:

“Some people just don't realise that you can't lock people up and throw away the key. There are people that just aren't going to function in society, and so for society's sake maybe we have to keep them incarcerated forever, but they are very few and far between. I think what people don't realise is that when people go to prison, they have to come out, and so when they come out I would rather a person comes out rehabilitated and not punished. If you come out punished, you will probably be angry, resentful, you won't have skills... you've got to start again. If you start again in a deficit 
model, I imagine that could go pretty poorly for you, hence reoffending." (Participant 3)

Participant 3 went on to connect this frustration to the specific experience of the individuals at the centre of this case - those $\sim 16$ individuals that were shifted as a result of the public outcry.

"I think the disappointing thing for me - and over the whole event I have sadness, I don't have anything else - I realised that there were offenders who had been placed there for a number of years. There was just an influx that caught people's eyes. The offenders that have been there have been working at reintegrating into society, we have had no issues with them, so I'm hoping that the reintegration and rehabilitation has been working. I reckon that's all gone to hell now, and I imagine that there is a lot of resentment from these ex-offenders, probably anger, probably disgust at how they've been treated and vilified. So, I reckon any rehabilitation and anything that was going on will be gone, and that's where I have my sadness." (Participant 3)

The appreciation of the difficult situation ex-prisoners exist in extended to some sophisticated commentary around the role of the state, with many community leaders holding very strong views on how the Department of Corrections failed, and how the process of prisoner release could operate more effectively in future. Such suggestions were generally made against a backdrop of scepticism of the intentions of the state, which has become so renowned in this community for its lack of consideration of their needs.

\section{The Role of the State}

In Ōtāhuhu, the actions of the Department of Corrections in this case did not demonstrate the pursuit of a positive result for the community or for the individuals being released. The Department clearly intended to keep these released individuals apart from the community to the greatest extent possible (while at the same time anticipating that the local community would be too weak to protest their presence should they find out), as evidenced by the zoning of the area of the boarding house, its location near a school so they could not 
move freely, and away from support services and housed with other offenders. When the group was removed a week after the media picked up the story, six of these offenders were temporarily moved onto prison grounds (Department of Corrections, 2018). The placement of six of the offenders on prison grounds following the public outcry frustrated community members, with Participant 4 explaining to me:

"The fact that they managed to get them out so quickly on the morning of the meeting demonstrated the power of Corrections, and the fact that six of them had to be moved onto prison grounds gave people a good idea of how serious the offending must have been. It was a really strong signal that they should never have been here in the first place." (Participant 4)

The result of this series of events has been severe damage to the reputation of the Department of Corrections within this community. Amongst a population where the state is already regarded with suspicion, this incident triggered a severe reaction against Corrections as a symbol of state power. Participant 4 crystallised this sentiment:

\footnotetext{
"The community perception of Corrections is very poor. Very, very poor... the community do think that they have been quite cynically abused in a systemic sense by Corrections behaviour." (Participant 4)
}

The bureaucratisation of the situation by Corrections officials was also offensive to community leaders, who value genuine and direct face to face discussions. As Participant 9 explained:

\footnotetext{
"It was all totally 'this is what's going to happen. We've told you. So if someone comes and asks if the Corrections Department have been here, we have, and you were told.' Even the meeting was tokenistic. It wasn't about care, it wasn't about unity for the community." (Participant 9)
} 
One community leader who had been on the periphery of a number of Corrections notifications expressed frustration with the results that the Department's communications process usually produce:

\begin{abstract}
"With the notification that does happen, the Department of Corrections often have a big kind of comms [sic] programme that they roll out... often that's when information starts to get shared out between parents and neighbours, that's where the worry generally starts to come from, from the people in the community feeling insecure about the safety of their families." (Participant 11)
\end{abstract}

The Accommodation Review commissioned by the Department in the wake of this case discussed the increasingly difficult task of sourcing appropriate housing to enable offenders to reintegrate into the community. Though the Department is not set up as an accommodation provider, it is increasingly required to organise housing in order to facilitate reintegration of a large number of offenders released from prison who do not have an existing appropriate address (Department of Corrections, 2018). The Department does not provide after care hostels or the like itself within the community setting. The review explains the difficulty of this task within the context of a national housing shortage, as well as public hostility to sex offenders and the ever-increasing pressure on the state housing system. The result of this, by the Department's own admission, has been that "a convenient and accessible alternative is accessed through boarding houses and in some instances emergency accommodation in motels" (Department of Corrections, 2018, p. 9). Though motels are no longer used to house child sex offenders (following another high-profile media exposé $)^{42}$, their use is illustrative of the questionable options the Department has resorted to in recent times. One state response to these ongoing and deeply sensitive issues has been to construct facilities such as Te Korowai - an alternative accommodation option for released sex offenders north of Wellington - on the prison grounds but outside the wire, it provides a non-punitive, 'last resort' option for these individuals. This regional facility adds

\footnotetext{
${ }^{42}$ According to the Department of Corrections (2018, p. 10) themselves, the practice of accommodating sex offenders in motels ceased due to public concerns following media reports of a child sex offender residing in the same motel as children and families managed by the Ministry of Social Development (in lieu of social housing).
} 
eleven beds to the stock across four other post-release sex offender facilities set up across the country. In part, at least because of the way in which the media has both reported on and further generated public anxieties about the release of sex offenders from prison, their reintegration is becoming so fraught, that the only option for many of them upon their release is to remain on prison property in another correctional facility.

The lack of government provision of supported accommodation was raised as a failure by Participant 4, who asked:

“Why aren't [the Department of Corrections] running proper rehabilitation centres with therapists on site? Where they can go to work and back. Why would you shove everybody into a terrible boarding house with no social areas and no outdoors, in appalling conditions, and expect them to get better?" (Participant 4)

Participant 9 explained their understanding of who is being prioritised by the government with the reintegration of sex offenders into the community:

"You can't house them in Remuera or Orakei, ${ }^{43}$ so they put them here. It's really sad that that's New Zealand's value of people. It really reflects the government's value of people - 'it only costs this much? Great, just put them in that community there'." (Participant 9)

For Participant 9, the actions of Corrections in this case were typical of a state that does not prioritise their community, and instead prioritises the interests of the elite in the liquified society that has come into existence in the course of restructuring:

"The government is pālagi, and pālagi will do what's good for pālagi. Who lives in Remuera and Mission Bay and that? Pālagi people do. So of course they're not going

\footnotetext{
${ }^{43}$ Both Remuera and Orakei are among the most exclusive and expensive suburbs in Auckland and in New Zealand.
} 
to put them there. When you can, you do - you protect what you know." (Participant 9)

\section{Conclusion}

The decision of the Department of Corrections to place a large number of sex offenders in a boarding house in Ōtāhuhu in 2018 triggered a series of actions that demonstrated the strength of the Ōtāhuhu community in the face of exposure to new risks by the state. Despite the withdrawal of the state from much of public life following neoliberal restructuring, the state periodically performs its 'spectacular rescues' (Pratt and Anderson, 2016) when there has been the perception of intolerable risks, posed by sex offenders especially. The swift removal of these 16 offenders from Ōtāhuhu following the public outcry was one such instance.

At the same time, it is evident that the cost of protecting communities from such risks is that the human rights of those deemed to be risky become secondary to the issue of protecting communities from them, as the movement of many of the offenders who had occupied the boarding house onto prison grounds, even as a temporary measure, illustrates. It would also seem that these levels of public protection from intolerable risk provided by the state are not shared equally. Until it was exposed by the media, the state had been demonstrably willing to expose a seemingly powerless, marginal, but solid state community to a disproportionately high level of risk. It had been prepared to transfer it to those who have the least resources to manage it.

For Ōtāhuhu, responsibility for risk control and management of particularly unwanted members of society has been delegated to them. Charged with this task however, they have still found themselves left with insufficient information to effectively manage the risks dropped in their laps by the state. Demands for notification in this community have grown out of this state-sanctioned exposure to risk, as residents seek to protect themselves and their children not just from the immediate risk of harm from these offenders, but from the duplicity of the state. The solid state nature of the Ōtāhuhu community has enabled its members to demonstrate a collectivity and unity uncharacteristic of liquid modernity. 
Though this community, along with others, has been left behind in the course of restructuring, its inertia has enabled the retention of a cohesive collectivity in contrast with more 'successful', sought after areas where individuals manage their own risks - through living in gated communities, for example. Collectivity and cohesion are what enabled the community to organise in opposition to the threat posed by the offenders, manifested in opposition to the Department of Corrections itself.

The official avenues for formal notification are murky and inconsistent, and the unofficial (and often illegal) means of notification cause problems for communities and individuals on release alike. However, they have also been instrumental in the revelation of government incompetence and poor, possibly dangerous decision making. Notification in the context of this case is representative of the desperation of the community in the face of the operation of the liquid state. Solid state communities are willing to tolerate (and are experienced in tolerating) risks. But they are unwilling to accept the state's additional risk delegation. The state is no longer a source of authority nor support for these kinds of communities - and so notification enables the community to manage their own risk.

This case is demonstrative of the ad hoc and unpredictable nature of sex offender release in New Zealand. The community leaders I interviewed in Ōtāhuhu wanted some form of community notification processes put in place to enable the community to continue to manage its own risk. Many specified that they would never trust Corrections or the Police to manage these risks effectively, or to do the right thing by the community - they could only trust their own representatives to do that now. The community in Ōtāhuhu did not demonstrate atomisation and anxiety in the face of risk. Though the national media sensationalised the story and undoubtedly triggered the anxieties of some members of the public, the conversations I had with community leaders on the ground seemed to show that this was not an example of overwhelming anxiety - it was a strong and very well-networked community fortifying against a common threat and a familiar foe in the state. Ōtāhuhu has a history of uniting as a community against common threats, which often involve the authorities. After the experiences it has endured, it would appear that this community is unwilling to take on more than what they view as their fair share of the risks delegated to them by an unfriendly state. 


\section{Chapter Eight - The Pain of the Thaw: Floating Ice Meets a Warming Ocean}

This research has shown how modern society - modernity - has lost its solidarity and indeed is rapidly dissolving and becoming liquified - as indicated, of course, by Bauman. The three qualitative case studies within this project have shown the contours of the spectrum of liquid modernity, and have provided detail on the lived experience of modern life in a fracturing, melting world. What has been revealed is the uncomfortable and sometimes painful reality of the transition away from solidity, certainty, stability, and cohesion for the respective communities: whether they are melting to liquid or being smashed into loose fragments of a previously united whole. Society moves one way along the spectrum as the conditions for solidity melt away and prevent new solid forms from being created. Individuals left behind in the thaw will be consumed by existential insecurity, while those willing and able to keep moving with the current and remain untethered will thrive (so long as they keep moving). As Bauman (2004, p. 116) described,

\footnotetext{
“at no other time has Robert Louis Stevenson's memorable verdict that 'to travel hopefully is better than to arrive' sounded truer than it does in our liquidised and fluid modern world."
}

Communities are fracturing and melting, and they "can no longer (and are not expected to) keep their shape for long, because they decompose and melt faster than the time it takes to cast them, and once they are cast for them to set" (Bauman, 2007, p. 1). Life in a liquid world means relentless pursuit: to stop moving is to sink into the depths of insecurity and anxiety. Those who are immobilised, paralysed by solidity on a personal or a community level, are unable to harness the opportunities of liquid modernity, and instead suffer its most negative consequences. On the other hand, those who continue to move with the tides of opportunity and travel lightly are those most likely to reap the rewards that are available in a liquified society. 
At one end of the 'spectrum' now spanning the possibilities of what constitutes modern society is what we might call 'solid modernity': where once there was solid ice as far as the eye could see, today this end of the shifting spectrum can be characterised as icebergs floating in a warming ocean. Emile Durkheim (as quoted in Giddens, 1972, p. 94) characterised the ethos of solid modernity, explaining that "actions which have a lasting quality are worthy of our volition, only pleasures which endure are worthy of our desires". Long-term planning and strategic action for the collective good of society fit into Durkheim's account of solid modernity. Similarly, the traditional notion of community described in Bauman's Liquid Modernity certainly sits at this solid end of the spectrum by its nature. Bauman (2000a, p. 182) explained the balance of traditional community life in solid modernity: "in the long and inconclusive search for the right balance between freedom and security, communitarianism stood fast on the side of the latter". Traditional community provided security, predictability, and collectivity for its members. This form of community remains in some places, however. Two of the case studies within this New Zealand based research, Whanganui and Ōtāhuhu, sit at the solid end of the modernity spectrum, and they retain remnants of solidity today, however it is a matter of time before these melt away, or become ever smaller, sinking, fragments.

Solid-state communities are relatively traditional in their retention of predictable structures and the measures of certainty derived from the retention of historic homogeneity of class, experience, and history. These communities, including Whanganui and Ōtāhuhu, have typically been hollowed out by the state through decades of deindustrialisation, divestment, chronic underfunding, withdrawal of services, and neglect. Within this research, leaders in communities characterised as solid-state were generally politically astute, extremely wellconnected with their constituency, and strategic in their resistance against the state and its representatives. ${ }^{44}$ Although resistance against the hallmarks of liquid modernity may be futile in the long term, leaders in solid-state communities are willing and able to mobilise their communities against what they perceive to be significant threats to their members.

\footnotetext{
${ }^{44}$ Obviously there were exceptions to this, as aforementioned in Chapter Four, where outliers expressed wildly different views around individual responsibility (including detailing surgical castration recommendations for sex offenders etc).
} 
As the certainty previously provided by the central government has been whittled away and safety nets of the past have become threadbare, solid-state communities have turned inward in defence against the barrage of attacks on their solidarity launched by the state. Trust is reserved for insiders: these interconnected communities were repeatedly described by participants as both 'tightknit' and 'insular'. In New Zealand, solid-state communities have been those worst affected by the neoliberal transformation of the 1980s onwards: those previously reliant on industry gutted by deindustrialisation; those that have not become urban hubs for entrepreneurialism and lifestyles; those now commissioned by the state as catchments for people deemed to be excess and undesirable. Beyond the case studies of Whanganui and Ōtāhuhu, many towns and cities in New Zealand would meet the criteria for this end of the modernity spectrum: from Whangarei, Huntly, Tokoroa, Kawerau, Wairoa, Hastings, Woodville, down to Greymouth, Gore, and Invercargill - these solid-state communities cling to a way of life built on foundations that have been smashed apart. Those individuals that have the means or opportunity to do so leave these shrinking icebergs, and the community left behind are offered none of the opportunities or rewards of liquid life despite the heavy price they have paid for the globalisation and free market economics necessary to sustain modernity in its liquified form.

Undermined by the state, and systemically disadvantaged by political and economic reforms going back to neoliberalism, solid-state communities are often unwilling to capitulate to the state that has caused them so much suffering. This is perhaps most strongly embodied in the resistance of solid-state communities to the allocation of released sex offenders to their area: these communities are unwilling to accept the state's decision to release into their midst dangerous offenders who are no longer welcome in their own communities. On the modernity spectrum, this research has found that those considered the most solid-state communities have experienced the strongest reactions to the notification of risks in their vicinity.

In an already uncertain world, communities retaining solid form do not welcome the introduction of new and unpredictable risks, no less those allocated to them by the state without consultation or warning. Bauman (2000a, p. 184) detailed that the community itself is one of the "last defensive outposts on the increasingly deserted battlefield on which the 
war for certainty, security and safety is waged daily with little, if any, respite". The other defensive outpost specified by Bauman is the body. The coalescence of the body and the community as battlegrounds for certainty produce a unique fear and consciousness of threats to the fabric of both the community and the body: epitomised by the stranger who sexually offends. Therefore, the processes of notification and sex offender release have a particular salience within the consideration of the risk society and liquid modernity.

In this vein, the introduction by the state of sex offenders to the communities of Ōtāhuhu and Whanganui held more significance than the sum of their parts. On a base level, the offenders themselves represent a dual threat to both community and bodily safety: attacks on what Bauman described as those last two bastions of certainty. For Whanganui and Ōtāhuhu however, the decisions around the placement of these individuals also embodied yet another state action perceived to disadvantage and threaten these communities already struggling with the compounding negative consequences of four decades of uninvited and (for them) detrimental reform. Foremost amongst these perspectives in state action is the lack of trust within solid-state communities of the central government and its representatives and institutions.

The actions of the Department of Corrections (as an institutional embodiment of the state) in both Ōtāhuhu and Whanganui elicited fierce resistance from these solid-state communities that were unwilling to shoulder the burden of this relocation of risk reallocated to their area from other parts of the country. Although individual leaders played important roles in co-ordinating resistance in Whanganui and Ōtāhuhu, this co-ordination relied on existing interconnectedness within the community, as well as political awareness and general willingness of the community to resist the state. For these communities, the state and its various institutions are viewed as unworthy of trust, and as ultimately selfinterested. The severity of the situation in Ōtāhuhu is a particularly disturbing illustration.

In Ōtāhuhu, the righteous anger of community members and their leaders was in response to a range of features of the decision of the Department of Corrections to place 16 high risk sex offenders into two boarding houses in their community. Frustration over the inhumane living conditions within the unconsented boarding houses the 16 individuals were released 
to; the seriousness of the risk of reoffending posed by the offenders; the density of their placement across two neighbouring boarding houses; and the lack of community support afforded to them were among the more serious concerns the community raised to their leaders, to the media, and at the community meeting on the issue. Regardless of the light in which this series of circumstances is examined, the actions of the Department of Corrections in Ōtāhuhu were demonstrably an egregious error on the part of the state. There is acknowledgement of this error in the report produced by the Department on accommodation issues for sex offenders in the wake of this case (Department of Corrections, 2018). For the local community, who were informed of the presence of these 16 individuals through a leak to the national news media, this scenario represented yet another exploitative and cruel act by the state, perpetrated against some of the most vulnerable members of society. In particular, the use of non-consented boarding houses which were unfit for human inhabitants demonstrated to the community the lack of any meaningful regard for rehabilitation, reintegration, or quality of life for the individuals concerned, or for the community. Succumbing to pressure from the community and the media within days, the Department of Corrections moved all of the offenders out of the boarding houses within one week of the information being leaked to the media.

In Whanganui, attempts by leaders within the Department of Corrections to 'front-foot' the media and community reaction to the release of Stewart Murray Wilson - the 'Beast of Blenheim' into this community backfired spectacularly. Again, without a basis of trust for the state as a benevolent power working in the interests of all in the community, the announcement by the Department of Corrections that this prominent sex offender was to be released into this community was met with frustration and outrage. Although certain individuals clearly took the opportunity to stoke the fires of anger within the community, the embers were already bright with fury and frustration over the decades of mistreatment the locals had experienced at the mercy of the state. Unwilling to accept responsibility for the riskiest member of a faraway town, the Department of Corrections eventually yielded to the demands of the community proper. Although Wilson was still placed in Whanganui, he was "released" to a house moved onto the grounds of Whanganui Prison in an extraordinary and ultra vires act by the state. Despite the completion of his finite sentence, Wilson has never been released back into the community. 
Solid-state communities are those most likely to offer a significant and co-ordinated response to the discovery of this kind of risk. Although the participants I spoke with from solid-state communities did not accept the placement of the sex offenders in these case studies, this was not necessarily due to the surface level appearance of risk of sexual harm to women and children (as the media reported relatively simplistically). The consciousness of the threat of sexual harm to members of the community was certainly elevated in Whanganui, where detailed explanations of Wilson's long history of serious sexual offending were published daily in the local paper. The nature of sexual violence as a threat to body and mind, as well as community, instil in people a particular kind of fear. In this case, the media certainly perpetuated these fears with lurid and detailed accounts of Wilson's offending published alongside descriptions and accounts of how fearful members of the community were at the time. Bauman (2007, p. 55) explained that "fear of suffering [is] the most vexacious and arguably the most aggravating specimen of suffering". Nevertheless, apart from the media-driven focus on sexual harm with Wilson in particular, the complexity of the justifications for their rejection of the placement of sex offenders in Whanganui and Ōtāhuhu was a surprise to me. Although risk of sexual harm was a factor among many others discussed by participants, the reactions of Whanganui and Ōtāhuhu, more than anything else, represent a reaction against the central state.

\section{The Changing Face of Community Life}

The value placed on lightness and mobility in modern society manifests in many ways. In a society where the long-term is no longer considered, and the 'community' of old does not have time to form, the gap between the 'haves' and the 'have nots' grows ever wider. Within the context of the spectrum of modernity that neoliberal restructuring has created, the 'haves' are typically good swimmers who are able to move with the currents of liquid life; and the 'have nots' are the poor, frightened swimmers clinging to the fragments of solid ice, unwilling or unable to take the plunge into the uncertainties of risk society. During the historic period when the social arrangements of modernity were much more solid, local communities were relatively fixed, and the ecosystem of actors dependent on and interconnected with each other was knowable and limited. Within such communities in New 
Zealand, this meant that the children of judges and doctors sat alongside the children of truck drivers and checkout operators in classrooms and sports teams, and elected officials worshipped alongside the unemployed at local churches, reflecting the relative homogeneity of class and experience. Today, the more liquidised the community, the more stark the remnants of solidity become. Ōtāhuhu provides an excellent example of this, with the high fences of King's College at its heart - New Zealand's most exclusive private school separating the children of the wealthy from those of the community's low decile local state schools.

The shift to liquid modernity has fuelled what Bauman (2007, p. 78) has called "the secession of the new elite". The opportunity for wealth and lifestyles created through the neoliberal reforms and the associated unmooring of the state and the individual from previous commitments to the long-term and to the collective good have produced a significant disconnect between the swimmers and the sinkers in society. State services have decayed as a result of chronic underfunding, and the market response within neoliberal New Zealand has been the development and growth of parallel private systems - exclusive to those who can pay. This has driven those with the means to do so to opt into private education for their children, and private healthcare for their families. Without the hitherto long-term, inbuilt nature of community connection across all levels of society, the elites created within the liquid modern social arrangements possess a "lofty indifference" to local issues (Bauman, 2007, p. 78). They are able to detach their cursory connections and move on at a moment's notice, and are not subjected to any of the engagement with the local populace one would have expected in the past. Bauman $(2007$, p. 79$)$ explains that

\footnotetext{
"the resulting spiritual/communication gap between the living/lived spaces of those who have seceded and those who have been left behind are arguably the most seminal of the social, cultural, and political departures associated with the passage from the 'solid' to the 'liquid' stage of modernity."
}

The liquidised communities populated by 'gold medal' swimmers, these newly minted 'elites', enable massive wealth inequality and fuel the decay of public services. 
Underinvestment in public services has had devastating effects on New Zealand's healthcare and education systems in particular. While these areas have been subjected to the creep of the user pays model and the structures of New Public Management, there are areas of government that have retained their inflated budgets - including the Department of Corrections. Retention of capability within the Corrections portfolio is essential to the modern state and its execution of spectacular rescues to prove that it is still on the side of the people, and to be seen to be ready to go to any lengths to protect them from the gravest risks they face. Now as modern society becomes more liquified, the state has taken previously restricted and impossible actions to contain and remove risks from the community. In New Zealand this has included the introduction of indefinite sentences (preventive detention dispensed at sentencing, civil detention assigned upon the expiry of a finite sentence), registration legislation, notification policies, and ultra vires actions like those taken by the Department of Corrections in the case of Stewart Murray Wilson. All of these measures contradict the previous limits on law in this country, which are perhaps now relics of solid modernity, including the principles of natural justice, and the Bill of Rights Act 1990, easily dismissed as 'red tape', an 'affront to common sense', or simply 'the price government pays' to ensure it is living up to its responsibilities to protect citizens from the gravest risks. However, although a driving force behind spectacular rescues that are then made in providing this protection, is confirmation that the state is in control, and the shoring up of public faith in the power of the state to manage risks when needed, the actions listed above do not seem to have produced this. In Whanganui and Ōtāhuhu, these initiatives appear to have in fact had the opposite effect, with trust in the state diminished as the community watches on as the state appears to be reactive and floundering when it comes to these kinds of offenders, as was evident in the bespoke solutions produced by the Department of Corrections following national media attention on each of these cases.

Despite longstanding limits built into criminal law and policy, these extraordinary legal and policy actions have been allowed, indicative of the way in which, in Liquid Modernity, concepts of justice and rights are themselves dissolving and taking new, transient forms. 'Public protection' temporarily brings these elements together, creating new forms of protections which have inverted the previous understandings of individual rights: rather than protecting individuals from excessive powers of the state, the state now acts in the 
interests of the nebulous concept of 'public safety' - often compromising individual rights to meet this end.

For the capable swimmers among us who remain mobile and light, any push or pull factor could change the current and move them on. However, the immobilisation of bodily harm (particularly the psychological and physical trauma of sexual harm) is an equalising force. By removing or relocating threats posed by certain members of society from liquidised communities, these swimmers can continue on, unobstructed. Through spectacular rescues, the shrunken state protects the flow of liquid life at the expense of those at the solid end of the spectrum, where it relocates the threat.

\section{Liquidising Communities}

Opposite solid modernity on the spectrum is liquid modernity. Here, the balance of security and freedom tips the other way, and individual freedoms trump all else. Successful elites maintain only superficial local connections, with the ability to follow the currents of opportunity at a moment's notice, wherever they may lead. Disconnected from state action at the central government level, those thriving within liquid modernity will see little connection between their lives and the actions of the central state, or indeed any authority. Should any specific state action become inconvenient or irksome, travelling on to a more comfortable locale is an option - wherever in the world that may be. Close knit communities and institutional solidarity which once provided protection and predictability to members on the inside melts away in favour of individual mobility and opportunity. The tides of liquid modernity are characterised by constantly changing circumstances, and the process of liquidisation was described by Bauman $(2007$, p. 3) as "vexingly volatile".

Liquidisation shifts communities along the spectrum of modernity and into much more fluid social arrangements. Based on the experiences of the case study communities in this research, the experience of liquidisation can vary significantly. While some communities appear to melt away relatively smoothly into their new liquid reality, another more traumatic experience of fragmentation of solid parts is evident in this research. Napier appears to have significantly benefitted over time from liquidisation and the neoliberal 
reformation and global community that has brought opportunity and capital to its shores. The social problems and Baumanesque 'waste' have been pushed out and evicted from the immaculately presented city. Reliant on being pretty and quaint for the tourism that fuels the local service economy, a series of local ordinances and public campaigns have sought to evict from the city streets those considered to spoil this façade, including beggars and the homeless. Elements of Napier have flourished with liquidisation, and those that have not moved with the tides have been pushed further and further out from the centre.

Image 14 Anti-begging Notice, Napier

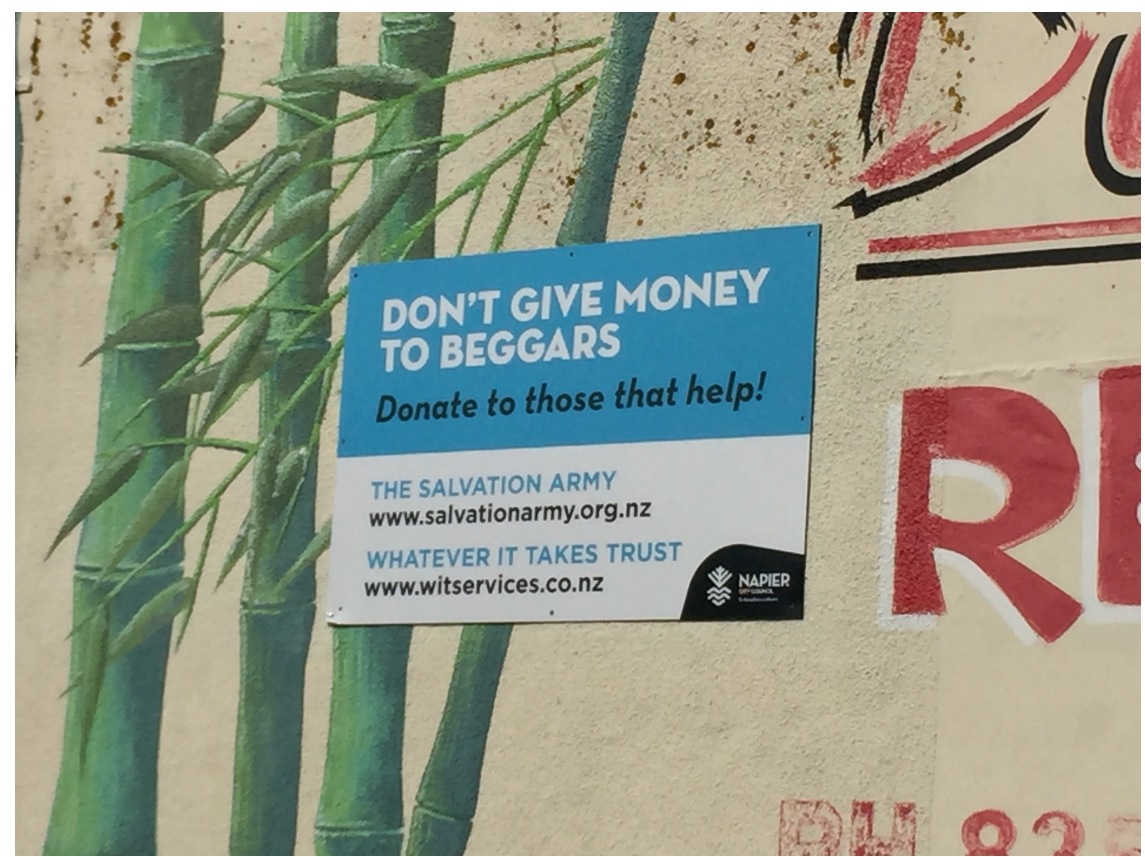

The powerful art deco branding of Napier extends to its attempts at crime prevention through environmental design (2021) 


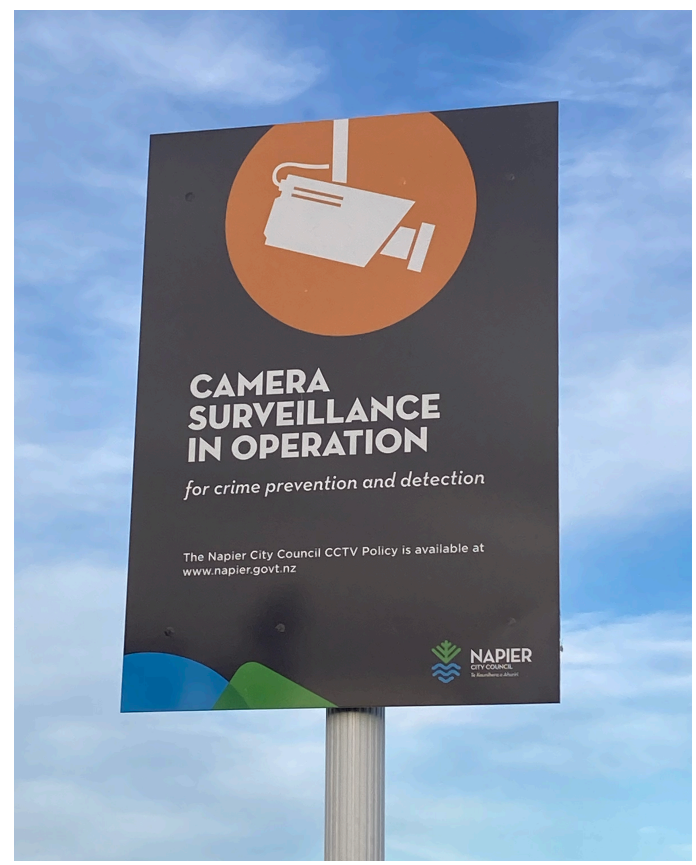

As in Image 14, the art deco branding extends to the notification of CCTV surveillance at Pandora Pond, Napier (2021)

Whanganui, on the other hand, has been decimated by the same reforms that have breathed life into the Napier economy. Deindustrialisation, unemployment, and withdrawal of government departments from Whanganui were described by Participant 13 as causing "a sense of depression and dismalness" in the town that has endured for more than 30 years. Whanganui as a community has reaped none of the rewards of liquid life, and has paid a hefty price for the benefits of the transformation seen by other communities.

A painful transition away from solidity can be observed in Ōtāhuhu, traditionally a receptacle of the 'waste' (in Baumanesque terms) of the urban metropolis of Auckland immigrants, refugees, released prisoners. Ōtāhuhu is in the process of being melted down and forced along the modernity spectrum into a much more liquified form. During my time there, community leaders expressed concern about the cost of living, about transience and community members living in cars and boarding houses. Since this time, the cost of living has continued to rise significantly, as have the house prices throughout the Auckland region. The result of the ever-rising housing prices and cost of living has been the creep of gentrification further and further south. Historically stereotyped as a dangerous place, fit for the human waste of the urban metropolis, South Auckland is now seen in a more favourable 
light as the Auckland property market reaches dizzying heights. The housing values in South Auckland are higher than ever before and are continuing to rise, causing developers to flock to the location for the demolition of state houses and construction of townhouses and apartments. Formerly state-owned lots have been sold off to private developers and redeveloped as enclaves like 'Ōtāhuhu Heights' - brand new townhouses designed to lure Auckland's young professionals south. As the median house price in Ōtāhuhu edges toward $\$ 1$ million, the existing members of this community are forced out and the poor swimmers or those who have never even dipped their toes in such turbulent waters will be pushed further out and away as the city limits shift with the flow of modern life, and the very nature of the city itself melts into a new form.

\section{Cities and Strangers}

Where cities were traditionally constructed to protect inhabitants against external threats, Bauman (2007, p 72) argues that "our cities are swiftly turning from shelters against danger into danger's principle source". Strangers in the city represent the unknown, potential threat to both body and community. For suburbs like Ōtāhuhu, the presence of strangers is an inevitable element of community life. As a settling place for new migrants, for refugees, and for reintegrating individuals released from prison, this community is constantly populated by strangers. Similarly, the low socio-economic status of the population of this area lends itself to transience. Ōtāhuhu currently represents one of the 'ghetto-like districts' Bauman referred to in Liquid Times:

\footnotetext{
"Residents without means, and for that reason viewed by the rest of the residents as potential threats to their safety, tend to be forced away from the more benign and agreeable parts of the city and crowded into separate, ghetto-like districts." (Bauman, 2007, p. 73)
}

Yet, the tolerance for risk, and the understanding within this relatively solid community of the contours of risk, is significant. While participants in Ōtāhuhu expressed willingness to take responsibility for reintegration of their own offenders, it was the intense concentration of individuals who had been shipped in from elsewhere in the country and unceremoniously 
'dumped' in their community (and into unfit housing) that triggered a severe reaction. In this instance, despite unusual levels of openness to assisting with offender reintegration, the actions of the state under the circumstances of this case study were so extreme that a significant reaction was elicited from this community. When faced with the dilemma of requiring housing for 16 high risk sex offenders, again the state glossed over and purposely ignored these "more benign and agreeable parts of the city" inhabited by liquid society's swimmers (Bauman, 2003, p. 73). These individuals ejected from their previous communities - the waste of another community - were discarded unceremoniously in substandard and illegal accommodation in Ōtāhuhu. The central government has treated this community as (in the words of many of my participants there, as well as the media reporting on this event) a 'dumping ground' for those individuals deemed unfit or unsafe for other New Zealand communities.

Amongst the "waste' are those who constitute the new "dangerous classes": an unassimilable group unfit for reintegration or rehabilitation (Bauman, 2007, p. 69). This group is subject to one of the few instances of permanence in what has become an impermanent world: exclusion from urban society. Those subject to indefinite prison sentences in New Zealand are amongst these new dangerous classes, rejected from society by a state intolerant of the risks they pose. Below this most severe example of the 'dangerous classes' are a group of offenders who are being released into communities to be managed there, beyond the prison wire, but still considered risky.

In addition to the administrative and actuarial elements of risk raised by Feeley and Simon (1992), which have certainly been borne out in the NZ context, the end of rehabilitation in New Zealand has been a concerning trend: policy and legislation would indicate greater concern today about the management and removal of risks than any genuine investment in or dedication to rehabilitation or reintegration. The New Zealand state has set the possibility of rehabilitation, reintegration, and concern with the offender and their social context aside, and shifted all concern to the distribution of risk exposure. This process of administrative risk management has reduced state culpability and responsibility, because the simple imperative now is to 'manage' these individuals, not rehabilitate or reintegrate them. This shift takes attention and pressure off of the correctional system, lowering the 
expectations on its performance. For those who are released into the community (into areas deemed expendable), again management becomes the priority, and this can be outsourced to private enterprise - further diluting the accountability held by the state for these individuals.

\section{Liquid Lives and Risk Management}

There is a much more explicit acceptance at the liquified end of the modernity spectrum of the delegation of the role of personal security and risk management to the individual. While community leaders did not necessarily welcome the presence of the particular individual who was the subject of this case study in Napier, there was a deeper context of acceptance of risk and individual responsibility that was not present amongst the community leaders of Whanganui and Ōtāhuhu. These participants in more solid-state communities were certainly aware of the delegation of risk that was occurring in the transaction between themselves and the central government (represented by the Department of Corrections in these instances), however their historic experiences of state abandonment meant they were simply unwilling to accept this delegation.

Having broadly benefitted from neoliberal reformation and the consequences of globalisation, leaders of the Napier community do not possess the scathing analysis of state power and its reach held by many solid-state community leaders. Napier is certainly not an ideal model of liquidity; larger New Zealand cities Wellington and Auckland would be located much further along the spectrum towards liquidity, and cities like London and New York much further still. Nevertheless, participants in Napier spoke of some of the hallmarks of the liquidised community: concern for self-interest, self-help, and self-care trumping all else. There exists in this community an acceptance of the delegation of risks by the state to individuals, and an indignation for any individual reckless enough to not take personal responsibility for risk management seriously. The community in Napier also took little specific notice of the media notification of the release of a high risk child sex offender being released in their area. 
In Napier, the general commentary from participants regarding the responsibility of parents to manage risks to themselves and their children, the continuous need for caution, and the uncertainty expressed about strangers, reflected a significant departure from the conception and acceptance of risk observed in solid-state communities. Although individuals within the Napier community, and indeed individual community leaders, may have had misgivings or concerns when reading about the placement of a high-risk child sex offender into their community, there was no collectivised resistance to the act. The people of Napier do not possess the levels of interconnectedness observed in solid-state communities, nor the tendency to mobilise effectively against the state. When 'community issues' have been raised, this has occurred in the form of amorphous and individualised concerns rather than a concerted or effective mobilisation of the community. For example, following a spate of gang-related violence in Napier in 2021, elected community leaders fronted the media asking the central government for more police on the city's streets (Kitchin, 2021, March 29). This request did not demonstrably reflect the wishes of the community, which in itself would be very hard to gauge given the level of atomisation in the area, and the lack of democratic process around the issue. Rather, the calls for action in this situation read more accurately as an attempt by elected officials to be seen to be taking action - the central government responded by declining the Mayor's request for more police on the streets.

\section{The End of Big Government and Safety Nets}

The state's renunciation of its previously monopolistic role as guarantor of certainty and security has had perhaps the most profound effect on the politics of the body and of the community (Bauman, 2000a). Liquidisation has meant the collapse of the foundation of long-term planning by the state. The decline of the welfare state and the withdrawal of the state from forward-thinking long-term planning for the collective good have transformed the nature of the interaction between citizen and state, and have had a profound impact on the lives of citizens. Long-term thinking, planning and acting have been superseded by fractured and disjointed reactive responses to issues which centre whatever action will generate the most political capital in that moment. Under these conditions, within liquid society "solidarity has little chance of sprouting and striking roots. Relationships are conspicuous mostly by their frailty and superficiality" (Bauman, 2004, p. 129). Indeed, the 
dissolution of collectivity and solidarity are necessary for liquidity, as such loyalties and responsibilities inhibit the ability of the individual to move with the currents, to travel lightly and unencumbered.

Alongside the state's shift away from strategic and evidence-based long-term planning, the limitations on any individual state's ability to effectively respond to the global issues that plague society must be considered. With globalisation, much of the ability and power of modern states to take effective action on issues has moved into the politically uncontrollable global space, while the reach of political action has remained local. The result of the limits of this reach can be observed throughout the case studies in this research. As local issues become the only ones that communities feel able to do anything about, they attempt to act on complex global issues in a local context (e.g. fighting climate change through individuals recycling and composting).

In all three case studies in this research, frustration with local issues and the actions (or inaction) of local and central government were raised. In Ōtāhuhu, concerns were raised over rubbish and road safety; in Whanganui there were repeated concerns over the centralisation of services (and the associated departure of offices of government departments from the city). It was in Napier, however, that the depth of frustration with local government was most significant: issues with drinking water, waste and storm water infrastructure, local council spending, and pollution were tabled by the majority of participants.

The level of investment in the actions of the central government waned with the position of each case study community on the modernity spectrum, with extreme solidity and extreme liquidity at opposite ends. In Whanganui there was a consistent sense among participants that the central government knew and cared little for their lives and experiences. The significant frustration and anger with the state's decision to place Wilson - the 'Beast of Blenheim' - in their community exemplifies this perception of state indifference. In Ōtāhuhu, trust for institutions associated with the central government was lacking, and participants almost universally expressed a lack of trust in the state's ability to manage risk and make decisions that consider and prioritise their community's interests. Participants in 
Napier however conveyed feeling relatively unaffected by central government actions (including their placement of a released sex offender in the local community). The sense gained from participants in these communities of the spectrum of responses to state institutions gives some detail to Bauman's $(2007$, p. 2$)$ idea that

\footnotetext{
"the extant political institutions, their initiatives and undertakings, are less and less relevant to the life problems of the nation-state's citizens and for that reason they draw less and less of their attention."
}

As communities and individuals fracture, melt, and shift along the spectrum toward liquidity, their distance from the functions and decisions of the central state increase, and eventually individuals see little relevance to their lives reflected in the institutions that comprise their experience of the state. This distance is magnified by the reality that many functions performed by the state in the past have been surrendered to the market, picked up by private enterprise, or taken on by individuals. For some solid state communities in New Zealand, such as Greymouth, deregulation has literally caused disaster - as was tragically evident in the Pike River Mine disaster which killed 29 men in 2011. For those with the financial means, almost all of the practical functions of local government can be provided by private enterprise.

In the more solid-state communities in this study, Whanganui and Ōtāhuhu, one response to this frustration with the central state has been the recalibration of how they conceptualise 'the state' and its institutions. Participants in both communities consistently explained how their trust extends to the individuals they know: certain police officers, specific elected officials; however these same participants retained significant distrust for the institutions themselves and the state they represent. The same sentiment was expressed in these two communities about "the media" - specific journalists were named as being trusted by the community, however general disdain for "the media" was consistently expressed. Solid-state communities, suspicious of the motivations of institutions and of the state, trust only their own. 


\section{Community Notification on the Spectrum}

Despite my knowledge of the academic literature on the ineffectual nature of sex offender registration and community notification as post-sentence regulatory measures to govern the movement of sex offenders, I was unexpectedly drawn into the justifications for notification that were posed by community leaders in Ōtāhuhu and Whanganui: that they could not trust the state to manage the risk, and therefore needed information to proactively manage it themselves. In these communities, historically battered by the state and the circumstances that neoliberal reforms have created over time, the level of trust the community holds for the state is so low that they simply do not trust state institutions to manage risks (including the risk of sexual offending by individuals on release in the community). Rather than setting up a public notification system to dispense information generally, in Ōtāhuhu community leaders were interested in a system of limited notification of community leaders to ensure that the Department of Corrections were held accountable. Similarly, in Whanganui, there was an appreciation of the dangers of public notification (given the frenzy triggered by the Department of Corrections announcement about Wilson), however the sense of injustice felt by the community that the state should choose to place one of New Zealand's most notorious sex offenders in their city - a place to which he had no previous connection - left the community wary of future actions by the Department of Corrections. Participants saw potential in community notification to offer them a sense of control around other risks the state might send their way.

On the other hand, in Napier there was very little demand for public or limited community notification. Even when the community are notified of the release of a high-risk child sex offender, as they were through the local newspapers and online media outlets in this case study, the reaction is not lasting nor collective. A clear illustration of this was the number of participants in Napier who knew of the case of the specific individual I was focussing this case study on - two out of eleven. The lack of interest in community notification is demonstrative of a lack of active disdain for and distrust of the central state. Rather than conveying an implicit trust in the ability of the state to manage risk, it reflects a profound disconnection from the operations of the state, and the extent of the responsibility taken on by the individual for their own personal risk management. 
This thesis has shown how local communities differentially experience de facto community notification in New Zealand. Within their reactions, we have seen a microcosm of the relationship between the people and the state: risks have been unevenly dispersed by the state around New Zealand communities, and therefore communities have demonstrated differential responses to them. The responses of these three communities (Whanganui, Napier, and Ōtāhuhu) to the risks the state has exposed them to have reflected their position on the spectrum of modernity: the spectrum of development from what I have called 'solid modernity', through to the Baumanesque Liquid Modernity.

This research has confirmed that the experience and consequences of notification are shaped in large part by the position of communities on this spectrum, which has been found here to have a determinative influence on the level of trust the community holds for the central state. The state's use of notification in 'liquid' - and therefore high-trust communities is broadly met with disinterest; whereas in 'solid' - and therefore low-trust communities, is poorly targeted and managed, and is perceived by these communities to be unclear and ad hoc. Community notification therefore has often had the opposite effect within the community to what the state has perhaps intended - that is, giving signs of reassurance that it was still in control of events, still a reliable source of protection from the gravest risks and so on.

\section{Spectacular Rescues: Spectacular Failure}

Instead, its 'spectacular rescues' have had the opposite effect in practice to what the state has intended. As has been argued here, these extraordinary actions are designed to assure the public that the state remains in control, and it retains the power to take decisive action when required. The way such actions have been received by communities however, is the reverse of this. In liquid/ising - therefore higher trust - communities (e.g. Napier), little attention is paid to the central state, and such actions are not viewed as personal to individuals within the community, nor consequential for them. The profound individualisation and delegation of risk accepted by these communities has resulted in the 
successful maximisation of individual responsibility: as Participant 25 in Napier explained, for example, "you don't let your six-year-old walk to the dairy alone". While this reality certainly produces anxieties, these are not quelled by spectacular rescues. Meanwhile, in Whanganui and Ōtāhuhu (communities at the solid end of the spectrum of modernity), when the Department of Corrections took extraordinary action to remove risk from these communities by removing offenders altogether, this served to draw further attention to their earlier willingness to expose the community to this level of risk in the first place.

Spectacular rescues like those seen in Whanganui and Ōtāhuhu are jarring for these solid communities, and in practice generate further distrust of the state amongst the affected public. Where communities feel they should be able to trust that the state can manage the risks they are placing into the community, these incidents confirm for communities and their leaders that they must remain constantly vigilant of the state, which continues to import external risks into their already vulnerable communities. These communities that have retained or created solidity in the face of liquidisation have typically fared worst through the restructuring and deindustrialisation on which liquidity is premised. For these communities, the state has then perpetuated a problematic cycle through divestment and underinvestment, followed by placement of risky sex offenders in these communities ostensibly due to rental affordability (affordability resulting from the lack of investment and opportunity in these locations) - and so the cycle continues. Although the Department of Corrections is normally simply charged with approving accommodation suitability for individuals being released, in both Whanganui and Ōtāhuhu, they directly facilitated the accommodation of these released individuals: an example of an informed decision by Corrections to place high-risk offenders in communities least equipped to manage these risks.

\section{De Facto Community Notification - Ad Hoc and Unhelpful}

The de facto operation of community notification in New Zealand, by the Department of Correction in particular, is inappropriate and unfit for purpose. The ad hoc and discretionary nature of notification, combined with sensational media coverage and existing layers of distrust of the state within 'solid' communities has led to very high tensions in these areas 
when it does happen. The lack of community education around what is expected of people (community leaders in particular) when such notifications are carried out, as one of the school principals interviewed for this research lamented, "doesn't seem right" (School Principal 1).

\section{Liquidisation and Waste}

Liquidisation has dissolved economic regulations and has set risk free from its previous restraints. This has meant that much of the social cohesion and collectivity that was built on these previously dependable foundations have also been dissolved. The spectrum of modernity has currents moving relentlessly toward liquidity, and, as urban areas become increasingly liquid, what Bauman (2004) described as 'waste' is forced elsewhere. In Napier for example, a liquidising city that has largely reaped the benefits of restructuring from the 1980s onwards, a dark underbelly of homelessness, deprivation, and issues with antisocial behaviour has grown. Behind the picturesque façade presented to tourists, Napier has the highest social housing waitlist per capita in the country (Kitchin, 2021, March 23), and the highest levels of fear of crime in the country (Fuller, 2021, June 17). For Napier, which is largely embracing liquidity with open arms, the waste problems are currently bearing out.

Ōtāhuhu was historically a haven for groups considered as such: immigrants, refugees, the working poor etc. The community of Ōtāhuhu has reinvented itself throughout history and, on the cusp of burgeoning central Auckland, with developments like 'Ōtāhuhu Heights' already in place, it is a matter of time before this area is reinvented once again through gentrification. The solidity that the people of the Ōtāhuhu community have generated for themselves is powerful, but temporary. Those unable to adapt to the coming tide will, as Participant 3 noted, be "forced further and further south" out of the city, toward floating remnants of solidity elsewhere. Meanwhile, in Whanganui, the extremes of wealth are not seen on the same scale in the city, and there as the most solid community examined in this study, it experiences the most even spread of wealth (albeit lesser wealth than more liquid areas). 


\section{Big Wins and Big Losses}

Liquid life is the good life for certain groups within society - in New Zealand, namely the upper echelons of $P \bar{a} k e h \bar{a}$, and primarily men. As has been briefly touched upon throughout this thesis, the 'solid' modernity of New Zealand was built on a foundation of colonial violence. As elements of this society move along the modernity spectrum, liquidity runs along pre-existing lines of division, deepening them for those remaining solid, and leaving those who have become liquid unaffected. For example, the liquid life is not pursued by indigenous groups fighting for the return of stolen land; nor women seeking to raise children within a safe community. The far end of the spectrum of modernity - liquidity essentially represents peak capitalism - a mode designed to benefit those with power. As we have seen in Ōtāhuhu, it takes collectivity to effectively resist in a liquid modern world, however by nature of this system, collectivity continues to be dissolved. 


\section{Reference List}

Aimer, P. (2012). Labour Party - First Labour government, 1935 to 1949. Te Ara

Encyclopedia. Retrieved from https://teara.govt.nz/en/labour-party/page-2

Anae, M. (2020). The Terror of the Dawn Raids. E-Tangata. Retrieved from https://etangata.co.nz/history/the-terror-of-the-dawn-raids/

Anderson, J. (In Press). The Community as a Liminal Correctional Space. Space and Culture.

Anti-social Behaviour, Crime and Policing Act 2014 (United Kingdom).

https://www.legislation.gov.uk/ukpga/2014/12/contents/enacted

Armstrong, L. (2012). Reflections on a research process: Exploring violence against sex workers from a feminist perspective. Women's Studies Journal, 26(1), pp. 2-10.

Art Deco Trust. (2021). About the Trust. Retrieved from https://www.artdeconapier.com/about/the-trust.html

Ashworth, A. (2002). Human Rights, Serious Crime and Criminal Procedures. London, UK: Sweet \& Maxwell.

Atkin, B., and McLay, G. (2012). Torts in New Zealand: Cases and Materials. Melbourne, Australia: Oxford University Press.

Baker, M., and Du Plessis, R. (2018). Family welfare - A model welfare state. Te Ara-the Encyclopedia of New Zealand. Retrieved from https://teara.govt.nz/en/family-welfare/page$\underline{4}$

Bauman, Z. (1995). Life in Fragments. Cambridge: MA, Blackwell Publishers.

Bauman, Z. (2000a). Liquid Modernity. Cambridge: UK, Polity Press. 
Bauman, Z. (2000b). Social Issues of Law and Order. British Journal of Criminology, 40(2), 205-221.

Bauman, Z. (2004). Wasted Lives: Modernity and its Outcasts. Cambridge, UK: Polity Press.

Bauman, Z. (2007). Liquid Times: Living in an Age of Uncertainty. Cambridge, UK: Polity Press.

Baxter, J. (2012, August 31). Freedom the Opposite of What He'll Experience. Dominion Post.

Baxter, P., \& Jack, S. (2008). Qualitative case study methodology: Study design and implementation for novice researchers. The Qualitative Report, 13(4), pp. 544-559.

Beck, U. (2002). 'The Terrorist Threat: World Risk Society Revisited'. Theory, Culture and Society, 19, pp. 39-55.

Beck, U. (1992). Risk Society: Towards a New Modernity. London, UK: Sage.

Beaglehole, D. (2015). 'Whanganui'. Te Ara Encyclopedia of New Zealand. Retrieved from https://teara.govt.nz/en/whanganui-places/page-1

Berg, B. L. (1998). Qualitative Research Methods for the Social Sciences (3 ${ }^{\text {rd }}$ Ed.). Boston, MA: Allyn and Bacon.

Berger, P. L., and Luckmann, T. (1967). The Social Construction of Reality: A Treatise in the Sociology of Knowledge. London: UK, Penguin.

Best, J. (1990). Threatened Children: Rhetoric and Concern about Child Victims. Chicago, IL: The University of Chicago Press. 
Blackstone, E. A., and Hakim, S. (2013). Competition versus monopoly in the provision of police. Security Journal, 26(2), p. 157-179.

Boshier, P. (2018). Report on an unannounced inspection of Whanganui Prison Under the Crimes of Torture Act 1989. Office of the Ombudsman. Retrieved from https://www.ombudsman.parliament.nz/sites/default/files/201903/opcat report whanganui - final - online.pdf

Boston, J., and Chapple, S. (2015). The Child Poverty Debate: Myths, Misconceptions and Misunderstandings. Wellington: NZ, Bridget Williams Books.

Boston, J., Dalziel, P., and St John, S. (Eds.). (1999). Redesigning the Welfare State in New Zealand: Problems, Policies, Prospects. Auckland: NZ, Oxford University Press.

Bottoms, A. (1977). Reflections on the Renaissance of Dangerousness. Howard Journal of Penology and Crime Prevention, 16(2), pp. 70-96.

Bradley, A. (2018). Maraenui: The suburb swallowed by synthetics. Radio New Zealand. Retrieved from https://shorthand.radionz.co.nz/maraenui/index.html

Bradley, T. (2016). Governing private security in New Zealand. Australia New Zealand Journal of Criminology, 49(2), pp. 159-178.

Braun, V., and Clarke, V. (2006). Using thematic analysis in psychology. Qualitative Research in Psychology, 3(2), pp. 77-101.

Brawley, S. (1993). 'No" White Policy" in NZ': Fact and Fiction in New Zealand's Asian Immigration Record, 1946-1978. New Zealand Journal of History, 27(1), 16-36.

Briggs, P. (2007). Looking at the Numbers: A view of New Zealand's economic history. Wellington, NZ: New Zealand Institute of Economic Research. Retrieved from 
https://nzier.org.nz/static/media/filer_public/11/2a/112a69bb-d259-4b80-bd32-

c1ab6b591f5b/looking at the numbers updated text 2007.pdf

Broadcasting Act 1989 (NZ). Retrieved from

https://www.legislation.govt.nz/act/public/1989/0025/latest/DLM155365.html

Brown v Attorney-General [2006] NZAR 552 DC (NZ).

Brown, D. (2020). 'Reflections on Risk Assessment in Community Corrections' in J. Pratt and J. Anderson (Eds.) Criminal Justice, Risk, and the Revolt Against Uncertainty, pp. 43-67. London, UK: Palgrave Macmillan.

Bruce, R. (1885). New Zealand Parliamentary Debates. Vol. 52, p. 515.

Charmaz, K., Thornberg, R., and Keane, E. (2018). 'Evolving grounded theory of social justice inquiry' in Norman K. Denzin \& Yvonne S. Lincoln (Eds.) The SAGE Handbook of Qualitative Research (5 $5^{\text {th }}$ Ed.), pp. 411-443. Thousand Oaks, CA: Sage.

Child Protection (Child Sex Offender and Government Registration) Act 2016 (NZ). Retrieved from

http://www.legislation.govt.nz/act/public/2016/0042/latest/whole.html\#DLM6463913

Child Protection (Child Sex Offender Government Agency Registration) Amendment Bill 2021 (16-1) (NZ). Retrieved from

https://www.legislation.govt.nz/bill/government/2021/0016/latest/d2019110e2.html

Christie, N. (2000) Crime Control as Industry: Towards Gulags, Western Style. England: Routledge.

Christie N. (1986) The Ideal Victim. In Ezzat A. Fattah (Ed.) From Crime Policy to Victim Policy. London, UK: Palgrave Macmillan. 
Coddington, D. (1996). The 1996 Paedophile and Sex Offender Index. Alister Taylor Publishers. Auckland: NZ.

Coddington, D. (2003a). 'Coddington Launches Second Sex Offender Index'. New Zealand Herald. Retrieved from

https://www.nzherald.co.nz/nz/news/article.cfm?c id=1\&objectid=3523989

Coddington, D. (2003b, July 30). Sex Offenders Registry Bill - First Reading. New Zealand Parliamentary Debates, 610, 7503. Retrieved from

https://www.parliament.nz/en/pb/hansard-

debates/rhr/document/47HansS 20030730 00001272/coddington-deborah-sex-offendersregistry-bill-first

Coddington, D. (2012, March 11). Key strategy still missing in fight against sex crime. New Zealand Herald. Retrieved from https://www.nzherald.co.nz/nz/deborah-coddington-keystrategy-still-missing-in-fight-against-sex-crime/VCY2JE4XRSVODUFB56ZXBTLFI/

Cohen, S. (1985). Visions of Social Control: Crime, Punishment and Classification. Cambridge, UK: Polity Press.

Cohen, S. (2002). Folk Devils and Moral Panics (3 ${ }^{\text {rd }}$ Ed). New York, NY: Routledge.

Collins, J. (2013, September 17). Public Safety (Public Protection Orders) Bill - First Reading. New Zealand Parliamentary Debates, 693, 13365. Retrieved from https://www.parliament.nz/en/pb/hansarddebates/rhr/document/50HansD 20130917/volume-693-week-54-tuesday-17-september$\underline{2013}$

Cook, D. (2002). 'Deregulation and broadcast news content: ONE network news 1984 to 1996' in J. Farnsworth \& I. Hutchinson (Eds.) New Zealand Television: A Reader, pp. 139-144. Palmerston North, NZ: Dunmore Press. 
Crotty, M. (1998). The Foundations of Social Research. Allen \& Unwin: New South Wales.

Cumming, G. (2000, September 6). Boarding Houses: The Neighbour Nobody Wants. New Zealand Herald. Retrieved from

https://www.nzherald.co.nz/nz/news/article.cfm?c id=1\&objectid=150325

$D$ v New Zealand Police [2021] NZSC 2 (NZ).

Daly, K. (2018). 'Using case study methods in criminological research' in P. Davies \& P. Francis (Eds.) Doing Criminological Research ( $3^{\text {rd }}$ Ed.). London, UK: Sage.

Dalziel, K. (2008). Should we name and shame? Disclosing personal information of child sex offenders. Paper for the Privacy Commissioner. Retrieved from https://www.privacy.org.nz/assets/Files/Privacy-Week-material/4.-Speaker-KathrynDalziel.doc

Davies, P., \& Wyatt, T. (2021). Crime and Power. London, UK: Palgrave Macmillan.

Davis, M. (2006). City of Quartz. London, UK: Verso.

de Young, M. (2004). The Day Care Ritual Abuse Moral Panic. Jefferson, N.C.: McFarland.

Department of Building and Housing. (2015). Inquiry into Boarding Houses - Initial briefing to Social Services Committee. Retrieved from https://www.parliament.nz/resource/enNZ/49SCSS ADV OODBSCH INQ 106331 A196208/454ff6f48588fc3d15d4b7c111b9226d5 $\underline{3093566}$

Department of Corrections. (2018). Accommodation Review. Released to me under the Official Information Act.

Department of Corrections. (2019). Prison facts and statistics - December 2019. Retrieved from 
https://www.corrections.govt.nz/resources/research_and statistics/quarterly_prison_statis tics/prison stats december 2019

Discover Whanganui. (2021). Whanganui: All You Need (and then some). Retrieved from https://discoverwhanganui.nz/

Dominion Post. (2013, February 5). 'Beast' OK.

Douglas, R. (1980). There's got to be a better way!: A practical ABC to solving New Zealand's major problems. Wellington, NZ: Fourth Estate Books.

Douglas, R. (1993). Unfinished Business. Auckland, NZ: Random House.

Doyle, A. (2007). Introduction: Trust, citizenship and exclusion in the risk society. In Law Commission of Canada (Eds.) Risk and Trust: Including or Excluding Citizens, pp. 7-22. Halifax, Canada: Fernwood.

Dudman, J. (2018, July 16). Kiwibank regional scorecard says Whanganui way ahead on rental yield. New Zealand Herald. Retrieved from https://www.nzherald.co.nz/business/news/article.cfm?c id=3\&objectid=12088362

Dunkelman, M. (2014). The Vanishing Neighbor: The Transformation of American Community. New York, NY: W. W. Norton \& Company.

Eaqub, S. (2014). Growing Apart: Regional Prosperity in New Zealand. Wellington, NZ: Bridget Williams Books.

Easton, B. (1998). The De-Industrialization of New Zealand. Labour, Employment and Work in New Zealand, pp. 38-46.

Easton, B. (2010). Economic History - Boom and Bust, 1870-1895. Te Ara - The Encyclopedia of New Zealand. Retrieved from https://teara.govt.nz/en/economic-history/page-5 
Eleven, B. (2015). Peter Ellis: Why the Civic Creche case won't go away. North and South. November issue, pp. 32-41.

Emerson, A. (2012a, August 18). Councillors Vow Legal Battle to Stop 'Beast'. Whanganui Chronicle.

Emerson, A. (2012b, August 31). Councillors on Trespass Notice Trail. Whanganui Chronicle.

Employment Contracts Act 1991 (NZ). Retrieved from

http://www.nzlii.org/nz/legis/hist_act/eca19911991n22280/

Ericson, R. (2007a). Governing Through Risk and Uncertainty. Economy and Society, 34:4, pp. $659-672$.

Ericson, R. (2007b). Crime in an Insecure World. Cambridge, UK: Polity Press.

Ericson, R., and Haggerty, K. (1997). Policing the Risk Society. Toronto, Canada: University of Toronto Press.

Family Court Act 1980 (NZ). Retrieved from

https://www.legislation.govt.nz/act/public/1980/0161/latest/DLM42254.html

Family Proceedings Act 1980 (NZ). Retrieved from

https://www.legislation.govt.nz/act/public/1980/0094/latest/DLM39723.html

Feeley, M., \& Simon, J. (1992). The New Penology. Criminology, 30(4), pp. 449-474.

Fernandes, K. (2017, October 30). 'Former National MP forced to apply for consent after boarding house complaints', Stuff, retrieved from

https://www.stuff.co.nz/business/98211444/former-national-mp-forced-to-apply-forconsent-after-boarding-house-complaints 
Flyvbjerg, B. (2006). Five misunderstandings about case study research. Qualitative Inquiry, 12(2), pp. 219-245.

Flyvbjerg, B. (2011). Case Study. In N. K. Denzin \& Y. S. Lincoln (Eds.), The Sage Handbook of Qualitative Research (4th ed), pp. 301-316. Thousand Oaks, CA: Sage.

Foucault, M. (1991). 'Governmentality' in G. Burchell., C. Gordon., \& P. Miller (Eds.) The Foucault Effect: Studies in Governmentality. Chicago, IL: University of Chicago Press.

Foucault, M. (1995). Discipline and Punish. New York, Vintage Books.

Franklyn, B. (2012, September 1). Beware Inciting Fear and Hatred. Dominion Post.

Freiberg, A. (2003). 'Guerillas in our midst? Judicial responses to governing the dangerous' in M. Brown \& J. Pratt (Eds.) Dangerous Offenders. London, UK: Routledge.

Fukuyama, F. (1995). Trust: The Social Virtues and the Creation of Prosperity. New York, NY: Free Press.

Fuller, C. (2021, June 17). Hawke's Bay's fear of crime is higher than any region in NZ. Hawkes Bay Today. Retrieved from https://www.nzherald.co.nz/hawkes-baytoday/news/hawkes-bays-fear-of-crime-is-higher-than-any-region-innz/EMKFIEDUY72ER4CBEFBLILMXKU/\#: :text=The\%20New\%20Zealand\%20Crime\%20and,10 \%20out\%20of\%2010\%22\%20safe

Fuller, T., and Loogma, K. (2009). Constructing futures: A social constructionist perspective on foresight methodology. Futures, 41(1), pp. 71-79.

Furedi, F. (2003). Culture of Fear: Risk-taking and the Morality of Low Expectations. London, UK: Continuum. 
Gallagher, J. (2020). Fertility rate: 'Jaw-dropping' global crash in children being born. BBC. Retrieved from https://www.bbc.com/news/health-53409521

Garland, D. (2001). The Culture of Control. Oxford, UK: Oxford University Press.

Garland, D. (2006). Concepts of Culture in the Sociology of Punishment. Theoretical Criminology, 10(4), pp. 419-447.

Gergen, K. J. (1985). The Social Constructionist Movement in Modern Psychology. American Psychologist, 40, pp. 266-275.

Ghahraman, G. (2021, March 17). Child Protection (Child Sex Offender Government Agency Registration) Amendment Bill 2021 - First Reading. New Zealand Parliamentary Debates. Retrieved from https://www.parliament.nz/en/pb/hansarddebates/rhr/combined/HansDeb_20210317 20210317 24

Giddens, A. (1972). Emile Durkheim: Selected Writings. Cambridge, UK: Cambridge University Press.

Giddens, A. (1990). The Consequences of Modernity. Cambridge, UK: Polity.

Goffman, E. (1961). Asylums: Essays on the Social Situation of Mental Patients and Other Inmates. New York, NY: Anchor Books, Doubleday \& Co.

Gómez, M, V. and Kuronen, M. (2011). Comparing local strategies and practices: recollections from two qualitative cross-national projects. Qualitative Research, 11(6), pp. 683-697.

Goodger, K. (1998). Maintaining Sole Parent Families in New Zealand: An Historical Review. Social Policy Journal of New Zealand, 10(1), pp. 122-153. 
Gower, P. (2007, August 18). Living a lie. New Zealand Herald. Retrieved from https://www.nzherald.co.nz/nz/living-a-lie/544GCTJW7SRBOYE3E23JCEJSMY/

Grbich, C. (2012). Qualitative Data Analysis: An Introduction (2 ${ }^{\text {nd }}$ Ed). Thousand Oaks, CA: Sage.

Greer, C., and Jewkes, Y. (2005). Extremes of Otherness: Media Images of Social Exclusion. Social Justice, 32(1), pp. 20-31.

Gwartney, J., and Lawson, R. (2007). Economic Freedom of the World: 2007 Annual Report. Vancouver, The Fraser Institute. Retrieved from https://www.fraserinstitute.org/sites/default/files/EconomicFreedomoftheWorld2007.pdf

Hacking, I. (1991). The Making and Moulding of Child Abuse. Critical Inquiry, 17(2), pp. 253288.

Hacking, I. (2003). Risk and Dirt. In R. Ericson., \& A. Doyle, Risk and Morality, pp. 22-47. Toronto, Canada: University of Toronto Press.

Haigh, D. (2014). Community Development and New Zealand Local Authorities in the 1970s and 1980s. New Zealand Sociology, 29(1), pp. 79-97.

Hakim, C. (2000). Research Design. Successful Designs for Social and Economic Research (2 ${ }^{\text {nd }}$ Ed.). London, UK: Routledge.

Hannah-Moffat, K. (2005). Criminogenic needs and the transformative risk subject: Hybridizations of risk/need in penality. Punishment and Society, 7(1), p. 29-51.

Hannah-Moffat, K. (2013). Actuarial Sentencing: An 'Unsettled' Proposition. Justice Quarterly, 30(2), pp. 270-296. 
Hanson, N. R. (1965). Patterns of Discovery: An Inquiry into the Conceptual Foundations of Science. Cambridge, UK: Cambridge University Press.

Harcourt, B. (2007). Against Prediction: Profiling, Policing and Punishing in an Actuarial Age. Chicago, IL: University of Chicago Press.

Hartley, J. (2004). Case study research. In Catherine Cassell \& Gillian Symon (Eds.), Essential Guide to Qualitative Methods in Organisational Research (pp. 323-333). London, UK: Sage.

Hawkes Bay Today. (2019, October 14). 'Fantastic': Napier voter turnout hits 50\%. Retrieved from https://www.nzherald.co.nz/hawkes-bay-today/news/fantastic-napier-voter-turnouthits-50-per-cent/TVHS7HNSUBXCKS5NSTCDKE57J4/

Hawkes Bay Tourism. (2020). Hawkes Bay Tourism industry website. Retrieved from https://hawkesbaytourism.nz/

Hawkes Bay NZ. (2021). Napier: The Art Deco Capital of New Zealand. Hawkes Bay NZ. Retrieved from https://www.hawkesbaynz.com/plan-your-stay/ourneighbourhoods/napier/

Hinds, L and Daly, K. (2001). 'The War on Sex Offenders: Community Notification in Perspective', Australian and New Zealand Journal of Criminology, 34(3). pp. 256-276.

Holcroft, M. H. (1968). New Zealand. Wellington, NZ: A. H. and A. W. Reed.

Hood, L. (2001). A City Possessed: The Christchurch Civic Creche Case. Otago, NZ: Otago University Press.

Hosking, M. (2018, July 2). Kids not walking to school just proves we've gone soft. New Zealand Herald. Retrieved from https://www.nzherald.co.nz/nz/mike-hosking-kids-notwalking-to-school-just-proves-weve-gone-soft/4PJZ2E2MALGFX7IK7XY362TJ3I/ 
Humpage, L. (2011). Neo-Liberal Reform and Attitudes Towards Social Citizenship: A Review of New Zealand Public Opinion Data 1987-2005. Social Policy Journal of New Zealand, 37, pp. 83-96.

Hunt, T. (2020, October 27). Notorious paedophile moves into Wellington home surrounded by kids. Stuff. Retrieved from https://www.stuff.co.nz/dominionpost/news/wellington/123202426/notorious--paedophile-moves-into-wellington-homesurrounded-by-kids

Ilea, A. (2018). What about 'the sex offenders'? Addressing Sexual Harm from an Abolitionist Perspective. Critical Criminology, 26(8), pp. 357-372.

Irwin, K. (1994). Māori Research Methods and Practices. Sites, 28, pp.25-43.

Jackson, M. (1988). Māori and the criminal justice system: He whaipaanga hou: A new perspective. Wellington, New Zealand: Department of Justice. Retrieved from https://safeandeffectivejustice.govt.nz/research/a-new-perspective-part-2/

Jenkins, P. (1996). Pedophiles and Priests: Anatomy of a Contemporary Crisis. Oxford, UK: Oxford University Press.

Jewkes, Y. (2015). Media and Crime. London, UK: Sage.

Jones, T and Newburn, T. (2013). 'Policy convergence, politics and comparative penal reform: Sex offender notification schemes in the USA and UK'. Punishment \& Society, 15(5). Pp. 439-467.

Joosse, P. (2018). Expanding Moral Panic Theory to Include the Agency of Charismatic Entrepreneurs. British Journal of Criminology, 58(4), pp. 993-1012. 
Kelle, U. (1995). 'Theories as heuristic tools in qualitative research' in Ilia Maso, Paul A. Atkinson, Sara Delamont, and Jef C. Verhoeven (Eds.) Openness in Research: The Tension Between Self and Other, pp. 33-50. Assen, The Netherlands: van Gorcum.

Kelsey, J. (1995). The New Zealand Experiment. Auckland, NZ: Auckland University Press.

Kennedy, B. L. (2018). 'Deduction, Induction, and Abduction' in Uwe Flick (Ed.) The SAGE Handbook of Qualitative Data Collection, pp. 49-64. London, UK: Sage.

King, K. (2012, August 13). Fight to Stop 'Beast'. Whanganui Chronicle.

King, M. (2003). The Penguin History of New Zealand. Auckland, NZ: Penguin Books.

King's College. (2021). Fees and Incidentals. Retrieved from

https://www.kingscollege.school.nz/admissions/fees-and-incidentals/

Kitchin, T. (2021, March 23). Napier has highest social housing waitlist per capita. Radio New Zealand. Retrieved from https://www.rnz.co.nz/news/national/438947/napier-has-highestsocial-housing-waitlist-per-capita

Kitchin, T. (2021, March 29). Napier police 'stretched to the limits' - mayor Kirsten Wise.

Radio New Zealand. Retrieved from https://www.nzherald.co.nz/hawkes-bay-

today/news/napier-police-stretched-to-the-limits-mayor-kirsten-

wise/ULKGBAWBYTNCX5XTLSWR4JYHGM/

Kuten, J. (2012, August 22). Out of Touch Government Fails Us Again in Wilson Case. Whanganui Chronicle.

Larsson, L. S., Butterfield, P., Christopher, S., and Hill, W. (2006). Rural Community Leaders' Perceptions of Environmental Health Risks: Improving Community Health. American Association of Occupational Health Nurses Journal, 54(3), pp. 105-112. 
Levi, R. (2000). The Mutuality of Risk and Community. Economy and Society, 29(4), pp. 578601.

Local Government New Zealand. (2016). Final Voter Turnout 2016. Retrieved from https://www.Ignz.co.nz/nzs-local-government/vote2016/final-voter-turnout-2016/

Local Government New Zealand. (2019). Final Voter Turnout 2019. Retrieved from

https://www.Ignz.co.nz/local-government-in-nz/vote2019/voters/final-voter-turnout-2019/

Locke, C. (2010). Ngā uniana - Māori and the union movement: Unemployment 1986-2016.

Te Ara - The Encyclopedia of New Zealand. Retrieved from:

https://teara.govt.nz/en/graph/22960/unemployment-1986-2016

Marshall, T. H. (1950, reprinted 2000). 'Citizenship and Social Class' in C. Pierson \& F. Castles (Eds.) The Welfare State Reader (pp. 32-41). Cambridge, UK: Polity Press.

Martin, L. (2021). 'Hyper-Incarceration: Inequality and Imprisonment' in E. Stanley; T. Bradley \& S. Monod de Froideville (Eds.) The Aotearoa Handbook of Criminology. Auckland, NZ: Auckland University Press.

McCauley, M. P., Ramanadhan, S., and Viswanath, K. (2015). Assessing opinions in community leadership networks to address health inequalities: a case study from Project IMPACT. Health Education Research, 30(6), pp. 866-881.

McDonald, A. (2017, September 26). 'Whanganui: how we voted'. Whanganui Chronicle. Retrieved from https://www.nzherald.co.nz/wanganuichronicle/news/article.cfm?c id $=1503426 \&$ objectid $=11926260$

McGoey, L. (2012). The logic of strategic ignorance. The British Journal of Sociology, 63(3), pp. 553-576. 
McIntosh, T. (2004). 'Living Southside' in I. Carter, D. Craig \& S. Matthewman (Eds.) Almighty Auckland?, pp. 135-147. Palmerston North, NZ: Dunmore Press.

McIntosh, T., \& Workman, K. (2017). 'Māori and prison' in A. Deckert, \& R. Sarre (Eds.), The Palgrave Handbook of Australian and New Zealand Criminology, Crime and Justice, pp. 725735. Auckland, NZ: Palgrave Macmillan.

McSherry, B. (2014). Managing Fear: The Law and Ethics of Preventive Detention and Risk Assessment. Oxon, UK: Routledge.

McSherry, B. (2020). 'Risk Assessment, Predictive Algorithms and Preventive Justice' in J. Pratt \& J. Anderson (Eds.) Criminal Justice, Risk, and the Revolt Against Uncertainty, pp. 1742. London, UK: Palgrave Macmillan.

Mediawatch. (2012, September 16). Origin of the 'Beast of Blenheim Moniker'. Retrieved from www.radionz.co.nz/national/programmes/mediawatch?letter=F\&page=7

Meredith, P. (2005). Urban Māori - Urbanisation. Te Ara - the Encyclopedia of New Zealand. Retrieved from https://teara.govt.nz/en/urban-maori/page-1

Merriam, S. B. (1998). Qualitative Research and Case Study Applications in Education. San Francisco, CA: Jossey-Bass.

Mills, C. W. (1959). The Sociological Imagination. Oxford, UK: Oxford University Press.

Ministry for Business, Innovation, and Employment. (2018). Reform of the Residential Tenancies Act: Discussion Document. Retrieved from https://infocouncil.aucklandcouncil.govt.nz/Open/2018/10/ENV_20181016_AGN 8219_AT files/ENV 20181016 AGN 8219 AT Attachment 63141 2.PDF

Ministry of Culture and Heritage. (2020). The 1981 Springbok Tour. Retrieved from https://nzhistory.govt.nz/culture/1981-springbok-tour 
Ministry of Justice. (2020). Key Initiatives: Hāpaitia te Oranga Tangata. Retrieved from https://www.justice.govt.nz/justice-sector-policy/key-initiatives/hapaitia-te-orangatangata/

Ministry of Primary Industries. (2021). Forestry and Wood Processing Data. Retrieved from https://www.mpi.govt.nz/forestry/new-zealand-forests-forest-

industry/forestry/\#: :text=Forestry\%20in\%20New\%20Zealand\&text=an\%20annual\%20expo rt\%20revenue\%20of,in\%20production\%2C\%20processing\%2C\%20and\%20commercialisation

Ministry of Social Development. (2020). Housing Register. Retrieved from

https://www.msd.govt.nz/about-msd-and-our-work/publications-

resources/statistics/housing/index.html

Morris, J. (1982). With All Our Strength: An account of the anti-tour movement in

Christchurch, 1981. Christchurch, NZ: Black Cat.

Mulligan, J. (2020, 6 August). Crimes NZ: The Unsolved Disappearance of Kirsa Jensen. Radio New Zealand. Retrieved from

https://www.rnz.co.nz/national/programmes/afternoons/audio/2018758273/crimes-nzthe-unsolved-disappearance-of-kirsa-jensen

Napier, S., Dowling, C., Morgan, A., and Talbot, D. (2018). What impact do public sex offender registries have on community safety? Trends \& Issues in Crime and Criminal Justice: Australian Institute of Criminology, 550. Retrieved from https://www.aic.gov.au/sites/default/files/202005/ti_what impact do public sex offender registries have on community safety 22051 8 $0 . p d f$ Nathan, D., and Snedeker, M. (1995). Satan's Silence: Ritual Abuse and the Making of a Modern American Witchhunt. New York, NY: Basic Books. 
Naylor, J. (2015, September 15). Child Protection (Child Sex Offender Register) Bill - First Reading. New Zealand Parliamentary Debates, 708, 6634. Retrieved from https://www.parliament.nz/en/pb/hansarddebates/rhr/document/51HansD 20150915 00000020/child-protection-child-sex-offenderregister-bill-first

National Business Review. (2017). What Sir John Key is worth on the NBR Rich List. National Business Review. Retrieved from https://www.nbr.co.nz/article/what-sir-john-key-worthnbrs-rich-list-b-p-205641

Neuman, L. W. (1997). Social Research Methods, Qualitative and Quantitative Approaches, ( $3^{\text {rd }}$ ed.). Boston, MA: Allyn and Bacon.

New Zealand Herald. (2003, September 17). Coddington launches second sex offender index. New Zealand Herald. Retrieved from https://www.nzherald.co.nz/nz/coddingtonlaunches-second-sex-offenders-index/CXNW5FB7RNEXEI3W3V77MGZUJ4/

New Zealand Index of Deprivation. (2013). Deprivation Index. Retrieved from http://www.imd.ac.nz/NZIMD Single_animation_w logos/atlas.html

New Zealand Parliament. (2017). Innovative bill protects Whanganui River with legal personhood. Retrieved from https://www.parliament.nz/en/getinvolved/features/innovative-bill-protects-whanganui-river-with-legal-personhood/

New Zealand Parliamentary Library. (2008). Immigration Chronology: Selected Events 18402008. Retrieved from https://www.parliament.nz/en/pb/researchpapers/document/00PLSocRP08011/immigration-chronology-selected-events-1840-2008

New Zealand Parliamentary Library. (2017a). Manukau East: Electorate Profile. Retrieved from https://www.parliament.nz/resource/enNZ/DBHOH_Lib_EP Manukau_East_Electoral_Profile/5337f58027afe3c10501c37c9c092068 $\underline{293 a a 415}$ 
New Zealand Parliamentary Library. (2017b). Napier Electorate Profile. Retrieved from https://www.parliament.nz/resource/en-

NZ/DBHOH_Lib_EP Napier_TOC/49989f2167acdf58cb12160fcf6b17617352b016

New Zealand Parliamentary Library. (2017c). Whanganui: Electoral Profile. Retrieved from https://www.parliament.nz/en/mps-and-electorates/electorate-profiles/electorate-profilesdata/document/DBHOH_Lib_EP_Whanganui_Electoral_Profile/whanganui-electoralprofile\# 9

New Zealand Parole Board. (2012). Decisions of Public Interest: Stewart Murray Wilson. Retrieved from http://www.paroleboard.govt.nz/decisions-statistics-andpublications/decisions-of-public-interest/WILSON - Stewart Murray- 07082012.html

New Zealand Parole Board. (2019). Decisions. Retrieved from https://www.paroleboard.govt.nz/decisions.html

New Zealand Police. (2019). Child Sex Offender (CSO) Register. Retrieved from http://www.police.govt.nz/about-us/programmes-and-initiatives/child-sex-offender-csoregister

OECD. (1993). OECD Economic Surveys: New Zealand 1993. Paris, France: OECD.

Old-age Pensions Act 1898 (NZ). Retrieved from http://www.nzlii.org/nz/legis/hist act/opa189862v1898n14239/

O'Malley, P. (2004). Risk, Uncertainty and Government. London, UK: Glasshouse Press.

O’Malley, P. (2010). Crime and Risk. London, UK: Sage.

O'Malley, V. (2015). Beyond the Imperial Frontier: The Contest for Colonial New Zealand. Wellington, NZ: Bridget Williams Books. 
O'Malley, V. (2019). The New Zealand Wars: Nga Pakanga o Aotearoa. Wellington, NZ: Bridget Williams Books.

Owen, L. (2014, July 12). NZ has zombie towns that need to close-economist. NBR.

Retrieved from https://www.nbr.co.nz/article/nz-has-zombie-towns-need-close\%E2\%80\%94-economist-ns-159124

Parole (Extended Supervision) Amendment Act 2004 (NZ). Retrieved from https://www.legislation.govt.nz/act/public/2004/0067/latest/DLM304061.html

Patton, M. (1990). Qualitative evaluation and research methods. Beverly Hills, CA: Sage.

Patton, E., and Applebaum, S. H. (2003). The case for case studies in management research. Management Research News, 26(5), pp. 60-71.

Phillips, J. (2015). The New Zealanders: Better Britons. Te Ara - the Encyclopedia of New Zealand. Retrieved from https://teara.govt.nz/en/the-new-zealanders/page-4

Phillips, J. (2014). Ideas in New Zealand: Wakefield and the 'Better Britain'. Te Ara Encyclopedia. Retrieved from https://teara.govt.nz/en/ideas-in-new-zealand/page-5

Pollock, K. (2012). Early childhood education and care - new developments, 1970s to 2000s. Te Ara - the Encyclopedia of New Zealand. Retrieved from https://teara.govt.nz/en/earlychildhood-education-and-care/page-3

Pollock, K. (2015). Hawkes Bay Region - European Settlement. Te Ara - the Encyclopedia of New Zealand. Retrieved from https://teara.govt.nz/en/photograph/23899/repudiation$\underline{\text { movement }}$

Pratt, J. (1992). Punishment in a Perfect Society: The New Zealand Penal System 1840-1939. Wellington, NZ: Victoria University Press. 
Pratt, J. (2005). Child sexual abuse: Purity and danger in an Age of Anxiety. Crime, Law and Social Change, 43(1), pp. 264-287.

Pratt, J. (2006). The Dark Side of Paradise: Explaining New Zealand's History of High Imprisonment. British Journal of Criminology, 46, pp. 541-560.

Pratt, J. (2007). Penal Populism. Oxon, UK: Routledge.

Pratt, J. (2014). 'Civilising and Decivilising Characteristics of the Contemporary Penal Field'. In T. S. Landhini \& F. Depelteau (Eds.) Norbert Elias and Empirical Research, pp. 63-82. New York: NY, Palgrave Macmillan.

Pratt, J. (2015). 'Immobilisation in the Age of Mobility' in A. Eriksson (Ed.) Punishing the Other: The Social Production of Immorality Revisited, pp. 208-229. Oxon, UK: Routledge.

Pratt, J. (2016). Risk Control, Rights and Legitimacy in the Limited Liability State. British Journal of Criminology, 57(6), pp. 1322-1339.

Pratt, J. (2020). Law, Insecurity and Risk Control: Neo-Liberal Governance and the Populist Revolt. London, UK: Palgrave Macmillan.

Pratt, J., and Anderson, J. (2016). "The Beast of Blenheim”, Risk and the Rise of the Security Sanction. Australian \& New Zealand Journal of Criminology, 49(4), pp. 528-545.

Pratt, J., and Lutyens, D. (2022 - In Press). The Pandemic as an Antidote to Populis: Punishment, Immobilization and Covid-19. Archiwun Kryminolgii.

Prentky, R.A. (1996). Community Notification and Constructive Risk Reduction. Journal of Interpersonal Violence, 11(2), 295-298. 
Prickett, N. (2002). Landscapes of Conflict: A Field Guide to the New Zealand Wars. Auckland, NZ: Random House.

Privacy Act 1993 (NZ). Retrieved from

https://www.legislation.govt.nz/act/public/1993/0028/latest/DLM296639.html

Privacy Commissioner. (2018). Sensible Sentencing Trust falsely labels man as paedophile.

Retrieved from https://www.privacy.org.nz/publications/statements-media-

releases/naming-sensible-sentencing-trust/

Public Safety Act 2014 (NZ). Retrieved from

https://www.legislation.govt.nz/act/public/2014/0068/latest/DLM4751015.html

Public Safety (Public Protection Orders) Bill 2012 (68-3) (NZ). Retrieved from

https://www.legislation.govt.nz/bill/government/2012/0068/latest/DLM4751015.html

Putnam, R. (2000). Bowling Alone. New York, NY: Simon and Schuster Paperbacks.

$R v$ Hannis [2019] NZDC 1272 DC (NZ).

Radio New Zealand. (2020, October 27). Officials apologise after high-risk paedophile on parole allowed to live near children. Retrieved from

https://www.nzherald.co.nz/nz/crime/officials-apologise-after-high-risk-paedophile-onparole-allowed-to-live-near-children/ZYZTJVB7ROED5GX72WTE5VOQEY/

Radio New Zealand. (2021, March 30). Widespread implications to wood shortage - industry leader. Retrieved from https://www.rnz.co.nz/news/national/439476/widespreadimplications-to-wood-shortage-industry-leader

Ramia, G., and Wailes, N. (2006). Putting wage-earners into wage earners' welfare states: The relationship between social policy and industrial relations in Australia and New Zealand. Australian Journal of Social Issues, 41(1), pp. 49-68. 
Rattansi, A. (2005). 'The Uses of Racialization: The Time-Spaces and Subject-Objects of the Raced Body' in K. Murji., \& J. Solomos (Eds.) Racialisation Theories in Study and Practice, pp. 271-301. Oxford, UK: Oxford University Press.

Rashbrooke, M. (2020, August 31). New Zealand's astounding wealth gap challenges our 'fair go' identity. The Guardian. Retrieved from

https://www.theguardian.com/world/2020/aug/31/new-zealands-astounding-wealth-gapchallenges-our-fair-go-identity

Riessman, C. K. (1993). Narrative Analysis. Thousand Oaks, CA: Sage.

Rose, N. (2000). Government and Control. British Journal of Criminology, 40(1), pp. 312-339.

Roy Morgan. (2021). Readership in New Zealand, 12 months to December 2020. Retrieved from http://www.roymorgan.com/industries/media/readership/readership-new-zealand

Rubin, B. (1972). Predictions of Dangerousness in Mentally III Criminals. Archives of General Psychiatry, 27(1), pp. 397-407.

Ryan, T., and Parham, B. (2002). The Colonial New Zealand Wars. Wellington, NZ: Grantham House.

Safer Whanganui. (2018). Housing Snapshot Report. Retrieved from

https://www.whanganui.govt.nz/files/assets/public/guides-and-information/housingsnapshot-report-5-december-2018.pdf

Schwandt, T. (1994). Constructivist, Interpretivist Approaches to Human Inquiry, in Norman K. Denzin \& Yvonne S. Lincoln (Eds.), Handbook of Qualitative Research, pp. 118-138. Thousand Oaks, CA: Sage. 
Sensible Sentencing Trust. (2018). Sensible Sentencing Trust Offenders Database. Retrieved from http://offenders.sst.org.nz/

Sennett, R. (1970). The Uses of Disorder: Personal Identity and City Life. New York, NY: Alfred Knopf.

Sewell, H. (1870, August 15 - September 13). Native Lands Frauds Prevention Bill. New Zealand Parliamentary Debates, 9, 361. Retrieved from https://babel.hathitrust.org/cgi/pt?id=uc1.32106019740304\&view=1up\&seq $=7$

Sex Offenders Registry Bill 2003 (Bills Digest No. 960). Parliamentary Library (NZ.).

Sexual Offences Act 2003 (UK). Retrieved from

https://www.legislation.gov.uk/ukpga/2003/42/pdfs/ukpga 20030042 en.pdf

Sharpe, M. (2017, April 18). Prisoner considered a 'high-risk sexual offender' will be released in October. Stuff. Retrieved from

https://www.stuff.co.nz/national/crime/91652204/prisoner-considered-a-highrisk-sexualoffender-will-be-released-in-october

Shaw, R. \& Eichbaum, C. (2011). Public Policy in New Zealand: Institutions, Processes and Outcomes. Auckland, NZ: Pearson.

Simon, J. (2007). Governing Through Crime. Oxford, UK: Oxford University Press.

Simpson, T. (1986). Te Riri Pākehā = The White Man's Anger. Auckland, NZ: Hodder \& Stoughton.

Smith, A. (2017, March 17). Napier fumes over beggars travelling from Hastings. Hawkes Bay Today. Retrieved from https://www.nzherald.co.nz/hawkes-bay-today/news/napier-fumesover-beggars-travelling-from-hastings/KS2JCLX7S4YYR5OFUEMQAW44TU/ 
Smith, S. (2015, September 15). Child Protection (Child Sex Offender Register) Bill - First Reading. New Zealand Parliamentary Debates, 708, 6634. Retrieved from https://www.parliament.nz/en/pb/hansarddebates/rhr/document/51HansD_20150915 00000020/child-protection-child-sex-offenderregister-bill-first

Spoonley, P. (2017). 'The Asianisation of Aotearoa: Immigration Impacts' in A. Bell., V. Elizabeth., T McIntosh., \& M. Wynyard (Eds.) A Land of Milk \& Honey? Making Sense of Aotearoa New Zealand, pp. 77-83. Auckland, NZ: Auckland University Press.

Stake, R. E. (2000). Case studies. In Norman K. Denzin \& Yvonne S. Lincoln (Eds.), Handbook of Qualitative Research (pp. 435-453). Thousand Oaks: CA, Sage.

Stake, R. E. (1995). The art of case study research. Thousand Oaks, CA: Sage.

State Owned Enterprises (Restructuring) Act 1987 (NZ). Retrieved from http://www.nzlii.org/nz/legis/hist bill/serb1987942408.pdf

Statistics New Zealand. (2013). Living Outside the Norm: An analysis of people living in temporary and communal dwellings, 2013 Census. Retrieved from http://archive.stats.govt.nz/Census/2013-census/profile-and-summary-reports/outside$\underline{\text { norm.aspx }}$

Statistics New Zealand. (2018). 2018 Census. Retrieved from https://www.stats.govt.nz/2018-census/

Statistics New Zealand. (2019). Marriages, civil unions, and divorces: Year ended December 2018. Retrieved from https://www.stats.govt.nz/information-releases/marriages-civilunions-and-divorces-year-ended-december-2018

Statistics New Zealand. (2020). Marriage falling out of favour. Retrieved from https://www.stats.govt.nz/news/marriage-falling-out-of-favour 
Statistics New Zealand. (2021). New Zealand's birth rate lowest on record, deaths drop in 2020. Retrieved from https://www.stats.govt.nz/news/new-zealands-birth-rate-lowest-onrecord-deaths-drop-in-

2020\#: :text=New\%20Zealand's\%20total\%20fertility\%20rate,1.61\%20births\%20over\%20the ir\%20lifetime.

Steadman, H. (1973). Implications from the Baxstrom Experience. Journal of the American Academy of Psychiatry and the Law, 1(3), pp. 189-196.

Steadman, H. (2000). From Dangerousness to Risk Assessment to Community Violence: Taking Stock at the Turn of the Century. Journal of the American Academy of Psychiatry and Law, 28(3), pp. 265-271.

Stenhouse, J. (2011). Religion and Society - Church adherence and attendance 1840-1920. Te Ara - the Encyclopedia of New Zealand. Retrieved from https://teara.govt.nz/en/religionand-society/page-2

Stowell, L. (2011, February 19). Past job losses were greater. Whanganui Chronicle.

Retrieved from https://www.nzherald.co.nz/whanganui-chronicle/news/past-job-losseswere-greater/DBXVBSFKO4NQRFYTD5VHP37J5Q/

Superannuation Schemes Act 1976 (NZ). Retrieved from http://www.nzlii.org/nz/legis/hist_act/ssa19761976n3287/

Taonui, R. (2011). Gangs and Society: Michael Laws and the patch ban. Te Ara Encyclopedia of New Zealand. Retrieved from https://teara.govt.nz/en/cartoon/28264/michael-laws-andthe-patchban\#: :text=Michael\%20Laws\%2C\%20the\%20mayor\%20of,and\%20other\%20specified\%20p ublic\%20places.\&text=Many\%20pubs\%20ban\%20patrons\%20from,with\%20members\%20of \%20other\%20gangs. 
Taylor, L., \& Hobbs, P. (2016, November 30). 'Unsupervised child sex offenders carry out cheap labour on former National MP's property near South Auckland primary school', 1 News, retrieved from https://www.tvnz.co.nz/one-news/new-zealand/exclusiveunsupervised-child-sex-offenders-carry-cheap-labour-former-national-mps-property-nearsouth-auckland-primary-school

Te Awa Tupua (Whanganui River Claims Settlement) Act 2017 (NZ). Retrieved from https://www.legislation.govt.nz/act/public/2017/0007/latest/whole.html

te Tiriti ō Waitangi [Translation of Māori version], February 6, 1840 (NZ). Retrieved from https://archives.govt.nz/discover-our-stories/the-treaty-of-waitangi

The Cyclopedia of New Zealand [Auckland Provincial District]. Volume 2. Auckland, NZ: Cyclopedia Company Ltd.

Thornberg, R. (2012). Informed grounded theory. Scandinavian Journal of Educational Research, 56(3), pp. 243-259.

Tolerton, J. (2010). Agricultural processing industries - Freezing works 1880 s to the 1970 s. Te Ara - the Encyclopedia of New Zealand. Retrieved from https://teara.govt.nz/en/agricultural-processing-industries/page7\#: :text=Freezing\%20works\%20were\%20New\%20Zealand's, paid\%20them\%20comparative ly\%20high\%20wages.

Tolley, A. (2015, September 15). Child Protection (Child Sex Offender Register) Bill - First Reading. Hansard.

Trevett, C. (2020, 24 January). Neve's First Visit to Rātana: PM Jacinda Ardern Fulfils a Promise. New Zealand Herald. Retrieved from https://www.nzherald.co.nz/nz/neves-firstvisit-to-ratana-pm-jacinda-ardern-fulfils-a-promise/VYJFYKZ3DTF3NIHIZ7EDRM2FLA/ 
Valentine, G. (1996). Angels and devils: moral landscapes of childhood. Environment and Planning D: Society and Space, 14, pp. 581-599.

Vance, A. (2012, May 11). Dangerous Paedophiles to be Caged Indefinitely. Dominion Post.

Wason, S. (2019). Food banks and food rescue organisations: Damned if they do; damned if they don't. Aotearoa New Zealand Social Work, 31(4), pp. 72-83.

Waxman, O, B. (2016). The U.S. is still dealing with the murder of Adam Walsh. Time.

Retrieved from https://time.com/4437205/adam-walsh-murder/

Webster, K. (2015). Social capital and voter turnout: The case of Auckland Supercity. The African and Asian Journal of Local Government Studies, 3.

'Wetterling Act' - Jacob Wetterling Crimes Against Children and Sexually Violent Offender Registration Act 1993. H.R. 324 (103rd) (US). Retrieved from https://www.govtrack.us/congress/bills/103/hr324/text

Whaanga, M. (2017). Ngāti Kahungunu - European Contact. Te Ara - the Encyclopedia of New Zealand. Retrieved from https://teara.govt.nz/en/ngati-kahungunu/page-6

Whanganui Chronicle. (2019, October 26). Whanganui's median house price hit new record in September. Retrieved from https://www.nzherald.co.nz/whanganuichronicle/news/whanganuis-median-house-price-hit-new-record-inseptember/KWNX4EH5LATCOT5MNG6CMOTBCU/

Wilkes, C. (1994). 'Class' in P. Spoonley., D. Pearson., \& I. Shirley (Eds.) New Zealand Society, pp. 66-80. Palmerston North, NZ: Dunmore Press.

Williams, G. (2018, September 16). Give Whanganui a chance. Stuff. Retrieved from https://www.stuff.co.nz/entertainment/tv-radio/107000850/guy-williams-give-whanganui$\underline{\text { a-chance }}$ 
Wilson, Z. (2018, November 9). Thanks to those who make Whanganui the volunteer capital. Whanganui Chronicle. Retrieved from https://www.nzherald.co.nz/surf-lifesaving/news/article.cfm?c id=90\&objectid $=12156872$

Wright Monod, S. (2017). Making Sense of Moral Panics. London, UK: Palgrave MacMillan.

Wynyard, M. (2017). 'Plunder in the Promised Land: Māori Land Alienation and the Genesis of Capitalism in Aotearoa New Zealand' in A. Bell., V. Elizabeth., T. McIntosh., and M. Wynyard (Eds.) A Land of Milk and Honey? Making Sense of Aotearoa New Zealand, pp. 1534. Auckland, NZ: Auckland University Press.

Yin, R. K. (2003). Case study research, design, and methods ( $3^{\text {rd }}$ ed). Thousand Oaks: CA, Sage.

Yin, R. K. (1994). Discovering the future of the case study method in evaluation research. Evaluation Practice, 15(3), pp. 283-290.

Zelizer, V. (1985). Pricing the Priceless Child: The Changing Social Value of Children. New York, NY: Basic Books Inc. Publishers. 


\section{Appendices}

\section{Appendix A - Information Sheet}

TE WHARE WĀNANGA O TE ŪPOKO O TE IKA A MĀUI

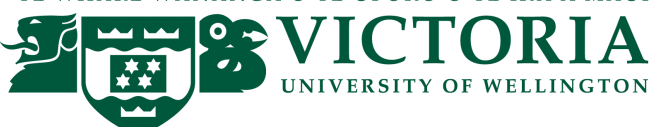

\section{Managing Risk of Sex Offenders Released from Prisons: An exploration of how local communities respond to these events INFORMATION SHEET FOR PARTICIPANTS}

My name is Jordan Anderson and I am a Doctoral student in Criminology at Victoria University of Wellington. This research project is funded through the Royal Society of New Zealand, and the research will contribute to my PhD thesis.

Thank you for your interest in this project. Please read this information before deciding whether or not to take part.

\section{Purpose of the Research}

The release of sex offenders from prison can often generate a great deal of public concern and national media interest. This research is about the way in which local communities and officials are managing their responsibilities for the risks posed by this group of offenders. Reintegration of sex offenders into the community often generates national concern and media interest and I am interested in finding out how these particular risks have been managed by you and your community.

As part of this project, I am conducting interviews with leaders of several New Zealand communities. I am interested in hearing your recollection of what happened in your community when [offender name] was released, and your views and experiences of responses to other risks to the wellbeing of local community life.

By gathering the perspectives and experiences of leaders of local communities in New Zealand, I hope to provide insight into the impact of penal policy at a community level, and 
to create recommendations as to how penal policy could be improved to suit the needs of communities.

This research has been approved by the Victoria University of Wellington Human Ethics Committee (Approval Number: 25737).

\section{How can you help?}

You have been invited to participate because I have identified you as a leader in the community of (Ōtāhuhu/Whanganui/Napier). If you agree to take part I will interview you at a café of your choosing, or your workplace if that is your preference. I will ask you questions about your community, your recollection of responses to the release of [offender name] (including the community notification procedures that took place), and other events your community has responded to or you think might respond to. The interview will take between 45-60 minutes. I will audio record the interview with your permission and write it up later. You can choose to not answer any question or stop the interview at any time, without giving a reason. You can withdraw from the study by contacting me at any time before 30 December 2018. If you withdraw, the information you provided will be destroyed or returned to you.

\section{What will happen to the information you give?}

Your participation in this research will be confidential and your contribution will be anonymous. This means that the researcher named below will not share details of your involvement and anything that you say during the interview will not be attributed to you in any reports, presentations, or public documentation. I will not identify you personally and will refer to you in generic terms alluding to your role (i.e. elected official, school principal). However, I will be identifying the locations of the cases and interviews, so there is a small possibility that others within your community could guess your identity.

Only my supervisors and I will read the notes or transcript of the interview. The interview transcripts, summaries and any recordings will be kept securely and destroyed five years after the research has been completed.

\section{What will the project produce?}


The information from my research will be used in my PhD report, and a summary of the results may be used in academic reports and/or presented at conferences.

If you accept this invitation, what are your rights as a research participant?

You do not have to accept this invitation if you don't want to. If you do decide to participate, you have the right to:

- $\quad$ choose not to answer any question;

- $\quad$ ask for the recorder to be turned off at any time during the interview;

- $\quad$ withdraw from the study before $30^{\text {th }}$ December 2018;

- $\quad$ ask any questions about the study at any time;

- $\quad$ receive a copy of your interview recording;

- $\quad$ receive a copy of your interview transcript;

- be able to read any reports of this research by emailing the researcher to request a copy.

If you have any questions or problems, who can you contact?

If you have any questions, either now or in the future, please feel free to contact either:

\section{Student:}

Jordan Anderson

Jordan.Anderson@vuw.ac.nz

\section{Supervisor:}

Professor John Pratt

John.Pratt@vuw.ac.nz

\section{Human Ethics Committee information}

If you have any concerns about the ethical conduct of the research you may contact the Victoria University HEC Convenor: Associate Professor Susan Corbett. Email susan.corbett@vuw.ac.nz or telephone +64-4-463 5480. 


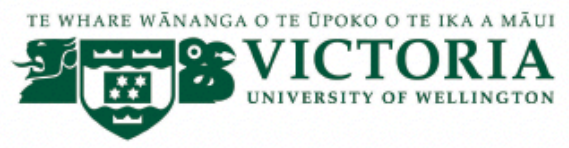

\section{Managing Risk of Sex Offenders Released from Prisons: An exploration of how local communities respond to these events \\ CONSENT TO INTERVIEW}

This consent form will be held for five years.

Researcher: Jordan Anderson, School of Social and Cultural Studies, Victoria University of Wellington.

- I have read the Information Sheet and the project has been explained to me. My questions have been answered to my satisfaction. I understand that I can ask further questions at any time.

- I agree to take part in an audio recorded interview conducted in person.

I understand that:

- I may withdraw from this study at any point before $30^{\text {th }}$ December 2018 , and any information that I have provided will be returned to me or destroyed.

- The identifiable information I have provided will be destroyed five years after the research is finished.

- $\quad$ Any information I provide will be kept confidential to the researcher and the supervisor.

- I understand that the results will be used for a PhD report, and a summary of the results may be used in academic reports, publications, and/or presented at conferences.

- Participation in this research is confidential. This means I will not be personally identified in any reporting. Anything I say will be identified at a group level (e.g. elected official, school principal). If a quote or piece of information looks like it could potentially identify me, the researcher will check with me and remove it if we agree this is best.

- I would like a copy of the transcript of my interview: $\quad$ Yes $\square$ No

- I would like to receive a copy of the final report and have added my email address Yes $\square$ No $\square$ below.

Signature of participant:

Date:

Name of participant:

Email: 


\section{Managing Risk of Sex Offenders Released from Prisons: An exploration of how local communities respond to these events}

$\rightarrow$ Discussion of Information Sheet/Consent Form

\section{Defining the Community Context}

I would like to start by asking you some general questions about community life here.

How long have you been a part of this community?

What does community mean to you?

Tell me about the nature of this community.

Liberal, family oriented, urban etc? Do they do things as a community - what kind of things? Are there virtual/physical community spaces/events? Would you describe it as diverse?

Having said that, is there anything that you see as distinctive about community in this area?

E.g. - people from the community I live in do...

Which methods of communication do you see your community members responding to?

E.g. - newspapers, social media, meetings.

If you wanted to get a message to everyone in the community, what platform would you use and why? When might you use a different platform?

Do people in this community use social media to share information with each other? (give examples to illustrate). Can you show me? Are these posts typical of the kind of things that are posted there? When would you use this/these sites to share information with the community?

\section{The Issue}

Now I want to talk about the reintegration of offenders into this community.

$\rightarrow$ Note on offender reintegration, particularly the reintegration of sex offenders as among the most successfully rehabilitated population. 
What have you observed in terms of any reaction to the release of sex offenders into the community here?

Prompts: What happened in the community when the release was announced?

What kinds of things did people say? What did they do?

How did people in roles like yours respond?

Are there any particular cases that come to mind in this community?

Are you aware of any cases that have elicited a strong reaction nationally?

Prompts: observations of: social media; newspapers; demographics of reactions; shape of discussion between community members.

How does this reaction affect what happens to offenders being placed back into the community here?

How do you think concerns over the release of sex offenders into the community rates in terms of other risks to this community in your experience?

\section{Threats to the Community}

Have you observed people in your community respond to other issues that they have gotten particularly upset about/felt threatened by? Tell me about that response.

Prompts - Was there agreement in the community, or were people divided?

Did anything about that response surprise you?

If you were able to protect this community from one or two [events/issues/persons] in your role, what would it/they be and why?

\section{Community Notification}

If they have already identified community notification as part of the reaction to the event, bring that up here.

Are you familiar with the term 'community notification'?

How about 'registration'?

Do you have any thoughts on these processes? 
Explain the concept of Community Notification and Registration if they are unfamiliar. Under what circumstances in your community would community notification be triggered and why? What elements are required?

What do communities need to be notified about?

Who should be doing the notifying?

How should it happen?

Who would need to be notified?

What are the risks of community notification?

(need to draw out how the process of community notification unfolds)

\section{Establishing Context}

Finding out about their role (what is it, what does it encompass, how long have you been doing it).

What do you find yourself dealing with all the time?

How does your position fit into this community?

How/does managing the risk of sex offenders figure as part of your role?

\section{Closing}

Briefly touch on each of the main points that have been discussed in the interview and ask if there was anything else they would like to add or comments they would like to make. 